Departamento de Ingeniería Telemática y Electrónica

Escuela Técnica Superior de Ingeniería y Sistemas de Telecomunicación

Doctorado en Ingeniería de Sistemas y Servicios para la Sociedad de la Información

UNIVERSIDAD POLITÉCNICA DE MADRID

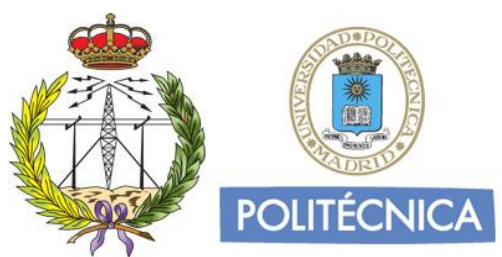

\title{
Modelo de estimulación cognitiva ubicua para pacientes con Parkinson
}

TESIS DOCTORAL

\begin{abstract}
Autora: Carolina García Vázquez
Máster en Sistemas y Servicios Accesibles para la Sociedad de la Información Ingeniera Técnica de Telecomunicación, especialidad en Telemática
\end{abstract}

Co-director: Miguel Ángel Valero Duboy

Doctor Ingeniero de Telecomunicación

Co-directora: Ana Gómez Oliva

Doctora Ingeniera en Informática

Madrid, 2017 



\section{TRIBUNAL}

Tribunal nombrado por el Magfco. y Excmo. Sr. Rector de la Universidad Politécnica de Madrid, el día de de 2017.

Presidenta: Dña. Encarnación Pastor Martín. Doctora Ingeniera de Telecomunicación. Catedrática de Universidad.

ETSI de Telecomunicación.

Universidad Politécnica de Madrid.

Vocales: Dña. Inmaculada Gómez Pastor. Doctora en Psicología (Neurociencia).

Directora Gerente del Centro de Referencia

Estatal de Atención al Daño Cerebral.

Instituto de Mayores y Servicios Sociales.

Dña. María José Catalán Alonso. Doctora en Medicina (Neurología).

Facultativo Especialista.

Hospital Clínico San Carlos.

Universidad Complutense de Madrid.

Dña. Nuria Máximo Bocanegra. Doctora en Terapia Ocupacional.

Profesora Titular de Universidad Interina.

Universidad Rey Juan Carlos.

Secretaria: Dña. María Luisa Martín Ruíz. Doctora en Ingeniería de Sistemas y

Servicios para la Sociedad de la Información

(Doctora por la Universidad Politécnica de

Madrid).

Profesora Ayudande Doctora.

ETSIS de Telecomunicación.

Universidad Politécnica de Madrid.

Suplentes: D. Vicente Tráver Salcedo. Doctor Ingeniero de Telecomunicación.

Profesor Contratado Doctor.

Instituto ITACA.

Universitat Politècnica de València.

Dña. Ángeles Gutiérrez García. Doctora en Educación.

Profesora Contratada Doctora.

Universidad Autónoma de Madrid.

Realizado el acto de lectura y defensa de la Tesis Doctoral el día de de 2017 en la Escuela Técnica Superior de Ingeniería y Sistemas de Telecomunicación de la Universidad Politécnica de Madrid.

LA PRESIDENTA

LAS VOCALES 

"Live in the moment, enjoy the day, make the most of what you have." Michael J. Fox. 2012. 



\section{Gracias...}

...a Ana Gómez y Miguel Ángel Valero, directores de esta tesis. Ana, me has ayudado a creer que era posible. Gracias por tus buenos consejos, tu paciencia y por ayudarme a desenmarañar el caos que tenía en mi cabeza. Miguel Ángel, al final llegó el momento. Gracias por darme la oportunidad.

...a Esther, mi compañera, mi amiga, mi hermana durante tantos años. No creo que haga falta que te diga que esto no existiría sin ti. Gracias, no solo por tu trabajo, sino por acompañarme siempre, ya sea estando juntas o desde la distancia.

...a mis compañeros de los trabajos por los que he ido pasando durante estos años. A los del T>SIC, que me habéis animado a seguir y me habéis convencido de que podría con ello. Me habéis ayudado a crecer académicamente, profesionalmente $y$, sobre todo, personalmente. Gracias también a los que habéis venido después, por vuestros ánimos, facilidades y ganas de colaborar en lo que fuera posible, por estar ahí al final de este viaje con todo lo que eso ha implicado.

...a mi entorno más cercano, los que más lo han sufrido. A mis padres por tener la paciencia suficiente para aguantar otra etapa más. A mi tía y mi abuela por sus ánimos pese a no entender qué estaba haciendo. A mi hermano, por tener siempre una tontería a mano para que me ría y se me olvide todo lo demás. Nene, gracias también por la pequeña Míriam, el mejor regalo y lo que más me ha ayudado a olvidarme del mundo dentro de este desastre. A mi familia postiza, que ha aguantado mis quejas, mi falta de tiempo y mi histeria.

....a David. ¿Qué puedo decir que no haya dicho ya durante todos estos años? Eres el punto sobre el que se sostiene mi cordura. Gracias por creer en mí y por tu apoyo incondicional, por animarme a seguir y por enseñarme a parar. Gracias por estar a mi lado desde que aprendí a leer y seguir creyendo en mí todavía, todos estos años y, estoy segura, todos los que aún nos quedan por pasar juntos. Estás presente en cada página de esta memoria. Gracias por hacerlo todo tan fácil.

...a las asociaciones de afectados de Parkinson y sus familiares y a la Federación Española de Parkinson, sin cuya colaboración este trabajo no tendría sentido. Gracias por vuestras ganas de trabajar y por creer que algo mejor es posible. Gracias, Mayca, por tu esfuerzo para ayudarme a conseguir los datos. Gracias, Tere, por tu profesionalidad y por todo lo que me has enseñado. Gracias, Susana y Laura, por implicaros desde hace tantos años en este proyecto y creer en él. Gracias, Lourdes, por tus ganas de que siguiéramos adelante.

...a los pacientes que han participado tanto en el diseño como en la experimentación. Vuestras ganas de colaborar, vuestro entusiasmo y, por encima de todo, vuestro afán de superación es lo que me ha animado a seguir adelante. Habéis creado una de las experiencias más bonitas que he tenido. GRACIAS. 



\section{Índice de contenidos}

ÍNDICE DE CONTENIDOS .1

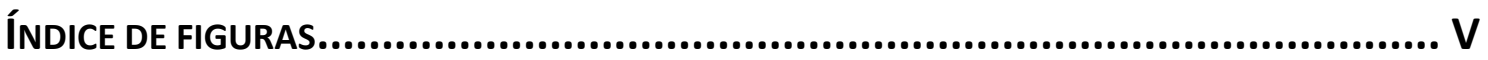

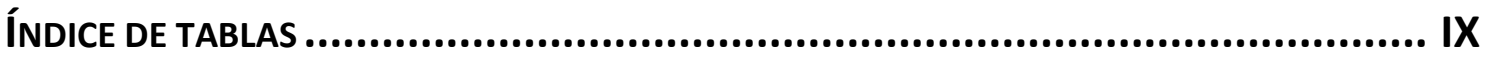

GLOSARIO DE ACRÓNIMOS .................................................................. XIII

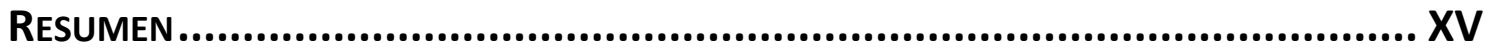

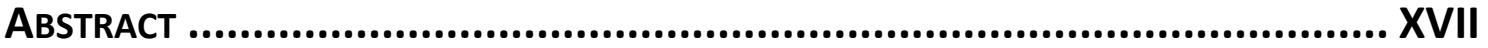

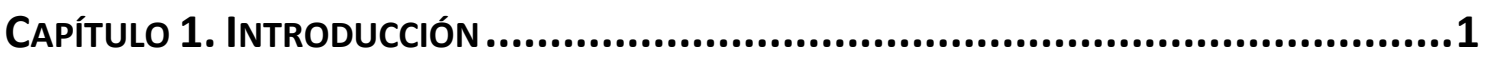

CAPÍTULO 2. DEFINICIÓN DE HIPÓTESIS Y OBJETIVOS ...........................................5

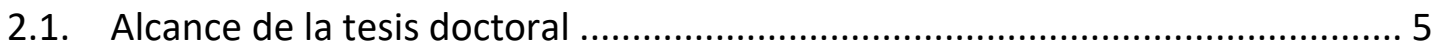

2.2. Formulación de las hipótesis .................................................................... 7

2.3. Metodología para la validación de las hipótesis............................................... 8

2.4. Objetivos perseguidos con este trabajo ….................................................. 9

CAPÍTULO 3. JUSTIFICACIÓN Y ANTECEDENTES ...............................................13

3.1. La Enfermedad de Parkinson (EP) ............................................................ 13

3.1.1. Descripción de la enfermedad .......................................................................... 13

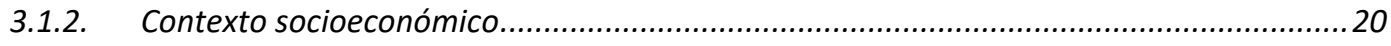

3.1.3. Terapias no farmacológicas para el tratamiento de la EP .........................................26

3.2. Contexto tecnológico ................................................................................. 29

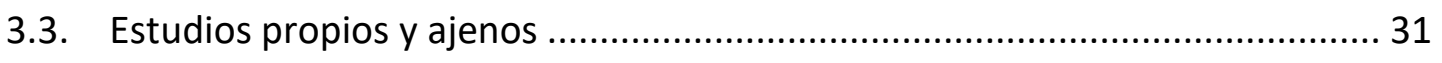

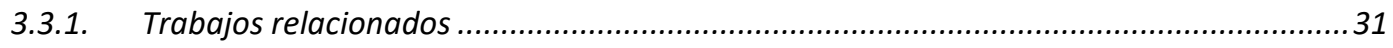

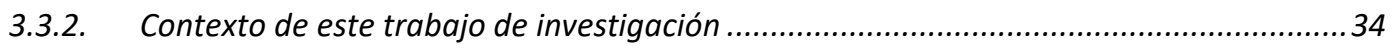




\section{Capítulo 4. Determinación de ReQuisitos de la Terapia de Estimulación Cognitiva PARA LA ENFERMEdAd de PARKINSON (EP)}

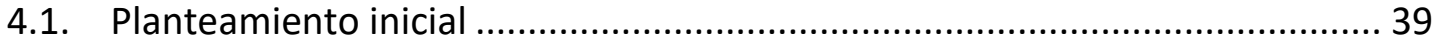

4.2. Metodología para la captura de requisitos ................................................. 40

4.3. Agentes implicados en la captura de requisitos .......................................... 42

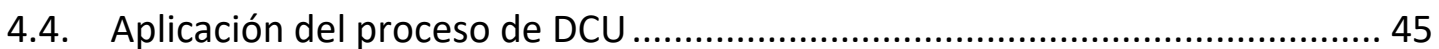

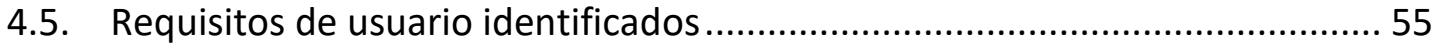

4.6. Relevancia de los requisitos de usuario identificados ..................................6 60

CAPÍTUlo 5. MATERIAles y MÉTOdOS....................................................65

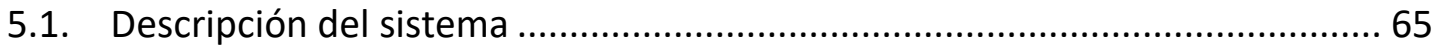

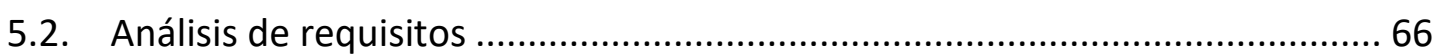

5.2.1. Diagrama de casos de uso general.................................................................6

5.2.2. Diagrama de casos de uso del paquete funcional Terapia ..........................................68

5.2.3. Diagrama de casos de uso del paquete funcional Gestión de usuarios........................... 70

5.2.4. Diagramas de secuencia del paquete funcional Terapia ............................................. 71

5.3. Diseño de la terapia de estimulación cognitiva ............................................. 74

5.3.1. Ejercicios de estimulación cognitiva tradicionales ...................................................... 74

5.3.2. Ejercicios de estimulación cognitiva adaptados a las TIC................................................. 78

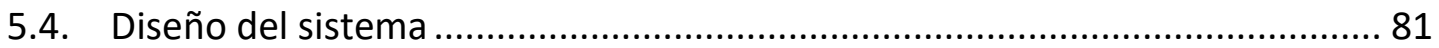

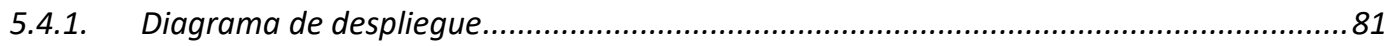

5.4.2. Diseño del protocolo de comunicación ..................................................................... 81

5.4.3. Metodología seguida para el diseño de las interfaces de usuario ....................................83

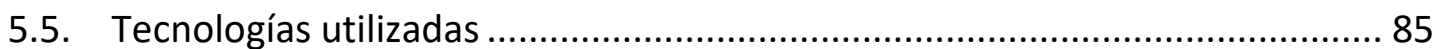

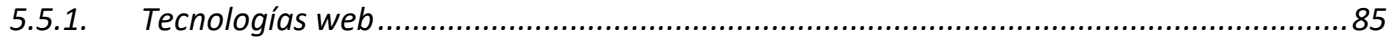

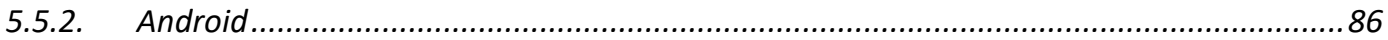

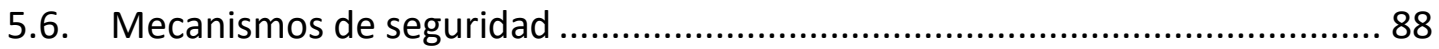

5.7. Implementación de las interfaces de usuario................................................ 91

5.7.1. Aplicación Android para el paciente.................................................................... 91

5.7.2. Plataforma web de seguimiento de la terapia y gestión de usuarios ............................96

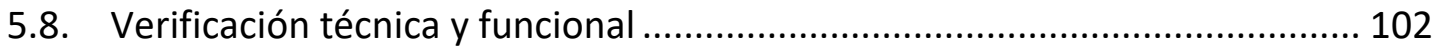

5.9. Relevancia de la implementación de la plataforma .................................... 103 
CAPÍTULO 6. EXPERIMENTACIÓN Y RESULTADOS 105

6.1. Resultados perseguidos con la experimentación ..................................... 105

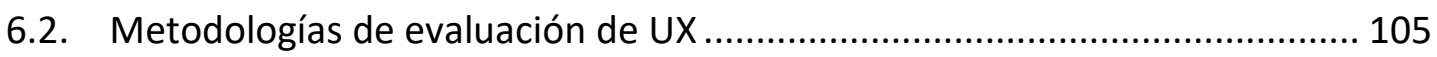

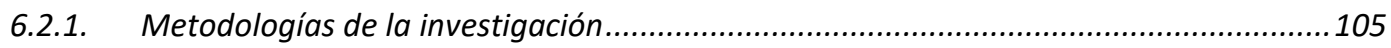

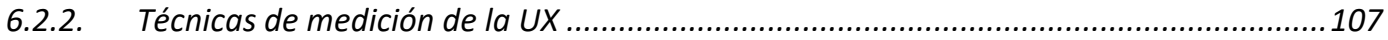

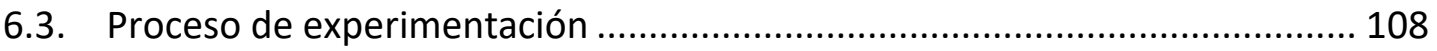

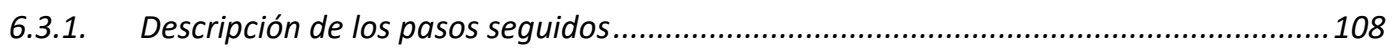

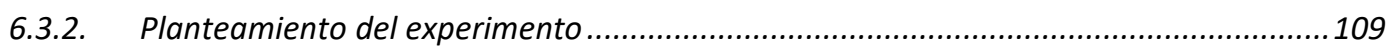

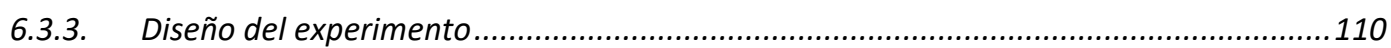

6.4. Realización del experimento................................................................ 111

6.4.1. Distribución de las asociaciones participantes en el experimento ..............................111

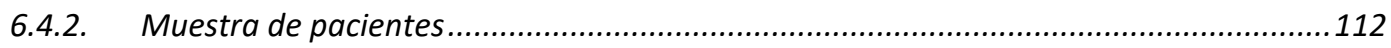

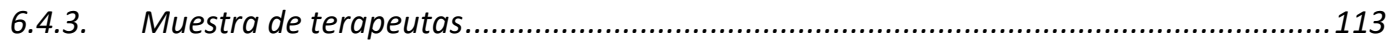

6.5. Experimentación adicional en domicilio.................................................. 113

6.6. Resultados de los experimentos ............................................................ 114

6.6.1. Adaptación de los resultados de los cuestionarios ...................................................114

6.6.2. Observaciones de pacientes y terapeutas ............................................................115

6.6.3. Análisis de resultados tras la experimentación .......................................................121

CAPÍtulo 7. Discusión de los ReSUltados eXPerimentaleS.........................123

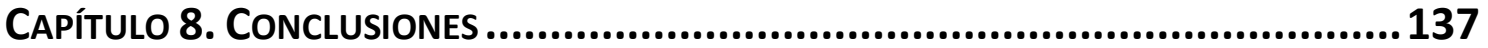

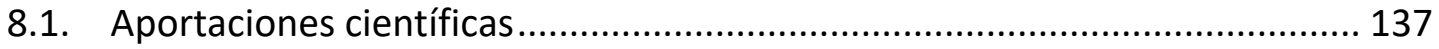

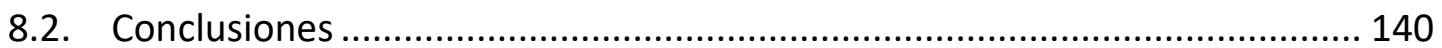

8.3. Futuras líneas de investigación ................................................................ 144

REFERENCIAS BIBLIOGRÁFICAS..................................................... 147

Anexo I. Cuestionario para el Consentimiento del PACIENTE.........................167

Anexo II. Formulario Comité de Ética. Universidad Polttécnica de MadRID .169 


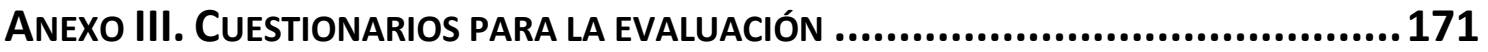

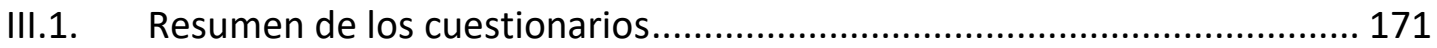

III.2. Cuestionarios para los pacientes ….................................................. 172

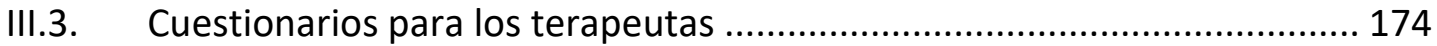

\section{ANEXo IV. DATOS DE LOS CUESTIONARIOS. EXPERIMENTACIÓN EN LAS ASOCIACIONES177}

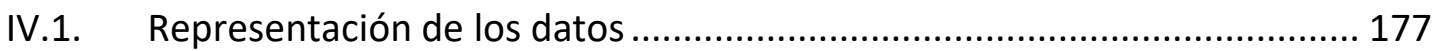

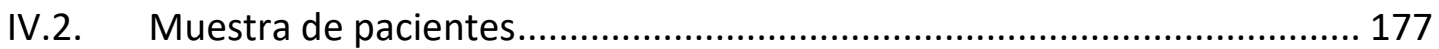

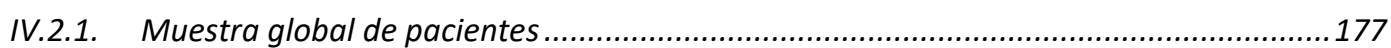

IV.2.2. Muestra de pacientes por asociación ..............................................................................181

IV.3. Datos globales por asociación ................................................................ 183

IV.4. Datos de los cuestionarios de los terapeutas .............................................. 186

ANEXo V. DATOS DE LOS CUESTIONARIOS. EXPERIMENTACIÓN EN DOMICILIO ...........191

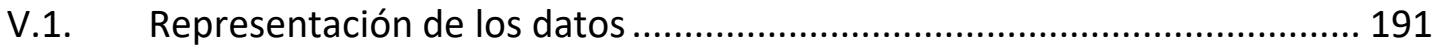

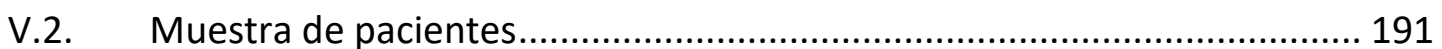

V.2.1. Muestra global de pacientes ...................................................................................191

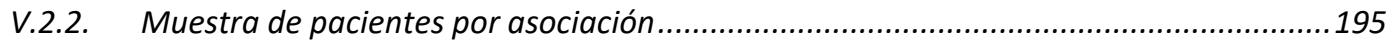

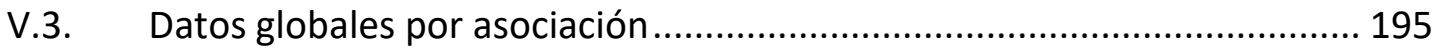

V.4. Datos de los cuestionarios de los terapeutas .......................................... 198 


\section{Índice de figuras}

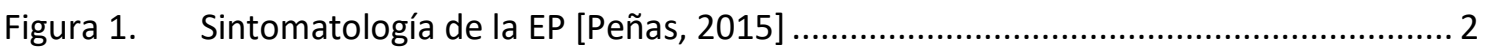

Figura 2. Cronograma de fases para la validación de las hipótesis ........................................ 9

Figura 3. Localización de la sustancia negra en el cerebro [Castillo, 2016] ...........................13

Figura 4. Disminución del nivel de dopamina en el cerebro [ENBM18, 2015] ...................... 14

Figura 5. PET de dos cerebros sanos y dos con EP (sin y con medicación) [NPF, 2011] ........ 19

Figura 6. Población española real en el año 2016 [INE, 2016] ............................................. 21

Figura 7. Proyección de la población española para el año 2066 [INE, 2016]........................ 21

Figura 8. Mayores de 65 años con enfermedad crónica diagnosticada [INE, 2008, 1] ......... 22

Figura 9. Diagnóstico de EP (en \%o). Datos por CCAA [INE, 2008, 2] ..................................... 23

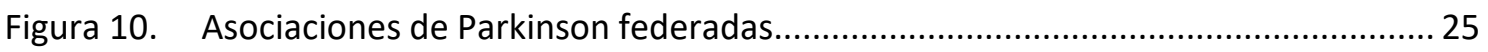

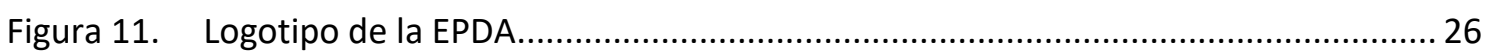

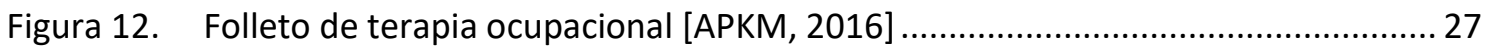

Figura 13. Métodos de acceso a internet en España [CNMC, 2015] .......................................29

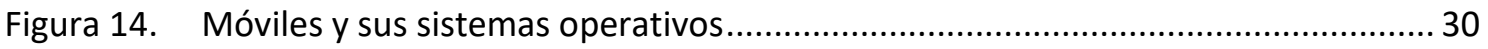

Figura 15. Penetración de los sistemas operativos móviles en el mundo [Richter, 2016]...... 31

Figura 16. Factores que intervienen en la UX [Hassan, 2005] ................................................. 41

Figura 17. Interacción de las fases del DCU [ISO 9241-210:2010] ........................................ 42

Figura 18. Extracto del informe para la adaptación de la TEC al entorno TIC .......................... 46

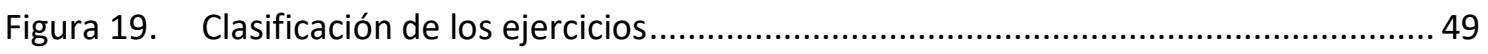

Figura 20. Diseño de la interfaz de creación de bloques de ejercicios................................... 49

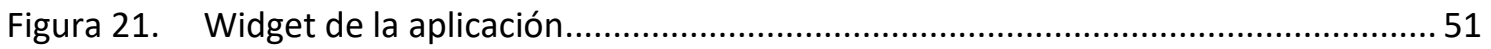

Figura 22. Página web para la descarga de la aplicación......................................................... 53

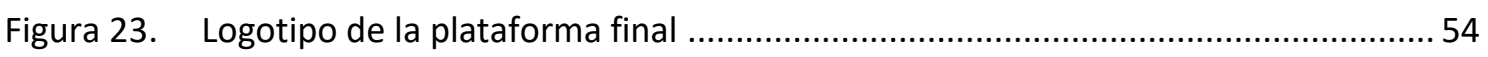

Figura 24. Ejemplos de los manuales de usuario realizados ................................................. 55

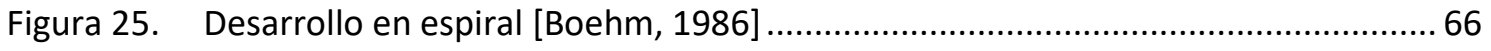

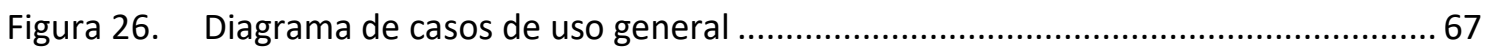

Figura 27. Diagrama de casos de uso del paquete funcional Terapia ....................................6 68 
Figura 28. Diagrama de casos de uso del paquete funcional Gestión de usuarios .................. 70

Figura 29. Diagrama de secuencia de asignación del primer bloque de ejercicios .................. 72

Figura 30. Diagrama de secuencia de realización de un bloque de ejercicios ........................ 72

Figura 31. Diagrama de secuencia de la introducción de valoración ....................................... 73

Figura 32. Diagrama de secuencia de consulta de valoración................................................. 73

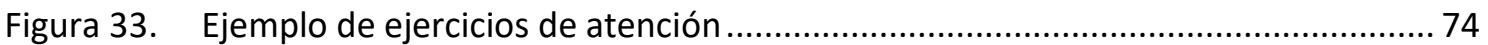

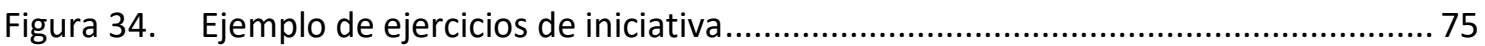

Figura 35. Ejemplo de ejercicios de categorización................................................................... 75

Figura 36. Ejemplo de ejercicios de seriación........................................................................ 76

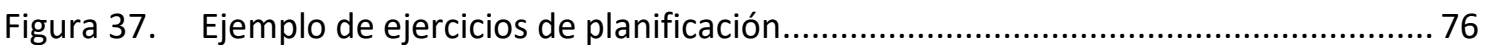

Figura 38. Ejemplo de ejercicio de memoria a largo plazo....................................................... 77

Figura 39. Ejemplo de ejercicio de memoria a corto plazo sobre personas............................ 77

Figura 40. Ejemplo de ejercicio de memoria a corto plazo sobre objetos ............................. 78

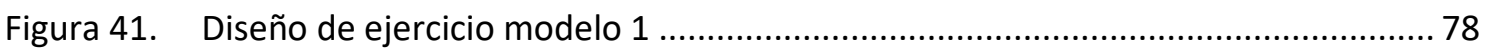

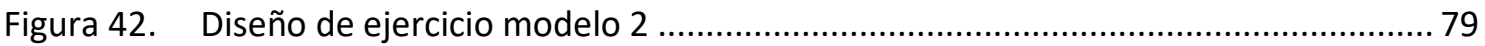

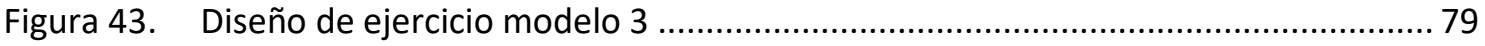

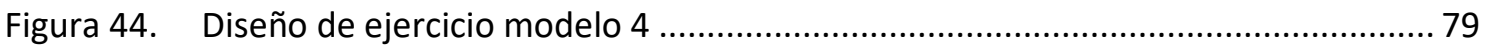

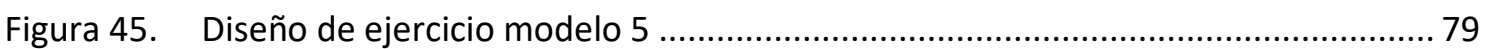

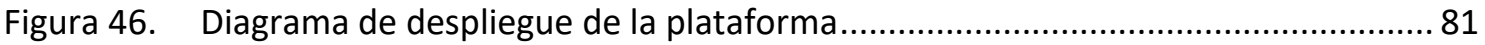

Figura 47. Unidades de datos del protocolo implementado ad-hoc...................................... 82

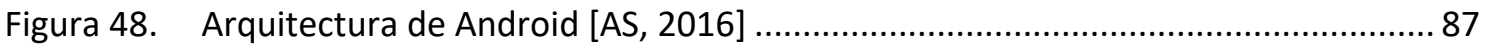

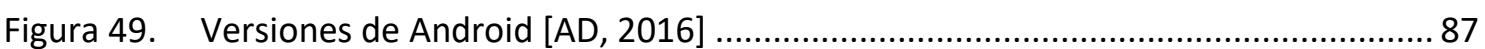

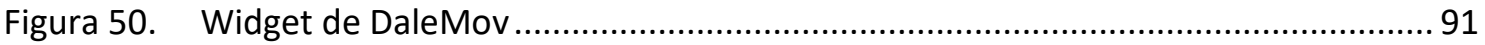

Figura 51. Diagrama de navegación de la aplicación del paciente............................................ 91

Figura 52. Pantalla de bienvenida de DaleMov ................................................................... 92

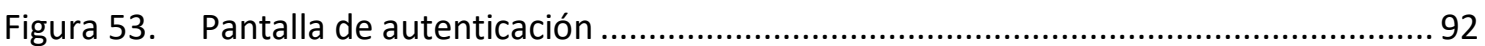

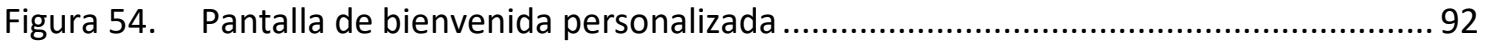

Figura 55. Menú principal de la aplicación del paciente .......................................................... 93

Figura 56. Menú de ejercicios de la aplicación del paciente ................................................ 93

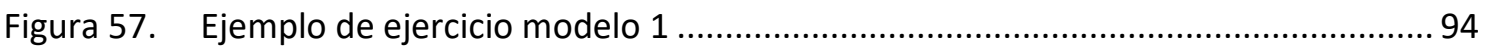

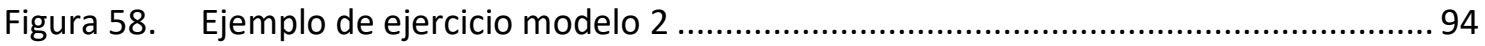

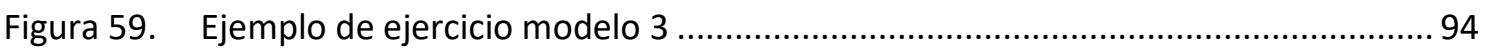

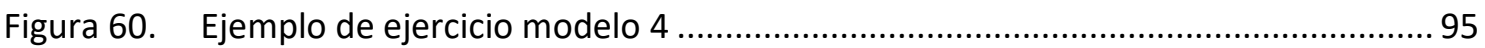


Figura 61. Ejemplo de ejercicio modelo 5 95

Figura 62. Ejemplo de resultados del paciente tras la realización de un bloque de ejercicios95

Figura 63. Ejemplo de valoración del terapeuta ................................................................. 96

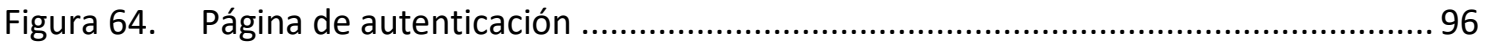

Figura 65. Diagrama de navegación por la plataforma para el perfil de terapeuta ................. 97

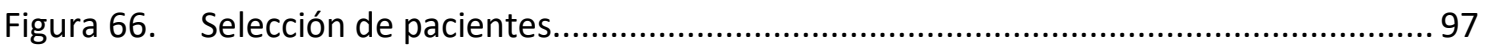

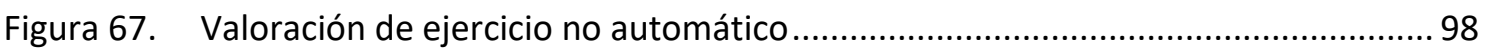

Figura 68. Introducción de valoración y siguiente bloque de ejercicios ................................. 98

Figura 69. Consulta de la evolución de un paciente............................................................. 99

Figura 70. Selección del modo de creación del bloque de ejercicios .......................................99

Figura 71. Parámetros para bloque de ejercicios automático ................................................ 99

Figura 72. Asignación de nombre y descripción al bloque de ejercicios ................................ 100

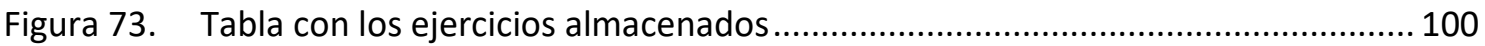

Figura 74. Primera pantalla de introducción de ejercicios ...................................................... 101

Figura 75. Segunda pantalla de introducción de ejercicios .................................................... 101

Figura 76. Eliminación de un ejercicio de estimulación ......................................................... 102

Figura 77. Hogar Digital Accesible de la UPM [HDA, 2006] .................................................. 103

Figura 78. Regiones de las asociaciones de EP que han participado en el experimento ....... 111

Figura 79. Madrid. Resultados globales de la experimentación en la asociación ................... 115

Figura 80. Extremadura. Resultados globales de la experimentación en la asociación ......... 117

Figura 81. Cataluña. Resultados globales de la experimentación en la asociación................. 118

Figura 82. Cádiz. Resultados globales de la experimentación en la asociación ..................... 118

Figura 83. Navarra. Resultados globales de la experimentación en la asociación ................. 120

Figura 84. Sevilla. Resultados globales de la experimentación en la asociación.....................120

Figura 85. Resultados medios por pregunta y asociación .................................................. 127

Figura 86. Resultados medios por pregunta y sesión....................................................... 128

Figura 87. Varianza entre las sesiones y varianza global .................................................... 128

Figura 88. Máximo, mínimo y promedio de las respuestas según estadio motor .................129

Figura 89. Máximo, mínimo y promedio de las respuestas según estado cognitivo ............. 129

Figura 90. Máximo, mínimo y promedio de las respuestas de pacientes a la pregunta 7 .... 130

Figura 91. Máximo, mínimo y promedio de las respuestas de pacientes a la pregunta 6 .... 131

Figura 92. Comparativa de respuestas entre pacientes con/sin contacto previo con NNTT 132

Figura 93. Comparativa entre sesiones de la pregunta 4 
Figura 94. Experimentación en las asociaciones. Distribución de pacientes por asociación 178

Figura 95. Experimentación en las asociaciones. Paridad entre hombres y mujeres 179

Figura 96. Experimentación en las asociaciones. Intervalo de edad y promedio .................. 179

Figura 97. Experimentación en las asociaciones. Estado cognitivo....................................... 180

Figura 98. Experimentación en las asociaciones. Estadio motor ........................................ 180

Figura 99. Experimentación en las asociaciones. Experiencia en nuevas tecnologías ........... 181

Figura 100. Madrid. Resultados globales de la experimentación en la asociación .................. 183

Figura 101. Extremadura. Resultados globales de la experimentación en la asociación ......... 184

Figura 102. Cataluña. Resultados globales de la experimentación en la asociación................ 184

Figura 103. Cádiz. Resultados globales de la experimentación en la asociación ...................... 185

Figura 104. Navarra. Resultados globales de la experimentación en la asociación .................. 185

Figura 105. Sevilla. Resultados globales de la experimentación en la asociación..................... 186

Figura 106. Madrid. Datos de las terapeutas. Experimentación en la asociación.................... 186

Figura 107. Extremadura. Datos de las terapeutas. Experimentación en la asociación .......... 187

Figura 108. Cataluña. Datos de las terapeutas. Experimentación en la asociación ................. 187

Figura 109. Cádiz. Datos de las terapeutas. Experimentación en la asociación ........................ 188

Figura 110. Navarra. Datos de los terapeutas. Experimentación en la asociación ...................188

Figura 111. Sevilla. Datos de las terapeutas. Experimentación en la asociación ...................... 189

Figura 112. Experimentación en domicilio. Distribución de pacientes por asociación ............ 192

Figura 113. Experimentación en domicilio. Paridad entre hombres y mujeres ...................... 192

Figura 114. Experimentación en domicilio. Intervalo de edad y promedio .............................. 193

Figura 115. Experimentación en las asociaciones. Estado cognitivo..................................... 193

Figura 116. Experimentación en domicilio. Estadio motor .................................................... 194

Figura 117. Experimentación en domicilio. Experiencia en nuevas tecnologías........................ 194

Figura 118. Madrid. Resultados globales de la experimentación en domicilio........................ 196

Figura 119. Extremadura. Resultados globales de la experimentación en domicilio................ 196

Figura 120. Cataluña. Resultados globales de la experimentación en domicilio ..................... 197

Figura 121. Navarra. Resultados globales de la experimentación en domicilio....................... 197

Figura 122. Sevilla. Resultados globales de la experimentación en domicilio ........................ 198 


\section{Índice de tablas}

Tabla 1. Escala de Hoehn y Yahr para la progresión de la EP [Hoehn, 1998]....................... 17

Tabla 2. Clasificación clínica de la demencia (CDR) según Hughes (sano a leve) .................. 18

Tabla 3. Clasificación clínica de la demencia (CDR) según Hughes (moderado a grave) ..... 18

Tabla 4. Número de internautas en España [ONTSI, 2016] ............................................... 29

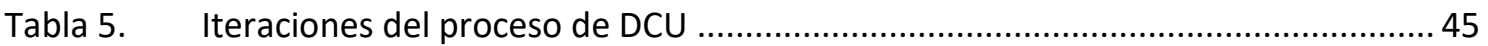

Tabla 6. Contenido de cada manual de usuario ................................................................. 54

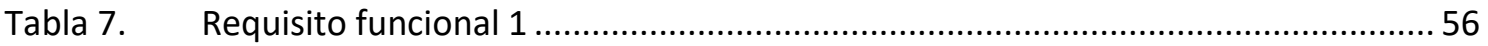

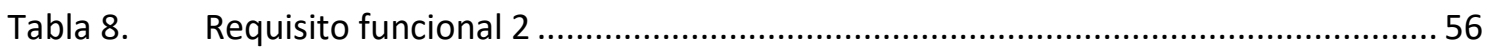

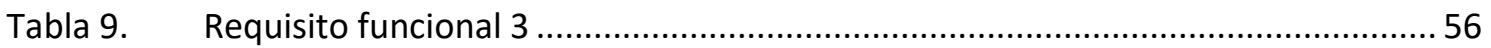

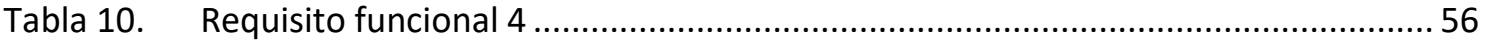

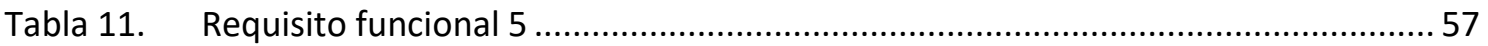

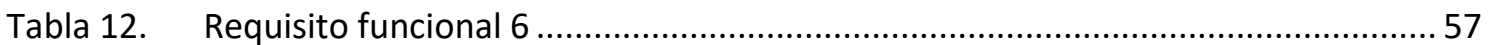

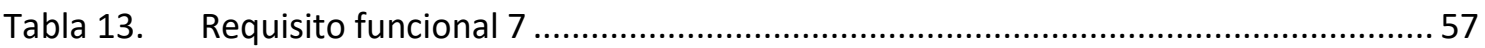

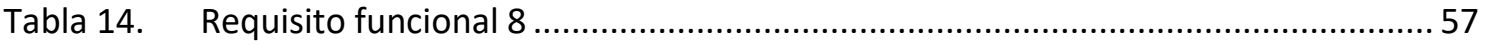

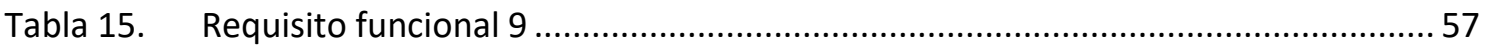

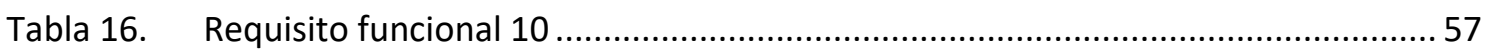

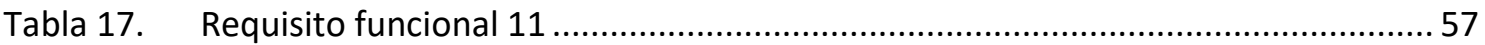

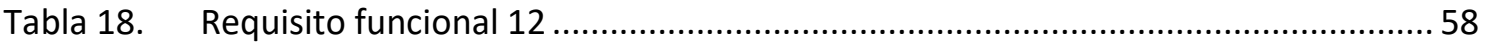

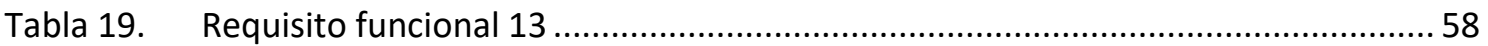

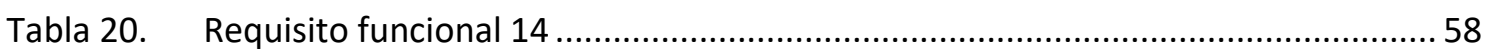

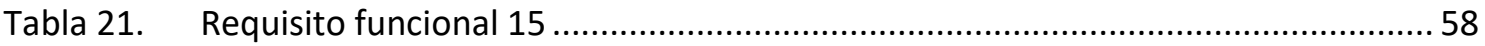

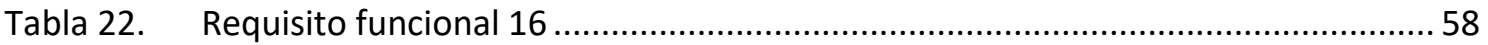

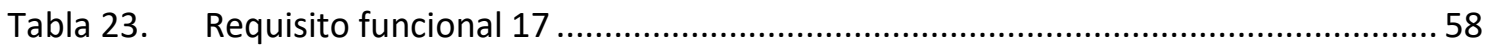

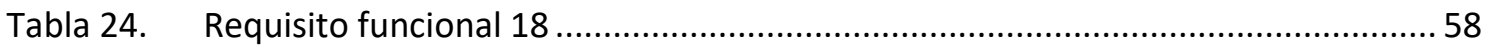

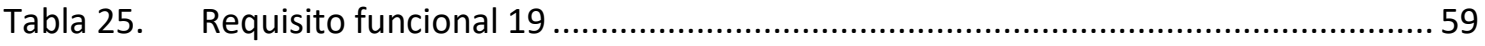

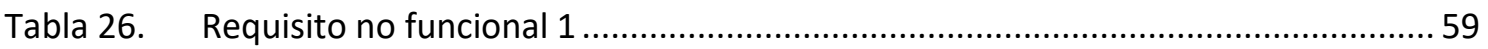




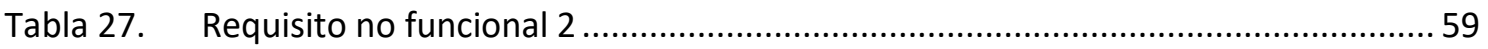

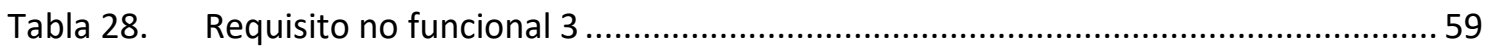

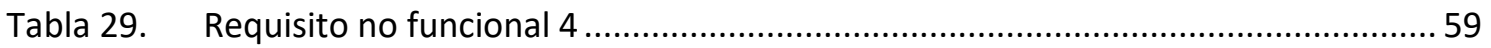

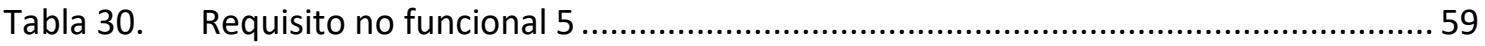

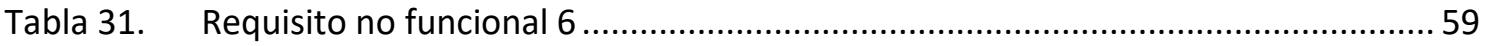

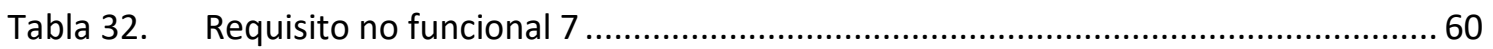

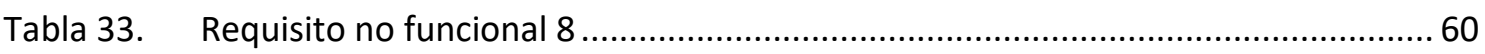

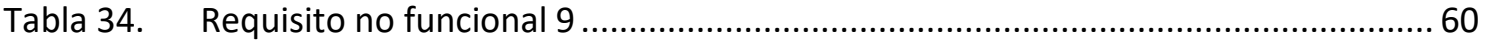

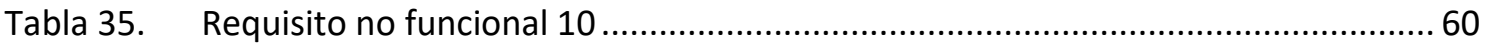

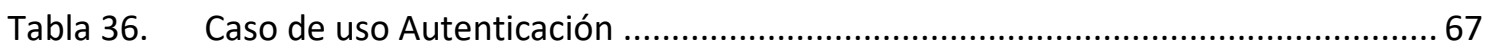

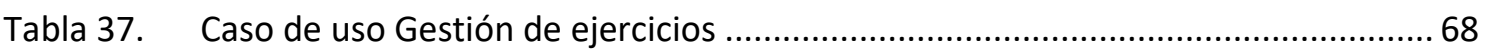

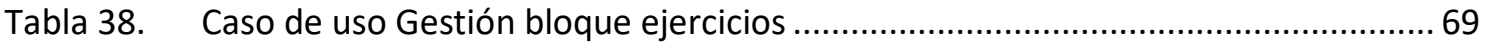

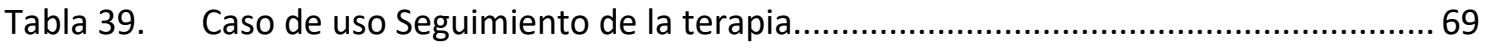

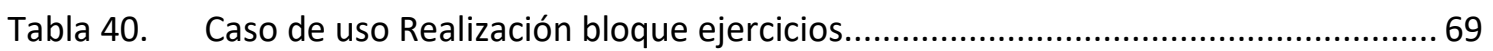

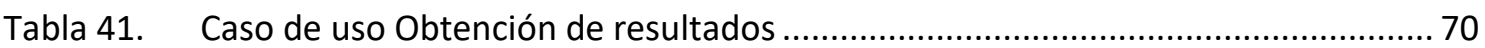

Tabla 42. Caso de uso Gestión de usuarios ............................................................................. 70

Tabla 43. Caso de uso Gestión de asociaciones ..................................................................... 71

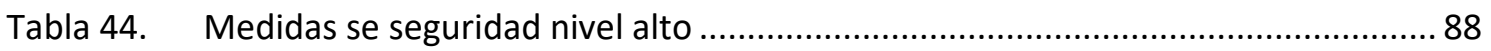

Tabla 45. Datos almacenados de cada usuario según su perfil.............................................. 89

Tabla 46. Denominación de asociaciones y fecha de experimentación................................. 112

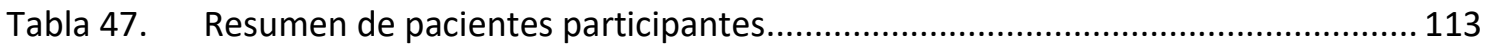

Tabla 48. Puntuaciones y abreviatura de cada respuesta a los cuestionarios......................115

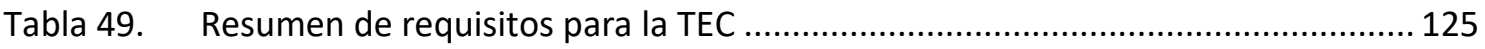

Tabla 50. Resumen de necesidades de una persona con EP.............................................. 126

Tabla 51. Resumen de mejoras en las TEC que aporta el modelo planteado....................... 134

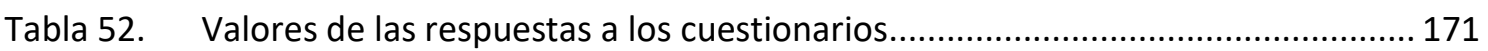

Tabla 53. Experimentación en las asociaciones. Muestra global de pacientes...................... 178

Tabla 54. Madrid. Muestra de pacientes en la asociación ................................................. 181

Tabla 55. Extremadura. Muestra de pacientes en la asociación.......................................... 182

Tabla 56. Cataluña. Muestra de pacientes en la asociación ................................................ 182

Tabla 57. Cádiz. Muestra de pacientes en la asociación ....................................................... 182

Tabla 58. Navarra. Muestra de pacientes en la asociación.................................................. 183

Tabla 59. Sevilla. Muestra de pacientes en la asociación .................................................... 183 
Tabla 60. Experimentación en domicilio. Muestra global de pacientes 191

Tabla 61. Madrid. Muestra de pacientes en la asociación. 195

Tabla 62. Extremadura. Muestra de pacientes en la asociación 195

Tabla 63. Cataluña. Muestra de pacientes en la asociación 195

Tabla 64. Navarra. Muestra de pacientes en la asociación. 195

Tabla 65. Sevilla. Muestra de pacientes en la asociación 195 


\section{Glosario de acrónimos}

\begin{tabular}{|l|l|}
\hline Acrónimo & Definición \\
\hline AOSP & Android Open Source Project \\
\hline APKM & Asociación Parkinson Madrid \\
\hline CEAPAT & Centro Estatal de Autonomía Personal y Ayudas Técnicas \\
\hline DCU & Diseño Centrado en el Usuario \\
\hline EP & Enfermedad de Parkinson \\
\hline EPDA & $\begin{array}{l}\text { Asociación Europea de Parkinson (European Parkinson's Disease } \\
\text { Association) }\end{array}$ \\
\hline FEP & Federación Española de Parkinson \\
\hline FVE & Fundación Vodafone España \\
\hline GUI & Interfaz Gráfica de Usuario (Graphic User Interface) \\
\hline HCI & Interacción persona-ordenador (Human-Computer Interaction) \\
\hline HDA & Hogar Digital Accesible de la Universidad Politécnica de Madrid \\
\hline I+D+i & Investigación, Desarrollo e Innovación \\
\hline IMSERSO & Instituto de Mayores y Servicios Sociales \\
\hline NNTT & Nuevas tecnologías \\
\hline PDU & Unidad de datos del protocolo (Protocol Data Unit) \\
\hline TEC & Terapias de Estimulación Cognitiva \\
\hline TIC & Téas de la Información y la Comunicación \\
\hline
\end{tabular}




\begin{tabular}{|l|l|}
\hline \multicolumn{1}{|l|}{ Acrónimo } & Definición \\
\hline T>SIC & $\begin{array}{l}\text { Grupo de Investigación de Sistemas Telemáticos para la Sociedad de la } \\
\text { Información y el Conocimiento }\end{array}$ \\
\hline UPM & Universidad Politécnica de Madrid \\
\hline UX & Experiencia de usuario (User experience) \\
\hline
\end{tabular}




\section{Resumen}

Esta tesis doctoral, titulada Modelo de estimulación cognitiva ubicua para pacientes con Parkinson, recoge el trabajo de investigación realizado para la definición de un marco de desarrollo de soluciones terapéuticas, basadas en Tecnologías de la Información y la Comunicación (TIC), orientadas a personas con enfermedad de Parkinson (EP). En particular, este trabajo se ha centrado en las terapias de estimulación cognitiva (TEC) llevadas a cabo con los pacientes en las asociaciones de Parkinson.

Las hipótesis de partida se han planteado a partir de la evidencia científica de las ventajas que ofrece el llevar a cabo este tipo de terapias con personas diagnosticadas de EP. Debido a ello, se ha intentado a través del modelo presentado en esta tesis comprobar hasta qué punto la introducción de las TIC en este contexto hace mejorar las terapias en los aspectos de eficiencia, satisfacción en el uso y adherencia al tratamiento. Estas hipótesis se han apoyado en un objetivo principal basado en el incremento de la calidad, la disponibilidad y la versatilidad de estas terapias a través de la introducción de las TIC. Para la definición de este modelo ha sido necesaria la creación de una relación de parámetros de las TEC orientadas a EP y de un resumen de necesidades de una persona con EP en sus dimensiones cognitiva, motora y emocional. Además, se ha llevado a cabo un experimento formal para evaluar la adecuación del modelo, la promoción de la adherencia a estas terapias fuera de las asociaciones y el impulso del uso de nuevas tecnologías en estos pacientes.

El enfoque novedoso para el planteamiento de este modelo surge de la necesidad de la introducción de las TIC en este tipo de terapias para poder dar a los pacientes un servicio más personalizado, mejorando de esta forma la calidad asistencial.

En el campo de la EP existe un movimiento asociativo muy importante, principalmente para el tratamiento no farmacológico de los síntomas físicos y psíquicos. Como consecuencia de ello, se ha optado por contactar con la Federación Española de Parkinson y sus asociaciones federadas para definir y evaluar el modelo. Para esta definición, se ha utilizado la metodología de diseño centrado en el usuario (DCU), que consiste en pequeñas iteraciones incrementales en las que, al final de cada una, se evalúa el resultado con los usuarios finales. El empleo de esta metodología ha hecho que los resultados finales hayan sido altamente satisfactorios, ya que la aplicación que implementa el modelo había sido desarrollada junto con el colectivo al que iba dirigido.

Los requisitos recogidos a lo largo de las distintas iteraciones del DCU han permitido llevar a cabo la definición del modelo, en el que se han obtenido tanto los parámetros de la TEC como las necesidades de una persona con EP a la hora de utilizar un sistema basado en TIC. Se ha constatado la importancia de la personalización de terapias y del seguimiento por parte de los terapeutas, así como la posibilidad de compartir recursos entre las distintas asociaciones. 
Estos requisitos han dado lugar a una plataforma compuesta por una aplicación para Android, diseñada para tableta, donde el paciente realiza sus ejercicios y puede visualizar la valoración introducida por su terapeuta. Los terapeutas disponen de una aplicación basada en web para la gestión de ejercicios, gestión de bloques de ejercicios y gestión de terapias. En esta última operación se incluyen la creación y asignación de bloques de ejercicios para cada paciente, personalizando así la terapia y pudiendo añadir una valoración que el paciente pueda visualizar a través de su aplicación en la tableta.

Tras esta implementación, se ha procedido a la definición de los parámetros para realizar los experimentos, llevando a cabo uno en 6 asociaciones de Parkinson y otro en pacientes en domicilio pertenecientes a 5 asociaciones. La evaluación se ha realizado a través de cuestionarios diseñados con expertos psicólogos en EP. Estos cuestionarios se han centrado en la evaluación de la experiencia de usuario, tratando de evaluar parámetros difícilmente cuantificables como son la adherencia al tratamiento aplicando las TIC, la eficiencia comparado con las terapias tradicionales o la satisfacción en el uso.

Los resultados tras la experimentación han sido muy satisfactorios. Las hipótesis de partida han sido sobradamente confirmadas con estos resultados. En todas las asociaciones participantes se han destacado varios aspectos en el campo de la eficiencia, como la utilidad cuando los pacientes no pueden asistir a las asociaciones, la personalización de las terapias, el aumento de los contenidos disponibles, el ahorro de tiempo y de material o el enriquecimiento de la intervención. Los pacientes también han destacado la eficiencia debido a la eliminación de la barrera que muchos perciben cuando deben utilizar lápiz y papel. Con respecto a la satisfacción en el uso, los terapeutas han detectado en los pacientes un entusiasmo añadido a la hora de llevar a cabo la TEC de esta forma, gracias a que la herramienta es novedosa y fácil de usar de forma autónoma. Los pacientes han subrayado que es más divertido, interesante y atractivo el efectuar la terapia utilizando las TIC. Asimismo, tanto pacientes como terapeutas destacan el interés de utilizarlo en domicilio y su gusto por la utilización de tecnología en este contexto.

Estas aportaciones de pacientes y terapeutas han ayudado a concluir que el experimento ha sido un éxito, principalmente por la utilidad que ambos colectivos han percibido de la plataforma TIC basada en el modelo propuesto. Por todo ello, se puede afirmar que el modelo planteado es más que válido para su aplicación en TEC para personas con EP.

La utilización de una plataforma basada en el modelo presentado en esta tesis doctoral puede hacer llegar a más personas con EP la ventaja de las terapias orientadas a mantener sus capacidades cognitivas durante el mayor tiempo posible. Esto deriva en el mantenimiento de su calidad de vida durante un periodo más largo e influiría en la mejora de la calidad asistencial ofrecida a las personas que sufren esta enfermedad. 


\section{Abstract}

This dissertation, entitled Ubiquitous model for cognitive stimulation oriented to patients with Parkinson's Disease, collects the research work for the definition of a therapeutic solutions framework, based on Information and Communication Technologies (ICT), aimed at people with Parkinson's disease (PD). In particular, this work has focused on cognitive stimulation therapies (CST) carried out with patients in Parkinson's associations.

Initial hypotheses are based on the scientific evidence of the advantages of this kind of therapies with people with PD. Due to that, we test the improvements of efficiency, satisfaction with use and treatment adherence with the introduction of ICT in this context. The main objective supports these hypotheses, and is based on the quality, availability and versatility improvement which arise with the introduction of ICTs in this context. The accomplishment of this objective is based on the definition of a set of parameters of CST applied to PD, as well as a summary of needs of people with PD in emotional, cognitive and motor dimensions. Furthermore, we need a formal experiment for testing the model, the promoting of the adherence of these therapies out of PD associations and the increase of the use of new technologies by people with PD.

Novel approach of this model arises from the need of the introduction of ICT in this kind of therapies, in order to give a personalize service to this people, thus improving the quality of care.

Associative movement around PD is very important, mainly for the non-pharmacological treatment oriented to physical and psychic symptoms. As a consequence, Spanish Federation of Parkinson's and its federated associations have taken part of the definition and evaluation of the model. For this definition, we use user-centred design methodology (UCD), which consists of a set of small and incremental iterations. At the end of each iteration, the results are evaluated with target group. The use of this methodology has made very satisfactory results, since the application that implements the model had been developed together with end users.

User requirements gathered throughout UCD iteration have allowed to carry out the model definition, both CST parameters and PD needs when they use an ICT solution. We verify the importance of personalizing therapies and the therapist monitoring, as well as the possibility of sharing resources among different associations.

These requirements have led us to a platform compound by an Android app, tablet-designed, where patients perform their exercise and visualize the evaluation introduced by their therapists. Therapists have a web-based application for exercise management, set of exercise management and therapy management. Therapy management includes the perform the therapy for each patient, allowing the addition of a specific set of exercise for this patient, and attaching a evaluation that patients can visualize through their tablet app. 
After the implementation, we defined a set of experiments, performing one in six PD associations and another at patients' home belonging to five association. The evaluation has done through questionnaires designed with the help of PD expert psychologists. These questionnaires have focused on the evaluation of user experience, trying to evaluate parameters that are difficult to evaluate, such as treatment adherence using ICT, compared efficiency between traditional therapies and this model or satisfaction with use.

Obtained results have been very satisfactory. Initial hypotheses have been well confirmed with these results. Therapies at the associations highlight the efficiency, such as the utility when patients cannot attend to association. Moreover, they emphasize the customization of therapies, the increase of available contents or the enrichment of the intervention. On the other hand, patients have also underlined the barrier removal that many perceive when using pencil and paper. In the case of the satisfaction with use, therapists have detected in patient an added enthusiasm carrying out CST in this way, thanks to the novel of the tool and the ease of use. Patients have stressed that is funnier, interesting and attractive to perform therapy using ICT. Also, both patients and therapists highlight the interest of using it at home and the liking for using technology in this context.

Patients and therapists contributions have helped to conclude the experiments has been a success, mainly due to the perceived utility of the platform based on proposed model. Therefore, we can resolve this model is more than valid for its application in CST for people with PD.

The use of a platform based on presented model in this dissertation ca reach more people with PD the advantages of therapies oriented to the maintenance of cognitive abilities for the longest time possible. This improve in their cognitive abilities gets in a maintenance of patients' quality of life over a longer period. 


\section{Capítulo 1. Introducción}

El primer capítulo de esta tesis doctoral describe a grandes rasgos el contenido de esta memoria. A través de una especificación del ámbito en el que se enmarca este trabajo, se pretende conseguir que el lector empiece a tener conciencia de cuáles son los problemas a los que se enfrentan las personas con enfermedad de Parkinson y qué es lo que este trabajo de investigación ha procurado abarcar. Al final del capítulo se describe la organización de la memoria de esta tesis doctoral.

El presente trabajo detalla la investigación, desarrollo y evaluación de un modelo ubicuo para la realización de Terapias de Estimulación Cognitiva (TEC) orientadas a tratar y monitorizar el deterioro cognitivo asociado a la Enfermedad de Parkinson (EP).

Las TEC se centran, generalmente, en programas de terapias grupales desarrolladas para personas con deterioro cognitivo. Se utilizan para la estimulación mental, reminiscencia, orientación y atención [Morey, 2014]. Estas terapias se diseñan a través de la evaluación de pruebas de investigación, por lo que son tratamientos basados en la evidencia [Spector, 2003]. El Gobierno de Reino Unido recomienda este tipo de tratamientos para personas con deterioro cognitivo leve a moderado, con independencia del tratamiento farmacológico que esté recibiendo el paciente [NICE, 2016].

En esta tesis, se ha pretendido evaluar un modelo de este tipo de terapias centradas en el deterioro cognitivo que presentan las personas con EP. El Libro Blanco del Parkinson en España, define esta enfermedad de la siguiente forma:

"La enfermedad de Parkinson es un trastorno neurodegenerativo crónico producido por la destrucción, por causas aún desconocidas, de las neuronas 'dopaminérgicas', que se encuentran en una región del cerebro denominada 'ganglios basales', en concreto en una parte del tronco del encéfalo llamada 'sustancia negra'. Estas neuronas actúan en el sistema nervioso central y utilizan como neurotransmisor primario la dopamina, encargada de transmitir la información necesaria para el correcto control de los movimientos» [Peñas, 2015].

De la definición anterior se puede concluir que, debido a este déficit de dopamina, aparecen los temblores, la rigidez y la lentitud de movimiento que tanto caracterizan a la EP. Sin embargo, existen otros ámbitos a analizar para el diagnóstico clínico, complejo sobre todo en las fases iniciales de la enfermedad. Además, de las alteraciones motoras, también aparecen otros trastornos, como pueden ser autonómicos, afectivos, del sueño, orgánicos o neuropsiquiátricos y cognitivos (alucinaciones, delirios, demencia, etc.). Estos síntomas no motores, aunque poco conocidos por la población en general, son una parte muy significativa de la enfermedad. Cuando los cambios en la cognición son leves, se le denomina deterioro cognitivo leve. Cuando 
estos cambios son más grandes e impiden realizar correctamente las actividades de la vida diaria, se convierte en demencia. Esta demencia suele aparecer en la persona diagnosticada de EP en fases avanzadas, apareciendo en un tercio de los diagnosticados. No obstante, las alteraciones cognitivas afectan a todos los pacientes [Ofarrill, 2016]. Es en el tratamiento del deterioro cognitivo leve asociado a la EP en el que se centran los trabajos de esta tesis.

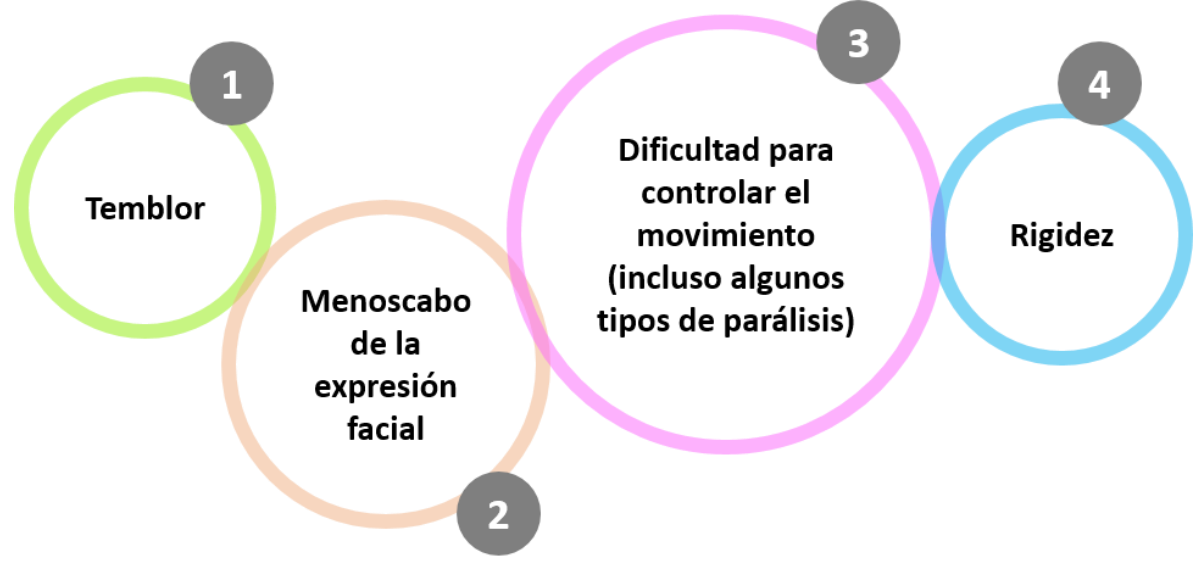

Figura 1. Sintomatología de la EP [Peñas, 2015]

A día de hoy, se desconocen las causas por las que aparece la EP. Si bien se han detectado factores de riesgo como pueden ser la edad, factores genéticos o factores medioambientales, aún no se han alcanzado a averiguar los motivos de esta pérdida neuronal. La edad media a la que suele aparecer la enfermedad de Parkinson está entre los 55 y 60 años, aunque excepcionalmente puede surgir de forma más precoz [ACP, 2016].

La EP afecta a 160.000 personas en España, aunque se estima que existe un $30 \%$ más que no están diagnosticados, ya que no acuden al médico al asociar su sintomatología al progreso normal del envejecimiento [Benito, 2003]. En Europa, hay más de 1,2 millones que ya han sido diagnosticadas según la European Parkinson's Disease Association (EPDA). La prevalencia a nivel mundial es de 6,3 millones de personas diagnosticadas en 2004 [OMS, 2004]. Según los estudios de la EPDA, se estima que la incidencia mundial en poco más de 15 años afectará a entre 8,7 y 9,3 millones de personas [EPDA, 2007].

La EP es una enfermedad neurodegenerativa que no tiene cura, por lo que los tratamientos farmacológicos y quirúrgicos palian los síntomas, pero no curan. Este tipo de pacientes, además de terapias farmacológicas, también siguen otras terapias de entrenamiento para mantener el mayor tiempo posible sus capacidades. Como ejemplo, cabe destacar la fisioterapia, la logopedia y la musicoterapia, entre otras. Dentro de estas terapias también existe una unidad de atención psicológica donde, además de ayudar al paciente a asumir su enfermedad, también se realizan talleres de memoria, relajación y estimulación cognitiva [APKM, 2017, 1]. Se ha demostrado que estas terapias de rehabilitación pueden ayudar a ralentizar el progreso de la enfermedad, mejorando considerablemente la calidad de vida de los pacientes [MJFF, 2016].

La mayor parte de estas terapias no farmacológicas se llevan a cabo en asociaciones con personal especializado en el tratamiento de la EP. Estas asociaciones no están disponibles en todo el territorio español, por lo que muchas veces surgen problemas de desplazamiento al tener que abarcar grandes distancias, tanto para el acceso a las consultas como para el acceso a las asociaciones. Estos problemas se agravan más aún cuando la enfermedad ha evolucionado 
debido al empeoramiento de la autonomía y de la movilidad del paciente [Peñas, 2015]. Estos desplazamientos podrían evitarse utilizando técnicas de salud electrónica (e-Salud, Salud 2.0), en las que, mediante la utilización de las Tecnologías de la Información y la Comunicación (TIC), los pacientes puedan contactar con sus profesionales, tanto en los hospitales como en las asociaciones, mejorando así la calidad asistencial a estos pacientes y haciendo llegar terapias de rehabilitación a entornos rurales donde no es viable el desplazamiento a una asociación.

En este ámbito, las TIC que se utilizan están principalmente orientadas a la videoconferencia médico-paciente. En el caso particular de esta tesis doctoral, se ha decidido, tras un amplio estudio de la bibliografía existente y numerosas entrevistas con comités de expertos en el tema (detalladas a lo largo de la presente memoria), utilizar las TIC para acercar a los pacientes con EP un tipo particular de terapia de rehabilitación que suele ser una gran olvidada en este campo: la estimulación cognitiva.

Las TIC pueden contribuir, como ya se ha demostrado a lo largo de los últimos años, a mejorar el seguimiento, la asignación de tratamientos y la atención prestada a los pacientes que, por problemas geográficos o de movilidad, no pueden asistir a centros sanitarios con regularidad [Khetrapal, 2015]. Actualmente en España, la penetración de los dispositivos móviles inteligentes es muy alta. Según el Informe de la Sociedad de la Información en España, en 2014 más del $80 \%$ de los usuarios de internet accedía a través de un dispositivo móvil [FT, 2015]. El mayor crecimiento de los internautas con respecto al año anterior ocurrió en la franja de edad entre los 55 y 64 años, creciendo 8,6 puntos en un año y llegando al 50,01\% en 2014 [INE, 2014]. Esto constata que las personas mayores cada vez aprecian más las ventajas que les ofrece internet en su día a día. Además, la tasa de penetración de conexión de banda ancha en el hogar también va al alza, así como el número de internautas global (conexiones fijas y móviles), llegando a alcanzar al finalizar el año 2016 a más de 31,5 millones de españoles [ONTSI, 2016]. Pese al crecimiento constante del número de hogares que disponen de banda ancha fija, este valor no se asemeja aún a las tasas que alcanza la banda ancha móvil. Esto se ha debido al abaratamiento de los dispositivos, gracias a las economías de escala y, principalmente, a la disponibilidad del acceso a los contenidos en cualquier lugar y en cualquier momento. Es por todo lo anterior por lo que se ha decidido que la utilización de dispositivos móviles inteligentes con conexión a internet sería una buena opción para la integración de las TEC.

Con el fin de conseguir el mayor grado de aceptación con el servicio prestado a las personas con $E P$, se ha contado con la ayuda de numerosas asociaciones de Parkinson en toda España y con el apoyo de la Federación Española de Parkinson (FEP). Gracias a estas colaboraciones, se han podido realizar entrevistas a en terapias de estimulación cognitiva en todo el territorio, como por ejemplo neuropsicólogos y psicólogos encargados de las TEC en las asociaciones Parkinson Madrid, Parkinson Sevilla y Parkinson Bahía de Cádiz. Con esta colaboración, se ha podido evaluar el cumplimiento de los objetivos inicialmente propuestos a través de experimentos formales con grupos de pacientes. Asimismo, el comité de expertos creado para esta colaboración también ha participado en la elección de la tecnología más idónea para su utilización por personas con EP, principalmente desde los puntos de vista del dispositivo de usuario final y de la interacción de los pacientes con el servicio.

Este trabajo de investigación ha sido llevado a cabo entre los años 2011 y 2016. Para detallarlo en profundidad, a lo largo de esa memoria se expondrán, en un primer lugar, los objetivos 
propuestos tras el análisis de la bibliografía y las entrevistas con el comité de expertos. A continuación, después de haber contextualizado la solución a partir de las necesidades del colectivo implicado, se detallarán de forma extensa las necesidades de las personas con EP a partir de la descripción de la enfermedad, sus datos epidemiológicos y las circunstancias económicas y sociológicas que enmarcan esta patología. Asimismo, se describirán en detalle los estudios propios y ajenos que pretenden mejorar la calidad de vida de los pacientes con EP. Una vez fijados estos objetivos y el contexto en el que se enmarcan, se procederá a la presentación de distintos métodos de captura de requisitos de usuario y la justificación de la selección del idóneo para este entorno, definiendo los requisitos funcionales y no funcionales necesarios para la realización del prototipo con el que se llevará a cabo la experimentación. El siguiente capítulo estará relacionado con el prototipo utilizado para comprobar el grado de satisfacción de la realización de TEC utilizando las TIC. Se abordará este prototipo desde el punto de vista de ingeniería del software, diferenciando entre su funcionalidad, la elección de tecnologías, el diseño de las interfaces y la verificación técnica, tanto a través de pruebas unitarias como de pruebas de sistema. Una vez mostrado el prototipo, se procederá a exponer el proceso llevado a cabo para realizar la experimentación con usuarios finales. Aquí, se separará el proceso de preparación de la experimentación y los agentes implicados en el mismo y los resultados obtenidos, desglosados según una gran diversidad de criterios que se han considerado relevantes. Por último, se revelarán las conclusiones obtenidas y el cumplimiento de los objetivos indicados inicialmente. 


\title{
Capítulo 2. Definición de hipótesis y objetivos
}

\author{
El presente capítulo, el segundo de esta tesis doctoral, describe el alcance de la \\ misma y presentan las hipótesis a ratificar, así como los objetivos perseguidos con \\ la realización de este trabajo de investigación, definiendo, a su vez, los resultados \\ esperados tras la experimentación.
}

\subsection{Alcance de la tesis doctoral}

El marco de la estimulación cognitiva en las personas diagnosticadas con EP, tal y como se ha detallado en el capítulo anterior, se presenta propicio para su provisión a través de las TIC. Al aumentar la esperanza de vida y, por tanto, existir una previsión del incremento de personas con EP, también se estima un crecimiento en el número de personas que sufran deterioro cognitivo asociado a esta enfermedad.

La introducción de las TIC en este ámbito permite, entre otras ventajas, el hacer llegar este tipo de terapias a lugares donde no estaban presentes, evitando así el aislamiento que estos pacientes pueden sufrir debido a la discapacidad percibida, aun en el caso de que el individuo no manifieste síntomas visibles. Asimismo, gracias a las TIC también se pueden crear terapias personalizadas para estos pacientes, adaptándolas a su nivel de deterioro cognitivo, nivel cultural o capacidades. Las TIC además pueden contribuir a aumentar la disponibilidad de estas terapias, ya que, a día de hoy, únicamente están presentes en asociaciones de pacientes o en residencias especializadas en EP.

El campo de actuación de la EP es muy amplio, como se detallará extensamente en el Capítulo 3. Justificación y antecedentes, por lo que se ha considerado oportuno acotar el alcance de esta tesis doctoral. Como se describió en el capítulo anterior, la EP es una enfermedad neurodegenerativa cuyos trastornos motores causan la mayor parte de la pérdida de la autonomía personal del individuo que la sufre. Pese a esto, existen otras deficiencias que se presentan, más o menos acusadas, asociadas a la enfermedad. Estas deficiencias, asociadas a la dimensión psíquica del individuo, son variadas, como las pérdidas de atención, disminución de la capacidad de cognición, depresión, cambios en el estado de ánimo o lentitud de pensamiento, entre otras [NPF, 2017]. Debido a la amplitud del espectro de la EP, en este trabajo de investigación nos hemos centrado en la posibilidad de mejora o mantenimiento de las capacidades cognitivas a través de terapias no farmacológicas [Bloem, 2015].

El deterioro cognitivo asociado a la EP no es igual que el debido a otras patologías como pueden ser la enfermedad de Alzheimer o a la demencia vascular, por lo que otras soluciones de estimulación diseñadas para estas patologías no son aplicables a la EP [Perry, 1985]. Es por ello que esta tesis doctoral se centra en la presentación de un modelo de estimulación cognitiva 
centrado específicamente en la EP y en las necesidades de estos pacientes que proporcione mejoras considerables en las TEC gracias al a introducción de las TIC.

La asignación de tratamientos individualizados, además, es uno de los objetivos recogidos en el programa de investigación, desarrollo e innovación de la Unión Europea, donde se marcan los objetivos para el año 2020, conocido como Horizonte 2020 [CDTI, 2017]. Esta estrategia se centra en tres pilares fundamentales: abordar los retos sociales definidos por la Comisión Europea, promover el liderazgo industrial en Europa y reforzar la excelencia de su base científica [H2020, 2017]. Los proyectos presentados tienen un carácter tanto orientado a investigación como innovación, difusión de resultados, proyectos piloto o estandarización, entre otros [CDTI, 2014]. Este programa fija diversas actuaciones, entre las que se incluyen el liderazgo industrial como motor para aplicar las políticas y los retos sociales que se consideran imprescindibles para poner a Europa en clara ventaja con respecto a la calidad de vida de sus habitantes y a la innovación. Como retos sociales (Societal Challenges) se han fijado siete iniciativas, según el campo al que van orientadas. Estas iniciativas son [CDTI, 2014]:

- Salud, cambio demográfico y bienestar.

- Seguridad alimentaria, agricultura y silvicultura sostenibles, investigación marina, marítima y de aguas interiores y bioeconomía.

- Energía segura, limpia y eficiente.

- Transporte inteligente, ecológico e integrado.

- Acción por el clima, medio ambiente, eficiencia de los recursos y materias primas.

- Europa en un mundo cambiante: Sociedades inclusivas, innovadoras y reflexivas.

- Sociedades seguras: proteger la libertad y la seguridad de Europa y sus ciudadanos.

Este trabajo de investigación estaría contemplado en el primer reto. Para cada reto se fija un programa de trabajo que abarca dos años, empezando en 2014 que fue cuando se definió esta estrategia, excepto para el último que abarca desde 2017 a 2020 incluidos. En el reto específico de salud, el programa de trabajo 2016-2017 contiene llamadas a la preparación de propuestas de proyectos en el ámbito de la medicina personalizada [H2020, 2016]. En este programa de trabajo se define, literalmente, que está orientado a la promoción del envejecimiento saludable y el cuidado sanitario personalizado. Las llamadas para la presentación de proyectos en el ámbito de la medicina personalizada se centran en enfermedades raras, tecnologías avanzadas, envejecimiento activo, analítica de datos o salud electrónica en general entre otras, siendo en esta última en la que se podría incluir el modelo propuesto en esta tesis doctoral.

Para la confirmación de la las mejoras aportadas y la utilidad del modelo presentado, ha sido necesario el desarrollo de una plataforma de estimulación cognitiva orientada a las necesidades de una persona con EF que, posteriormente, ha sido evaluada por estos pacientes y por sus terapeutas. En esta evaluación se han tenido en cuenta varios factores, como son:

- Selección de pacientes según su deterioro cognitivo / deterioro motor / utilización de nuevas tecnologías (NNTT).

- Selección de terapeutas participantes en terapias de estimulación cognitiva (TEC) de forma tradicional en asociaciones de pacientes. 
- Estudio y selección de las NNTT disponibles en el mercado para la implementación del modelo siguiendo criterios de eficiencia, accesibilidad, usabilidad y bajo coste.

- Evaluación de la viabilidad del modelo a través de medidas de experiencia de usuario (UX).

En este trabajo no se ha considerado la posibilidad de comprobar la mejora clínica a través de este tipo de terapias debido a la necesidad de plantear un ensayo clínico. Los ensayos clínicos son estudios que permiten determinar si nuevos tratamientos, medicamentos o dispositivos contribuyen a prevenir, detectar o tratar una enfermedad [THI, 2017]. Normalmente es necesario controlar la medicación que están recibiendo los pacientes y, en el caso particular de la EP, también su estado de ánimo porque pueden interactuar con la cognición. En este caso en particular, el ensayo clínico debería haber estado orientado a los medios de tratamiento para evaluar la eficacia de la TEC del modelo. Debido a la complejidad, el tiempo y la necesidad de acceder a los tratamientos de los pacientes, se ha optado por dejar definido el modelo y, si la aceptación de los usuarios es positiva, poder dejarlo abierto para un futuro ensayo clínico que compruebe la efectividad del tratamiento no farmacológico de estimulación cognitiva planteado.

Una vez definido el alcance de este trabajo, se procede a la definición de las hipótesis a validar en esta tesis doctoral, que serán apoyadas por objetivos.

\subsection{Formulación de las hipótesis}

Visto todo lo anterior, las hipótesis de partida de esta tesis doctoral se presentan desde tres enfoques distintos, cada uno de ellos orientado a un aspecto concreto que debe ser contemplado para mejorar la estimulación cognitiva en personas con EP a través de la introducción de TIC. La validación de estas hipótesis, descrita posteriormente, se basa en la utilidad del modelo presentado en esta memoria. Por ello, la primera hipótesis se plantea de la forma siguiente:

\section{HIPÓTESIS1. Las actuales terapias de estimulación cognitiva orientadas a personas con enfermedad de Parkinson pueden mejorar su eficiencia a través de las tecnologías de la información y la comunicación.}

Esta primera hipótesis se plantea desde el enfoque de la eficiencia entendida, en este caso particular, como la comparación entre el tiempo y esfuerzo que supone la realización de TEC en las asociaciones de la forma tradicional y según el modelo propuesto. Esto partirá de la apreciación de pacientes y terapeutas a través de la experimentación.

La segunda hipótesis propuesta en esta tesis doctoral toma otro enfoque, como se presenta a continuación:

HIPÓTESIS2. La aplicación de las tecnologías de la información y la comunicación a las terapias de estimulación cognitiva orientadas a personas diagnosticadas de enfermedad de Parkinson aumentan la satisfacción en el uso. 
La satisfacción en el uso se contemplará desde el punto de vista de UX. Para ello, se analizarán los distintos métodos de análisis de la UX, eligiendo el idóneo según el contexto que nos ocupa. La satisfacción en el uso es un parámetro imprescindible a cumplir a la hora de introducir nuevas técnicas en cualquier contexto. Esto es debido a que, si los usuarios no disfrutan, no aprecian la novedad o no se sienten cómodos con la utilización de estas nuevas técnicas, no aceptarán la introducción de las mismas y, por tanto, dejarán de utilizar el modelo.

Además, la satisfacción en el uso puede de forma indirecta hacer crecer la utilización del sistema, lo que conseguiría que los pacientes estuvieran deseosos de llevar a cabo sus terapias orientadas a la estimulación cognitiva. Esto hace necesario la formulación de una tercera hipótesis, enfocada a la adherencia a los tratamientos:

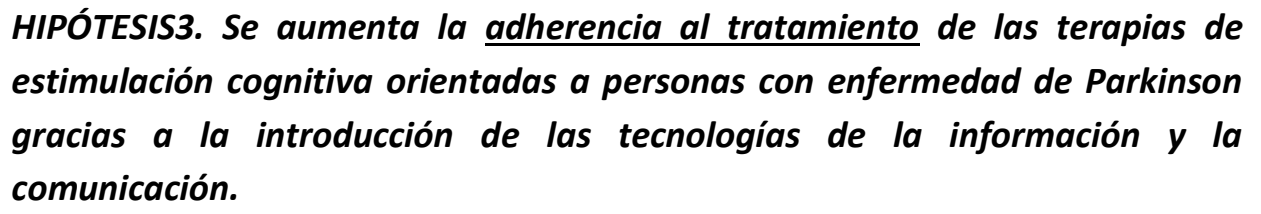
estimulación cognitiva orientadas a personas con enfermedad de Parkinson gracias a la introducción de las tecnologías de la información y la comunicación.

Esta tercera hipótesis, enfocada desde el punto de vista de la adherencia al tratamiento, se centra en la trascendencia que tiene este parámetro en cualquier entorno clínico. La Organización Mundial de la salud define la adherencia a un tratamiento como el cumplimiento del mismo [WHO, 2003]. La adherencia a los tratamientos es muy importante, ya sean farmacológicos o no farmacológicos, ya que, en el caso de no seguir las indicaciones, no se puede comprobar su eficacia. En el caso particular de este trabajo de investigación, la adherencia al tratamiento puede permitir que, en casos de pacientes con EP que vivan en zonas rurales aisladas o que, por problemas de discapacidad temporal o permanente no se puedan desplazar a las asociaciones a llevar a cabo TEC, tengan la posibilidad de realizarlas desde cualquier lugar y en cualquier momento gracias a la ubicuidad que se contempla en el modelo.

\subsection{Metodología para la validación de las hipótesis}

A la vista de las hipótesis planteadas en el apartado anterior, se puede comprobar que su validación no es algo trivial. Para poder asegurar su cumplimiento, ha sido necesaria la generación de una metodología compuesta de seis fases, que nos han permitido demostrar la utilidad y las mejoras que aparecen en el contexto de las TEC a través de la introducción de la tecnología. Estas fases son las siguientes:

1) Estudio de las metodologías de diseño existentes y elección de la idónea en este contexto de uso. Para esta elección se tuvo en cuenta que los usuarios finales, tanto pacientes como terapeutas, debían participar en todas las fases del diseño.

2) Creación de una relación de parámetros que permitan la definición de las TEC orientadas a personas EP que puedan ser incluidos en el modelo presentado en este trabajo de investigación. Esto permitió la implementación posterior de una plataforma, necesaria para llevar a cabo la experimentación con usuarios. De esta forma, se pudo validar que las mejoras planteadas en las hipótesis de partida eran correctas. 
3) Elaboración de un resumen de necesidades a nivel general de una persona con EP en sus dimensiones cognitiva, motora y emocional para futuras aplicaciones orientadas a estos pacientes. Estas consideraciones se tuvieron en cuenta en la implementación para adecuar la plataforma basada en el modelo a las necesidades de estos pacientes a la hora de interactuar con las TIC.

4) Implementación del modelo en una plataforma para poder realizar experimentos tanto con pacientes como terapeutas con el fin de validar las mejoras que aparecen en las TEC a partir del modelo propuesto basado en TIC.

5) Experimentación con usuarios finales (pacientes y terapeutas). Evaluación de estos cuestionarios a partir de metodologías de investigación.

6) Extracción de conclusiones del modelo generado a partir de los resultados de la experimentación con la plataforma. Este análisis de los resultados permitió la validación de las mejoras definidas inicialmente en las hipótesis.

Estas fases se realizaron en cascada con pequeñas superposiciones entre ellas. A continuación en la Figura 2 se muestra el cronograma de seguimiento de estas fases.

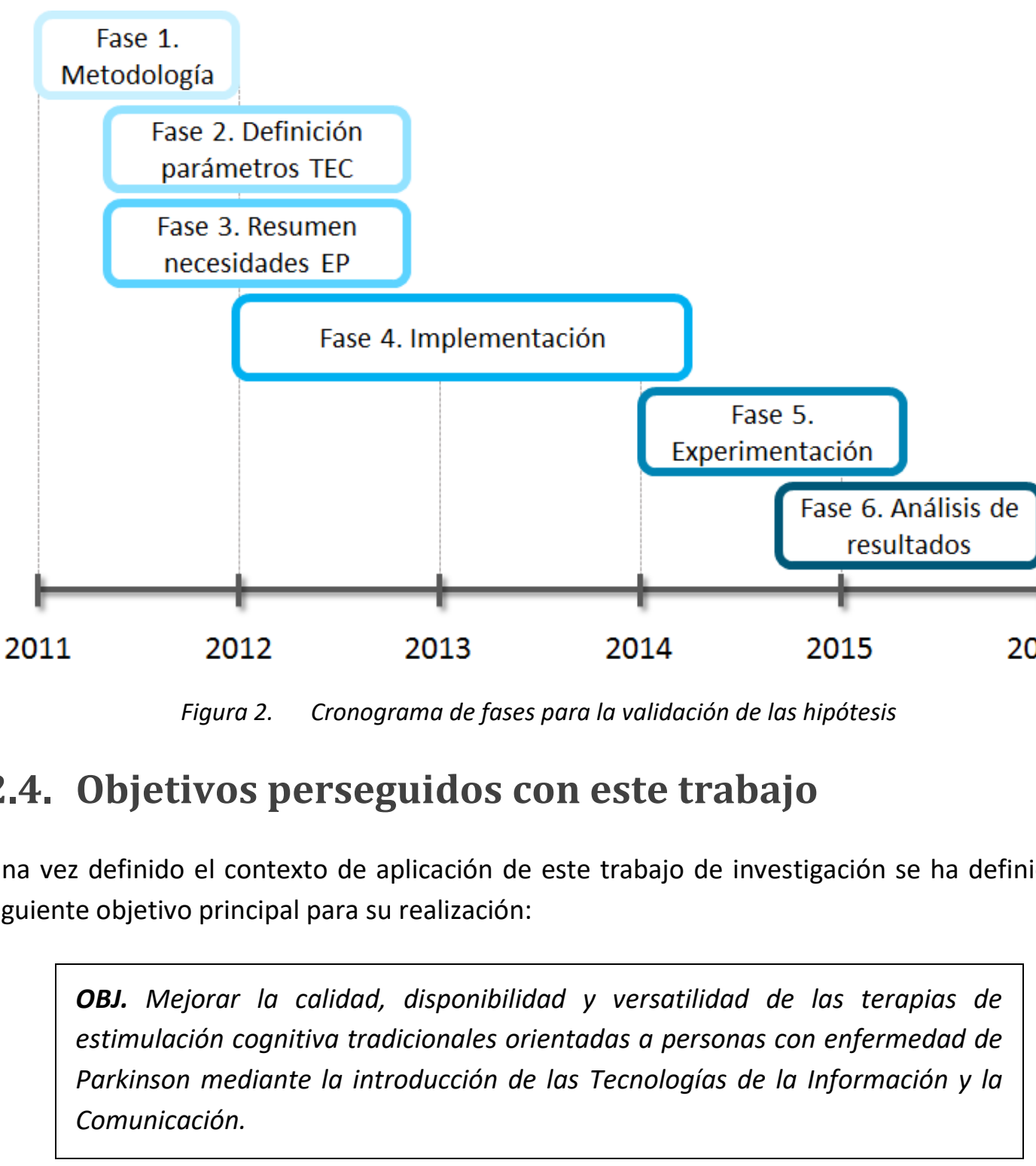


En este objetivo principal se recogen varios conceptos que deben tenerse en cuenta para la finalización a éxito de este trabajo de investigación. Estos conceptos son:

- Mejorar: según el Diccionario de la lengua española, mejorar es "adelantar, acrecentar algo, haciéndolo pasar a un estado mejor" [RAE, 2014, 1]. A través de la introducción de las TIC y tal y como se ha descrito en las hipótesis, se pretende mejorar las TEC desde tres puntos de vista: la eficiencia, la satisfacción en el uso y la adherencia al tratamiento. Para ello, es necesario considerar como aspectos de mejora la calidad, la disponibilidad y la versatilidad de estas terapias.

- Calidad: la mejora de la calidad desde un enfoque médico se centra en el análisis del trabajo y el esfuerzo en un contexto determinado [DU, 2017]. Esta calidad se describe de forma similar a la mejora de la eficiencia, relativa a la comparación entre tiempo y esfuerzo entre las TEC tradicionales y el modelo propuesto en este trabajo.

- Disponibilidad: según el Diccionario de la lengua española, disponibilidad es "cualidad o condición de disponible", y disponible, "dicho de una cosa: que se puede disponer libremente de ella o que está lista para usarse o utilizarse" [RAE, 2014, 2]. La introducción de las TIC y la ubicuidad de la que se quiere dotar al modelo permitirá la realización de estas terapias en cualquier momento y lugar, asegurando esta mejora de la disponibilidad.

- Versatilidad: el Diccionario de la lengua española define versatilidad como "cualidad de versátil", y versátil como "capaz de adaptarse con facilidad y rapidez a diversas funciones" [RAE, 2014, 3]. Esta capacidad de adaptación le aportará a nuestro modelo un amplio abanico de recursos para que los terapeutas puedan personalizar las terapias para cada paciente, haciendo que la base de datos de ejercicios de estimulación cognitiva sea dinámica. De esta forma, el servicio que se le da a cada paciente está más adaptado a sus necesidades y, por tanto, se mejora la calidad asistencial que se le presta en este contexto.

- Terapias de estimulación cognitiva (TEC): tal y como se describe a lo largo de esta memoria, son aquellas terapias que se llevan a cabo tradicionalmente para mejorar o mantener las capacidades cognitivas de un individuo [Spector, 2003].

- Enfermedad de Parkinson: como se ha definido a lo largo de esta memoria, es una enfermedad neurodegenerativa que afecta principalmente a las áreas del cerebro encargadas del control del movimiento. Esta enfermedad también presenta deficiencias en el plano intelectual como, por ejemplo, trastornos en la capacidad de cognición del individuo.

- Tecnologías de la Información y la Comunicación (TIC): este término abarca todas las tecnologías emergentes, que van evolucionando alrededor de los ordenadores, el software, las redes de comunicación y los sistemas de información [UKY, 2017]. Estas tecnologías serán las que se utilicen para las mejoras de la TEC reflejadas en puntos anteriores.

A partir de este objetivo principal, se han definido una serie de objetivos específicos que recogen los logros parciales necesarios para alcanzarlo. Teniendo en cuenta que uno de los conceptos recogidos en el objetivo principal es la disponibilidad de las TEC gracias al a introducción de las tecnologías, el primer objetivo específico se centra en las ventajas de esta disponibilidad: 
OBJ1. Fomentar la realización de las terapias de estimulación cognitiva fuera de las asociaciones.

Uno de los aspectos que se pretende mejorar con el planteamiento de este modelo es la disponibilidad de las terapias, independientemente del tiempo y el lugar. Para conseguir la consecución de este objetivo es necesario dotar al modelo de la ubicuidad descrita tanto en el título de esta tesis doctoral, definida de la siguiente forma:

- Ubicuidad: el Diccionario de la lengua española define ubicuidad como "cualidad de ubicuo" y ubicuo de la siguiente forma: "Dicho principalmente de Dios: que está presente a un mismo tiempo en todas partes" [RAE, 2014, 4]. Esta definición nos puede acercar al término técnico de la ubicuidad que, en el contexto TIC, se utiliza para denotar tecnologías en movilidad y en las que el lugar donde se realizan los procesos es indiferente, ya que lo importante es la disponibilidad del servicio en cualquier momento y lugar, tal y como se ha detallada previamente.

Asimismo, es imprescindible que la experiencia de los usuarios en la interacción con la plataforma que implementa al modelo sea satisfactoria para que, de esta forma, se pueda garantizar que los terapeutas lo asignen como terapia complementaria y los pacientes se sientan capaces de realizarla. Uno de los parámetros clave para la consecución de este objetivo es el seguimiento por el terapeuta. De esta forma, aunque se haya introducido la tecnología, el factor humano sigue estando presente detrás de ella.

Las ventajas del modelo a plantear son numerosas. En particular, por la promoción de la realización de terapias sin necesidad de que el paciente de EP se tenga que presentar en una asociación, lo que puede ayudar tanto a complementar las terapias con las que ya realizan allí como a asignárselas a pacientes nuevos que no puedan acceder a las asociaciones de personas con EP. La continuidad en los tratamientos, ya sean farmacológicos o no farmacológicos, son importantes para la mejora o el mantenimiento de la situación actual del paciente para cualquier patología [WHO, 2003]. En particular, en el caso de las personas con EP, es imprescindible para el mantenimiento de las capacidades cognitivas el mayor tiempo posible, lo que implica, a su vez, el mantenimiento de su calidad de vida y sus capacidades psíquicas, psicológicas y de socialización. Es por ello que el segundo objetivo se formula de la siguiente manera:

OBJ2. Promover la adherencia a las terapias de estimulación cognitiva como tratamiento no farmacológico para personas con enfermedad de Parkinson.

Este objetivo es uno de los más ambiciosos de esta tesis doctoral. Debido a la dificultad de validación, nos basaremos para cumplirlo en la percepción que sientan tanto los pacientes como los terapeutas que participen en la experimentación formal definida en la fase 5 del proceso de verificación de las hipótesis. Para ello, se contemplará en la planificación del experimento el incluir cuestiones relacionadas con el interés presentado por todo el colectivo del uso cotidiano de una aplicación de TEC basada en el modelo propuesto en esta tesis doctoral. 
Tras la consecución de estos dos objetivos anteriores, se debe considerar si es posible la eliminación de la brecha digital ${ }^{1}$ que muchos de los pacientes presentan en el acceso a las nuevas tecnologías. Esta brecha digital suele aparecer en el ámbito de la EP debida a la edad de los pacientes y al contexto cultural. La importancia de la eliminación de la brecha digital es para paliar, gracias a las enormes posibilidades de comunicación que ofrecen las TIC, el aislamiento de los individuos que sufren EP [Dunlap-Shohl, 2016]. Por ello, el tercer objetivo específico de esta tesis doctoral es:

OBJ3. Impulsar el uso de las nuevas tecnologías a las personas con enfermedad de Parkinson.

Este tercer y último objetivo específico es el más difícil de evaluar pese a la realización de una experimentación formal con los pacientes, ya que pretende confirmar si la utilización de una plataforma digital ayuda a los pacientes a perder el miedo a interactuar con NNTT. Este objetivo quedaría fuera del alcance de la tesis doctoral, pero puede ser útil comprobar si esta brecha digital puede verse mermada cuando un entorno en el que confían, como son las asociaciones de Parkinson, les dan acceso a ellas. De esta forma, a través de terapias basadas en TIC, ya sea para el mantenimiento de las capacidades cognitivas o para otro tipo de tratamientos no farmacológicos, estas asociaciones pueden ayudar a acercar la tecnología a las personas con EP. Este último objetivo es el más difícil de evaluar debido a la necesidad de un experimento más amplio en el tiempo y que abarque más tecnologías que las que se utilicen para la implementación del modelo. Pese a ello, se incluirá en los perfiles de los pacientes si están o no familiarizados con las nuevas tecnologías para luego comprobar la dificultad y el interés de utilizarlas en este contexto, entendiendo la posibilidad de extrapolación a otros entornos TIC.

Una vez definidas las hipótesis de partida y los objetivos perseguidos para su consecución, a continuación, se detalla de forma más amplia la situación actual de la EP, donde se espera que el lector de esta tesis doctoral comprenda mejor la necesidad de este trabajo de investigación.

\footnotetext{
${ }^{1}$ La brecha digital se define como la separación cada vez más acusada entre los individuos de mayores ingresos, nivel cultural y menor edad y los miembros desfavorecidos de la sociedad, principalmente las personas con menos ingresos, sin estudios, mayores y discapacitados, que no tienen acceso a las NNTT (ordenadores, móviles, internet, etc.), ya sea por sus recursos económicos o por sus capacidades [Marchick, 1999].
} 


\title{
Capítulo 3. Justificación y antecedentes
}

\begin{abstract}
Este tercer capitulo de la presente memoria de tesis doctoral describe en detalle la enfermedad de Parkinson. Para ello, en un primer lugar se expondrán sus causas y sintomatología, continuando con el contexto socioeconómico en el que se encuadra y finalizando con las terapias no farmacológicas que se utilizan para paliar sus síntomas. La segunda parte de este capítulo describe el contexto tecnológico actual, presentando las tecnologías más avanzadas a día de hoy en movilidad para dotar al modelo de la ubicuidad planteada inicialmente. Por último, se presenta un amplio estudio de la bibliografía existente sobre soluciones tecnológicas orientadas a terapias no farmacológicas en la EP, centrándonos tanto en los productos comerciales como en los que están en fase de investigación. Asimismo, en este último apartado, se incluirá una parte donde se presenten los estudios previos de la doctoranda.
\end{abstract}

\subsection{La Enfermedad de Parkinson (EP)}

\subsubsection{Descripción de la enfermedad}

El Parkinson es una enfermedad neurodegenerativa, incapacitante y crónica que actualmente no tiene cura y que produce en aquellos que lo padecen un deterioro progresivo de sus facultades físicas.

Como ya se comentó en el Capítulo 1. Introducción, la EP afecta a las neuronas dopaminérgicas, las encargadas de la secreción de dopamina, un neurotransmisor imprescindible en la función motora del organismo [Beck, 2005]. Estas neuronas se encuentran en una parte del cerebro denominada sustancia negra, situada en el mesencéfalo y una parte importante de los ganglios basales. En la Figura 3 se observa mejor dónde se sitúa la sustancia negra.

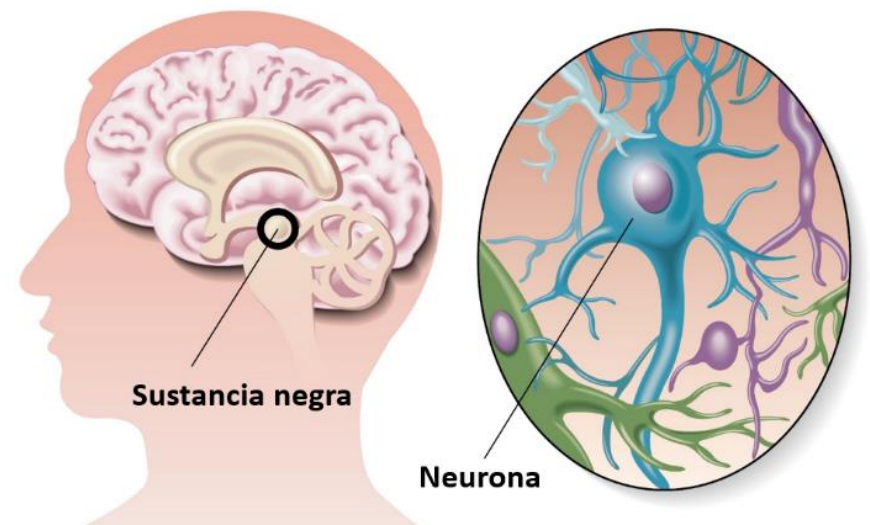

Figura 3. Localización de la sustancia negra en el cerebro [Castillo, 2016] 
La disminución de dopamina en el organismo provoca que no se creen puentes eléctricos entre neuronas dopaminérgicas, perjudicando a la sinapsis neuronal y, por tanto, el control de los movimientos de la persona [PDF, 2017, 1]. En la Figura 4 se presenta esta disminución.

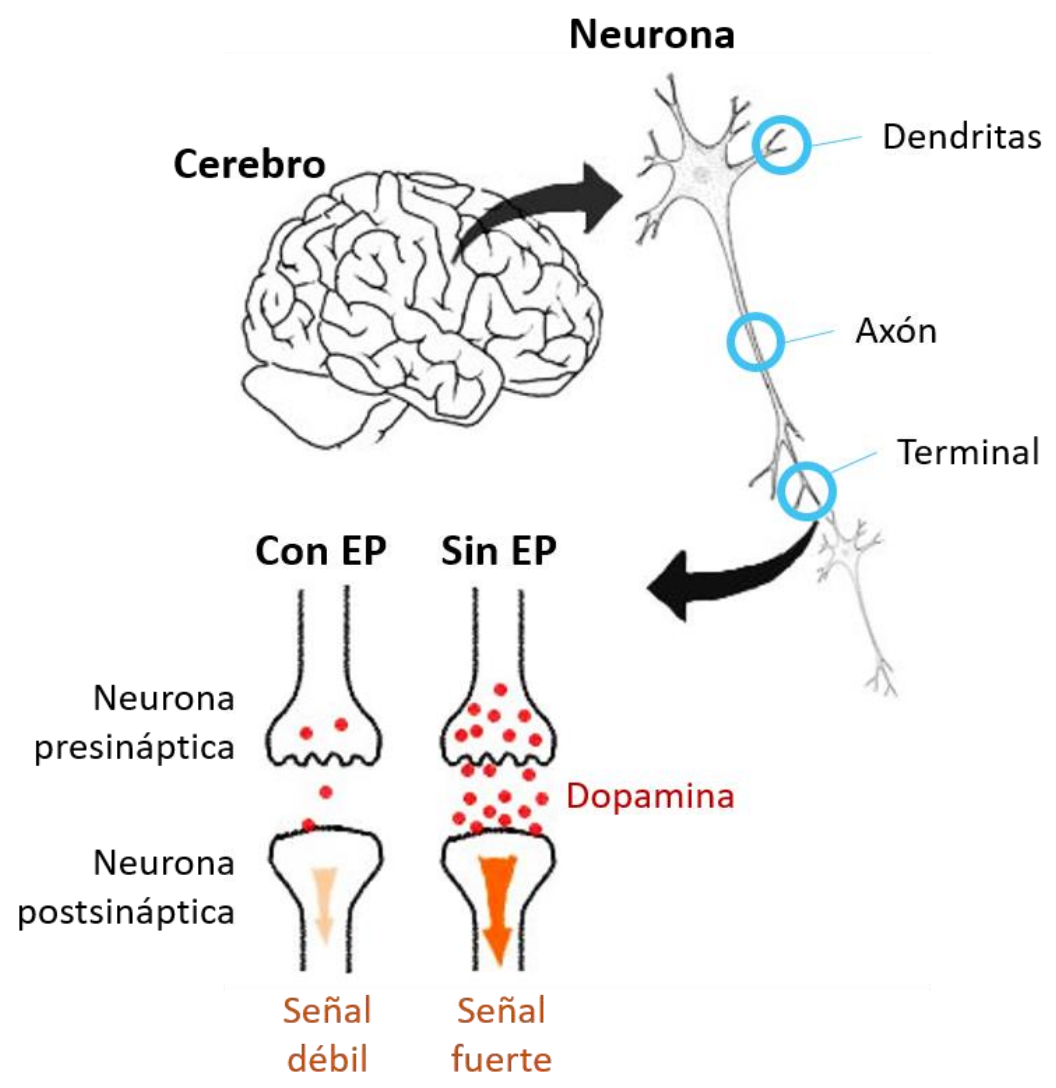

Figura 4. Disminución del nivel de dopamina en el cerebro [ENBM18, 2015]

A pesar de todos los avances de la neurología, hoy en día se desconoce la etiología de la enfermedad, por lo que también se desconoce cómo prevenirla. Afecta tanto a hombres como a mujeres, y más del $70 \%$ de las personas diagnosticadas de EP supera los 65 años de edad, siendo la prevalencia a partir de esta edad del $2 \%$. Sin embargo, no es una enfermedad exclusivamente de personas de edad avanzada, ya que el $20 \%$ de los diagnosticados es menor de 50 años [APKM, 2017, 1]. Un tercio de los afectados están aún en edad laboral y cada vez es mayor el aumento de afectados jóvenes. Otro factor a tener en cuenta es que la enfermedad aumenta su incidencia al elevarse también la edad de la población.

La EP evoluciona de tal manera que, a medida que la enfermedad avanza, los afectados se convierten en dependientes de otras personas para realizar las tareas básicas y cotidianas (asearse, caminar, levantarse de un sillón o de la cama, alimentarse, etc.). Los síntomas más conocidos son los motores: temblor, rigidez, pérdida de equilibrio, lentitud en los movimientos o trastornos en la capacidad para comunicación, pero la EP también afecta a otras áreas de la persona como son su estado de ánimo, su cognición, sus relaciones con la familia, su pareja, su entorno o su ocio. Es decir, se trata de una enfermedad que desestructura y rompe la vida de los afectados y la de los que los rodean.

De hecho, la EP conlleva depresión asociada en más de un 50\% de los casos [Levy, 2002]. También padecen ansiedad, estrés, demencia tipo Parkinson, trastornos de relación o 
conductuales entre otros, por lo que se producen importantes trastornos psicológicos, familiares y sociales.

Tanto por los problemas de accesibilidad (la discapacidad física y su inmovilidad), como por los trastornos en el lenguaje, así como las complicaciones psicológicas, se produce un aislamiento del afectado en su domicilio rompiendo las relaciones con los demás y abandonando todo tipo de actividades de ocio, laborales y sociales.

Al describir la enfermedad, James Parkinson planteó en su obra original que los sentidos permanecían indemnes. Sin embargo, las investigaciones realizadas en las últimas décadas han revelado que los trastornos cognitivos forman parte de la sintomatología clínica de la enfermedad de Parkinson [Vera, 2006].

Los síntomas de los trastornos cognitivos en la EP pueden hacer su aparición desde los inicios de la enfermedad, si bien cada persona es muy diferente. Así pues, la distribución de síntomas cognitivos en el proceso de evolución de la enfermedad es meramente orientativa. Sin embargo, se puede decir que los trastornos cognitivos son comunes en enfermos de EP, incluso en los que tienen un diagnóstico reciente, mostrándose los mayores déficits en los campos de la memoria y de las funciones ejecutivas [Muslimovi, 2005].

El deterioro cognitivo que se asocia a esta enfermedad afecta en torno a un $80 \%$ de la población de enfermos de EP [Meireles, 2012]. Desde el inicio de la enfermedad, pueden aparecer ciertos déficits cognitivos como la lentitud en el procesamiento de la información, dificultades de atención, impulsividad, falta de inhibición, rigidez, etc., que poco a poco se irán acentuando según vaya avanzando la enfermedad.

Casi todos los pacientes de EP muestran de moderada a intensa lentitud de velocidad del pensamiento y del procesamiento de la información (bradipsiquia). Por eso tardan en entender una cuestión y en dar una respuesta a una pregunta, aunque la lógica básica aplicada no se encuentre muy alterada. Presentan dificultades para mantener la atención durante un tiempo relativamente prolongado, olvidando incluso la instrucción. Si además hay desmotivación la atención se ve muy afectada.

Las funciones ejecutivas se definen como los procesos que asocian ideas, movimientos y acciones simples y los orientan a la resolución de conductas complejas. Los componentes de las funciones ejecutivas pueden ser dirección de la atención, reconocimiento de los patrones de prioridad, formulación de la intención, plan de consecución o logro, ejecución del plan y reconocimiento del logro.

Los pacientes con trastornos cognitivos presentan un síndrome disejecutivo, término que se ha acuñado para definir las dificultades que exhiben algunos pacientes con una marcada dificultad para centrarse en la tarea y finalizarla sin un control ambiental externo. En segundo lugar, presentan dificultades en el establecimiento de nuevos repertorios conductuales y una falta de habilidad para utilizar estrategias operativas. En tercer lugar, muestran limitaciones en la productividad y en la creatividad con falta de flexibilidad cognitiva. En cuarto lugar, su conducta pone de manifiesto una incapacidad para la abstracción de ideas mostrando dificultades para anticipar las consecuencias de su comportamiento, lo que provoca una mayor impulsividad o incapacidad para posponer una respuesta. 
Los pacientes de EP pueden tener dificultades para calcular las distancias, la posición relativa entre varios objetos y la visión en tres dimensiones. También pueden tener dificultades para atender a canales multisensoriales, como por ejemplo ver y oír simultáneamente.

En cuanto a los problemas de memoria que son tan característicos de las demencias, tanto los pacientes con demencia tipo Alzheimer como aquellos con EP presentan trastornos de la memoria que difieren en el perfil clínico. Si comparamos el desorden mnésico general en ambas poblaciones con similar nivel de deterioro cognitivo encontramos mayor deterioro en los Alzheimer que en los Parkinson. Los enfermos de Alzheimer fallan más en la memoria semántica, memoria a corto plazo o en la episódica, además aun usando facilitadores les cuesta mucho o incluso no pueden llegar a la información porque no la han registrado.

En el caso del Parkinson los pacientes mejoran el recuerdo cuando se les facilitan claves. Esto nos indica que la información mnésica estaría archivada y conservada, pero en ellos el fallo está en la búsqueda espontánea de la información. Si nosotros les damos alguna clave, acceden fácilmente al archivo. Podemos inferir que los enfermos de Parkinson tienen una capacidad de aprendizaje mayor y que utilizando estrategias y claves semánticas podríamos facilitar su recuerdo. Esto es fundamental de cara a todo el proceso rehabilitador y terapéutico que nos propongamos trabajar tanto con el enfermo como con la familia, ya que nos proporciona la esperanza de que el enfermo pueda mejorar o mantener por más tiempo algunas de sus capacidades y sobre todo el beneficio en su autoestima y su autoeficacia tan importantes para su calidad de vida.

Con respecto a los síntomas, los más conocidos de esta enfermedad son los motores, aunque no son los únicos. A continuación, se presenta una lista de los más comunes. Como se ha expuesto anteriormente, tanto la gravedad de los síntomas como el orden en el que aparecen depende de la persona que sufra la enfermedad [Sinapsis, 2017]:

- Síntomas motores: falta de expresión en la cara, lentitud y torpeza para la realización de movimientos automáticos (parpadear, tragar, balancear los brazos al caminar) y voluntarios (vestirse, levantarse de una silla, escribir), escritura lenta y con trazos pequeños (micrografía), temblor, rigidez motora en las extremidades, inclinación de la cabeza y del tronco hacia adelante, falta de equilibrio, anomalías al andar (incapacidad de levantar los pies completamente), bradicinesia (lentitud de movimientos).

- Depresión.

- Cambios en los hábitos intestinales: estreñimiento.

- Trastornos urinarios.

- Trastornos de la actividad sexual.

- Trastornos del sueño.

- Sudoración.

- Trastornos respiratorios.

- Trastornos oculares.

- Trastornos cognoscitivos.

- Demencia. 
La atención psicológica ayuda a encarar la enfermedad y a manejar los trastornos derivados de la misma: depresión, trastornos cognitivos, ansiedad, problemas de familia y de relación con los demás.

El grado de afectación del individuo diagnosticado de EP se mide según la escala de Hoehn y Yahr [Hoehn, 1998]. Esta escala es la más utilizada para valorar la progresión y severidad de la EP. Se centra en los trastornos motores asociados a esta enfermedad, ya que son los que causan mayor dependencia al individuo. La Tabla 1 presenta los estadios contemplados en esta escala y la sintomatología asociada a cada uno.

Tabla 1. Escala de Hoehn y Yahr para la progresión de la EP [Hoehn, 1998]

\section{Estadio Sintomatología}

\begin{tabular}{|l|l|}
\hline $\mathbf{0}$ & No hay signos de enfermedad. \\
\hline $\mathbf{1}$ & Enfermedad unilateral. \\
\hline $\mathbf{2}$ & Enfermedad bilateral, sin alteración del equilibrio. \\
\hline $\mathbf{3}$ & $\begin{array}{l}\text { Enfermedad bilateral leve a moderada con inestabilidad postural; físicamente } \\
\text { independiente. }\end{array}$ \\
\hline $\mathbf{4}$ & Incapacidad grave, aún capaz de caminar o permanecer en pie sin ayuda. \\
\hline $\mathbf{5}$ & Permanece en silla de ruedas o encamado si no tiene ayuda. \\
\hline
\end{tabular}

En este trabajo de investigación nos vamos a centrar en el deterioro cognitivo asociado a la EP. El $80 \%$ de las personas diagnosticadas de EP sufren demencia a los 8 años de este diagnóstico, y son conscientes de ello [Meireles, 2012]. Sin embargo, no hay una escala específica que permita clasificar, en la medida de lo posible, el deterioro cognitivo asociado a la EP. Es por ello que se utiliza la Clasificación Clínica de la Demencia (CDR), que se diseñó para personas con enfermedad de Alzheimer. Esta clasificación distingue entre 5 niveles con valor numérico, que son los siguientes [Hughes, 1982]:

- Estado cognitivo sano (0).

- Estado cognitivo cuestionable $(0,5)$.

- Deterioro cognitivo leve (1).

- Deterioro cognitivo moderado (2).

- Deterioro cognitivo grave (3).

La Tabla 2 y la Tabla 3 detallan en más profundidad la sintomatología asociada a cada uno de los niveles de la CDR. Para llevar a cabo esta clasificación se tienen en cuenta diversas áreas que se encuentran presentes tanto a nivel del individuo como de las actividades de la vida diaria o de la interacción con el entorno y con otras personas. Estas áreas son: memoria, orientación, juicio y resolución de problemas, vida social, hogar y aficiones y cuidado personal [Hughes, 1982]. 
Tabla 2. Clasificación clínica de la demencia (CDR) según Hughes (sano a leve)

\begin{tabular}{|c|c|c|c|}
\hline Área & Sanos (CDR 0) & Cuestionable (CDR 0,5) & Leve (CDR 1) \\
\hline Memoria & $\begin{array}{l}\text { Sin pérdida de memoria. } \\
\text { Olvidos de poca } \\
\text { importancia. }\end{array}$ & $\begin{array}{l}\text { Olvidos consistentes } \\
\text { leves: recuerdo parcial } \\
\text { de acontecimientos. } \\
\text { Olvidos "benignos". }\end{array}$ & $\begin{array}{l}\text { Pérdida de memoria } \\
\text { moderada, más } \\
\text { marcada para } \\
\text { acontecimientos } \\
\text { recientes; el defecto } \\
\text { interfiere con } \\
\text { actividades diarias. }\end{array}$ \\
\hline Orientación & $\begin{array}{l}\text { Completamente } \\
\text { orientado. }\end{array}$ & $\begin{array}{l}\text { Completamente } \\
\text { orientado }\end{array}$ & $\begin{array}{l}\text { Algunas dificultades con } \\
\text { relaciones temporales; } \\
\text { orientados por lugar y } \\
\text { persona durante la } \\
\text { prueba, pero puede } \\
\text { haber desorientación } \\
\text { geográfica. }\end{array}$ \\
\hline $\begin{array}{l}\text { Juicio y resolución } \\
\text { de problemas }\end{array}$ & $\begin{array}{l}\text { Resuelve bien } \\
\text { problemas cotidianos; } \\
\text { juicio bueno en relación } \\
\text { al rendimiento pasado. }\end{array}$ & $\begin{array}{l}\text { Sólo deterioro dudoso } \\
\text { en la resolución de } \\
\text { problemas. Similitudes/ } \\
\text { diferencias }\end{array}$ & $\begin{array}{l}\text { Dificultad moderada } \\
\text { para manejar problemas } \\
\text { complejos; juicio social } \\
\text { suele mantenerse. }\end{array}$ \\
\hline Vida social & $\begin{array}{l}\text { Función independiente } \\
\text { en nivel habitual de } \\
\text { trabajo, compras, } \\
\text { negocios y asuntos } \\
\text { financieros, grupos } \\
\text { sociales y voluntarios. }\end{array}$ & $\begin{array}{l}\text { Deterioro dudoso o leve } \\
\text { si es que existe, en estas } \\
\text { actividades. }\end{array}$ & $\begin{array}{l}\text { Incapaz de funcionar } \\
\text { independientemente en } \\
\text { estas actividades, } \\
\text { aunque todavía puede } \\
\text { realizar algunas; puede } \\
\text { aparecer normal en } \\
\text { contacto casual. }\end{array}$ \\
\hline $\begin{array}{l}\text { El hogar y las } \\
\text { aficiones }\end{array}$ & $\begin{array}{l}\text { Vida doméstica, } \\
\text { aficiones, intereses } \\
\text { intelectuales se } \\
\text { mantienen bien. }\end{array}$ & $\begin{array}{l}\text { Vida doméstica, } \\
\text { aficiones, intereses } \\
\text { intelectuales se } \\
\text { mantienen bien, sólo } \\
\text { ligeramente } \\
\text { deteriorados. }\end{array}$ & $\begin{array}{l}\text { Leve pero definitivo } \\
\text { deterioro de función } \\
\text { doméstica; se } \\
\text { abandonan las tareas } \\
\text { más difíciles; se } \\
\text { abandonan aficiones e } \\
\text { intereses más } \\
\text { complejos. }\end{array}$ \\
\hline Cuidado personal & $\begin{array}{l}\text { Totalmente capaz de } \\
\text { cuidarse de sí mismo. }\end{array}$ & $\begin{array}{l}\text { Totalmente capaz de } \\
\text { cuidarse de sí mismo. }\end{array}$ & $\begin{array}{l}\text { Necesita estimulación } \\
\text { ocasional. }\end{array}$ \\
\hline
\end{tabular}

Tabla 3. Clasificación clínica de la demencia (CDR) según Hughes (moderado a grave)

\begin{tabular}{|l|l|l|}
\hline Área & Moderada (CDR 2) & \multicolumn{2}{|c|}{ Grave (CDR 3) } \\
\hline Memoria & $\begin{array}{l}\text { Grave pérdida de memoria; retención } \\
\text { exclusiva de material muy importante; } \\
\text { pérdida rápida de material nuevo. }\end{array}$ & $\begin{array}{l}\text { Grave pérdida de memoria, sólo quedan } \\
\text { fragmentos. }\end{array}$ \\
\hline
\end{tabular}




\begin{tabular}{|l|l|l|}
\hline Orientación & $\begin{array}{l}\text { Habitualmente desorientación temporal, } \\
\text { a menudo de lugar. }\end{array}$ & Orientación sólo respecto a personas. \\
\hline $\begin{array}{l}\text { Juicio y resolución } \\
\text { de problemas }\end{array}$ & $\begin{array}{l}\text { Manejo de problemas gravemente } \\
\text { deteriorado. Similitudes/diferencias; } \\
\text { juicio social suele estar deteriorado. }\end{array}$ & $\begin{array}{l}\text { Incapaz de intentar juicios o resolver } \\
\text { problemas. }\end{array}$ \\
\hline Vida social & $\begin{array}{l}\text { Ninguna pretensión de funcionamiento } \\
\text { independiente fuera del hogar. }\end{array}$ & $\begin{array}{l}\text { Ninguna pretensión de funcionamiento } \\
\text { independiente fuera del hogar. }\end{array}$ \\
\hline $\begin{array}{l}\text { El hogar y las } \\
\text { aficiones }\end{array}$ & $\begin{array}{l}\text { Sólo se conservan las tareas más sencillas; } \\
\text { intereses muy limitados. Mantenimiento } \\
\text { pobre. }\end{array}$ & $\begin{array}{l}\text { Ninguna función doméstica significativa } \\
\text { fuera de la habitación propia. }\end{array}$ \\
\hline Cuidado personal & $\begin{array}{l}\text { Necesita asistencia para vestirse, lavarse y } \\
\text { cuidar de sus efectos personales. }\end{array}$ & $\begin{array}{l}\text { Requiere mucha ayuda para el cuidado } \\
\text { personal; a menudo incontinente. }\end{array}$ \\
\hline
\end{tabular}

Antes de centrarnos en el tratamiento para la EP, es necesario aclarar dos conceptos. En este trabajo nos estamos centrando en el Parkinson idiopático, es decir, en la sintomatología asociada a la EP diagnosticada. Esto no hay que confundirlo con los parkinsonismos, que consisten en una conjunción de síntomas similares a los de la EP (lentitud, rigidez, temblor en reposo, alteraciones de la marcha y del equilibrio, etc.), pero que pueden tener distintas causas, que van desde efectos secundarios de ciertos medicamentos hasta isquemia cerebral [UCP, 2016]. En el caso de la EP, el tratamiento farmacológico habitual del Parkinson idiopático se centra en la administración de levodopa. La levodopa es el precursor metabólico de la dopamina, es decir, hace a las neuronas segregar dopamina [López, 2008]. La dopamina no se administra directamente porque no puede atravesar la barrera hematoencefálica, por lo que no podría llegar al espacio sináptico y, por tanto, no tendría efecto en los pacientes. En cambio, la levodopa sí que tiene esta capacidad de penetración. Debido a la interacción de la levodopa por vía oral con otros aminoácidos de la dieta, normalmente se administra por vía intravenosa [Hiroshima, 2014]. El mayor problema que tiene la administración de levodopa es que, al cabo de un tiempo, termina perdiendo efectividad [PDF, 2017, 1].

Para mostrar de forma más clara cómo afecta la EP a la actividad cerebral y cómo actúa la levodopa, la Figura 5 presenta el resultado de una tomografía por emisión de positrones (PET) en dos personas sanas y dos personas diagnosticadas de EP antes de administrarles levodopa (pre) y después (post).
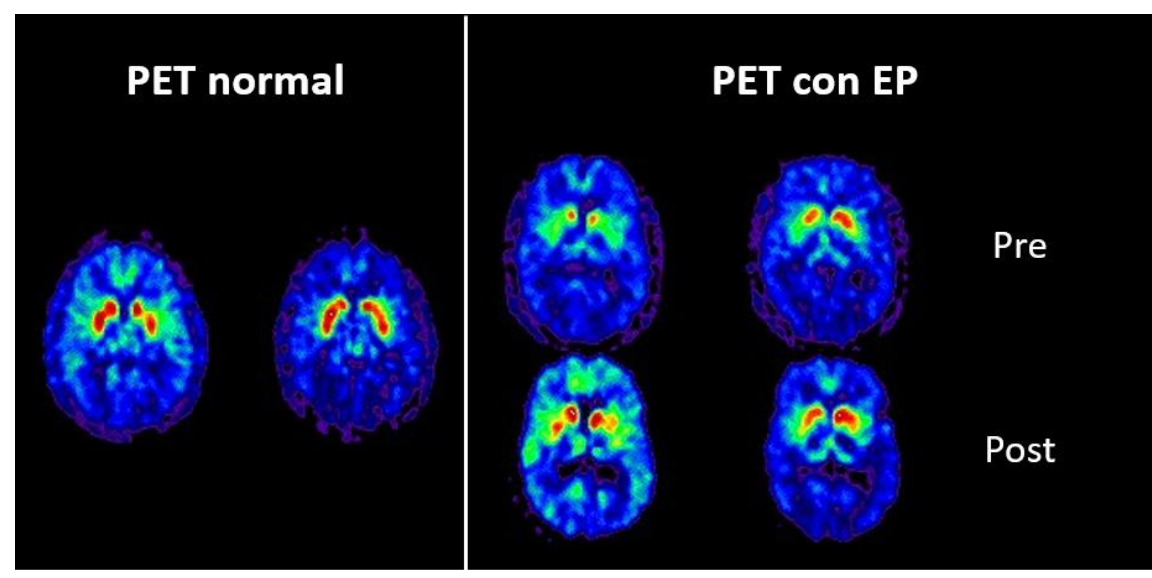

Figura 5. PET de dos cerebros sanos y dos con EP (sin y con medicación) [NPF, 2011] 
En estas imágenes se puede observar en una escala de color la cantidad de dopamina en el cerebro de la persona, siendo el color rojo el que refleja mayor densidad de esta sustancia. Mientras que en el caso de individuos sanos se puede apreciar una zona homogénea coloreada en rojo, las personas que sufren EP presentan una zona menor de este color, ya sea sin medicación como con ella. Por otro lado, las zonas con color son las que el individuo puede utilizar. En las personas con EP la actividad cerebral se percibe menor.

Los síntomas motores son los que causan la mayor pérdida de autonomía de las personas con EP [FEP, 2016]. La mayoría de los pacientes presentan inclinación del tronco, flexión de codos y rodillas y alteraciones en la marcha por lo que resulta difícil mantener el equilibrio y se pueden producir caídas con frecuencia [CCM, 2009]. Aunque estos síntomas son más acusados en fases avanzadas de la EP, los bloqueos son comunes desde que comienzan a presentarse los trastornos motores del paciente. La congelación o bloqueo de la marcha (FoG, Freezing of Gait) son episodios breves e intermitentes que eliminan la capacidad para caminar, describiéndose por los pacientes como la sensación de tener los pies pegados al suelo. Puede aparecer al inicio de la marcha o por cambios en la misma (modificación de la velocidad, del sentido del paso, caminar en espacios estrechos, etc.). Estos bloqueos son uno de los factores principales de la pérdida de autonomía y la calidad de vida de las personas con EP, dado que, en muchos de los casos, estos bloqueos tienen como consecuencia una caída [FEP, 2016].

A causa de esta pérdida de autonomía, la mayor parte de los esfuerzos investigadores relacionados con la EP se centran en paliar la sintomatología motora. Sin embargo, como ya se ha presentado previamente, existe gran cantidad de síntomas no motores [Poewe, 2008] entre los que se incluye el deterioro cognitivo, que es en el que se centra este trabajo de investigación.

Hoy en día las únicas armas que se tienen para luchar contra la EP son los medicamentos farmacológicos y quirúrgicos que palian los efectos de los síntomas, pero no curan. Las terapias complementarias son el otro gran mecanismo de defensa: terapia ocupacional, fisioterapia, logopedia, musicoterapia, etc. Éstas enlentecen la progresión de la enfermedad y procuran una mejor calidad de vida a las personas afectadas.

\subsubsection{Contexto socioeconómico}

La EP es la segunda enfermedad neurodegenerativa de mayor incidencia, superada solo por la enfermedad de Alzheimer. Afecta prácticamente igual a hombres y a mujeres, aunque sí hay ligeras variaciones entre razas y continentes [APKM, 2017, 1].

La EP no está obligatoriamente ligada al envejecimiento, aunque la mayoría de las personas que se diagnostican de esta enfermedad tienen más de 50 años [APKM, 2016]. Esto hace pensar que, aunque no se han descubierto sus causas, puede estar relacionada con el envejecimiento de la población. Debido a la mejora de la calidad de vida y a los avances de la medicina, la esperanza de vida está aumentando y esta tendencia se mantendrá a lo largo de los próximos años, por lo que se espera que aumente el número de personas diagnosticadas de EP. En la Figura 6 y en la Figura 7 se presentan dos pirámides de población confeccionadas a partir de los datos del Instituto Nacional de Estadística (INE). La primera de ellas refleja la distribución de la población española en el año 2016. La segunda representa la proyección llevada a cabo por el INE para dentro de 50 años, es decir, para el año 2066. A la vista de esta figura se puede comprender 
mejor hasta qué punto aumenta esta esperanza de vida, existiendo un valor bastante alto para los mayores de 100 años en el año 2066.

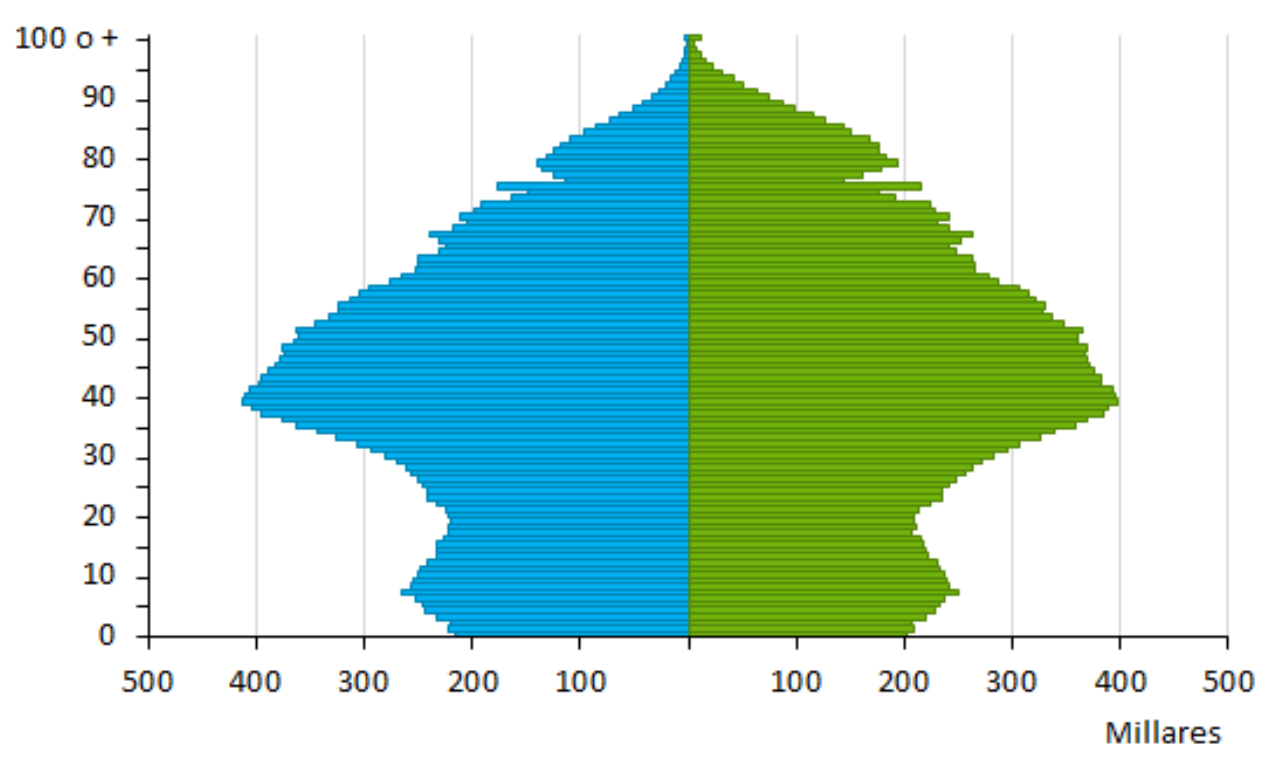

$\square$ Hombres $\square$ Mujeres

Figura 6. Población española real en el año 2016 [INE, 2016]

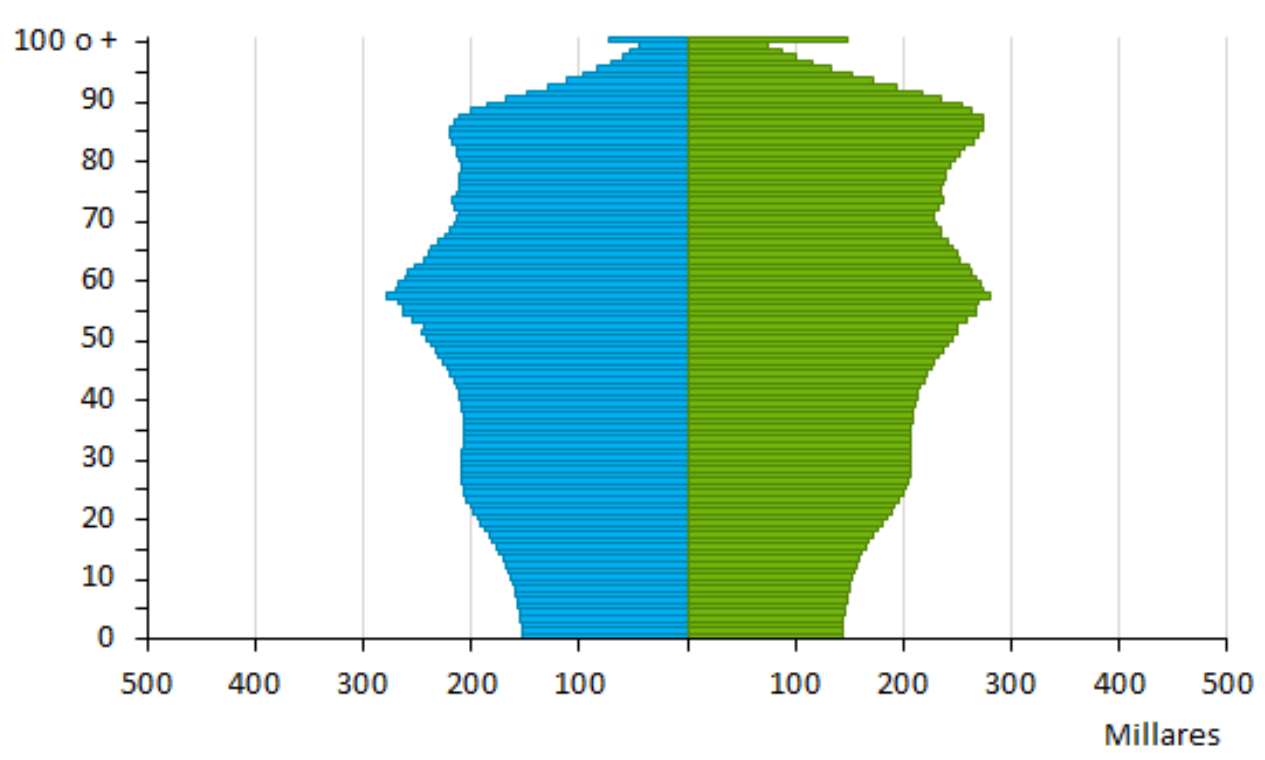

$\square$ Hombres $\square$ Mujeres

Figura 7. Proyección de la población española para el año 2066 [INE, 2016]

En las gráficas anteriores se puede observar un incremento constante de la población mayor de 65 años. El proceso de envejecimiento en España no es igual en todas las zonas, ya que el 71,7\% reside en municipios urbanos el $17,3 \%$ en municipios rurales intermedios y el $11 \%$ en municipios propiamente rurales. Aunque la mayor parte de la población mayor reside en zonas urbanas, muchas veces no tienen acceso a servicios diseñados para ellos, ya sea por los problemas de 
accesibilidad a los edificios, a los transportes o la discapacidad asociada a la persona. En el medio rural la problemática de la dispersión de los núcleos y la distancia entre ellos hace que se complique considerablemente la prestación de servicios [Sancho, 2007].

Estos servicios asistenciales están orientados principalmente al seguimiento de patologías crónicas. La prevalencia de este tipo de enfermedades aumenta con la edad. La Encuesta de Discapacidad, Autonomía Personal y Situación de Dependencia realizada por el INE en el año 2008 refleja la incidencia en ese año de las enfermedades crónicas más comunes, entre las que aparece la EP. La Figura 8 representa el número de personas mayores de 65 años que estaban diagnosticadas de estas enfermedades crónicas en el año 2008.

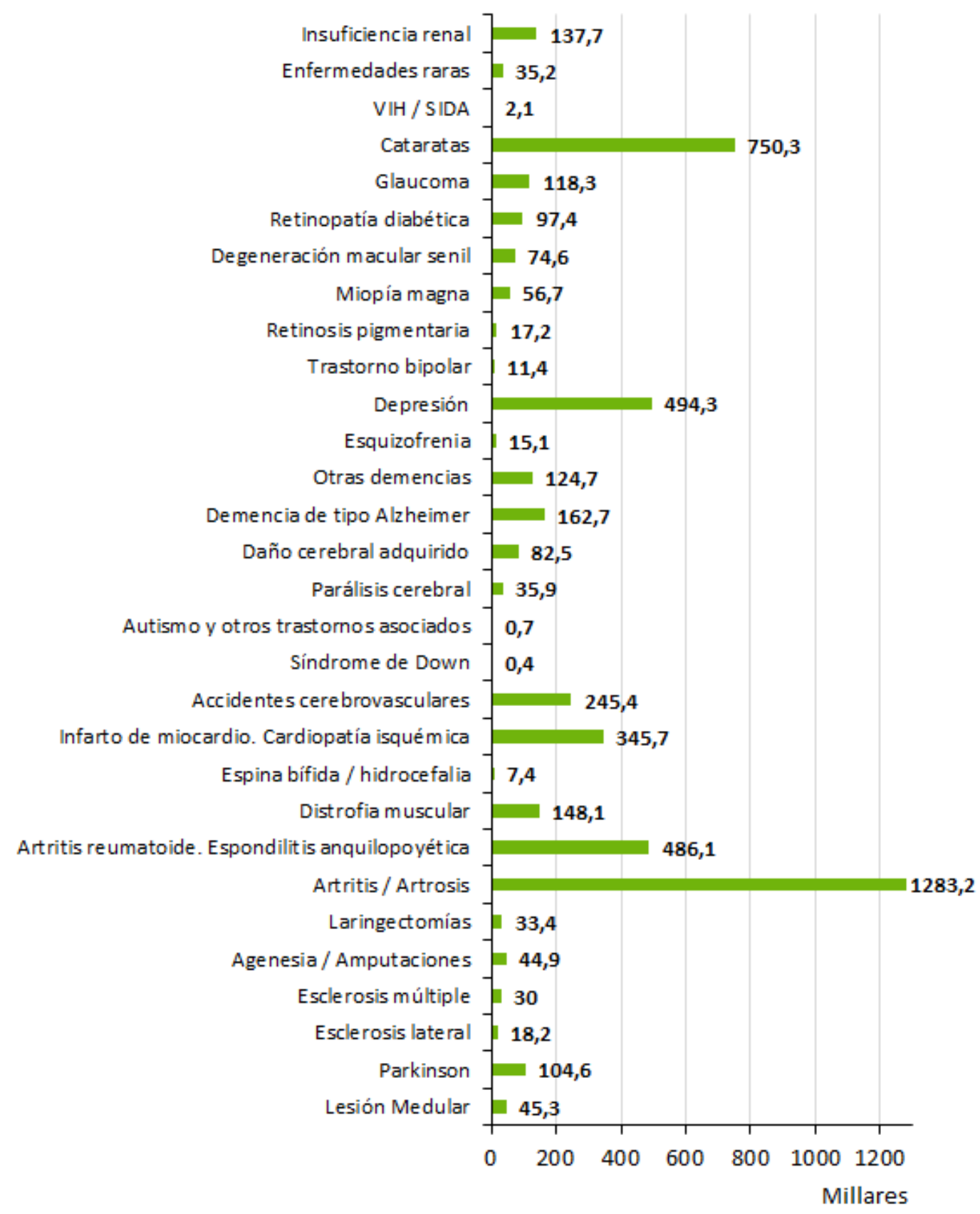

— 65 o más años

Figura 8. Mayores de 65 años con enfermedad crónica diagnosticada [INE, 2008, 1] 
En España se calcula que hay alrededor de 150.000 personas que sufren EP (presentado por sexo y comunidad autónoma en la Figura 9), estimándose una población afectada de 6,3 millones de personas a lo largo del mundo [Dorsey, 2007]. El coste de la enfermedad es alto. Teniendo en cuenta los costes directos (tratamientos, seguridad social) y los indirectos (cuidados informales, ausencias laborales) en Estados Unidos se estima que alcanzan los 25 millones de \$ al año. La medicación individual puede alcanzar los 2.500 \$ anuales y la cirugía terapéutica puede llegar hasta los 100.000 \$ por paciente [PDF, 2017, 2]. En el caso europeo, en 2005 los costes por deficiencias cerebrales superaron los 798.000 millones de $€$, donde los costes directos supusieron un $37 \%$, los costes no médicos un $23 \%$ y los costes indirectos un $40 \%$, siendo la media por habitante de $5.550 €$ a año [Olesen, 2012]. Esto implica que, aunque el cuidado médico sea muy alto, el coste personal para las familias debido a la dependencia que surge de la enfermedad es mayor que el coste terapéutico.

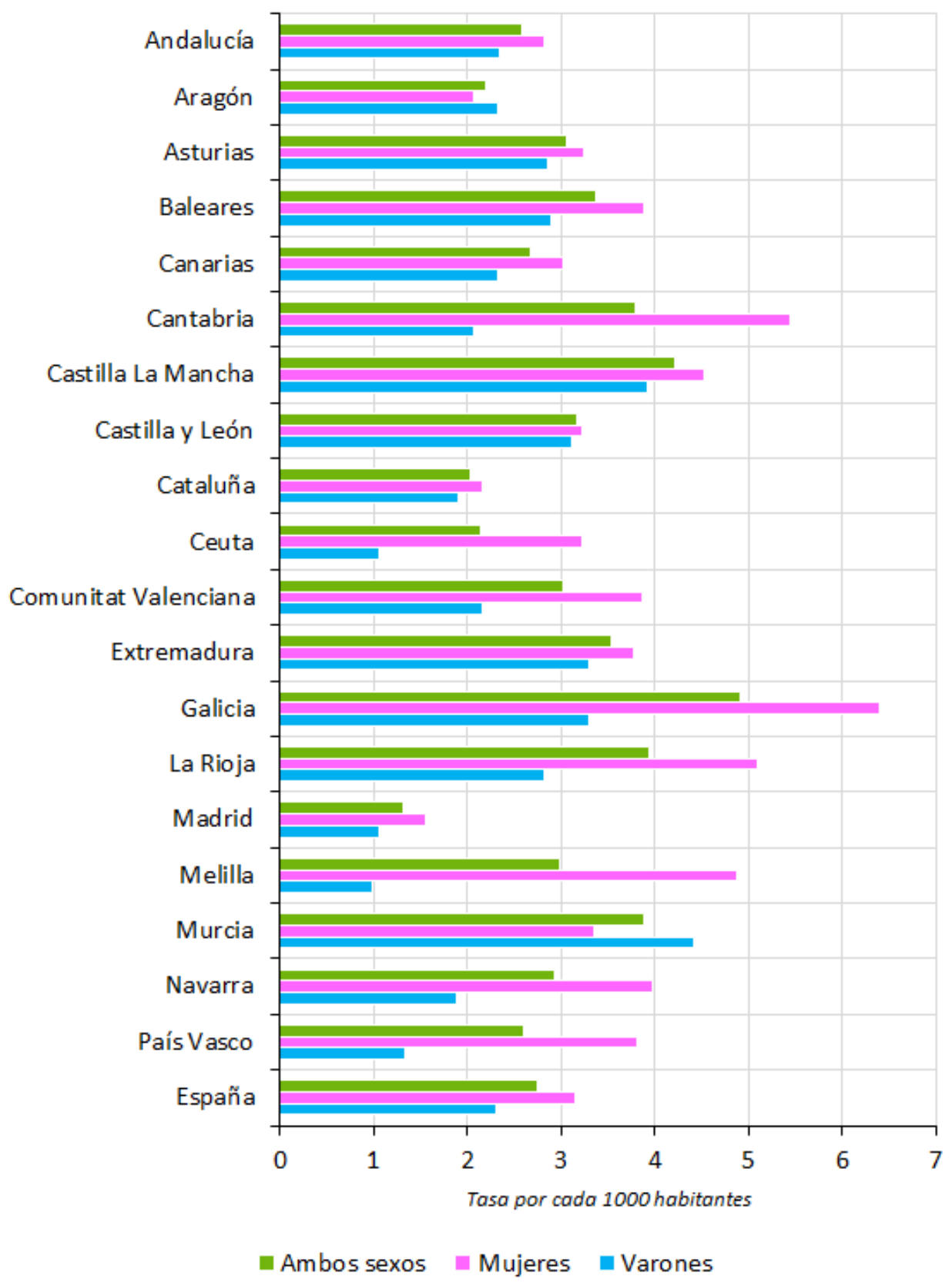

Figura 9. Diagnóstico de EP (en \%o). Datos por CCAA [INE, 2008, 2] 
El envejecimiento y las enfermedades crónicas asociadas tienen consecuencias en la estructura familiar. El proceso normal del envejecimiento termina siendo incapacitante para la persona. En España en 2005 había 1.125.190 personas en situación de dependencia grave o muy grave, de las que 826.551 eran mayores de 65 años [IMSERSO, 2004]. Esta dependencia hace que se requiera de la asistencia de algún cuidador. Comúnmente, los cuidadores son los familiares más cercanos, aunque esta tendencia va disminuyendo, siendo cada vez más frecuentes los mayores que viven solos, principalmente las mujeres [Sancho, 2007]. Esto es posible ya que el $72,6 \%$ de la población mayor tiene familiares que viven en el mismo barrio, pueblo o ciudad, disponiendo de una red de apoyo social y emocional.

Hasta la mitad de los pacientes diagnosticados de EP necesitan un cuidador durante los primeros 5 años, lo que provoca que hasta un $85 \%$ de estos cuidadores acabe sufriendo estrés emocional. Hasta un $25 \%$ de estos cuidadores emplean más de 70 horas semanales a la atención de estos pacientes, por lo que sufren pérdidas económicas debido a que terminan reduciendo su jornada laboral o abandonando el trabajo [Europa Press, 2017]. Además, alrededor del $72 \%$ de estos cuidadores padece fatiga, ansiedad, depresiones, problemas de concentración y memoria, tristeza y cambios de humor, ya que tienen mayor carga de trabajo que los cuidadores de otros enfermos crónicos [Goldsworthy, 2008].

Para las personas con EP es complicado asumir el diagnóstico de la enfermedad. De hecho, para logar la aceptación muchos de los afectados pasan algunas o todas las fases del duelo. Las fases del duelo tradicionalmente se han orientado únicamente a la pérdida de alguien cercano [Zimmerman, 2015]. Estas fases, conocidas como el modelo de Kübler-Ross, son, por este orden, negación, ira, negociación, depresión y aceptación [Kübler-Ross, 1970]. Según el individuo, ya sea una persona que acaba de recibir el diagnóstico de EP, o un familiar cercano, puede sufrir el proceso completo de duelo, no sufrirlo o pasar únicamente algunas de las fases. En los diagnosticados esto puede llegar a ocurrir por padecer una discapacidad sobrevenida que, además, lleva cuadros de depresión asociados como síntoma. Aun así, al contrario que lo que ocurre con otros colectivos que presentan discapacidades sobrevenidas, como puede ser la lesión medular [Conde, 2013], los individuos con EP tienden al aislamiento. Para ellos, el padecer problemas de movilidad y hablar más bajo y más lento hace que se presente una barrera, más percibida que real, de interaccionar con el mundo [Dunlap-Shohl, 2016]. Es por este aislamiento por el que las personas con EP tienden a sufrir depresiones profundas, lo que afecta enormemente a su humor y, por tanto, a su entorno. Los grupos de ayuda mutua pueden ser muy útiles tanto para los pacientes como sus familiares para conocer otros casos similares y la forma de enfrentarse a los problemas de otras personas que están pasando por la misma situación [Rivera, 2005].

Como consecuencia de los problemas que tiene la aceptación de este tipo de diagnóstico y la sensación de aislamiento social que sufren los pacientes de EP, ha surgido un importante movimiento asociativo alrededor de esta enfermedad. En el caso de España, a partir de la Constitución de 1978, se recogieron por primera vez las necesidades de las personas con discapacidad [CE, 1978]. Fue entonces cuando comenzó el movimiento asociativo en España, tanto de personas con discapacidad como de familiares de personas con esta condición [Maraña, 2003]. En el ámbito de la EP, en 1985 nació en Barcelona la primera asociación de Parkinson, cuyo objetivo principal era el mejorar la calidad de vida tanto de los afectados como de sus familiares. A partir de entonces, comenzaron a surgir más asociaciones en todo el 
territorio, asociándose muchas de ellas a la Federación Española de Parkinson, fundada en 1996 [FEP, 2017]. A día de hoy, hay un total de 45 asociaciones federadas repartidas por todo el territorio, tal y como se muestra en la Figura 10.

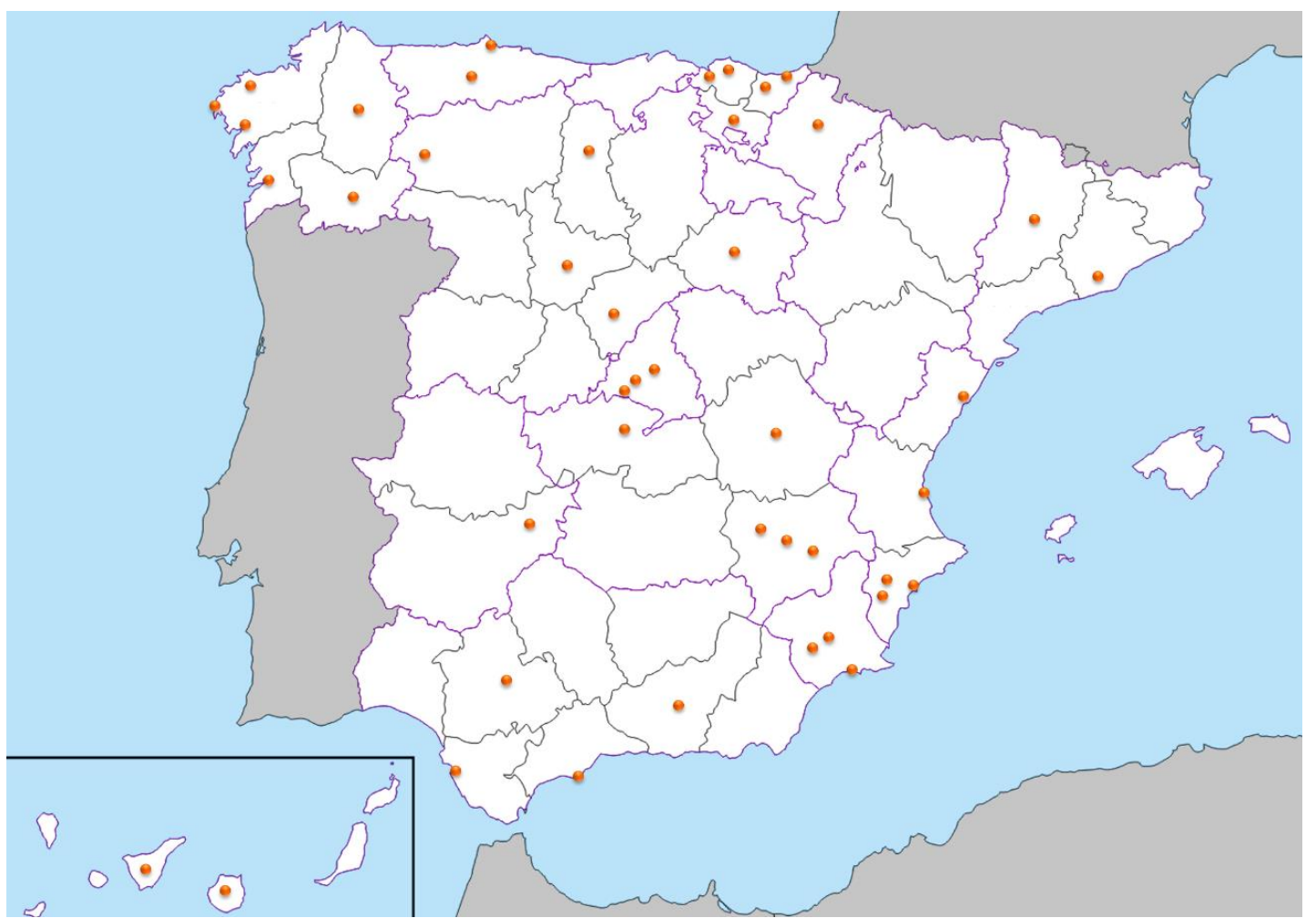

Figura 10. Asociaciones de Parkinson federadas

Además de estas asociaciones, existen multitud que no están federadas, como son Asociación de Parkinson de Aragón, Asociación Balear de Parkinson o la Associació Catalana per al Parkinson, entre otras.

La labor de estas asociaciones es muy amplia. Pese a que el seguimiento continuo de la evolución de la EP para cada paciente se realiza en el hospital por su neurólogo, las asociaciones tienen una gran importancia en el seguimiento psicológico de los pacientes. Como se ha descrito anteriormente, el diagnóstico de la enfermedad es muy difícil de aceptar, tanto por los pacientes como por sus familiares.

Debido a esto, la mayor parte de las asociaciones de Parkinson disponen de terapias orientadas a la prevención y el tratamiento de la depresión. Además, en estas asociaciones se les ofrecen terapias grupales, principalmente para que perciban que no están solos y se prevenga, de esta forma, el aislamiento del individuo [APKM, 2017, 1].

Alrededor de la EP han surgido diversos mitos. La EP es un proceso neurodegenerativo multisistémico que afecta al sistema nervioso central, siendo una enfermedad de causas desconocidas de tipo crónico, progresivo e incurable. A causa de las lagunas de conocimiento que aún existen alrededor de ella, la mayor parte de la población desconoce muchas de sus características, siendo la más conocida la relativa a los temblores. En las asociaciones se encargan de desterrar estos mitos. Entre ellos, se encuentran los siguientes [APKM, 2016]:

- ¿La enfermedad es contagiosa? No, en ningún caso.

- ¿Es mortal? No, la esperanza de vida de los afectados es casi idéntica a la media nacional. 
- ¿Solo afecta a ancianos? No, el $20 \%$ de las personas con EP de la Comunidad de Madrid tiene menos de 50 años.

- ¿La EP solo es temblor? No todas las personas que tiemblan tienen EP (pueden ser parkinsonismos) ni todas las personas diagnosticadas de EP tienen temblor.

- ¿Es igual que el Alzheimer? Pese a ser ambas enfermedades neurodegenerativas, el Alzheimer es un trastorno de memoria que rara vez tiene síntomas motores. La EP afecta al movimiento y no en todos los casos se desarrolla demencia.

- ¿Provoca demencias? El deterioro cognitivo asociado a la EP es más leve que en otras demencias y puede aparecer después de varios años de evolución.

Las asociaciones tienen una labor informativa y de apoyo muy importante para pacientes y familiares. Les hace darse cuenta de que no están solos, dándoles ayuda psicológica, social e informativa, además de soluciones prácticas o de nivel terapéutico. Para los familiares, además de darles apoyo psicológico y emocional, disponen de talleres de formación y cursos para el cuidado de los pacientes.

Además de tratamiento farmacológico que los pacientes reciben de su neurólogo, las asociaciones disponen de sesiones de rehabilitación y atención sociosanitaria para ellos, dándoles también terapias no farmacológicas, como se describirá en el siguiente apartado.

Muchas de las asociaciones de Parkinson utilizan un tulipán en su logo. Esto es porque, en 1981, un horticultor alemán diagnosticado de EP puso de nombre Dr. James Parkinson a una especie de tulipán. A día de hoy, el tulipán evoca la esperanza del encuentro de una cura para esta enfermedad con su florecimiento cada primavera. Desde 1995 las asociaciones comenzaron a integrarlo en su logo [APS, 2017]. En el caso de la European Parkinson's Disease Association (EPDA) el tulipán está muy presente, tal y como se muestra en la Figura 11.

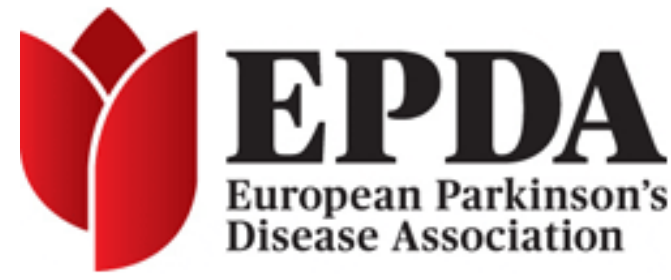

Figura 11. Logotipo de la EPDA

\subsubsection{Terapias no farmacológicas para el tratamiento de la EP}

En las asociaciones de personas con EP se llevan a cabo terapias no farmacológicas para paliar la sintomatología de la enfermedad, principalmente orientadas al mantenimiento de capacidades o, en algunos casos, a la rehabilitación. Como se ha destacado previamente, la atención psicológica es muy importante tanto para los pacientes como para sus familiares, que suelen ser sus cuidadores informales. Además de esto, en las asociaciones se puede recibir asesoramiento en el ámbito de la terapia ocupacional. La terapia ocupacional, según la Organización Mundial de la Salud, son el conjunto de técnicas, métodos y actuaciones que, a través de actividades aplicadas con fines terapéuticos, previene la enfermedad y mantiene la salud, favorece la restauración de la función, cumple las deficiencias incapacitantes y valora los supuestos del comportamiento y su significación profunda para conseguir la mayor independencia y reinserción posible del individuo en todos sus aspectos laboral, mental, físico y 
emocional [WFOT, 2016]. En el desarrollo del servicio de terapia ocupacional dado desde las asociaciones, el terapeuta desarrolla un plan personalizado, acorde a las necesidades de cada paciente, que le ayude a relacionarse correctamente con el entorno y a desenvolverse correctamente en las actividades de la vida diaria desde su nueva situación. Entre las acciones más relevantes, se suelen dar directrices para adaptar el domicilio del paciente creando un ambiente accesible, el asesoramiento sobre ayudas técnicas o la elaboración de una rutina diaria, todas ellas actividades para mejorar la autonomía personal del individuo [APKM, 2016]. En la Figura 12 se presenta el folleto relativo al servicio de terapia ocupacional de la Asociación Parkinson Madrid (APKM).

\section{Terapia Ocupacional \\ ¿cómo trabajamos? \\ El servicio de asesoramiento de Terapia Ocupacional de la Asociación Parkinson Madrid atiende y guía a los afectados de párkinson y sus familias a superar las dificultades que se presentan en su día a día con la combinación de:}

$\downarrow$ Ayudas técnicas

$\downarrow$ Aprendizaje correcto de elementos del hogar

- Adaptación de tu vivienda para la enfermedad de Parkinson

Estas acciones te ayudarán a mejorar tu autonomía diaria y harán de tu hogar un espacio accesible, seguro y sin riesgos para tu salud.

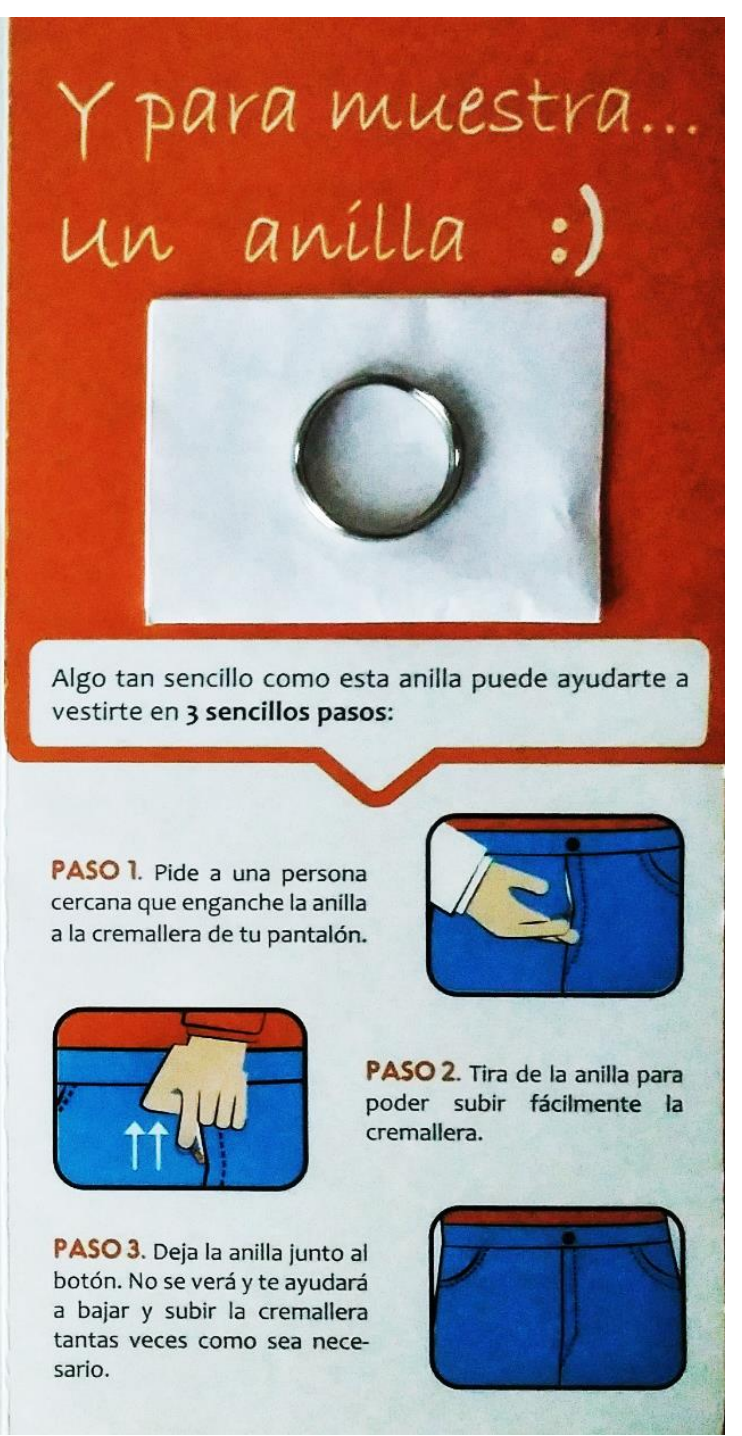

PASO 1. Pide a una persona cercana que enganche la anilla la cremallera de tu pantalón.

PASO 2. Tira de la anilla para poder subir fácilmente cremallera.

Figura 12. Folleto de terapia ocupacional [APKM, 2016]

La gran mayoría de los servicios ofertados por las asociaciones está centrado en atenuar los síntomas motores asociados a la EP. Uno de los tratamientos más ofertados es la fisioterapia, que ayuda a disminuir las molestias, mantenimiento la elasticidad muscular y la amplitud de movimientos. Los objetivos de la fisioterapia son numerosos, entre ellos están el entrenamiento de la relajación muscular, la mejora del equilibrio y la coordinación, evitar las caídas, superar los bloqueos, educar la postura corporal, reducir el dolor y estimular la coordinación y los reflejos [APKM, 2016]. Además de la fisioterapia, se provee de tratamientos individuales centrados en el rostro o el cuerpo. 
Los problemas motores también ocasionan deficiencias en el habla y la deglución. La logopedia aplicada a estos pacientes no se centra únicamente en la mejora del lenguaje, sino en la disminución del exceso de salivación, asegurar la masticación segura para prevenir atragantamientos, evitar la inexpresividad facial y mejorar el tono de la voz, el habla y, sobre todo, la respiración.

Centrado en la comunicación con el entorno, se ha demostrado que la musicoterapia como rehabilitación participativa ayuda a la interacción social de las personas con EP [APKM, 2016]. A través de ella se puede lograr el recuperar el ritmo y el equilibrio, fundamentales para evitar las caídas en caso de bloqueo del paciente, mejorar la estabilidad del individuo, mejorar el estado de ánimo o favorecer la coordinación de los movimientos.

Para disminuir los efectos del deterioro cognitivo, los pacientes con EP se pueden beneficiar de técnicas de rehabilitación cognitiva que sean específicamente diseñadas para mejorar las funciones ejecutivas [Sohlberg, 2001] [Koven, 2007]. Determinadas técnicas de estimulación cognitiva tienen un impacto en la evolución de determinados tipos de pacientes [García, 2000]. Estas técnicas podrían ser incorporadas a programas multidisciplinares de rehabilitación, integrando el papel de la neuropsicología con otros métodos de tratamiento como la terapia ocupacional y la fisioterapia [Trend, 2002].

Son muchas las asociaciones de Parkinson que utilizan técnicas de estimulación cognitiva como parte de la utilización de terapias adicionales para mejorar la calidad de vida de los afectados. En concreto y como ejemplo podemos citar el trabajo realizado en el Centro de Prevención de Deterioro Cognitivo del Ayuntamiento de Madrid que cuenta con diferentes tipos de estimulación cognitiva: en grupo, por ordenador y en el domicilio [CPDC, 2017].

Durante las últimas décadas se han realizado numerosas investigaciones encaminadas a demostrar que la actividad mental puede ayudar a prevenir o retrasar la aparición de déficits cognitivos [Prats, 2007]. La realización de ejercicios específicos para trabajar las funciones cognitivas suponen una estimulación que intenta reducir el impacto de estos síntomas en la vida diaria.

Hay evidencia científica y mucha actividad investigadora en curso sobre el efecto positivo de la estimulación cognitiva para enfermedades de tipo neurodegenerativo [Spector, 2003]. Sin embargo, en general, la actividad científica está más enfocada a otras enfermedades como el Alzheimer. En el caso de Parkinson no se ha encontrado evidencia científica sobre el resultado de experiencias realizadas haciendo uso de las TIC para terapias de estimulación cognitiva.

El uso de las TIC en el campo de la estimulación cognitiva puede suponer una herramienta importante para mejorar la cantidad y calidad de los servicios que se puede ofrecer a los enfermos, en especial a aquéllos que, como en el caso de las personas que padecen EP, tienen movilidad reducida y problemas de accesibilidad.

Cada persona diagnosticada de EP dispone de una historia clínica electrónica de su enfermedad en el sistema de salud. En el caso de que este paciente acuda a alguna asociación de Parkinson para la realización de terapias, también dispone de un historial terapéutico. Estas terapias constan de logopedia, fisioterapia o entrenamiento cognitivo, entre otras [Conde, 2011]. 


\subsection{Contexto tecnológico}

Tal y como se ha presentado en el título de esta tesis doctoral y en el Capítulo 2. Definición de hipótesis y objetivos, uno de los requisitos del modelo a desarrollar es la ubicuidad. El diseñar y evaluar un modelo ubicuo impone la apertura del acceso a las TEC en cualquier lugar y momento. Debido a ello, es necesaria la utilización de tecnologías móviles. A día de hoy, la mayor parte de los terminales móviles existentes en España son inteligentes (smartphones y tabletas) gracias a su abaratamiento por las economías de escala, al incremento constante de los contenidos disponibles y a la alta disponibilidad de cobertura tanto $3 \mathrm{G}$ como 4G. Es por ello que un dispositivo de estas características puede ser muy útil en este contexto de uso. De hecho, como se puede comprobar en la Figura 13, la tendencia es que vaya aumentando el porcentaje de la población que tiene acceso a internet a través solo de móvil o de fijo y móvil.

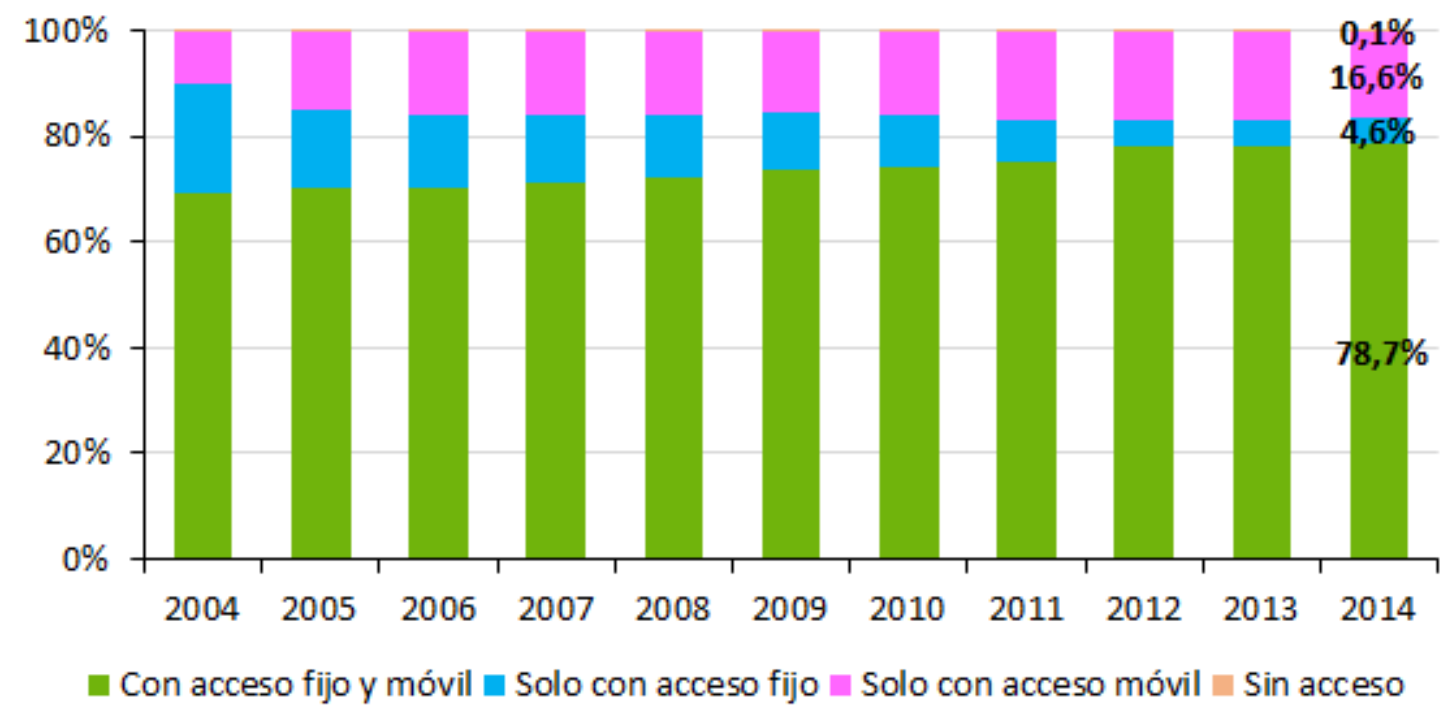

Figura 13. Métodos de acceso a internet en España [CNMC, 2015]

En España, al igual que en el resto de países del entorno, se ha ido incrementando el número de internautas con el transcurso de los años. Entre 2014 y 2015 este número aumentó en un millón de personas. Entre 2015 y 2016 este incremento llegó hasta el millón y medio, como se puede apreciar en la Tabla 4.

Tabla 4. Número de internautas en España [ONTSI, 2016]

\begin{tabular}{|l|l|l|l|}
\hline Año & 2014 & 2015 & 2016 \\
\hline Número de internautas & 29.924 .415 & 30.912 .406 & 31.568 .229 \\
\hline
\end{tabular}

El aumento del número de internautas se debe en gran medida a la cantidad de contenidos y servicios disponibles a través de los terminales móviles inteligentes. El número de este tipo de terminales en España representa ya el $87 \%$ del total de teléfonos móviles existentes, lo que sitúa a nuestro país en la primera posición a nivel europeo, superando incluso el número de ordenadores. A nivel de las tabletas, los otros dispositivos móviles inteligentes, las ventas a nivel mundial están descendiendo, aunque en España las ventas siguen creciendo, alcanzando ya una penetración del 72\% [AMIC, 2016]. Este descenso a nivel mundial es debido, en gran parte, al aumento del tamaño de la pantalla de los smartphones, aunque no alcanzan tamaños como los de las tabletas (hasta 13"). 
Estos dispositivos disponen de sistemas operativos diseñados ad hoc para entornos de recursos limitados, aunque cada vez tienen más capacidad de procesamiento, almacenamiento y conectividad por los avances en el campo de la nanotecnología. Los sistemas operativos más extendidos en el entorno móvil han sido, en primer lugar, Symbian, que surgió en el año 1997 de la mano de Nokia (Figura 14, 1), aunque también se implantó en terminales de otras marcas, como Samsung o Motorola. Su servicio dejó de estar disponible a finales de 2012 [Accenture, 2011]. Symbian se implantó sobre todo para móviles dirigidos al usuario común de los que la inmensa mayoría no utilizaban el móvil para conectarse a internet. Para los ejecutivos que sí usaban servicios de internet como el correo electrónico se implantó Blackberry como solución (Figura 14, 2). Además de unas mejores características de conectividad, disponían de teclado completo, por lo que escribir era mucho más sencillo y rápido. Con el fin de hacer llegar estos servicios al público común, en 2007 se lanzó el iPhone 3 (Figura 14, 3) de la mano de Apple, considerado el primer smartphone comercial [Molina, 2017]. A raíz de este hecho, en 2008, Google liberó la primera versión de Android, aunque no sería hasta 2010 cuando comenzarían a comercializarse los dispositivos de alta gama basados en este sistema operativo, como la primera versión del Samsung Galaxy S (Figura 14, 4) [AD, 2016]. Windows Phone surge a partir de Windows Mobile, que intentó hacerle la competencia a Blackberry pero no consiguió implantarse de forma satisfactoria. En 2010, en el Mobile World Congress de Barcelona, Microsoft presentó Windows Phone, con el que pretendía hacerle la competencia a otros smartphones (Figura 14, 5). A día de hoy, Android es el sistema operativo más extendido en los dispositivos inteligentes al uso (smartphones y tabletas), llegando a superar el $85 \%$ de tasa de penetración en el mercado mundial en el primer semestre de junio de 2016 [Richter, 2016].

1
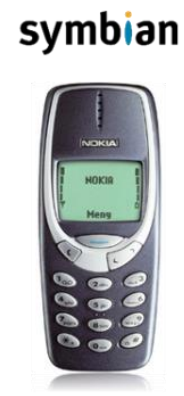

NOKIA

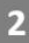

¥:

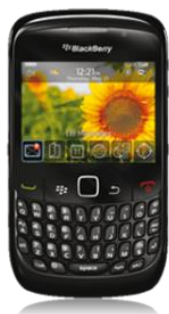

:: BlackBerry
3

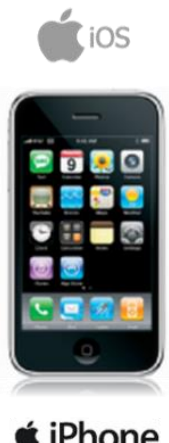

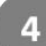

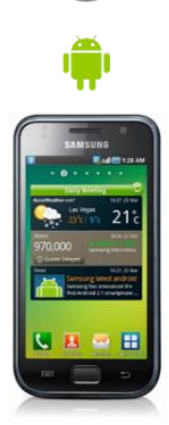

SAMSUNG
5

Windows Phone

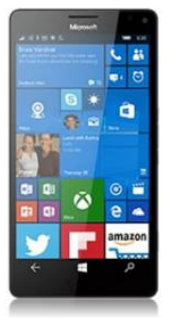

Microsoft

Figura 14. Móviles y sus sistemas operativos

La Figura 15 presenta la tasa de penetración de sistemas operativos de entorno móvil hasta junio de 2016. En esta figura, se puede apreciar la alta presencia de Android en los terminales vendidos. 


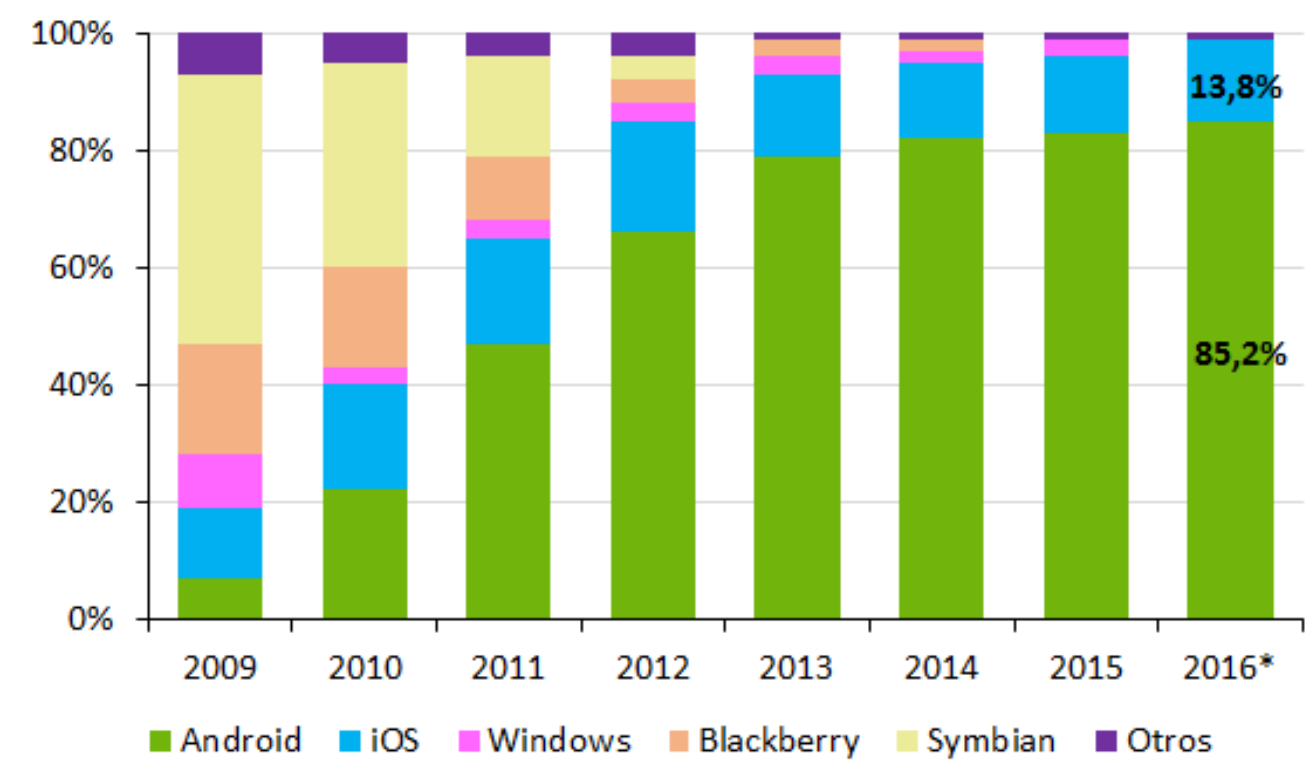

* Desde enero hasta junio de 2016

Figura 15. Penetración de los sistemas operativos móviles en el mundo [Richter, 2016]

Este análisis del contexto tecnológico actual nos permite sacar varias conclusiones, como son:

- Cada vez se accede más a internet.

- Gran parte de estos accesos a internet se realizan en movilidad, es decir, fuera del hogar.

- La evolución de los terminales y la ampliación de la cobertura de la red de datos, así como los precios asequibles, hacen que la tasa de penetración de los smartphones continúe subiendo.

- Android es el sistema operativo más extendido en los dispositivos móviles inteligentes utilizados por los usuarios.

Estas conclusiones se incluirán en el modelo propuesto en esta tesis doctoral, ya que caracterizan la tecnología a utilizar a la hora de implantar dicho modelo.

\subsection{Estudios propios y ajenos}

\subsubsection{Trabajos relacionados}

Tras el análisis de las terapias de estimulación cognitiva utilizando las Tecnologías de la Información y Comunicaciones (TIC) se ha llegado a la conclusión de que ninguna ofrece el valor añadido del seguimiento por parte de los terapeutas si se realiza fuera de las asociaciones.

Las tendencias en el telecuidado y las necesidades de la sociedad justifican la inclusión de tecnología en el desarrollo de nuevos servicios de salud desde que comenzaron a aplicarse las TIC a nivel global [Tan, 2005]. La computación ubicua provee de soluciones óptimas para el desarrollo de estos servicios gracias al respaldo de nuevas posibilidades tanto para el diagnóstico como para la realización de terapias de forma remota [Muras, 2006]. Los servicios para este tipo de cuidado son desarrollados de forma que permitan garantizar un tratamiento médico adaptado y personalizado para cada paciente, resolviendo con elementos tecnológicos los 
problemas que surgían tradicionalmente por la distancia y la disponibilidad de los servicios entre pacientes y médicos.

Debido a la pérdida de autonomía sufrida por los pacientes a causa de los trastornos motores provocados por la EP, han surgido numerosas iniciativas que pretenden detectar los bloqueos, la mayor causa de caídas en este contexto [Chakrabortya, 2013]. La tecnología móvil ha permitido proyectos orientados a estos bloqueos, como puede ser el caso del proyecto CuPid, que utiliza un teléfono inteligente para el preprocesamiento de los datos de aceleración de los pasos del paciente para detectar y prevenir bloqueos [Mazilu, 2012]. También se han desarrollado soluciones basadas en sensores wearables que monitorizan el movimiento involuntario del individuo y procuran, a través de análisis de la señal de estos sensores, detectar de forma temprana la aparición de los bloqueos [Bachlin, 2010].

En España, Telefónica ha participado en un proyecto europeo centrado en el 70 Programa Marco de la Unión Europea que se centraba también en la detección temprana de los bloqueos a través de sensores wearables y que actuaba en consecuencia para intentar evitar el bloqueo. Este proyecto, titulado REMPARK, utilizaba un sensor colocado en la cadera del paciente para detectar la señal del movimiento a través de acelerómetros y giroscopios, un terminal móvil conectado que analizaba la señal recibida y un altavoz que transmitía sonidos rítmicos para que, en el caso de que se detectase la posibilidad de un bloqueo, volver a darle un patrón sonoro para que el individuo volviera a coger el ritmo de la marcha [REMPARK, 2015]. Sin embargo, no se han encontrado iniciativas de comercialización.

A principios de la década de 2010 surgieron numerosas iniciativas de programas informáticos para la estimulación del deterioro cognitivo que podían ejecutarse tanto desde PC (Smartbrain o MindFit), como en videoconsolas (BrainTraining) a través del móvil (Mobile Brain Trainer) o por internet (MyBrainTrainer). Muchas de estas aplicaciones entraron dentro de los llamados Brain Games que se popularizaron para el entrenamiento y la estimulación del cerebro [García, 2010]. La mayor parte de estas aplicaciones ofrecían a los usuarios una herramienta para la realización de ejercicios de estimulación cognitiva, pero carecían de interacción y seguimiento de profesionales que controlaran la evolución de la persona que estaba realizando los ejercicios.

Un paso más en la aplicación de las TIC en el campo de la estimulación cognitiva consistió en la denominada "tele-estimulación cognitiva". Esta técnica puede ayudar a que personas con deterioro cognitivo puedan recibir sesiones de estimulación desde su domicilio, proporcionando un método de evaluación del deterioro de forma remota [Díaz, 2006]. Gracias a las TIC es posible desarrollar sistemas accesibles no sólo para los pacientes sino también para los profesionales que los tratan. Éstos pueden acceder a los resultados de los ejercicios realizados por sus pacientes y pueden adaptarlos a cada uno de ellos en función del nivel de deterioro para reducir al mínimo la evolución del mismo. El uso de este tipo de plataforma tecnológica permite que los resultados puedan ser almacenados y analizados para extraer conclusiones sobre la validez de la terapia utilizada. Inicialmente las soluciones se planteaban sobre PC. Posteriormente, con el avance de los dispositivos inteligentes (smartphones y tabletas) y su asequibilidad se dotó a este tipo de soluciones de disponibilidad en el contexto de la estimulación cognitiva.

Uno de los primeros desarrollos de la tele-estimulación cognitiva en España fue la plataforma GRADIOR, desarrollada por la fundación INTRAS, de la que se ha comprobado que permite captar la atención del paciente, consiguiendo así que interactúe sin rechazo con el PC [Franco, 2010]. 
Esta plataforma contiene baterías de ejercicios, que se van actualizando, distinguiendo entre los de atención, percepción, memoria, cálculo, lenguaje y orientación. Con esta aplicación se facilita a los profesionales el entrenamiento cerebral y la rehabilitación en personas con demencia, esquizofrenia, parálisis cerebral, retraso mental, etc. [INTRAS, 2004].

El programa GRADIOR fue de los más utilizados en entornos que requieran estimulación cognitiva, según Margarita Sebastián Herranz, psicóloga del CEAPAT-IMSERSO, especializada en este tipo de terapias. Sin embargo, no permitía el seguimiento de los terapeutas de forma remota a los ejercicios realizados por el paciente.

Posteriormente a estos trabajos comenzaron a aparecer en el mercado sistemas basados en tabletas y centrados en el tratamiento de información médica. En este segmento el más popular es Parkinson's toolkit, que ha sido diseñado pensando en personal médico que necesita conocer más información sobre los síntomas y el tratamiento de la enfermedad de Parkinson [NPF, 2013]. Esta herramienta se encuentra disponible tanto para iOS como para Android. También existen aplicaciones orientadas al paciente como Parkinson Home Exercises sobre iPad [EFHE, 2013]. Esta aplicación se centra principalmente en ejercicios de rehabilitación física que el paciente puede realizar en su domicilio.

También existen soluciones que ayudan a prevenir el aislamiento del individuo. Este es el caso del proyecto IntouchFun [Meza-Kubo, 2010], que provee de un marco colaborativo para integrar a familiares y cuidadores informales en una red social familiar, de forma que sus miembros puedan participar en las actividades de estimulación cognitiva de la persona y permitiendo que las actividades realizadas por el paciente puedan estar mediadas por interfaces multimodales adecuadas para cada miembro de la red.

En el campo más actual de la estimulación cognitiva, las terapias tienden cada vez más a la implantación de alternativas terapéuticas de entretenimiento, denominadas serious games [Skiba, 2008]. Esta tendencia se centra principalmente en la rehabilitación, aunque también se utiliza parar promocionar la actividad física y unifica la actividad de proveedores de salud y de empresas de videojuegos. La principal ventaja de la utilización de serious games es que presenta un reto hacia los pacientes y captura su atención más que las formas tradicionales de terapia, que pueden ser aburridas y repetitivas [Rego, 2010].

El ejemplo más claro de estos serious games utilizando las TIC se puede encontrar en el sistema RehaCom, que hoy en día es un sistema de referencia en este contexto [Rego, 2010]. RehaCom es un sistema asistido por ordenador modular. Este sistema está formado por diferentes módulos para el entrenamiento de distintas habilidades como pueden ser atención, memoria, funciones ejecutivas o motóricas. Cada entrenamiento consiste en una tarea específica que el paciente debe cumplir [Schuhfried, 2009] [Mak, 2008]. Este sistema está orientado a los terapeutas, que deben ser los que ordenen las tareas a los pacientes y controlar que estos las ejecuten correctamente.

Por último, destacar que los serious games no se han orientado únicamente a la implementación de soluciones TIC, sino que esta idea también se ha aplicado a terapias tradicionales. Es el ejemplo del proyecto Cognipark [APKM, 2017, 2] desarrollado por la APKM. Este proyecto se ha centrado en el entrenamiento de la memoria, la atención y la orientación a través de terapias ocupacionales y musicoterapia. Cognipark se basa en la plasticidad neuronal, término referente a la creación de nuevas conexiones entre neuronas a través del entrenamiento [May, 2007]. En 
este proyecto han utilizado elementos cotidianos para la parte relativa a la terapia ocupacional y tanto equipos de música como instrumentos para la parte de la musicoterapia. Con esta nueva forma de asignar tratamientos grupales realizaron un experimento con tres pilotajes, en los que participaron pacientes de la asociación. Se registraron el estado cognitivo, el estado de ánimo y la soltura en las actividades de la vida diaria, tanto antes como después de los pilotos. Esta experimentación dio unos resultados muy satisfactorios en todos los aspectos analizados, por lo que han incluido este proyecto en sus terapias habituales.

El trabajo de investigación que se presenta en esta tesis doctoral comenzó en 2011. Como se ha podido observar a partir del análisis del estado del arte, esta idea es pionera en el campo de la tele-estimulación cognitiva, ya que entonces no existía ninguna solución específica para el deterioro cognitivo asociado a la EP que dispusiera de ubicuidad, que permitiera una personalización sencilla de las terapias y que le diera el total control de los ejercicios de estimulación y del seguimiento de los pacientes a los terapeutas. Posteriormente a esta investigación se han desarrollado trabajos para evaluar el deterioro cognitivo, como las soluciones que desarrolla CogniFit, que se centran en el análisis de este deterioro. También dispone de baterías de estimulación, pero están centradas en otras patologías [CogniFit, 2017]. En el campo de la estimulación cognitiva han surgido también nuevas herramientas. Este es el caso de NeuronUP, que es una plataforma de neuro-rehabilitación cognitiva para los profesionales, a los que se les dan amplitud de recursos para las sesiones de estimulación cognitiva y un gestor de pacientes para guardar los resultados de manera ordenada. Esto permite la personalización de las terapias. Está disponible para PC y pantallas táctiles, así como ejercicios con lápiz y papel [NeuronUP, 2017]. Las limitaciones que presenta esta solución son que no está destinada específicamente para personas con EP y que los recursos disponibles dependen de agentes externos, no de los propios terapeutas.

\subsubsection{Contexto de este trabajo de investigación}

La doctoranda tiene una larga experiencia en el campo de las terapias de estimulación cognitiva. En el año 2006, con el fin de obtener del título de Ingeniería Técnica de Telecomunicación, especialidad en Telemática, defendió su Proyecto Fin de Carrera titulado Aplicación web para la planificación y valoración de ejercicios de estimulación cognitiva accesibles desde dispositivos móviles, en el que, junto con el presentado por Esther Moreno para la obtención del mismo título, que llevaba por nombre Plataforma J2ME para la realización y seguimiento de ejercicios de estimulación cognitiva accesibles mediante un servicio web, presentaba una plataforma completa para la realización de terapias de estimulación cognitiva para personas con enfermedad de Alzheimer [García, 2006] [Moreno, 2006]. Ambos Proyectos Fin de Carrera estuvieron dirigidos por Miguel Ángel Valero, de la Universidad Politécnica de Madrid. Para la realización de este trabajo, la doctoranda comenzó a profundizar en su investigación sobre cómo afectan al cerebro y a las capacidades del individuo los distintos tipos de demencia. En el caso del Alzheimer, en el que se centraba este trabajo, se orientaron las terapias al mantenimiento de las capacidades mnemotécnicas del individuo. Este prototipo no pudo ser testeado con pacientes y terapeutas. Esta plataforma dio lugar a un registro software titulado Plataforma de estimulación cognitiva vía móvil (EsCoM), registrado en el Registro Territorial de la Propiedad Intelectual de la Comunidad de Madrid, n. M-001035/2011, con fecha 24/01/2012. 
Posteriormente, en el año 2010, la doctoranda, que había continuado con su investigación sobre terapias no farmacológicas aplicadas al deterioro cognitivo, presentó el Trabajo Fin de Máster titulado Diseño de un modelo interactivo basado en Televisión Digital para estimulación cognitiva para la obtención del título de Máster en Sistemas y Servicios Accesibles para la Sociedad de la Información [García, 2010], trabajo también dirigido por Miguel Ángel Valero. Este trabajo se centraba en las terapias para la estimulación cognitiva de personas diagnosticadas de EP, siendo la interfaz de usuario la televisión interactiva. En este caso, gracias al proyecto Estimulación Cognitiva a través de la TDT (EsCOTDT), financiado por el Instituto de Mayores y Servicios Sociales (IMSERSO), cuyo investigador principal fue Miguel Ángel Valero, se pudo llevar a cabo experimentación con usuarios finales en la APKM, donde, pese a las restricciones tecnológicas que presentaba la televisión digital entonces y los problemas de rendimiento que presentaba la aplicación de los pacientes, todos los participantes alabaron el trabajo realizado, destacando su originalidad y su utilidad. Gracias a ello, se registró la plataforma desarrollada en el Registro Territorial de la Propiedad Intelectual de la Comunidad de Madrid, n. M001031/2011 con fecha 24/01/2012, Ilevando por título Sistema de estimulación cognitiva para pacientes con Parkinson a través de la televisión e internet interactiva y personalizable (DALE). Además, se publicó un artículo en la revista IEEE Transactions on Information Technology in Biomedicine que llevó como título Distributed System for Cognitive Stimulation Over Interactive $T V$, en el que se publicaban los resultados obtenidos tras la experimentación con los usuarios en la APKM [García, 2012]. Durante esta experimentación, los pacientes y los terapeutas rellenaban cuestionarios sobre percepción de mejora con el uso de la televisión como interfaz de usuario del paciente para llevar a cabo las TEC. Tras el análisis de los resultados de estos cuestionarios, se concluyó que la televisión se formulaba como un entorno idóneo para eliminar la reticencia que tenían los pacientes participantes, en su mayoría analfabetos digitales, para interactuar con las NNTT, ya que la televisión era un dispositivo conocido. El inconveniente que presentaba esta solución es que, al estar basada en las primeras versiones de decodificadores interactivos para televisión, la aplicación funcionaba de forma muy lenta. Además, para muchos pacientes era difícil escribir las respuestas a través del mando de la televisión.

En el año 2012 surgió DaleMov, gracias al interés que presentó la Fundación Vodafone España (FVE) sobre los desarrollos que se habían realizado para estimulación cognitiva y, principalmente, para personas con EP. La FVE estaba en contacto con la Asociación Parkinson Extremadura, que les había comunicado que tenían interés en la creación o financiación de algún sistema de estimulación cognitiva utilizando las TIC. Gracias a ellos, se pudo firmar un convenio de colaboración entre la FVE y la UPM y entre la FVE y la FEP en los meses de julio y agosto de 2012 respectivamente. El nombre de este proyecto fue DaleMov: Servicios ubicuos de estimulación cognitiva accesibles para afectados de Parkinson. En este proyecto el investigador principal de la UPM fue Miguel Ángel Valero.

El objetivo principal que persiguió este proyecto fue el realizar la adaptación del dispositivo de acceso de los pacientes a la plataforma a entorno móvil y mejorar el rendimiento del lado del servidor, así como la adición de nuevas funcionalidades. Las tareas asignadas al grupo de investigación Sistemas Telemáticos para la Sociedad de la Información y el Conocimiento (T>SIC), adscrito a la Universidad Politécnica de Madrid (UPM) y al que pertenece esta doctoranda, fueron el diseño, desarrollo y validación de la plataforma final, realizando el mantenimiento 
técnico necesario durante los pilotos experimentales. Por otro lado, la FVE debía proveer de los medios técnicos necesarios para la validación (dispositivos móviles táctiles con conexión a internet) y supervisaría la fase de evaluación con los usuarios finales.

Pese a que el cronograma del proyecto pretendía haber finalizado los trabajos, incluyendo los pilotos, en el plazo de un año, se realizaron más mejoras de las que había contempladas en un principio, llevando a cabo, además, pruebas de verificación funcional con los usuarios implicados cada vez que se sacaba una nueva versión tanto de la parte cliente como de la parte servidor. Estas mejoras estuvieron orientadas a convertir la plataforma de seguimiento de la terapia en un entorno multiasociación, en el que los terapeutas pudieran compartir los recursos generados para las terapias con los pacientes. De esta manera, un terapeuta no disponía solo de los ejercicios de estimulación cognitiva de su asociación, sino que podía beneficiarse de lo que hubieran generado en el resto de asociaciones participantes.

Finalizada este primer proyecto, se celebró una reunión el 10 de julio de 2013 a la que asistieron los neuropsicólogos y psicólogos de varias asociaciones de Parkinson en España. Fue en esta reunión donde se definieron las nuevas categorías de ejercicios que debían estar presentes en el sistema. También se aprovechó para presentar el servicio a otras asociaciones que, por no estar incluidas en los pilotos iniciales, no lo conocían. Esta reunión estuvo dirigida por Dña. Susana Donate, neuropsicóloga de la APKM, que, desde los inicios de los trabajos de T>SIC en el área de la estimulación cognitiva asociada a la EP, había aportado su conocimiento y su experiencia a las mejoras de la plataforma. También asistieron los miembros de T>SIC que participaban en el proyecto y la directora de la FEP.

Aunque, tras el análisis de la reunión por parte de la APKM, se comenzó a trabajar en las mejoras de la plataforma, el nuevo acuerdo con la FVE no se firmó hasta diciembre de 2013, retrasándose los trabajos por falta de financiación.

La primera versión de la plataforma final según las mejoras acordadas en la reunión de julio de 2013 se liberó en mayo de 2014, por lo que se prepararon unas jornadas organizadas por la FVE en su sede y dirigidas por Dña. Mayca Marín, Responsable de Formación de la FEP, y por T>SIC a través de Dña. Carolina García, autora de este trabajo, y Dña. Esther Moreno, ingeniera de dicho grupo de investigación. Estas jornadas fueron celebradas el 28 y 29 de mayo de 2014 . A estas jornadas asistieron terapeutas de todas las asociaciones de España que iban a participar en los pilotos. Estas asociaciones fueron:

- Asociación Parkinson Madrid.

- Asociación Regional Parkinson Extremadura.

- Associació Catalana per al Parkinson.

- Asociación Parkinson Bahía de Cádiz.

- Asociación de Parkinson de Sevilla.

- Asociación Navarra de Parkinson.

Estas seis asociaciones participaron en los pilotos. Primero, se llevaron a cabo los pilotos en las tres primeras $\mathrm{y}$, tras los comentarios positivos de los terapeutas participantes en ellas, se continuó con la experimentación en el resto. Cada asociación, a la finalización de las pruebas piloto, enviaba una memoria a la FEP. Esta memoria y las hojas de cálculo con las respuestas de 
pacientes y terapeutas, así como los perfiles de los mismos, se enviaban a la UPM y a Dña. Carolina García en particular para su posterior análisis.

Esta plataforma también ha dado lugar a un registro software, titulado DaleMov: Servicios ubicuos de estimulación cognitiva accesibles para afectados de Parkinson, inscrita en el Registro Territorial de la Propiedad Intelectual de la Comunidad de Madrid con fecha 05/02/2016 y con número de registro $\mathrm{M}-007249 / 2014$. 


\title{
Capítulo 4. Determinación de requisitos de la Terapia de Estimulación Cognitiva para la enfermedad de Parkinson (EP)
}

\begin{abstract}
El cuarto capítulo de la memoria de este trabajo de investigación tiene como objetivo el presentar los requisitos de la terapia de estimulación cognitiva. En este capítulo se detallará el proceso de captura de requisitos, así como los agentes implicados en el mismo. Por último, se presentarán los requisitos identificados, diferenciando entre requisitos funcionales como no funcionales.
\end{abstract}

\subsection{Planteamiento inicial}

Las Terapias de Estimulación Cognitiva (TEC) son un tipo de tratamiento no farmacológico aplicado a diversas patologías. Tienen como objetivo la mejora y la rehabilitación de las capacidades cognitivas del individuo. Estas terapias suelen llevarse a cabo por psicólogos o neuropsicólogos, aunque también, según el tipo de terapia, se pueden dar en un escenario más interdisciplinar [García, 2009].

Como se ha destacado en el primer capítulo de esta memoria, el deterioro cognitivo depende de la patología que sufra el paciente. Es por ello, que las TEC se plantearán de forma distinta según el tipo de patología que haya provocado este deterioro. En el caso particular de la EP, casi todos los individuos presentan cierto grado de deterioro cognitivo durante el transcurso de la enfermedad [Marsh, 2009]. Mientras que la demencia implica dificultades extensas en múltiples áreas de la cognición evitando que el paciente pierda la capacidad de vivir de forma independiente, los trastornos cognitivos tratan de cambios pequeños que pueden afectar a algunas áreas de la vida diaria del individuo.

Las funciones cognitivas alteradas por la EP difieren con respecto a las de otras patologías. En el ejemplo particular de la enfermedad de Alzheimer, el área que más sufre este deterioro es la memoria a corto plazo, área que no se deteriora de forma tan severa en la EP [Tárraga, 1999].

Las dificultades cognitivas asociadas a la EP rara vez hacen que el paciente pierda la capacidad de vivir de forma independiente, manteniendo sus facultades intelectuales generales y su base de conocimiento, así como la memoria a corto y largo plazo. En particular, las dificultades cognitivas que sufre la persona con EP son [Marsh, 2009]:

- Disfunción ejecutiva relacionada con los procesos de resolución de problemas, planificación, iniciación y seguimiento, o la ejecución de varias tareas de forma simultánea. 
- Alteraciones de la memoria, por lo que es necesario recordar lo aprendido a través de claves y utilizar la repetición para que la persona con EP retenga nuevos conocimientos.

- Dificultades de atención de forma proporcional a la dificultad de la situación. Esto afecta tanto a sus procesos intelectuales como a las actividades cotidianas.

- Bradifrenia asociada a la lentitud del procesamiento mental. Esto afecta a la resolución de problemas, la recuperación de información y a actividades cotidianas como conversar.

- Disfunción del lenguaje, apareciendo problemas para utilizar o comprender lenguaje complejo y para nombrar objetos.

- Perturbaciones visuo-espaciales relacionadas con percibir, procesar, discriminar y actuar a partir de la información visual del entorno. A veces, estas perturbaciones pueden llevar a error en la percepción o a la creación de ilusiones.

Para el diagnóstico del estado cognitivo del paciente con EP es preciso realizar una evaluación cognitiva, existiendo hoy día diversos métodos de evaluación. El más habitual suele ser la realización de entrevistas con las personas cercanas a él, comprobando de esta forma los cambios que van apareciendo en su cognición, y cómo estos cambios afectan a las actividades de la vida diaria. Quien lleva a cabo esta evaluación es el neuropsicólogo a través del Patrón $o r{ }^{2}$, que incluye varias pruebas para comprobar el estado de las áreas cognitivas. Estas pruebas pueden requerir respuesta oral o escrita dependiendo de las capacidades del paciente y el área cognitiva a evaluar y tienen una duración que varía desde media hora a varias horas [Goldman, 2011].

\subsection{Metodología para la captura de requisitos}

Para la captura de requisitos se ha considerado, en primer lugar, la utilidad percibida por el usuario y su experiencia en la utilización del sistema (UX). La UX se define como el conjunto de factores y elementos relativos a la interacción del usuario con un entorno o dispositivo concretos, cuyo resultado es la generación de una percepción positiva o negativa de dicho servicio, producto o dispositivo [Hassan, 2005]. Forma parte del paradigma de la interacción persona-ordenador $(\mathrm{HCl})$, que es un área de estudio centrada en el fenómeno de interacción entre usuarios y sistemas informáticos, cuyo objetivo es proporcionar bases teóricas, metodológicas y prácticas para el diseño y evaluación de productos interactivos que puedan ser usados de forma eficiente, eficaz, segura y satisfactoria [Hartson, 1998].

Los factores que intervienen en la UX son cinco: el propio usuario, los factores sociales, los factores culturales, el contexto de uso y el producto en sí. Los aspectos emocionales juegan un papel fundamental en la interacción del usuario, ya que los estados emocionales afectan a los procesos cognitivos, en concreto afectan a la capacidad de atención, memorización, rendimiento del usuario y valoración del producto [Brave, 2002].

De la interacción entre estos factores, surge la experiencia de usuario. Esto se puede apreciar de forma más clara en la Figura 16.

\footnotetext{
2 El patrón oro es el elemento de valoración del éxito o fracaso de una nueva estrategia terapéutica. Comparación enmascarada con una prueba de referencia («patrón oro») [Mosby, 2009]
} 


\section{Experiencia de usuario}

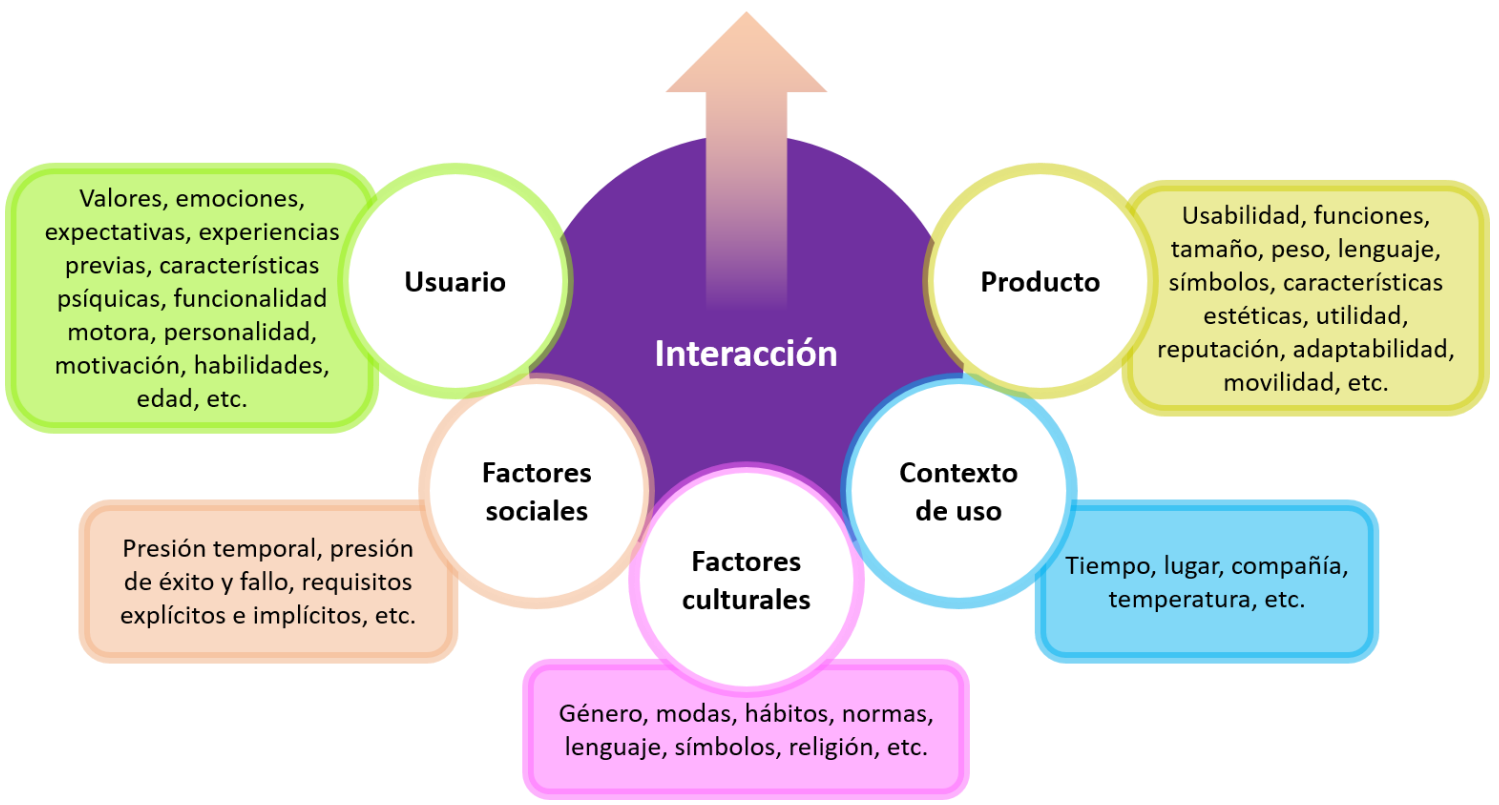

Figura 16. Factores que intervienen en la UX [Hassan, 2005]

El campo de la $\mathrm{HCl}$, como tónica general, se ha centrado en el comportamiento racional del usuario, ignorando su comportamiento emocional. Al ignorar las emociones, no se están considerando muchos de los factores importantes de la UX, ya que, normalmente, se centran mucho en el contexto de uso y el producto, pero poco en el usuario y sus factores sociales y culturales [Jordan, 1998]. Para tener en cuenta correctamente toda esta complejidad del usuario se utiliza el Diseño Centrado en el Usuario (DCU). El DCU está centrado principalmente en el cumplimiento de los niveles de usabilidad requeridos para el producto final, considerando todos los elementos constituyentes del individuo [Hassan, 2005]. El DCU se basa en la premisa de que el enfoque de este diseño debe estar dirigido hacia las personas a las que está destinado [ISO 9241-210:2010], en este caso, los pacientes diagnosticados con EP y sus terapeutas.

El DCU consta de cuatro fases que se ejecutan de forma cíclica, iterativa y mejorada incrementalmente para así conseguir que en cada iteración se mejore el diseño generado, repitiendo estas iteraciones hasta que el sistema satisfaga los requisitos planteados inicialmente. Estas fases son:

7) Especificación del contexto, es decir, identificación de las personas a las que la solución va dirigida.

8) Especificación de los requisitos, es decir, definir los objetivos y las expectativas que tienen los usuarios finales.

9) Producción del diseño, que puede estar dividida en varias etapas secuenciales.

10) Evaluación del diseño, donde se valida la solución con los usuarios finales.

La Figura 17 presenta un diagrama con la secuencia de estas cuatro fases, así como la interacción entre ellas. 


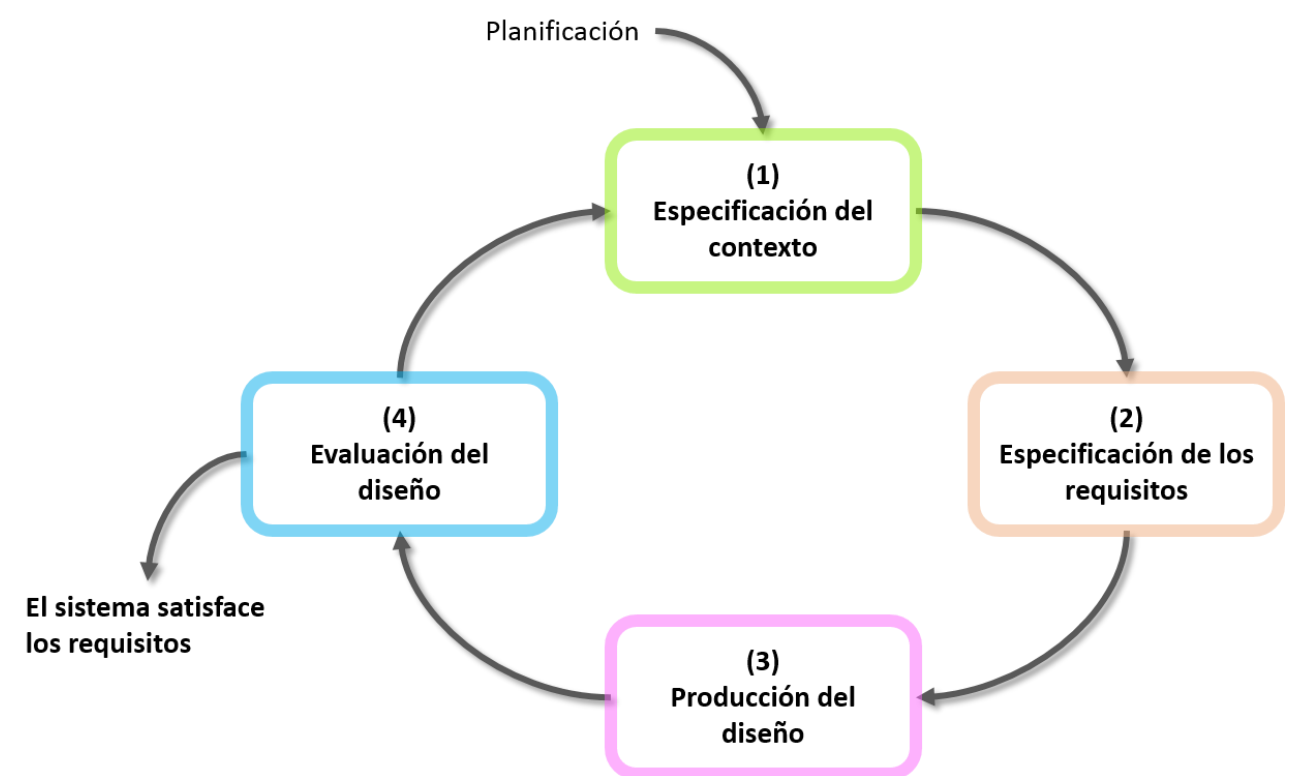

Figura 17. Interacción de las fases del DCU [ISO 9241-210:2010]

EI DCU refleja en el diseño las necesidades y los intereses de los usuarios a los que la solución va destinada. Es por ello que, de forma indirecta, también recoge parámetros de usabilidad de este diseño y no solo de accesibilidad.

En el caso de esta tesis doctoral, se ha aplicado esta metodología, realizando entrevistas y evaluaciones periódicas tanto con pacientes con EP como con los terapeutas implicados. En los puntos siguientes se describirán los agentes implicados y las iteraciones que se han realizado durante el proceso.

En los siguientes apartados se presenta en más detalle en primer lugar, los agentes identificados para participar en la recogida de requisitos de usuario y, en segundo lugar, el proceso realizado con las iteraciones del ciclo de vida del DCU.

\subsection{Agentes implicados en la captura de requisitos}

Una vez estudiadas las necesidades de las personas con EP y el estudio previo de cómo las TIC podrían aplicarse en este contexto para mejorar la calidad asistencial de estas personas, se comenzó la primera fase del DCU a través de la especificación del contexto, donde se definieron los agentes implicados.

Los agentes implicados en la captura de requisitos fueron de dos tipos:

- Usuarios finales, como pacientes con EP y terapeutas.

- Agentes externos a la terapia, como administradores de asociaciones de Parkinson y diseñadores/desarrolladores expertos en tecnología.

En el campo de los usuarios finales participaron personas de la APKM. La APKM puso a disposición de esta investigación a Susana Donate, la neuropsicóloga que realiza el seguimiento cognitivo y psicológico de los pacientes en esta Asociación. En principio, únicamente participó ella en la toma de requisitos como terapeuta y experta en personas con EP y su deterioro. Posteriormente, se incluyó en la captura de requisitos a la logopeda María Teresa Martínez, que se encarga de las terapias de estimulación cognitiva de los pacientes en esta Asociación. Con 
respecto a los agentes externos a la terapia, también se contó con la ayuda de la directora de la APKM, Laura Carrasco, que participó en la primera iteración del diseño para evaluar si era viable el introducir este tipo de terapias dentro de las asociaciones.

Una vez identificadas las terapeutas que debían participar en la captura de requisitos, fueron ellas las encargadas de seleccionar a los pacientes. Para la elección de los pacientes que participaron en la evaluación de cada resultado del diseño, se tuvo en consideración que estos ofrecieran una muestra variada, representando la heterogeneidad de los enfermos de EP:

- Deterioro cognitivo del paciente. En una primera fase de diseño, se buscaron pacientes con deterioro cognitivo leve o leve-moderado. Posteriormente, se incluyeron pacientes con deterioro cognitivo moderado.

- Paridad entre hombres y mujeres.

- Personas no familiarizadas con las nuevas tecnologías.

- Disfunciones motoras como máximo hasta el estadio 3 [Hoehn, 1998].

En cada fase de evaluación de cada iteración del ciclo de vida del DCU se involucraron entre tres y cinco pacientes. Con cada iteración, algunos se mantenían y se añadían otros nuevos para constatar que se iban incluyendo los requisitos identificados y verificar si existían otros nuevos a incluir en el diseño final.

Para la recogida de requisitos de usuario y la evaluación, tanto de los diseños como de los desarrollos parciales, se creó un comité de expertos en el que se incluyeron todos los perfiles implicados en un sistema de estas características.

Por parte del colectivo implicado participaron:

- A través de la APKM para la selección de usuarios y las evaluaciones parciales de cada iteración del proceso de DCU (descrito anteriormente):

- Susana Donate, neuropsicóloga.

- María Teresa Martínez, logopeda.

- Laura Carrasco, directora.

- Pacientes seleccionados por Susana Donate y María Teresa Martínez. Estos pacientes se escogían a partir del perfil necesario para la realización de las evaluaciones.

- A través de la Federación Española de Parkinson (FEP) colaboraron tanto para la preparación de los pilotos como para la gestión de asociaciones durante ellos:

- Mayca Marín, responsable de formación, psicóloga clínica y trabajadora social.

- María Gálvez, directora.

Por otro lado, respecto al contexto tecnológico de la solución, se han implicado activamente las siguientes entidades:

- A través de la Fundación Vodafone España (FVE):

- Mari Satur Torre, ingeniera de telecomunicación y directora técnica de la FVE.

- Rosendo Amor, gestor de proyectos de I+D+i. 
- A través de la UPM se llevó a cabo la dirección, el diseño, la implementación y la gestión de las pruebas con usuarios de este trabajo de investigación, realizada por el Grupo de Investigación de Sistemas Telemáticos de la Sociedad de la Información y el Conocimiento ( $>>S I C)$, localizado en la Escuela Técnica Superior de Ingeniería y Sistemas de Telecomunicación (ETSIST):

- Miguel Ángel Valero, doctor ingeniero de telecomunicación, profesor titular de la UPM en el Departamento de Telemática y Electrónica (DTE) de la ETSIST, director del T>SIC y co-director de esta tesis doctoral. Desde diciembre de 2014 es el director del Centro Estatal de Autonomía Personal y Ayudas Técnicas (CEAPAT), perteneciente al Instituto de Mayores y Servicios Sociales (IMSERSO), dependiente de Ministerio de Sanidad, Servicios Sociales e Igualdad [Zamarro, 2014]. Miguel Ángel participó como investigador principal por parte del equipo de la UPM, realizando las tareas de gestión del proyecto DaleMov.

- Carolina García, autora del presente trabajo, ingeniera técnica de telecomunicación y máster en sistemas y servicios accesibles para la sociedad de la información con amplia experiencia en la realización de proyectos de Investigación, Desarrollo e Innovación $(I+D+i)$ centrados en las necesidades de personas con discapacidad, principalmente con deterioro cognitivo asociado a diversas patologías, investigadora del T>SIC. Carolina fue el punto de contacto entre las entidades participantes en este proceso. Además, realizó la investigación inicial sobre las necesidades y productos existentes, la primera parte sobre todo a través de entrevistas en la APKM. Asimismo, desarrolló las distintas aplicaciones web y diseñó la experimentación. Por último, analizó los resultados obtenidos tras esta experimentación.

- Esther Moreno, ingeniera técnica de telecomunicación y máster en sistemas y servicios accesibles para la sociedad de la información que ha trabajado activamente durante los últimos años en la investigación y desarrollo de interfaces de usuario accesibles utilizando una gran diversidad de tecnologías, en las que se incluyen las relacionadas con la movilidad y entornos de televisión interactiva, investigadora del T>SIC. Esther se encargó del análisis de las terapias tradicionales y, con el apoyo de la doctoranda, diseñó los modelos de ejercicios. También implementó la aplicación del paciente a partir de los requisitos recogidos en las fases previas y realizó el mantenimiento de la misma durante la experimentación.

- Rafael Conde, doctor en sociología y experto en la realización de estudios orientados a la percepción de usuarios finales con respecto a la tecnología, investigador del T>SIC. Rafael colaboró en esta experiencia a través de la revisión de los cuestionarios para los pacientes y en el análisis de necesidades de las personas con EP.

En cada fase, según sus características, participaba el comité de expertos completo o de forma parcial, salvo en el caso de APKM y UPM, que participaron en todas las iteraciones del proceso. 


\subsection{Aplicación del proceso de DCU}

Se llevaron a cabo varias iteraciones del proceso de DCU hasta dar con un diseño que cumpliera las expectativas de los usuarios finales. La Tabla 5 presenta a modo de resumen de las once iteraciones que se llevaron a cabo en este proceso, detallándose posteriormente.

Tabla 5. Iteraciones del proceso de DCU

\begin{tabular}{|c|c|c|}
\hline Iteración & Resultado obtenido & Resultado evaluación \\
\hline 1 & $\begin{array}{l}\text { Determinación del colectivo destinatario } \\
\text { de la TEC } \\
\text { Adaptación de los ejercicios de TEC } \\
\text { tradicionales al escenario TIC }\end{array}$ & Evaluación positiva \\
\hline 2 & $\begin{array}{l}\text { Selección del dispositivo de usuario para } \\
\text { la aplicación del paciente } \\
\text { Primera aproximación a la GUI de la } \\
\text { aplicación del paciente }\end{array}$ & $\begin{array}{l}\text { Evaluación positiva del dispositivo de } \\
\text { usuario: tableta } \\
\text { Necesidad de mejorar la GUI aplicando } \\
\text { más criterios de usabilidad }\end{array}$ \\
\hline 3 & $\begin{array}{l}\text { Selección de la tecnología para gestión de } \\
\text { la TEC } \\
\text { Definición de las funcionalidades } \\
\text { principales de la plataforma de gestión de } \\
\text { la TEC }\end{array}$ & $\begin{array}{l}\text { Evaluación positiva de la tecnología para } \\
\text { la gestión de la TEC: web } \\
\text { Necesidad de añadir nuevas } \\
\text { funcionalidades a la plataforma de gestión } \\
\text { de la TEC }\end{array}$ \\
\hline 4 & $\begin{array}{l}\text { Redefinición de las funcionalidades de } \\
\text { seguimiento de la TEC }\end{array}$ & Necesidad de mejorar la navegabilidad \\
\hline 5 & $\begin{array}{l}\text { Mejora de la navegabilidad de la } \\
\text { aplicación de seguimiento de la TEC }\end{array}$ & Evaluación positiva \\
\hline 6 & Desarrollo de la aplicación del paciente & $\begin{array}{l}\text { Adaptación a los requisitos de un paciente } \\
\text { con EP }\end{array}$ \\
\hline 7 & Finalización de la aplicación del paciente & Evaluación positiva \\
\hline 8 & Securización de las transmisiones & Evaluación positiva \\
\hline 9 & $\begin{array}{l}\text { Desarrollo de la web de descarga de la } \\
\text { aplicación del paciente }\end{array}$ & Evaluación positiva \\
\hline 10 & $\begin{array}{l}\text { Unificación de la GUI entre las } \\
\text { aplicaciones de paciente y terapeuta }\end{array}$ & Evaluación positiva \\
\hline 11 & Manuales de usuario & Evaluación positiva \\
\hline
\end{tabular}

Las iteraciones de este proceso fueron:

- Iteración 1 del DCU: en esta primera iteración se analizó la posibilidad de adaptar las TEC a un entorno TIC, conservando la capacidad de estimulación que estas presentan.

- Especificación del contexto: al inicio, se llevó a cabo un estudio de la bibliografía existente para poder definir de forma correcta los agentes que estaban implicados en este tipo de terapias, tal y como se ha presentado en el capítulo anterior. Asimismo, se llevaron a cabo entrevistas con la neuropsicóloga de la APKM. En esta iteración, se 
definió el escenario donde se iba a aplicar la solución y el colectivo destinatario de la misma. También, se determinó que las personas que supervisarían la TEC serían los terapeutas que normalmente llevan a cabo este tipo de terapias en las asociaciones de forma tradicional.

- Especificación de los requisitos: en esta fase de la primera iteración del proceso de DCU, se definieron los parámetros que debía tener un ejercicio de estimulación cognitiva para poder llevar a cabo la adaptación de las TEC tradicionales a un entorno TIC. Para ello, se utilizaron los cuadernos de ejercicios donde se recogen los realizados de forma tradicional en las asociaciones [APKM, 2007]. Además, se definió un primer requisito de la aplicación de seguimiento de la terapia: la introducción de forma sencilla e intuitiva de nuevos ejercicios de estimulación para que no fuera necesaria la intervención de un programador y lo pudieran hacer directamente los terapeutas. Asimismo, se definieron los niveles de deterioro cognitivo que podrían tener diagnosticados los pacientes para poder llevar a cabo terapias de estimulación cognitiva. Estos niveles fueron leve, leve-moderado, moderado o, en casos excepcionales (como la experiencia previa en tecnologías), moderado-grave.

- Producción del diseño: como resultado de esta iteración, se preparó un informe con una primera adaptación de la TEC a las TIC, teniendo en cuenta los tipos de ejercicios de los cuadernos [APKM, 2007] y definiendo los modelos de interfaz en los que se adaptarían los mismos. En el informe presentado se mostraban ejemplos de adaptación de las nueve áreas de estimulación cognitiva recogidas en los cuadernos de ejercicios mencionados anteriormente. Estos ejercicios se clasificaron en cinco modelos, como se puede ver en la Figura 18.

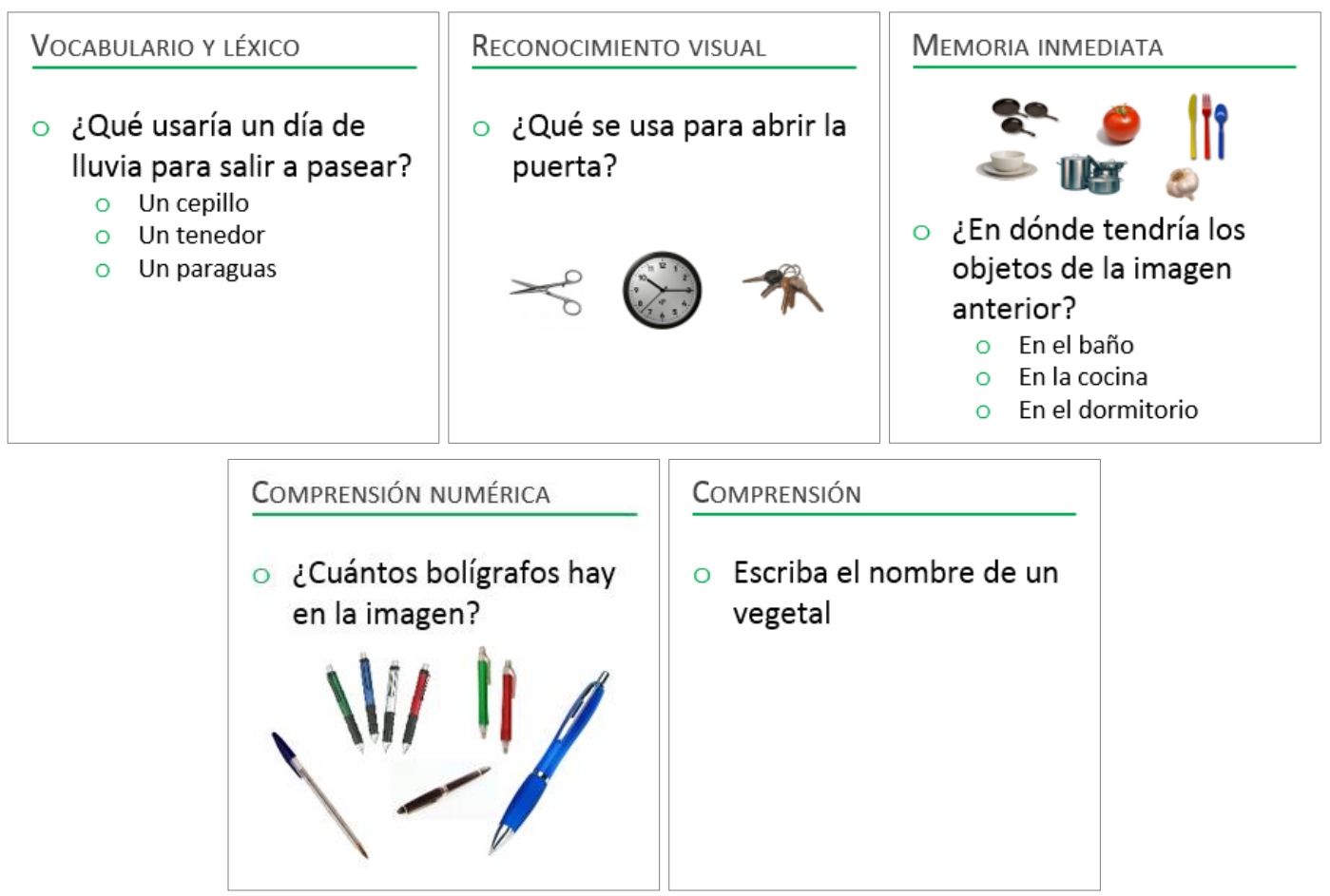

Figura 18. Extracto del informe para la adaptación de la TEC al entorno TIC 
- Evaluación del diseño: el informe de los modelos de interfaz ejemplificado con ejercicios reales fue evaluado por la neuropsicóloga de la APKM, que dio el visto bueno para continuar con la siguiente iteración.

- Iteración 2 del DCU: la segunda iteración consistió en un primer acercamiento tecnológico al dispositivo de usuario que utilizaría el paciente.

- Especificación del contexto: una vez definido el escenario a nivel de usuario, se procedió a elegir el posible dispositivo de usuario. Pese a que el DCU se centra en el diseño de las interfaces y la interacción persona-máquina, en este caso era muy importante la definición del hardware desde el inicio. Tras un amplio análisis de las necesidades y capacidades de una persona con EP y tras numerosas entrevistas con el personal especializado de la APKM y de la FEP, se decidió que lo que más se adaptaba a la premisa de disponibilidad en cualquier momento y en cualquier lugar y que, además, podría ser sencillo de utilizar para personas poco familiarizadas con la tecnología y que presenten problemas de movilidad era una tableta de, al menos, 10" de pantalla.

- Especificación de los requisitos: en la segunda iteración, se definió una primera aproximación a la interfaz gráfica de usuario (GUI) que debía tener la aplicación del paciente. Para ello, se definieron criterios de accesibilidad y usabilidad, como el tamaño de fuente, el contraste entre texto y fondo, el uso de fotografías para los ejercicios en vez de dibujos, la utilización de menús sencillos con pocos niveles de profundidad, teclado accesible, etc.

- Producción del diseño: se implementó una pequeña aplicación Android para tableta que contemplara los requisitos definidos en la fase anterior con cinco ejercicios de ejemplo. Esta aplicación consistía en una primera pantalla con un teclado numérico para añadir la clave de acceso, la selección de realización de ejercicios en un menú, la respuesta de esos cinco ejercicios y el volver al menú inicial para salir de la aplicación.

- Evaluación del diseño: el equipo terapéutico de la APKM seleccionó a cinco pacientes para que llevaran a cabo la validación de este diseño. Cada uno tenía que completar todas las fases definidas en la producción del diseño. Como resultado, tras el análisis con estos pacientes y con el equipo de la APKM, se acordó que el teclado utilizado debía tener las teclas más grandes y habría que controlar las pulsaciones muy seguidas que aparecían a causa de los problemas motores asociados a la EP. Por último, se comprobó que una tableta podría ser el dispositivo de usuario idóneo para los pacientes, siempre que se tuvieran en cuenta las consideraciones de diseño necesarias acordes a las capacidades de este colectivo.

- Iteración 3 del DCU: la tercera iteración del DCU sirvió para la definición de la tecnología utilizada para la gestión de la TEC de los pacientes, así como la funcionalidad.

- Especificación del contexto: en esta iteración se estudiaron las tecnologías existentes en el mercado que se adaptaran a las necesidades de los terapeutas. Asimismo, se creó un primer documento de funcionalidades que debería contener la plataforma de seguimiento de las terapias de los pacientes. 
- Especificación de los requisitos: uno de los principales criterios para la selección de la tecnología utilizada para el seguimiento de las terapias fue la disponibilidad a través de cualquier dispositivo, ya fuera dispositivo móvil inteligente u ordenador. Es por ello, que se decidió la utilización de tecnologías web. Por otro lado, se definió un primer acercamiento al comportamiento de esta plataforma, contemplando funciones como la evaluación de los ejercicios realizados por cada paciente, la introducción de nuevos ejercicios de forma simple e intuitiva y la personalización de la terapia para cada paciente. También debían contemplarse criterios de accesibilidad y usabilidad. Por el lado de los ejercicios de estimulación cognitiva, se convino en su forma de clasificación. Estos ejercicios se ordenarían por área de estimulación cognitiva y por nivel de dificultad. De esta forma, aparecían bloques de ejercicios formados por nueve ejercicios, cada uno perteneciente a un área de estimulación (descritas posteriormente en el apartado 5.3 .2 . Ejercicios de estimulación cognitiva adaptados a las TIC) y todos ellos del mismo nivel de dificultad. El terapeuta, a la hora de definir la terapia para un paciente, elegiría uno de los bloques según el nivel de dificultad acorde a la terapia de ese paciente. Una vez el paciente terminara el bloque de ejercicios, sus resultados se almacenarían en el servidor para que, cuando su terapeuta accediera a la plataforma, pudiera evaluar sus resultados y asignarle el siguiente bloque de ejercicios de estimulación cognitiva según dichos resultados.

- Producción del diseño: se preparó una primera aproximación a la GUI de seguimiento, así como de la relativa a la gestión de usuarios. Esta interfaz se realizó directamente utilizando tecnologías web.

- Evaluación del diseño: el grupo de expertos en TEC para personas con EP realizó la evaluación del diseño presentado. Aunque la tecnología seleccionada en la especificación de requisitos fue evaluada satisfactoriamente, no ocurrió lo mismo con la funcionalidad de la plataforma. En esta evaluación se recogieron nuevos requisitos, dando lugar a la siguiente iteración del proceso de DCU.

- Iteración 4 del DCU: en esta iteración se presentaron las nuevas funcionalidades de la plataforma de seguimiento de la terapia, cuyos requisitos parten de la iteración anterior.

- Especificación del contexto: no se realizaron tareas. El contexto fue definido a partir de la evaluación de la iteración anterior. Esta especificación del contexto se llevó a cabo en una reunión, además de con los expertos de APKM, FEP, FVE y UPM, contando con la colaboración de expertos en TEC de otras asociaciones de España.

- Especificación de los requisitos: se añadieron más funcionalidades a la plataforma de seguimiento de la terapia. Estas funcionalidades estaban orientadas a mejorar la personalización de la terapia para cada paciente. Para ello, se definieron otras nueve áreas de estimulación cognitiva y los ejercicios se clasificaron únicamente en tres niveles de dificultad, sin número máximo de ejercicios para cada área y nivel. A partir de esto, serían los terapeutas los encargados de crear los bloques de ejercicios a realizar por los pacientes, adaptando la terapia, de esta forma, mucho mejor a las necesidades de cada uno de ellos. Los ejercicios creados y los bloques de ejercicios estarían disponibles para todos los terapeutas para compartir mejor el trabajo entre unas asociaciones y otras. Por otro lado, se definió que la aplicación debía ser sencilla 
y de uso intuitivo, además de accesible. Para garantizar la accesibilidad a la plataforma, se tuvieron en cuenta las Guías de Accesibilidad del Contenido Web en su versión actual, la 2.0 (WCAG 2.0), definida por el Consorcio de la Web (W3C) [WCAG, 2008]. En estas recomendaciones se recogen pautas como la relación de contraste entre texto y fondo, el tamaño del texto, el comportamiento de los objetos (formularios, enlaces, botones, etc.), la navegabilidad y coherencia de la plataforma o la utilización de gramáticas formales, entre otras. Estas pautas se clasifican en niveles de conformidad, siendo de obligatorio cumplimiento en España para ciertas entidades el nivel de conformidad AA (nivel medio) [UNE 139803:2012], que es el que se tuvo en cuenta para la implementación, tanto de los prototipos como de la plataforma final.

- Producción del diseño: se modificó la GUI y la funcionalidad de la plataforma de seguimiento de las terapias para añadir las nuevas funcionalidades. Asimismo, se definió la nueva clasificación de los ejercicios según los requisitos recogidos, representado en la Figura 19 y con el ejemplo de diseño de la interfaz en la Figura 20. Además, se creó un repositorio de imágenes, de forma que cualquiera de las imágenes subidas a la plataforma por un terapeuta estuviera disponible para otro.

\begin{tabular}{|c|c|c|c|c|c|c|c|c|c|}
\hline \multirow[b]{2}{*}{$\begin{array}{l}\text { Nivel de } \\
\text { deterioro }\end{array}$} & \multicolumn{9}{|c|}{ Área de estimulación } \\
\hline & $\begin{array}{l}\text { Atención } \\
\text { sostenida }\end{array}$ & $\begin{array}{l}\text { Atención } \\
\text { dividida }\end{array}$ & Cálculo & Lenguaje & $\begin{array}{l}\text { Memoria } \\
\text { CP }\end{array}$ & $\begin{array}{c}\text { Memoria } \\
\text { LP }\end{array}$ & $\begin{array}{c}\text { Función } \\
\text { visuo- } \\
\text { espacial }\end{array}$ & $\begin{array}{l}\text { Funciones } \\
\text { ejecutivas }\end{array}$ & $\begin{array}{l}\text { Ejercicios } \\
\text { motivac. }\end{array}$ \\
\hline \multirow{3}{*}{ 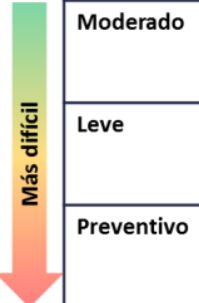 } & $\begin{array}{l}\text { Ejercicio } \\
\text { Ejercicio } \\
\ldots\end{array}$ & $\begin{array}{l}\text { Ejercicio } \\
\text { Ejercicio } \\
\ldots\end{array}$ & $\begin{array}{l}\text { Ejercicio } \\
\text { Ejercicio } \\
\ldots \\
\end{array}$ & $\begin{array}{l}\text { Ejercicio } \\
\text { Ejercicio } \\
\ldots \\
\end{array}$ & $\begin{array}{l}\text { Ejercicio } \\
\text { Ejercicio } \\
\ldots\end{array}$ & $\begin{array}{l}\text { Ejercicio } \\
\text { Ejercicio } \\
\ldots\end{array}$ & $\begin{array}{l}\text { Ejercicio } \\
\text { Ejercicio } \\
\ldots\end{array}$ & $\begin{array}{l}\text { Ejercicio } \\
\text { Ejercicio } \\
\ldots\end{array}$ & $\begin{array}{l}\text { Ejercicio } \\
\text { Ejercicio } \\
\ldots\end{array}$ \\
\hline & $\begin{array}{l}\text { Ejercicio } \\
\text { Ejercicio } \\
\ldots \\
\end{array}$ & $\begin{array}{l}\text { Ejercicio } \\
\text { Ejercicio } \\
\ldots \\
\end{array}$ & $\begin{array}{l}\text { Ejercicio } \\
\text { Ejercicio } \\
\ldots \\
\end{array}$ & $\begin{array}{l}\text { Ejercicio } \\
\text { Ejercicio } \\
\ldots \\
\end{array}$ & $\begin{array}{l}\text { Ejercicio } \\
\text { Ejercicio } \\
\ldots \\
\end{array}$ & $\begin{array}{l}\text { Ejercicio } \\
\text { Ejercicio } \\
\ldots \\
\end{array}$ & $\begin{array}{l}\text { Ejercicio } \\
\text { Ejercicio } \\
\ldots \\
\end{array}$ & $\begin{array}{l}\text { Ejercicio } \\
\text { Ejercicio } \\
\ldots \\
\end{array}$ & $\begin{array}{l}\text { Ejercicio } \\
\text { Ejercicio } \\
\ldots \\
\end{array}$ \\
\hline & $\begin{array}{l}\text { Ejercicio } \\
\text { Ejercicio } \\
\ldots\end{array}$ & $\begin{array}{l}\text { Ejercicio } \\
\text { Ejercicio } \\
\ldots\end{array}$ & $\begin{array}{l}\text { Ejercicio } \\
\text { Ejercicio } \\
\ldots\end{array}$ & $\begin{array}{l}\text { Ejercicio } \\
\text { Ejercicio } \\
\ldots\end{array}$ & $\begin{array}{l}\text { Ejercicio } \\
\text { Ejercicio } \\
\ldots\end{array}$ & $\begin{array}{l}\text { Ejercicio } \\
\text { Ejercicio } \\
\ldots\end{array}$ & $\begin{array}{l}\text { Ejercicio } \\
\text { Ejercicio } \\
\ldots\end{array}$ & $\begin{array}{l}\text { Ejercicio } \\
\text { Ejercicio } \\
\ldots\end{array}$ & $\begin{array}{l}\text { Ejercicio } \\
\text { Ejercicio } \\
\ldots\end{array}$ \\
\hline
\end{tabular}

Figura 19. Clasificación de los ejercicios

Planificación de los ejercicios de estimulación $\odot$ Automática $\bigcirc$ Manual

Áreas de estimulación

1. Atención sostenida

2. Atención dividida

3. Cálculo

4. Lenguaje

5. Memoria Corto Plazo

6. Memoria Largo Plazo

7. Función Visuoespacial

8. Funciones Ejecutivas

9. Ejercicios Motivacionales $\square$

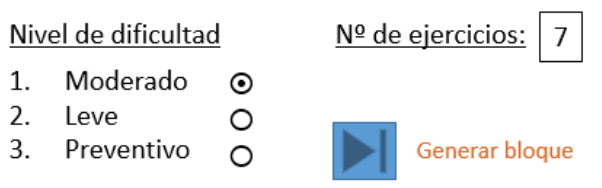

\begin{tabular}{|c|c|c|c|c|c|c|}
\hline \multicolumn{7}{|c|}{ Propuesta de bloque generado } \\
\hline 1 & 2 & 3 & 4 & 5 & 6 & 7 \\
\hline AS & $\mathrm{C}$ & L & EM & $\mathrm{C}$ & $\mathrm{L}$ & EM \\
\hline 12 & 18 & 34 & 49 & 21 & 37 & 53 \\
\hline \multicolumn{7}{|c|}{ Ejercicio seleccionado: 34} \\
\hline \multicolumn{7}{|c|}{$\begin{array}{l}\text { Descripción: Elementos cotdianos } \\
\text { Enunciado: ¿Qué usaria un dila de likia para sairr a pasear? }\end{array}$} \\
\hline \multirow{2}{*}{\multicolumn{3}{|c|}{$\begin{array}{l}\text { Tipo de respuesta: Tres respuestas } \\
\text { textuales }\end{array}$}} & \multicolumn{3}{|c|}{ Tiempo máximo: 2 minutos } & Resp. correcta: 3 \\
\hline & & Respuesta1: Un cepillo & \multicolumn{3}{|c|}{ Respuesta2: Un tenedor } & Respuesta3: Un paraguas \\
\hline \multicolumn{6}{|c|}{ Nombre del bloque: } & \multirow{2}{*}{ Almacenar bloque } \\
\hline \multicolumn{6}{|c|}{ Ejercicios cálculo/leng/at. 1} & \\
\hline
\end{tabular}

Figura 20. Diseño de la interfaz de creación de bloques de ejercicios

- Evaluación del diseño: para la evaluación de este diseño colaboraron, además de los miembros del comité de expertos formado para este trabajo de investigación, formado por personas de APKM, FEP, FVE y UPM, miembros responsables de la supervisión de TEC en otras asociaciones de Parkinson de España. La evaluación del diseño fue 
satisfactoria, si bien, a la hora de la evaluación de la aplicación por parte del comité de expertos, se comprobó que era necesario mejorar la navegabilidad. Se valoró muy positivamente la interacción persona-máquina en este entorno, pero este comité de expertos decidió que podría ser interesante utilizar menos niveles de navegación y utilizar técnicas de navegación coherentes que permitieran al terapeuta la identificación sencilla de la posición en la que se encontraba dentro de cada proceso.

- Iteración 5 del DCU: en esta iteración, se modificó el diseño de la plataforma de seguimiento de la TEC para mejorar la navegabilidad.

- Especificación del contexto: no se realizaron tareas.

- Especificación de los requisitos: el requisito principal en esta iteración fue la mejora de la navegabilidad. Para ello, se definió la reducción de los niveles de navegación de la aplicación y la utilización de títulos más claros en cada página. Además, se puntualizó la utilidad de inserción de un apartado relativo a la ayuda de la aplicación.

- Producción del diseño: tal y como se había indicado en los requisitos recogidos a través de la evaluación de la cuarta iteración del proceso de DCU, se simplificaron los niveles de navegación, dejando el proceso más complejo con tres niveles. Se modificaron los títulos de cada página, mostrándolos tanto en la barra de título del navegador y en la propia página. Asimismo, se añadió al inicio de la página el nombre del usuario autenticado. Esto se consideró necesario debido a que, en la misma asociación, existirían varios terapeutas utilizando el mismo dispositivo para la evaluación de ejercicios de los pacientes. Por último, se creó la ayuda de la aplicación, global a todas las páginas, pero personalizada para cada proceso.

- Evaluación del diseño: la evaluación del diseño por parte de los terapeutas del comité de expertos fue satisfactoria.

- Iteración 6 del DCU: en esta iteración, se implementó la aplicación de realización de ejercicios utilizada por el paciente.

- Especificación del contexto: no se realizaron tareas.

- Especificación de los requisitos: los requisitos se habían definido en la segunda iteración del proceso de DCU. Los requisitos de accesibilidad y usabilidad contemplados fueron:

- Alto contraste entre frente (texto e imágenes) y fondo. Si bien este criterio se tuvo en cuenta en esta fase, no se buscaron colores identificativos para la aplicación porque, posteriormente, esta tendría que guardar coherencia con la plataforma web de seguimiento de la TEC.

- Información fácilmente comprensible apoyada por iconografía sencilla.

- Pantallas simples.

- Pocos niveles de navegación.

- Facilidad de aprendizaje.

- Control de pulsaciones muy seguidas. 
- Aplicación ligera para una rápida respuesta.

- Producción del diseño: se finalizó la implementación de la aplicación a partir de los requisitos anteriores.

- Evaluación del diseño: la evaluación, llevada a cabo por el comité de expertos y pacientes con EP, concluyó en que era necesario revisar el rendimiento de la aplicación, así como la mejora de los mensajes de error cuando hay problemas de conectividad y los mensajes de motivación al finalizar un bloque de ejercicios. Además, se sugirió que se buscara una solución para encontrar la aplicación cómodamente en la pantalla principal de la tableta.

- Iteración 7 del DCU: el objetivo de esta iteración fue la finalización de la implementación de la aplicación del paciente a partir de la evaluación recibida en la iteración anterior del proceso de DCU.

- Especificación del contexto: no se realizaron tareas.

- Especificación de los requisitos: los requisitos habían sido definidos en la fase de evaluación de la iteración anterior.

- Producción del diseño: se revisó de forma más amplia el rendimiento de la aplicación, así como los mensajes de error que aparecían en la aplicación. Para ello, se creó un entorno de pruebas con los posibles errores que podrían surgir (corte de conexión durante la comunicación, la falta de espacio en la memoria de la tableta o la utilización de conexiones lentas). Esto se verificó técnicamente en laboratorio antes de pasar a la fase de evaluación. Por otro lado, también se modificaron los mensajes de motivación para que siempre fueran positivos y así incitaran al paciente a seguir utilizando este tipo de TEC. Por último, para mejorar el acceso a la aplicación, se creó un widget de gran tamaño (cuatro celdas de ancho por dos celdas de alto) para que fuera más localizable en la pantalla principal de la tableta. Este widget se muestra en la Figura 21.

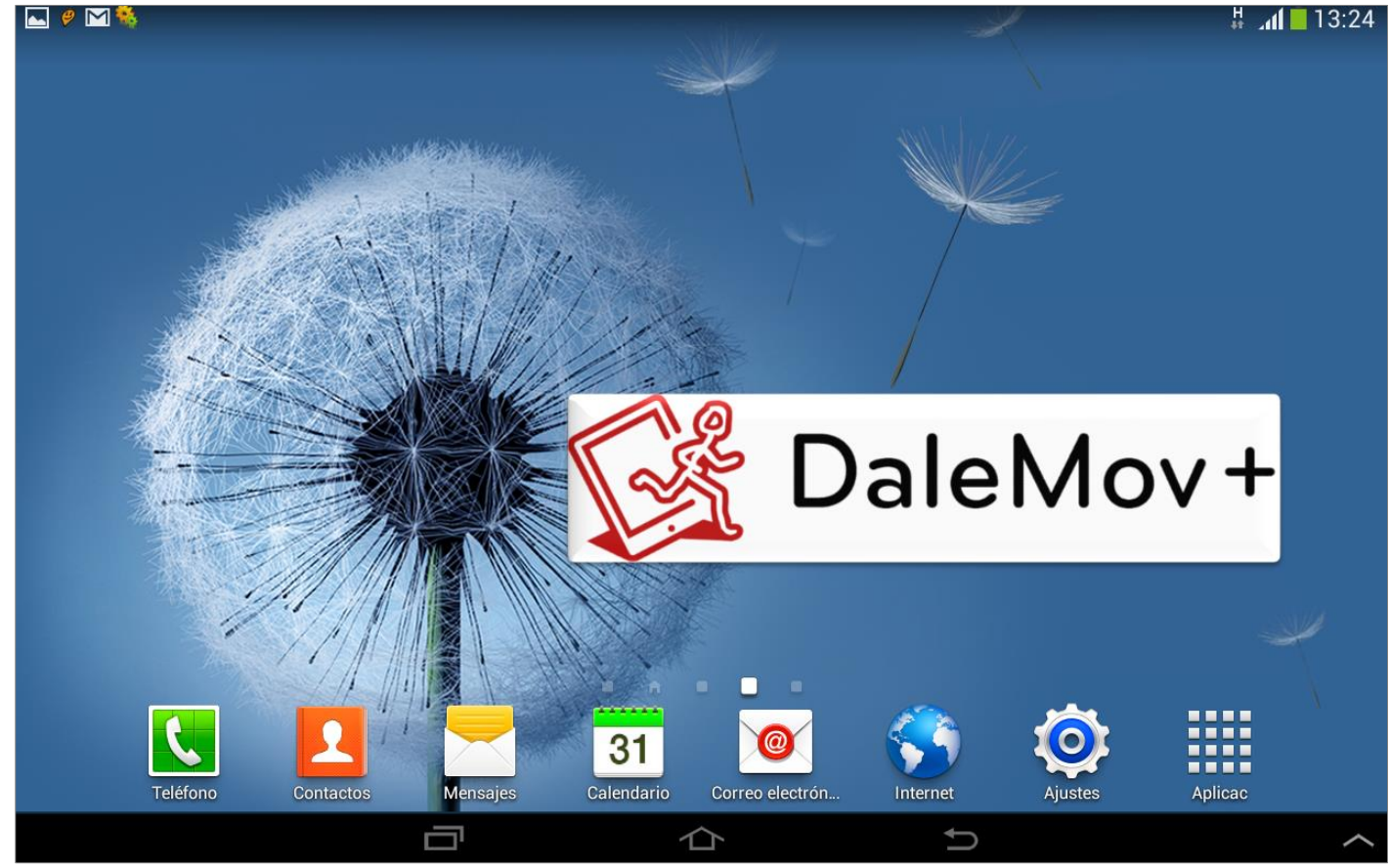

Figura 21. Widget de la aplicación 
- Evaluación del diseño: la evaluación recibida por el comité de expertos fue positiva.

- Iteración 8 del DCU: en esta iteración, se securizaron las transmisiones entre el dispositivo del paciente y el servidor y entre el servidor y el navegador del terapeuta.

- Especificación del contexto: no se realizaron tareas.

- Especificación de los requisitos: los requisitos de seguridad que debía cumplir esta plataforma son los reflejados en la Ley Orgánica de Protección de Datos de Carácter Personal (LOPD) [LOPD, 1999]. El nivel de seguridad requerido era alto puesto que los datos personales manejados (nombre y apellidos, fecha de nacimiento, etc.) correspondían necesariamente a pacientes con EP y, por tanto, tenían la consideración de información relativa a la salud. Es por ello que el nivel de seguridad aplicable debe ser el más restrictivo posible.

- Producción del diseño: por la parte que respecta a las conexiones, se utilizó el protocolo SSL (Secure Sockets Layer). En el lado de la aplicación del paciente, al haber utilizado un entorno como Android, no es necesario evitar accesos malintencionados por parte de terceros por el grado de abstracción que implementa, como se describirá en el capítulo siguiente a la hora de describir la tecnología empleada. Aun así, se cifraron los datos del usuario antes de almacenarlos. Por el lado del servidor se aplicaron las medidas de seguridad exigidas por la LOPD, que son las siguientes:

- Personal: se definieron perfectamente los perfiles de usuario y la información que se almacenaría de cada uno de ellos.

- Incidencias: se almacena un archivo de incidencias de todos los errores ocurridos en el servidor. Estos errores se almacenan en un fichero XML donde se incluye la fecha, la hora, la operación realizada y el error ocurrido.

- Control de accesos: el control informático de acceso se realiza mediante identificador y contraseña, no pudiendo acceder los usuarios que no estén dados de alta en el sistema con anterioridad. Además, se genera un fichero XML con el registro de accesos, informando de la fecha, hora, tipo de acceso y si ha sido permitido o denegado. Con respecto al acceso físico a los locales donde se encuentran los sistemas de información, el servidor y las bases de datos para prestar el servicio se encuentran ubicados en el Centro de Cálculo del Departamento de Telemática y Electrónica de la UPM. Este centro sólo es accesible por los dos administradores del sistema, que han sido autorizados tanto por la UPM como por dicho departamento. En este Centro de Cálculo, se realizan copias de seguridad periódicas.

- Cambio de contraseñas: al dar de alta a un usuario en el sistema, se le asigna una contraseña por defecto que deberá cambiar antes de llevar a cabo cualquier otra acción.

- Almacenamiento de contraseñas: las contraseñas se almacenan cifradas en una tabla distinta de la base de datos a la que se almacena el identificador del usuario. Lo mismo ocurre con el identificador del paciente, que no está relacionado con sus datos personales. 
- Evaluación del diseño: se llevó a cabo una sesión con personas con EP en la APKM para comprobar el grado de aceptación que presentaba el compartir la información relativa a las terapias con las personas que interactuarían con la plataforma (terapeutas y administradores de las asociaciones). La evaluación realizada fue satisfactoria.

- Iteración 9 del DCU: en esta iteración se preparó el entorno para la descarga de la aplicación del paciente.

- Especificación del contexto: no se realizaron tareas.

- Especificación de los requisitos: los requisitos que debía cumplir el entorno fueron la facilidad para acceder a la descarga, la claridad en la información dada al usuario, la accesibilidad y la usabilidad.

- Producción del diseño: se definió junto al comité de expertos que la forma más sencilla de descargarse e instalarse la aplicación sería a través de una web. Se implementó esta página con el enlace a la descarga y reservando un futuro enlace para el manual de usuario de la aplicación. Esta web se llevó a cabo teniendo en cuenta criterios de accesibilidad web [WCAG 2.0, 2008]. En la Figura 22 se muestra la página desarrollada.

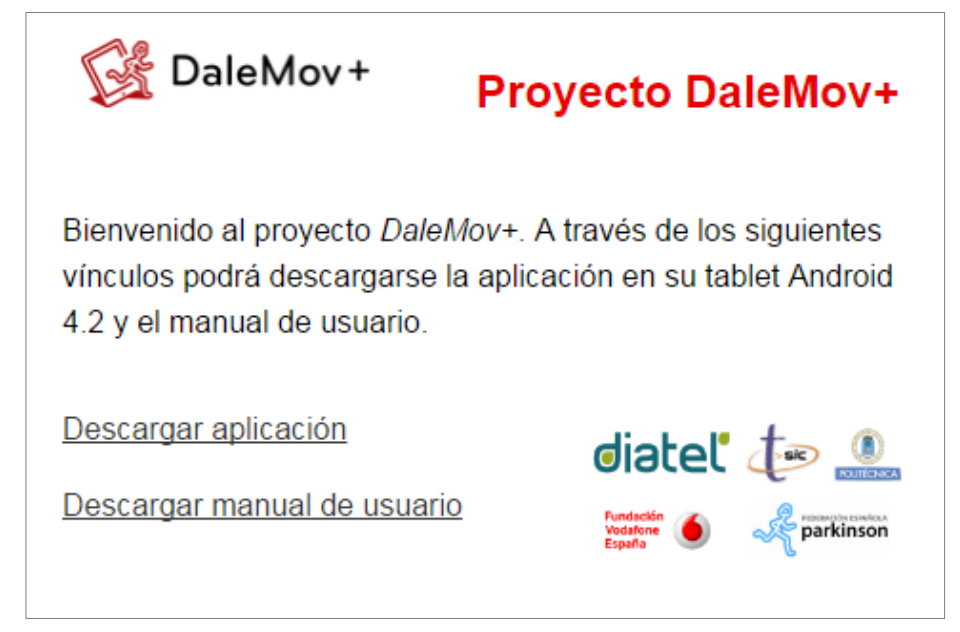

Figura 22. Página web para la descarga de la aplicación

- Evaluación del diseño: la evaluación del resultado de esta iteración fue positiva.

- Iteración 10 del DCU: en la décima iteración del proceso de DCU se definió un nuevo tipo de interfaz para unificar fuentes y colores entre la plataforma de seguimiento de la TEC y la aplicación utilizada por el paciente.

- Especificación del contexto: se analizó el documento de la identidad gráfica de las tres entidades participantes en el trabajo de investigación para que las GUI de paciente y terapeuta tuvieran cierto grado de coherencia entre ellas, así como con las páginas de estas entidades.

- Especificación de los requisitos: el requisito contemplado en esta fase fue, como se ha definido anteriormente, la coherencia gráfica de las aplicaciones de usuario con las entidades participantes. Las restricciones fueron el contraste entre fuente y fondo, los tamaños de letra adecuados al colectivo y la coherencia entre aplicación del paciente y de seguimiento de la terapia. Se utilizaron aplicaciones para la medición del contraste, como Colour Contrast Analyzer [TPG, 2017]. 
- Producción del diseño: se modificaron los estilos utilizados, tanto en la aplicación del paciente como en la plataforma de seguimiento de la TEC. Asimismo, se modificó el logotipo de la aplicación conforme a los criterios definidos en la especificación de requisitos. El logotipo final de la aplicación se presenta en la Figura 23.

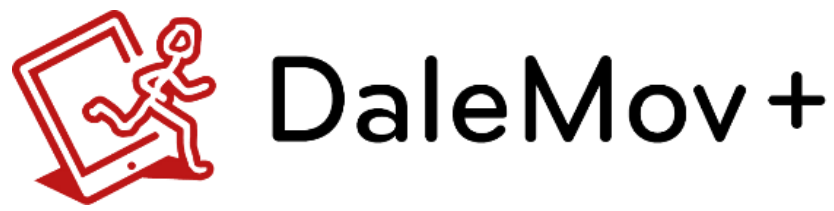

Figura 23. Logotipo de la plataforma final

- Evaluación del diseño: la evaluación del diseño, en este caso, fue llevada a cabo por FEP, FVE y UPM, con resultado positivo.

- Iteración 11 del DCU: por último, en la undécima iteración del proceso de DCU, se crearon los manuales de usuario, tanto de la aplicación del paciente como de la plataforma de seguimiento. También se llevaron a cabo la redacción de los manuales de usuario de la gestión de usuarios y de la FEP para la gestión de asociaciones.

- Especificación del contexto: no se realizaron tareas.

- Especificación de los requisitos: los manuales de usuario debían contener la información necesaria para que los usuarios pudieran utilizar cómodamente la plataforma, ya fuera la aplicación Android en el caso del paciente, o la plataforma web para el terapeuta (gestión de la TEC) o la gestión de usuarios (llevada a cabo por los administradores en las asociaciones y la FEP).

- Producción del diseño: se preparó un manual de usuario para cada uno de los roles que iban a utilizar el sistema. En la Tabla 6 se muestra el contenido de cada manual de usuario y, tras ella, la Figura 24 con una fotografía de los manuales.

Tabla 6. Contenido de cada manual de usuario

\begin{tabular}{|l|l|}
\hline Usuario destinatario & \multicolumn{1}{l}{ Contenidos de manual } \\
\hline \multirow{2}{*}{ Paciente } & $\begin{array}{l}\text { Requisitos de la tableta } \\
\text { Cómo realizar la descarga, instalación y personalización del widget } \\
\text { Acceso a la aplicación e identificación del usuario } \\
\text { Realización de bloques de ejercicios } \\
\text { Consulta de la última valoración del terapeuta }\end{array}$ \\
\hline Terapeuta & $\begin{array}{l}\text { Gescripción del entorno, acceso a la plataforma y localización de la ayuda } \\
\text { bloques de ejercicios, modificación de la última valoración introducida, } \\
\text { consulta del histórico de un paciente } \\
\text { Gestión de bloques de ejercicios de estimulación: creación, inserción o } \\
\text { eliminación de un bloque de ejercicios de estimulación } \\
\text { Gestión de ejercicios: información, inserción o eliminación de ejercicio } \\
\text { Gestión de usuarios: búsqueda de datos de un paciente, cambio de la } \\
\text { contraseña }\end{array}$ \\
\hline
\end{tabular}




\begin{tabular}{|l|l|}
\hline \multirow{4}{*}{ Administrador } & $\begin{array}{l}\text { Descripción del entorno, acceso a la plataforma y localización de la ayuda } \\
\text { Consulta de los datos enviados a cada dispositivo de paciente } \\
\text { Gestión de usuarios: creación, modificación o eliminación de pacientes y } \\
\text { terapeutas, cambio de la contraseña }\end{array}$ \\
\hline FEP & $\begin{array}{l}\text { Descripción del entorno, acceso a la plataforma y localización de la ayuda } \\
\text { Administración de asociaciones: creación, consulta, eliminación o } \\
\text { modificación de los datos de una asociación } \\
\text { Cambio de la contraseña }\end{array}$ \\
\hline
\end{tabular}

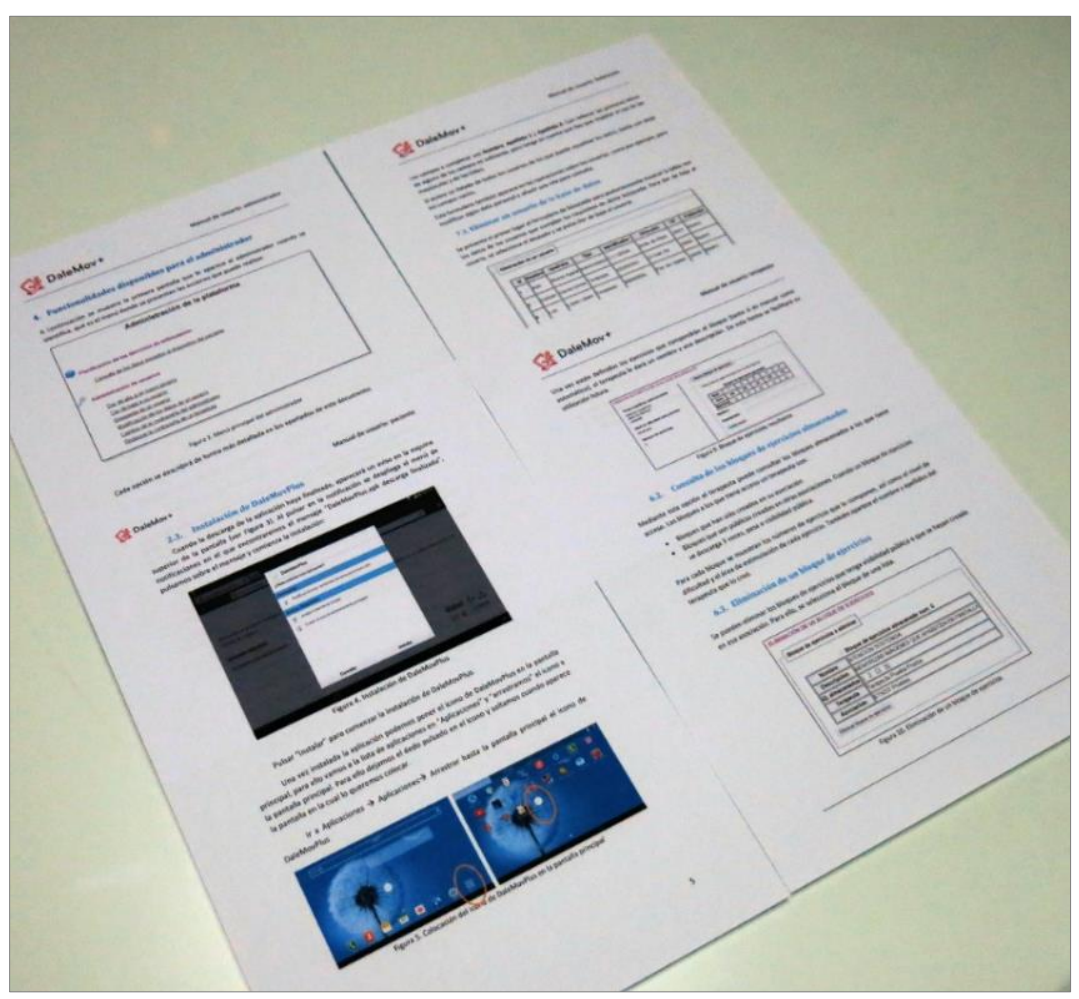

Figura 24. Ejemplos de los manuales de usuario realizados

- Evaluación del diseño: la evaluación de los manuales de usuario fue positiva.

Una vez alcanzada la undécima iteración del proceso de DCU, se dio por concluido el diseño.

\subsection{Requisitos de usuario identificados}

Según se ha detallado de forma extensa en el apartado anterior, se utilizó el proceso de DCU para la captura de los requisitos de usuario.

Según las metodologías clásicas de ingeniería del software, la captura de requisitos se lleva a cabo en la fase de análisis, donde se definen cuáles son las necesidades del usuario final y la funcionalidad que tendrá el sistema, independientemente de la tecnología utilizada. Estos requisitos recogen los servicios que se deben ofrecer, así como las restricciones asociadas al funcionamiento del sistema. Una vez definidos los requisitos, se pasa a una fase de diseño, en la que se modelan los componentes hardware y software que tendrá el sistema final. A continuación, una vez seleccionada la tecnología, se continúa con la codificación, pasando para finalizar a la fase de pruebas [DECSAI, 2016]. Este proceso también se utiliza en otras 
metodologías, como pueden ser las metodologías ágiles. En particular, Scrum, la más extendida a día de hoy, utiliza este proceso en cada iteración [SA, 2017].

Aunque el proceso de creación de la herramienta no se ha llevado a cabo de la forma tradicional, donde las fases se realizan en cascada, en este apartado se reúnen los requisitos funcionales y no funcionales identificados durante el proceso de DCU. La diferencia entre ambos tipos de requisitos es la siguiente [DECSAI, 2016]:

- Los requisitos funcionales expresan la naturaleza del sistema, es decir, cómo interactúa el sistema con su entorno y cuál va a ser su funcionamiento.

- Los requisitos no funcionales están orientados a las restricciones del sistema, esto es, características centradas en el rendimiento, la fiabilidad, diseño de las interfaces, proceso de desarrollo, etc.

En resumen, los requisitos funcionales recogen qué hace el sistema y los requisitos no funcionales cómo lo hace.

Durante la realización de este trabajo de investigación, se han identificado 19 requisitos funcionales (Tabla 7 a $\underline{\text { }}$ ) y 10 requisitos no funcionales (Tabla 26 a Tabla 35 ).

\subsubsection{Requisitos funcionales}

Tabla 7. Requisito funcional 1

RF-01. Disponibilidad aplicación paciente

\begin{tabular}{|l|l|l|l|}
\hline Categoría & Funcional & Prioridad & Obligatorio \\
\hline Descripción & La aplicación del paciente debe de estar disponible en cualquier momento y lugar. \\
\hline
\end{tabular}

Tabla 8. Requisito funcional 2

RF-02. Ejercicios adaptados

\begin{tabular}{|l|l|l|l|}
\hline Categoría & Funcional & Prioridad & Obligatorio \\
\hline Descripción & Los ejercicios de TEC tradicionales deben adaptarse a las TIC. \\
\hline
\end{tabular}

Tabla 9. Requisito funcional 3

RF-03. Generación dinámica de ejercicios

\begin{tabular}{|l|l|l|l|}
\hline Categoría & Funcional & Prioridad & Obligatorio \\
\hline Descripción & La aplicación del paciente debe generar los ejercicios dinámicamente. \\
\hline
\end{tabular}

Tabla 10. Requisito funcional 4

RF-04. Envío de los resultados

\begin{tabular}{|l|l|l|l|}
\hline Categoría & Funcional & Prioridad & Obligatorio \\
\hline Descripción & Los resultados de los ejercicios realizados por el paciente deben enviarse al servidor. \\
\hline
\end{tabular}


Tabla 11. Requisito funcional 5

\section{RF-05. Consulta de resultados}

\begin{tabular}{|l|l|l|l|}
\hline Categoría & Funcional & Prioridad & Obligatorio \\
\hline Descripción & El terapeuta debe poder consultar los resultados del paciente. \\
\hline
\end{tabular}

Tabla 12. Requisito funcional 6

\section{RF-06. Inserción de valoración}

\begin{tabular}{|l|l|l|l|}
\hline Categoría & Funcional & Prioridad & Obligatorio \\
\hline Descripción & $\begin{array}{l}\text { El terapeuta debe poder introducir una valoración para a la vista de los resultados } \\
\text { del paciente. }\end{array}$ \\
\hline
\end{tabular}

Tabla 13. Requisito funcional 7

\section{RF-07. Asignación de bloque de ejercicios}

\begin{tabular}{|l|l|l|l|}
\hline Categoría & Funcional & Prioridad & Obligatorio \\
\hline Descripción & $\begin{array}{l}\text { El terapeuta debe poder seleccionar un bloque de ejercicios para asignárselo al } \\
\text { paciente a la vista de sus resultados. }\end{array}$ \\
\hline
\end{tabular}

Tabla 14. Requisito funcional 8

\section{RF-08. Visualización de valoración}

\begin{tabular}{|l|l|l|l|}
\hline Categoría & Funcional & Prioridad & Obligatorio \\
\hline Descripción & $\begin{array}{l}\text { El paciente debe poder visualizar la valoración introducida por el terapeuta a través } \\
\text { de su aplicación. }\end{array}$ \\
\hline
\end{tabular}

Tabla 15. Requisito funcional 9

\section{RF-09. Asignación de bloque de ejercicios}

\begin{tabular}{|l|l|l|l|}
\hline Categoría & Funcional & Prioridad & Obligatorio \\
\hline Descripción & $\begin{array}{l}\text { El paciente debe poder descargarse el siguiente bloque de ejercicios asignado por } \\
\text { su terapeuta. }\end{array}$ \\
\hline
\end{tabular}

Tabla 16. Requisito funcional 10

\section{RF-10. Control del tiempo entre pulsaciones}

\begin{tabular}{|l|l|l|l|}
\hline Categoría & Funcional & Prioridad & Obligatorio \\
\hline Descripción & La aplicación del paciente debe controlar el tiempo entre pulsaciones. \\
\hline
\end{tabular}

Tabla 17. Requisito funcional 11

\section{RF-11. Tiempo máximo de ejercicio}

\begin{tabular}{|l|l|l|l|}
\hline Categoría & Funcional & Prioridad & Obligatorio \\
\hline Descripción & \multicolumn{2}{|c|}{ Los ejercicios deben tener un tiempo máximo de realización. } \\
\hline
\end{tabular}


Tabla 18. Requisito funcional 12

\section{RF-12. Nuevos ejercicios}

\begin{tabular}{|l|l|l|l|}
\hline Categoría & Funcional & Prioridad & Obligatorio \\
\hline Descripción & \multicolumn{2}{|l|}{ Los terapeutas deben poder introducir ejercicios nuevos. } \\
\hline
\end{tabular}

Tabla 19. Requisito funcional 13

\section{RF-13. Nuevos bloques de ejercicios}

\begin{tabular}{|l|l|l|l|}
\hline Categoría & Funcional & Prioridad & Obligatorio \\
\hline Descripción & \multicolumn{2}{|l|}{ Los terapeutas deben poder crear bloques de ejercicios. } \\
\hline
\end{tabular}

Tabla 20. Requisito funcional 14

\section{RF-14. Personalización de la terapia}

\begin{tabular}{|l|l|l|l|}
\hline Categoría & Funcional & Prioridad & Obligatorio \\
\hline Descripción & $\begin{array}{l}\text { Los terapeutas deben poder personalizar la terapia orientada a las necesidades de } \\
\text { un paciente en concreto. }\end{array}$ \\
\hline
\end{tabular}

Tabla 21. Requisito funcional 15

\section{RF-15. Visualización de pacientes}

\begin{tabular}{|l|l|l|l|}
\hline Categoría & Funcional & Prioridad & Obligatorio \\
\hline Descripción & $\begin{array}{l}\text { Los terapeutas de una asociación solo pueden visualizar la información de los } \\
\text { pacientes de esa asociación. }\end{array}$ \\
\hline
\end{tabular}

Tabla 22. Requisito funcional 16

\section{RF-16. Alta de pacientes y terapeutas}

\begin{tabular}{|l|l|l|l|}
\hline Categoría & Funcional & Prioridad & Obligatorio \\
\hline Descripción & Las asociaciones deben poder dar de alta tanto a terapeutas como pacientes. \\
\hline
\end{tabular}

Tabla 23. Requisito funcional 17

\section{RF-17. Alta de asociaciones}

\begin{tabular}{|l|l|l|l|}
\hline Categoría & Funcional & Prioridad & Obligatorio \\
\hline Descripción & La Federación de EP debe poder dar de alta a asociaciones. \\
\hline
\end{tabular}

Tabla 24. Requisito funcional 18

\section{RF-18. Autenticación}

\begin{tabular}{|l|l|l|l|}
\hline Categoría & Funcional & Prioridad & Obligatorio \\
\hline Descripción & Los usuarios deberán autenticarse para acceder a la plataforma. \\
\hline
\end{tabular}


Tabla 25. Requisito funcional 19

RF-19. Comunicaciones cifradas

\begin{tabular}{|l|l|l|l|}
\hline Categoría & Funcional & Prioridad & Obligatorio \\
\hline Descripción & Las comunicaciones deben estar cifradas. \\
\hline
\end{tabular}

4.5.1.2. Requisitos no funcionales

Tabla 26. Requisito no funcional 1

\begin{tabular}{|l|l|l|l|}
\hline \multicolumn{3}{|l|}{ RNF-01. Interfaces accesibles } \\
\hline Categoría & No funcional & Prioridad & Obligatorio \\
\hline Descripción & Las interfaces gráficas de los usuarios deben cumplir criterios de accesibilidad. \\
\hline
\end{tabular}

Tabla 27. Requisito no funcional 2

\section{RNF-02. Interacción clara}

\begin{tabular}{|l|l|l|l|}
\hline Categoría & No funcional & Prioridad & Obligatorio \\
\hline Descripción & \multicolumn{2}{|c|}{ Se debe diseñar la interacción del usuario de forma clara. } \\
\hline
\end{tabular}

Tabla 28. Requisito no funcional 3

\section{RNF-03. Curva de aprendizaje pequeña}

\begin{tabular}{|l|l|l|l|}
\hline Categoría & No funcional & Prioridad & Obligatorio \\
\hline Descripción & $\begin{array}{l}\text { Las aplicaciones de usuario deben tener una curva de aprendizaje pequeña para } \\
\text { personas poco familiarizadas con la tecnología. }\end{array}$ \\
\hline
\end{tabular}

Tabla 29. Requisito no funcional 4

\section{RNF-04. Mensajes motivantes}

\begin{tabular}{|l|l|l|l|}
\hline Categoría & No funcional & Prioridad & Obligatorio \\
\hline Descripción & Los mensajes hacia el paciente deben ser motivantes. \\
\hline
\end{tabular}

Tabla 30. Requisito no funcional 5

\section{RNF-05. Disponibilidad}

\begin{tabular}{|l|l|l|l|}
\hline Categoría & No funcional & Prioridad & Obligatorio \\
\hline Descripción & El servicio debe estar siempre disponible. \\
\hline
\end{tabular}

Tabla 31. Requisito no funcional 6

\section{RNF-06. Interoperabilidad}

\begin{tabular}{|l|l|l|l|}
\hline Categoría & No funcional & Prioridad & Obligatorio \\
\hline Descripción & El sistema debe permitir la interoperabilidad entre agentes de usuario. \\
\hline
\end{tabular}


Tabla 32. Requisito no funcional 7

\section{RNF-07. Aplicación del paciente estable y eficiente}

\begin{tabular}{|l|l|l|l|}
\hline Categoría & No funcional & Prioridad & Obligatorio \\
\hline Descripción & $\begin{array}{l}\text { La aplicación del paciente debe ser estable y eficiente, diseñada para un dispositivo } \\
\text { de recursos limitados. }\end{array}$ \\
\hline
\end{tabular}

Tabla 33. Requisito no funcional 8

RNF-08. Cantidad de información intercambiada

\begin{tabular}{|l|l|l|l|}
\hline Categoría & No funcional & Prioridad & Obligatorio \\
\hline Descripción & $\begin{array}{l}\text { El intercambio de información entre el dispositivo del paciente y el servidor debe } \\
\text { ser el menor posible. }\end{array}$ \\
\hline
\end{tabular}

Tabla 34. Requisito no funcional 9

\section{RNF-09. Ejercicios adaptados}

\begin{tabular}{|l|l|l|l|}
\hline Categoría & No funcional & Prioridad & Obligatorio \\
\hline Descripción & Los ejercicios deben adaptarse a las necesidades de una persona con EP. \\
\hline
\end{tabular}

Tabla 35. Requisito no funcional 10

RNF-10. Ayuda

\begin{tabular}{|l|l|l|l|}
\hline Categoría & No funcional & Prioridad & Obligatorio \\
\hline \multirow{2}{*}{ Descripción } & $\begin{array}{l}\text { Toda la aplicación web deberá contar con una página de Ayuda asociada a la } \\
\text { pantalla en la que se encuentre el usuario. } \\
\text { También será necesaria la generación de manuales de usuario. }\end{array}$ \\
\hline
\end{tabular}

\subsection{Relevancia de los requisitos de usuario identificados}

Los requisitos de usuario identificados a lo largo de este capítulo tienen una gran importancia para la validación tanto de las hipótesis de partida como de los objetivos iniciales.

Para la recogida de requisitos se ha contado con la colaboración del colectivo implicado en la aplicación del modelo, como son las personas con EP y los terapeutas responsables de las TEC en las asociaciones de Parkinson. Esto se ha ido destacando a lo largo del capítulo, concretamente durante el proceso de DCU, ya que se ha contado con la evaluación de los expertos durante toda la fase de diseño.

Los requisitos de usuario, tanto los funcionales como los no funcionales, son la base principal para la definición de los parámetros que debe contener el modelo para la asignación de terapias orientadas a la estimulación cognitiva para personas diagnosticadas de EP, esto es, con Parkinson idiopático. Asimismo, en estos requisitos se recogen las necesidades de estos pacientes cuando se enfrentan a las NNTT que pretenden ser la base de la aplicación desarrollada a partir del modelo propuesto.

En el área específica de los parámetros de la TEC, nos hemos encontrado con multitud de argumentos, muchos de ellos extrapolables a otras patologías que también presenten deterioro 
cognitivo. Entre estos parámetros se encuentran la disponibilidad del servicio, ya que la importancia principal de este modelo es el introducir una alternativa eficiente que permita a los pacientes la realización de terapias personalizadas y supervisadas por su terapeuta en cualquier momento y lugar. Esta disponibilidad habilita que, además de poder llevar a cabo las TEC en la asociación, también se puedan realizar desde otros lugares. Esto puede ser muy útil para personas que no puedan desplazarse a las asociaciones, ya sea por discapacidad temporal o permanente o por personas con EP que vivan en zonas rurales y no tengan la posibilidad de asistir a asociaciones para la realización de terapias no farmacológicas. Asimismo, se puede utilizar como terapia complementaria para los pacientes que ya estén acudiendo a la asociación.

Del mismo modo, la personalización de terapias y el seguimiento por el terapeuta es un aspecto muy relevante que puede darse gracias a las TIC. En el supuesto de que las TEC se realizaran en la asociación en la presencia del terapeuta, el seguimiento podría hacerse en el momento y no sería tan relevante, pero la idea es poder utilizar este tipo de TEC como herramienta complementaria. La personalización puede ser muy útil al no disponer de herramientas para las terapias que sean estáticas, ya que las TIC le dan un aspecto dinámico al disponer de una base de datos de ejercicios cada vez más grande que permite personalizar cada sesión de TEC con un paciente concreto.

Este aumento de la base de datos es posible gracias al trabajo colaborativo entre asociaciones en el ámbito de los contenidos que forman parte de la terapia. En el modelo planteado se contempla que la introducción de nuevos ejercicios y la creación de bloques para asignárselos a los pacientes sea lo más intuitiva posible. De esta forma, son los propios terapeutas los que crean ejercicios y estos ejercicios están disponibles para todas las asociaciones, lo que incrementa el número de herramientas disponibles de forma considerable.

Por supuesto, se ha detectado la importancia de que las interfaces sean usables y accesibles. Principalmente en el área de la usabilidad de la aplicación del paciente, se han tenido en cuenta para su diseño las necesidades que presentan las personas con EP cuando se enfrentan a las TIC.

Con respecto a las necesidades de estas personas, se han identificado requisitos de usuario asociados a ellos y no tanto a los parámetros de definición de la TEC. Este es el caso de la necesidad de elementos clicables grandes, el control de las pulsaciones o el control de tiempo de realización de los ejercicios, todas ellas relacionadas con la discapacidad motora presentada por estos pacientes debido a su enfermedad. Se han identificado otras dimensiones, como son la cognitiva y la emocional. Con respecto a la cognitiva, es necesario un tiempo máximo de realización de los ejercicios por las pérdidas de atención que sufren las personas con EP. Asimismo, la aplicación desarrollada debe ser sencilla e intuitiva, con mensajes claros y breves, además de disponer de imágenes que apoyen la información textual. En el contexto de la dimensión emocional se han detectado multitud de necesidades, como son que la curva de aprendizaje debe ser pequeña, que hay que añadir mensajes motivantes para que el paciente se encuentre más dispuesto a utilizar la plataforma, que los ejercicios que capten la atención del paciente o que se perciba la personalización de la terapia para que los pacientes no lo vean como un juego, sino como una herramienta que les ayude a mantener sus capacidades cognitivas.

Gracias a las conclusiones de este capítulo se van percibiendo considerables mejoras con la introducción de las TIC en este contexto de uso, lo que derivará en capítulos posteriores en el 
cumplimiento de las hipótesis iniciales. A lo largo de este capítulo se han detallado las tres primeras fases para la validación de las hipótesis, tal y como se muestra a continuación:

- Fase 1. Selección de la metodología. Se ha optación por la selección del proceso de DCU principalmente por la colaboración de los usuarios finales en todas las fases. Esto ha permitido la realización de diseños y la implementación de módulos parciales que han sido verificados con pacientes y terapeutas de la APKM. Además, la versatilidad de esta metodología ha permitido añadir una iteración relativa a los manuales de usuario.

- Fase 2. Modelado de la TEC. Los parámetros relativos a la creación de TEC en un contexto tecnológico se han ido recogiendo en la segunda fase del proceso de DCU. Muchos de los parámetros no estarían disponibles si no nos encontramos en un entorno tecnológico. A modo de resumen, estos parámetros son:

- Terapias disponibles en cualquier momento y lugar.

- Generación dinámica de ejercicios para que puedan ser introducidos en la base de datos por personas no familiarizadas con la tecnología.

- Seguimiento de los resultados del paciente por el terapeuta.

- Realimentación al paciente por parte del terapeuta a la vista de sus resultados.

- Personalización de la terapia para cada paciente.

- Compartición de recursos entre asociaciones.

- Interfaces accesibles.

- Cumplimiento de la legislación sobre protección de datos de carácter personal.

- Fase 3. Resumen de las necesidades de una persona con EP en sus dimensiones cognitiva, motora y emocional. En la segunda fase del proceso de DCU, además, se han recogido las necesidades de los afectados de EP cuando se enfrentan a un entorno tecnológico y se han clasificado según la dimensión a la que corresponde, como se detalla a continuación:

- Dimensión motora:

- Elementos para la interacción grandes.

- Control de las pulsaciones.

- Control del tiempo de realización de los ejercicios.

- Dimensión cognitiva:

- Tiempo máximo de realización de los ejercicios.

- Información visual apoyada por texto.

- Textos claros y breves.

- Dimensión emocional:

- Mensajes motivantes para el paciente.

- Utilización de imágenes que no sean infantiles.

- Mostrar la personalización de la terapia al paciente. 
ㅁ Dimensiones cognitiva y emocional:

- Curva de aprendizaje de la aplicación pequeña.

- Ejercicios que intenten mantener la atención del paciente.

El modelo presentado en esta tesis doctoral abarca un amplio estudio tanto de los parámetros de la terapia como de las necesidades de los pacientes en un entorno TIC, con el fin de mejorar la calidad asistencial que se le da a los pacientes en este contexto, tal y como se recoge en las hipótesis definidas al inicio de este trabajo. Llegados a este punto, se comienzan a apreciar elementos que no serían posibles sin la introducción de las TIC, como la disponibilidad de las terapias o la personalización de las mismas. Sin embargo, el cumplimiento de la validación de las hipótesis, descrita de forma más amplia en el Capítulo 7. Discusión de los resultados experimentales, dependerá en gran medida de los resultados obtenidos tras la experimentación. 


\section{Capítulo 5. Materiales y métodos}

En este capítulo se detallan análisis, diseño, implementación y pruebas realizadas del prototipo necesario para la comprobación de la validez de los objetivos de partida de esta tesis doctoral.

\subsection{Descripción del sistema}

A partir de los requisitos de usuario recogidos en fases previas y descritos en detalle en el capítulo anterior de esta memoria, se va a proceder a la descripción técnica de la plataforma basada en el modelo para la realización de los experimentos. En este apartado se describirá el trabajo de investigación en ingeniería para utilizar las tecnologías más acordes a las necesidades de los usuarios que, como se puntualizó en la fase de requisitos, se ha llevado a cabo con ayuda de un comité de expertos en la materia.

El diseño y desarrollo de esta plataforma se ha llevado a cabo dentro del proyecto de investigación DaleMov, financiado por la Fundación Vodafone España y en el que han colaborado APKM y FEP, además de la UPM, como se detalló en el apartado 3.2.2. Contexto de este trabajo de investigación.

Como se describió en el capítulo anterior, se ha seguido el proceso de DCU para llevar a cabo el diseño del sistema y la recogida de requisitos de usuario, colaborando con los usuarios finales (pacientes diagnosticados de EP y terapeutas de TEC) para certificar que la solución tenía un alto grado de innovación al contar con ellos en todas las fases. Las cuatro fases en las que se descompone el DCU, ya detallado en el capítulo anterior, son la especificación del contexto, la especificación de los requisitos, la producción en el diseño y su evaluación. Para llevar a cabo la descripción del sistema en la fase de producción en el diseño, se ha utilizado el enfoque tradicional de ingeniería del software. La ingeniería del software es, en palabras de Boehm [Boehm, 1976]:

Ingeniería de software es la aplicación práctica del conocimiento científico al diseño y construcción de programas de computadora y a la documentación asociada requerida para desarrollar, operar y mantenerlos. Se conoce también como desarrollo de software $o$ producción de software [Boehm, 1976]

Boehm también fue el primero que presentó el desarrollo en espiral, mediante el cual se cambiaba el modelo tradicional en cascada por iteraciones más pequeñas en forma de espiral [Boehm, 1986]. A través de esta metodología de desarrollo se ha implementado cada iteración del proceso de DCU. Las fases del proceso de desarrollo en espiral son: 
- Análisis: se estudian los requisitos de usuario capturados. Estos requisitos se adaptan a lenguajes de modelado para identificar los casos de uso que tendrá el sistema, entre otros. Sirve para definir la funcionalidad del sistema.

- Diseño: se identifica la arquitectura del sistema a partir de la funcionalidad de la fase anterior. También se pueden utilizar lenguajes de modelado para presentarlo.

- Implementación: desarrollo de lo descrito en el diseño.

- Pruebas: verificación técnica y funcional de la solución implementada.

Estas fases se muestran de forma más clara en la Figura 25.

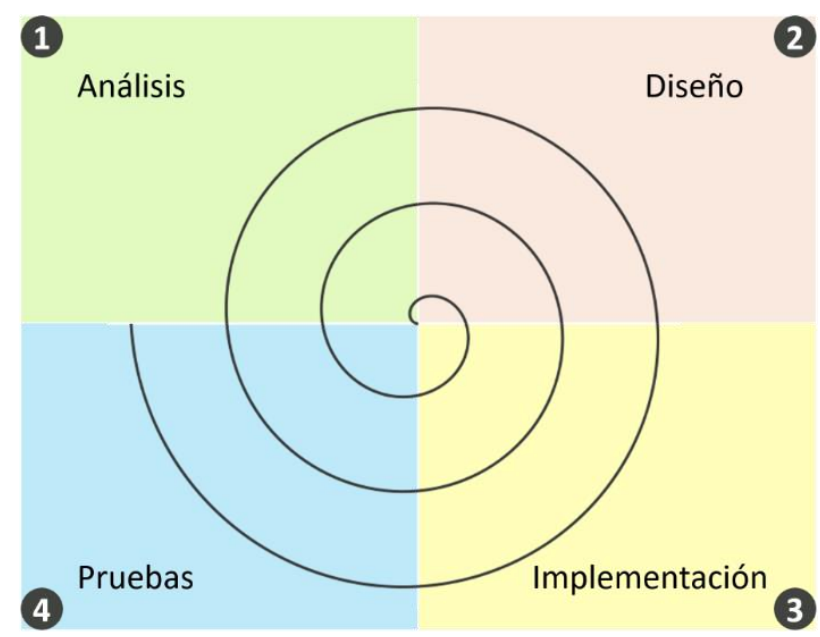

Figura 25. Desarrollo en espiral [Boehm, 1986]

En el caso particular que nos encontramos, se ha utilizado UML (Unified Modeling Language, Lenguaje Unificado de Modelado) para la representación del análisis de requisitos y del diseño del sistema. UML es un lenguaje gráfico que permite visualizar, especificar, construir y documentar un sistema. Se ha elegido este lenguaje por ser el más extendido hoy en día a la hora de modelar software.

\subsection{Análisis de requisitos}

El análisis de los requisitos identificados en el capítulo anterior se ha llevado a cabo utilizando el lenguaje UML. En este apartado se presentan los diagramas de casos de uso y de secuencia de las funcionalidades principales generados a partir de los requisitos funcionales definidos en el capítulo anterior. En primer lugar, se presenta el diagrama general y, posteriormente, el desglose de los paquetes funcionales. Finalmente, se muestra el diagrama de secuencia de la realización de TEC.

\subsubsection{Diagrama de casos de uso general}

La Figura 26 presenta el diagrama de casos de uso general del sistema. En este diagrama aparecen dos paquetes funcionales que se describirán más adelante: Gestión de ejercicios y Gestión de usuarios. 


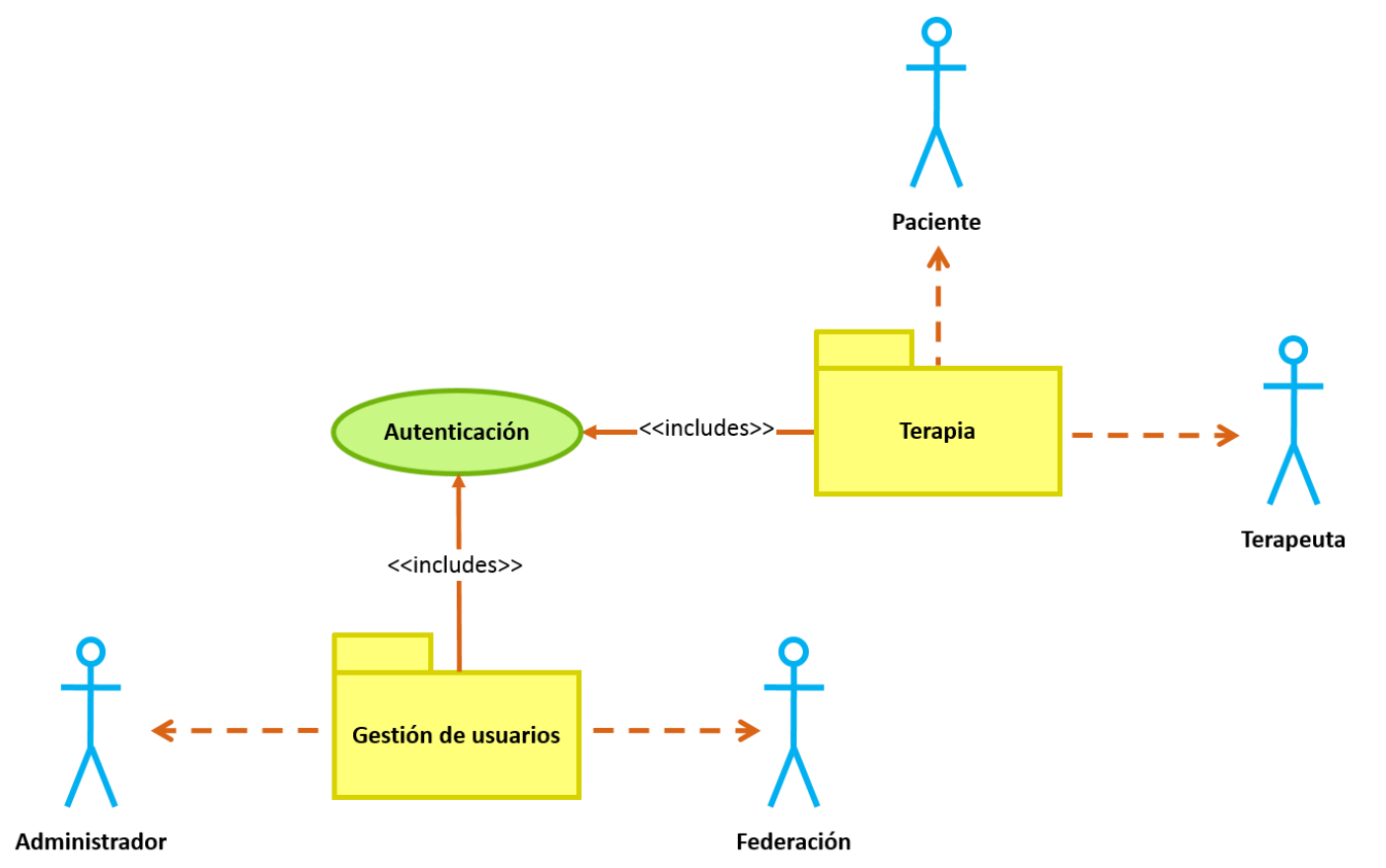

Figura 26. Diagrama de casos de uso general

En este diagrama se pueden apreciar los roles de los usuarios que pueden interactuar con el sistema. Estos son:

- Paciente: descarga y realiza bloques de ejercicios de estimulación cognitiva y consulta la valoración de su terapeuta a la vista de sus resultados.

- Terapeuta: selecciona los bloques de ejercicios que se descargará el paciente, valora los resultados obtenidos por el mismo personalizando la terapia y gestiona los ejercicios y los bloques de ejercicios del sistema.

- Administrador: lleva la gestión de usuarios de pacientes y terapeutas de su asociación.

- Federación: lleva la gestión de asociaciones.

En el diagrama de casos de uso general se aprecian dos paquetes funcionales que se expondrán más adelante y un caso de uso, que se detalla en la tabla a continuación.

Tabla 36. Caso de uso Autenticación

\begin{tabular}{|l|l|}
\hline CU-01 & Autenticación \\
\hline Descripción & Autenticación de los usuarios previa a realizar cualquier operación. \\
\hline Precondición & El usuario está dato de alta en la plataforma. \\
\hline Secuencia & $\begin{array}{l}\text { El usuario introduce sus datos de acceso. } \\
\text { Si los datos existen en la base de datos, se le permite el acceso, pudiendo ver todas } \\
\text { las operaciones que puede llevar a cabo según su rol. }\end{array}$ \\
\hline Postcondición & El usuario accede a la plataforma. \\
\hline Excepciones & $\begin{array}{l}\text { En el caso de que no haya registro de un usuario con esos datos identificativos, se } \\
\text { mostrará un mensaje de error. }\end{array}$ \\
\hline
\end{tabular}




\subsubsection{Diagrama de casos de uso del paquete funcional Terapia}

El diagrama de casos de uso del paquete funcional Terapia se presenta en la Figura 27.

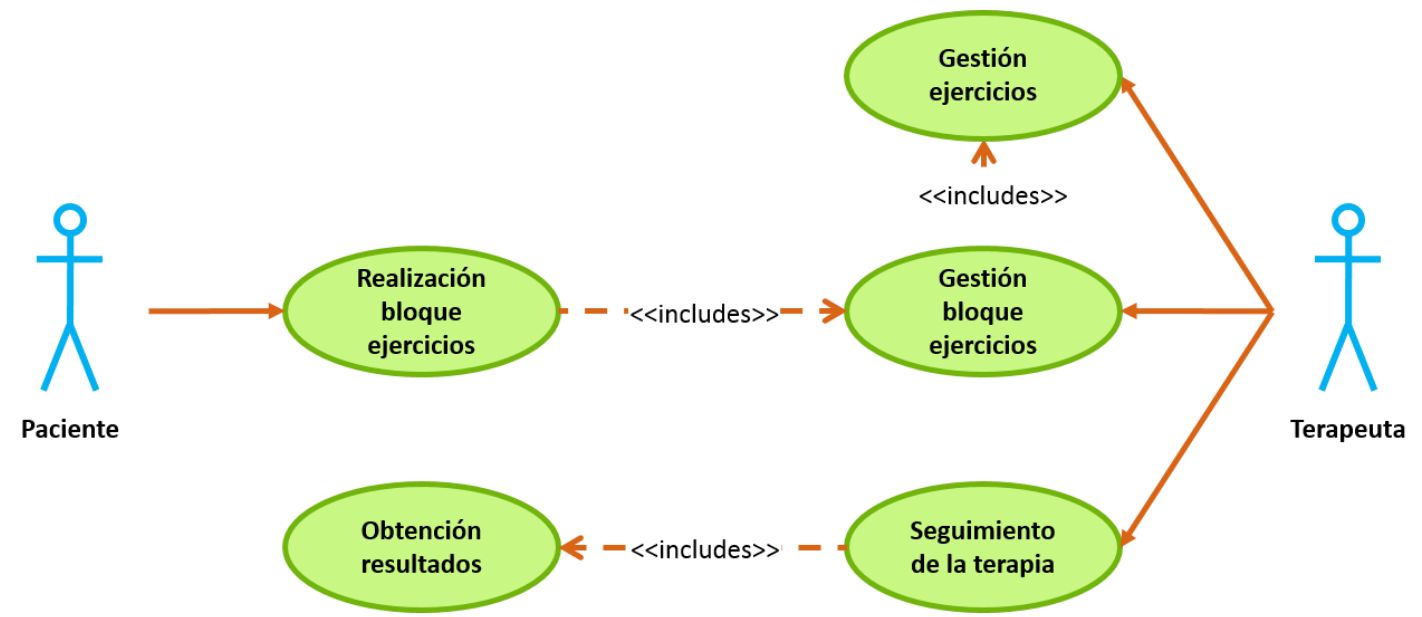

Figura 27. Diagrama de casos de uso del paquete funcional Terapia

A la vista de la imagen anterior, se puede observar que los roles de usuario que intervienen en este caso de uso son Paciente y Terapeuta.

En el diagrama anterior se ha omitido el caso de uso del diagrama general Autenticación para no complicarlo, pero sería necesario para cualquier operación.

Estos casos de uso se presentan con más detalle en la Tabla 37 a Tabla 41.

Tabla 37. Caso de uso Gestión de ejercicios

\begin{tabular}{|c|c|}
\hline CU-02 & Gestión de ejercicios \\
\hline Descripción & $\begin{array}{l}\text { Incluye la creación, modificación y eliminación de ejercicios de estimulación } \\
\text { cognitiva. }\end{array}$ \\
\hline Precondición & N/A \\
\hline Secuencia & $\begin{array}{l}\text { Para la creación de un ejercicio: } \\
\text { El terapeuta define los datos del ejercicio. } \\
\text { El terapeuta previsualiza los datos y, si está de acuerdo, pulsa Crear ejercicio. } \\
\text { Para la modificación de un ejercicio: } \\
\text { El terapeuta busca el ejercicio que desea modificar. } \\
\text { El terapeuta selecciona los datos a modificar. } \\
\text { El terapeuta previsualiza los datos y, si está de acuerdo, pulsa Modificar ejercicio. } \\
\text { Para la eliminación de un ejercicio: } \\
\text { El terapeuta busca el ejercicio a eliminar. } \\
\text { El terapeuta previsualiza los datos y, si está de acuerdo, pulsa Eliminar ejercicio. }\end{array}$ \\
\hline Postcondición & $\begin{array}{l}\text { El ejercicio se almacena en la base de datos, se modifica o se elimina } \\
\text { respectivamente. }\end{array}$ \\
\hline Excepciones & N/A \\
\hline
\end{tabular}


Tabla 38. Caso de uso Gestión bloque ejercicios

\begin{tabular}{|c|c|}
\hline CU-03 & Gestión bloque ejercicios \\
\hline Descripción & Incluye las tareas de creación y de eliminación de un bloque de ejercicios. \\
\hline Precondición & N/A \\
\hline Secuencia & $\begin{array}{l}\text { Para la creación de un bloque de ejercicios: } \\
\text { El terapeuta define los parámetros del bloque de ejercicios. } \\
\text { Si se desea la generación automática, definirá las áreas de estimulación y el nivel de } \\
\text { dificultad. } \\
\text { Si es de generación manual, seleccionará el nivel de dificultad y elegirá uno por uno } \\
\text { los ejercicios a incluir en el bloque. } \\
\text { El terapeuta previsualiza los datos y, si está de acuerdo, pulsa Crear bloque de } \\
\text { ejercicios. } \\
\text { Para la eliminación de un bloque de ejercicios: } \\
\text { El terapeuta busca el bloque de ejercicios a eliminar. } \\
\text { El terapeuta previsualiza los datos y, si está de acuerdo, pulsa Eliminar bloque de } \\
\text { ejercicios. }\end{array}$ \\
\hline Postcondición & Bloque de ejercicios creado o eliminado. \\
\hline Excepciones & N/A \\
\hline
\end{tabular}

Tabla 39. Caso de uso Seguimiento de la terapia

\begin{tabular}{|c|c|}
\hline CU-04 & Seguimiento de la terapia \\
\hline Descripción & $\begin{array}{l}\text { El terapeuta visualiza los resultados obtenidos por los pacientes e incluye una } \\
\text { valoración a los mismos, así como el nuevo bloque de ejercicios que se descargará } \\
\text { cada paciente para continuar con la terapia. }\end{array}$ \\
\hline Precondición & El paciente ha realizado ejercicios. \\
\hline Secuencia & $\begin{array}{l}\text { La aplicación web presenta la lista de pacientes con ejercicios pendientes de valorar. } \\
\text { El terapeuta selecciona un paciente. } \\
\text { Se presentan los resultados de ese paciente. } \\
\text { El terapeuta escribe una valoración que el paciente podrá consultar en su dispositivo } \\
\text { y asigna el siguiente bloque de ejercicios que debe realizar. } \\
\text { El terapeuta previsualiza la valoración y, si está de acuerdo, pulsa Insertar valoración. }\end{array}$ \\
\hline Postcondición & Se almacena la valoración y el siguiente bloque en la base de datos. \\
\hline Excepciones & En el caso de que el bloque a asignar no exista, deberá crearse primero. \\
\hline
\end{tabular}

Tabla 40. Caso de uso Realización bloque ejercicios

\section{CU-05 Realización bloque ejercicios}

\begin{tabular}{|l|l} 
Descripción & $\begin{array}{l}\text { El paciente se descarga y realiza un bloque de ejercicios de estimulación cognitiva, } \\
\text { enviándose sus respuestas al servidor. }\end{array}$ \\
\hline Precondición & El paciente tiene asignado un bloque de ejercicios por parte del terapeuta. \\
\hline
\end{tabular}




\begin{tabular}{|l|l|}
\hline \multirow{2}{*}{ Secuencia } & $\begin{array}{l}\text { El paciente selecciona la opción Comenzar bloque de ejercicios. } \\
\text { Se busca el siguiente bloque que debe realizar y se envía a su dispositivo. } \\
\text { El paciente realiza el bloque. } \\
\text { Los resultados del bloque se envían al servidor. }\end{array}$ \\
\hline Postcondición & Los resultados del paciente se almacenan en la base de datos. \\
\hline Excepciones & $\begin{array}{l}\text { En el caso de que no se hayan podido enviar los resultados al servidor por problemas } \\
\text { de conexión, se intentará de nuevo y, si no se consiguiera, se volvería a intentar } \\
\text { cuando se volviera a abrir la aplicación. }\end{array}$ \\
\hline
\end{tabular}

Tabla 41. Caso de uso Obtención de resultados

\begin{tabular}{|c|c|}
\hline CU-06 & Obtención de resultados \\
\hline Descripción & El paciente consulta la valoración escrita por el terapeuta. \\
\hline Precondición & $\begin{array}{l}\text { El paciente ha finalizado un bloque de ejercicios que ha sido valorado por el } \\
\text { terapeuta. }\end{array}$ \\
\hline Secuencia & $\begin{array}{l}\text { El paciente selecciona la opción Consultar valoración. } \\
\text { Se envía la petición al servidor, que busca en la base de datos la última valoración } \\
\text { introducida. } \\
\text { Se presenta la valoración al paciente. }\end{array}$ \\
\hline Postcondición & El dispositivo del paciente muestra la valoración. \\
\hline Excepciones & Si el paciente no tiene valoraciones, se mostrará un mensaje de error. \\
\hline
\end{tabular}

\subsubsection{Diagrama de casos de uso del paquete funcional Gestión de usuarios}

Por otro lado, el diagrama de casos de uso del paquete funcional Gestión de usuarios resultó como se muestra en la Figura 28.
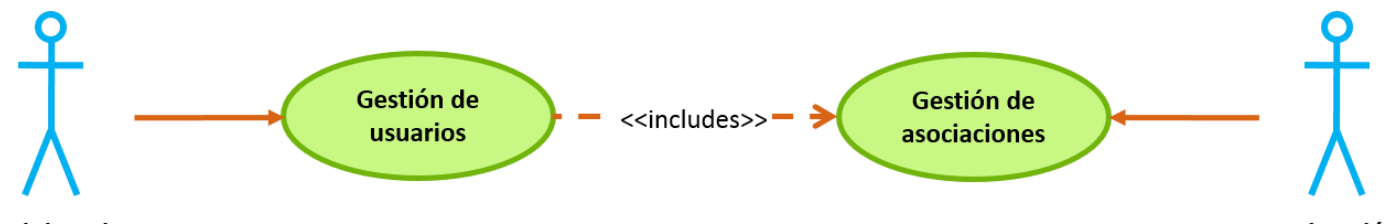

Administrador

Federación

Figura 28. Diagrama de casos de uso del paquete funcional Gestión de usuarios

Los casos de uso anteriores se detallan en la Tabla 42 y la Tabla 43.

Tabla 42. Caso de uso Gestión de usuarios

\begin{tabular}{|c|c|}
\hline CU-07 & Gestión de usuarios \\
\hline Descripción & $\begin{array}{l}\text { Incluye las tareas de dar de alta, modificar y dar de baja tanto a pacientes como a } \\
\text { terapeutas de una asociación. }\end{array}$ \\
\hline Precondición & La asociación está creada y se ha creado un usuario Administrador de la misma. \\
\hline Secuencia & $\begin{array}{l}\text { Para dar de alta a un usuario: } \\
\text { El administrador define los datos del usuario. } \\
\text { El administrador visualiza los datos y, si está conforme, pulsa Dar de alta usuario. }\end{array}$ \\
\hline
\end{tabular}




\begin{tabular}{|l|l|}
\hline & Para la modificación de los datos de un usuario: \\
& El administrador busca al usuario que desea modificar. \\
El administrador modifica la información correspondiente. \\
El administrador visualiza los datos y, si está de acuerdo, pulsa Modificar usuario. \\
Para dar de baja a un usuario: \\
El administrador busca el usuario a dar de baja. \\
El administrador visualiza los datos y, si está de acuerdo, pulsa Dar de baja usuario.
\end{tabular}

Tabla 43. Caso de uso Gestión de asociaciones

\begin{tabular}{|c|c|}
\hline CU-07 & Gestión de usuarios \\
\hline Descripción & $\begin{array}{l}\text { Incluye las tareas de dar de alta, modificar y dar de baja a una asociación, así como al } \\
\text { usuario inicial que será el encargado de la gestión de usuarios de su asociación. }\end{array}$ \\
\hline Precondición & $\mathrm{N} / \mathrm{A}$ \\
\hline Secuencia & $\begin{array}{l}\text { Para dar de alta a una asociación: } \\
\text { El usuario federación define los datos de la asociación. } \\
\text { El usuario federación previsualiza los datos y, si está de acuerdo, pulsa Dar de alta } \\
\text { asociación. } \\
\text { Para la modificación de los datos de una asociación: } \\
\text { El usuario federación busca a la asociación que desea modificar. } \\
\text { El usuario federación modifica la información correspondiente. } \\
\text { El usuario federación previsualiza los datos y, si está de acuerdo, pulsa Modificar } \\
\text { asociación. } \\
\text { Para dar de baja a una asociación: } \\
\text { El usuario federación busca la asociación a dar de baja. } \\
\text { El usuario federación previsualiza los datos y, si está de acuerdo, pulsa Dar de baja } \\
\text { asociación. }\end{array}$ \\
\hline Postcondición & $\begin{array}{l}\text { Los datos de la asociación se almacenan en la base de datos, se modifican o se } \\
\text { eliminan respectivamente. }\end{array}$ \\
\hline Excepciones & $\mathrm{N} / \mathrm{A}$ \\
\hline
\end{tabular}

\subsubsection{Diagramas de secuencia del paquete funcional Terapia}

La siguiente figura presenta el diagrama de secuencia del paquete funcional Terapia con las acciones más relevantes llevadas a cabo para la realización de la TEC. En este diagrama aparecen tanto el paciente como el terapeuta, así como la tableta como dispositivo del usuario, el servidor y la base de datos, como se puede ver en las figuras siguientes. La Figura 29 presenta la asignación del primer bloque de ejercicios a un paciente. La Figura 30 describe el proceso de solicitud y realización de un bloque de ejercicios por parte del paciente. La Figura 31 detalla la 
introducción de una valoración por parte del terapeuta. Por último, la Figura 32 muestra la consulta de esta valoración por el paciente a través de su dispositivo de usuario.

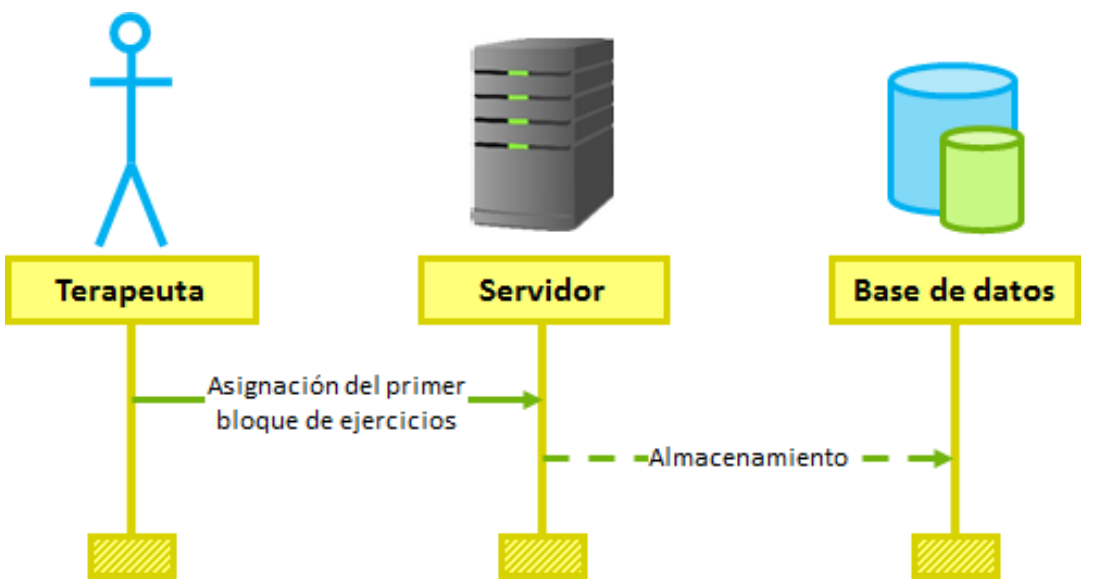

Figura 29. Diagrama de secuencia de asignación del primer bloque de ejercicios

La Figura 29 es relativa a la asignación del primer bloque de ejercicios. El terapeuta da de alta al paciente en la TEC asignándole el primer bloque de ejercicios que debe realizar en cuanto comience a realizar la terapia. Este bloque debe estar creado previamente.

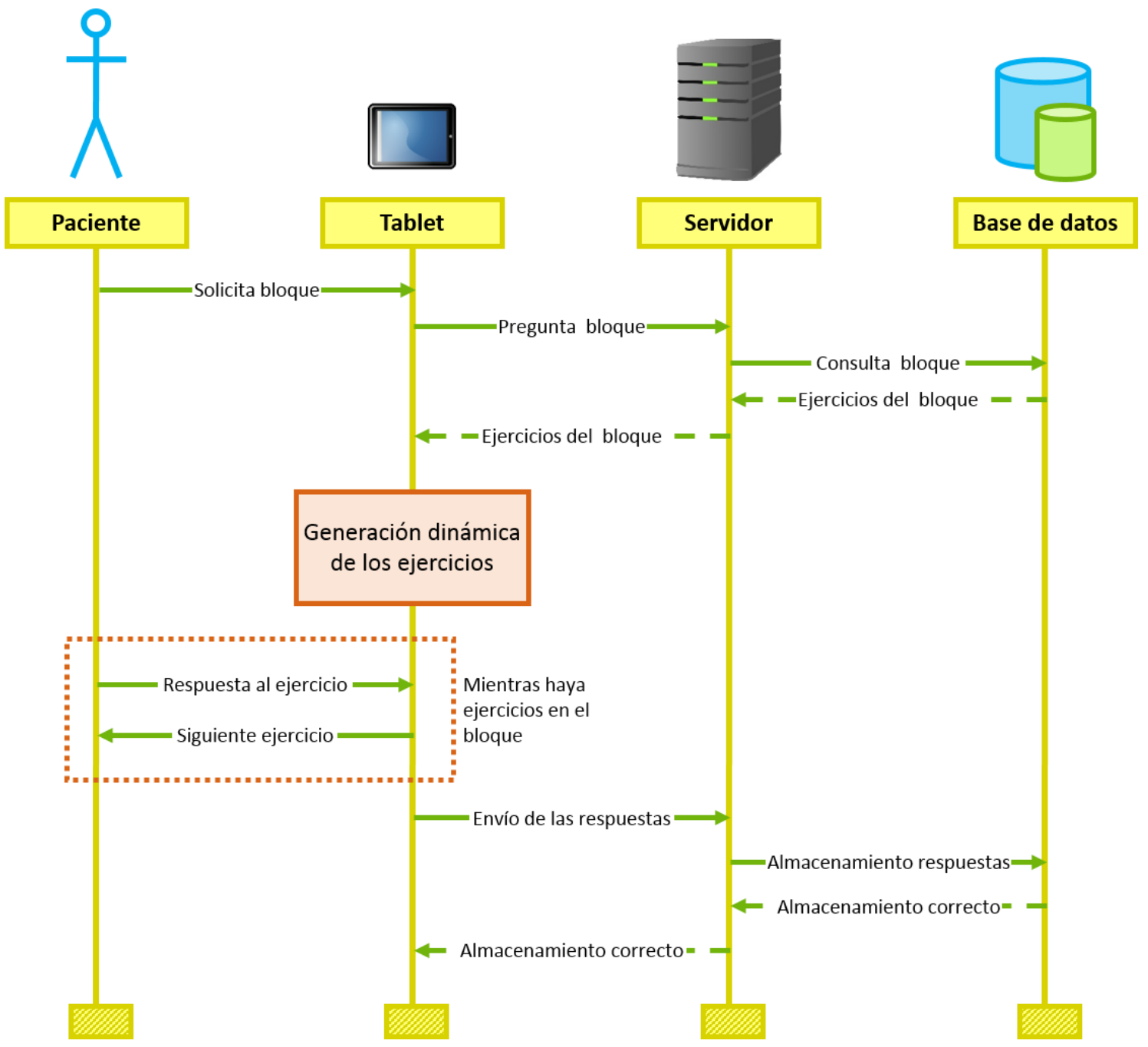

Figura 30. Diagrama de secuencia de realización de un bloque de ejercicios 
La Figura 30 se relaciona con la realización del bloque de ejercicios. El paciente solicita un bloque de ejercicios a través de una opción en el menú de su aplicación. Esta solicitud se envía al servidor, que consultará en la base de datos cuál es el siguiente bloque de ejercicios. La base de datos devuelve la información de los ejercicios que componen el bloque para que, a través del servidor, se le envíe al dispositivo del paciente. La aplicación del paciente, a partir de la información recibida, genera los ejercicios de forma dinámica y se los muestra al usuario. Una vez finalizados todos los ejercicios del bloque, las respuestas del paciente se envían al servidor y se almacenan en la base de datos, esperando ser consultadas por el terapeuta.

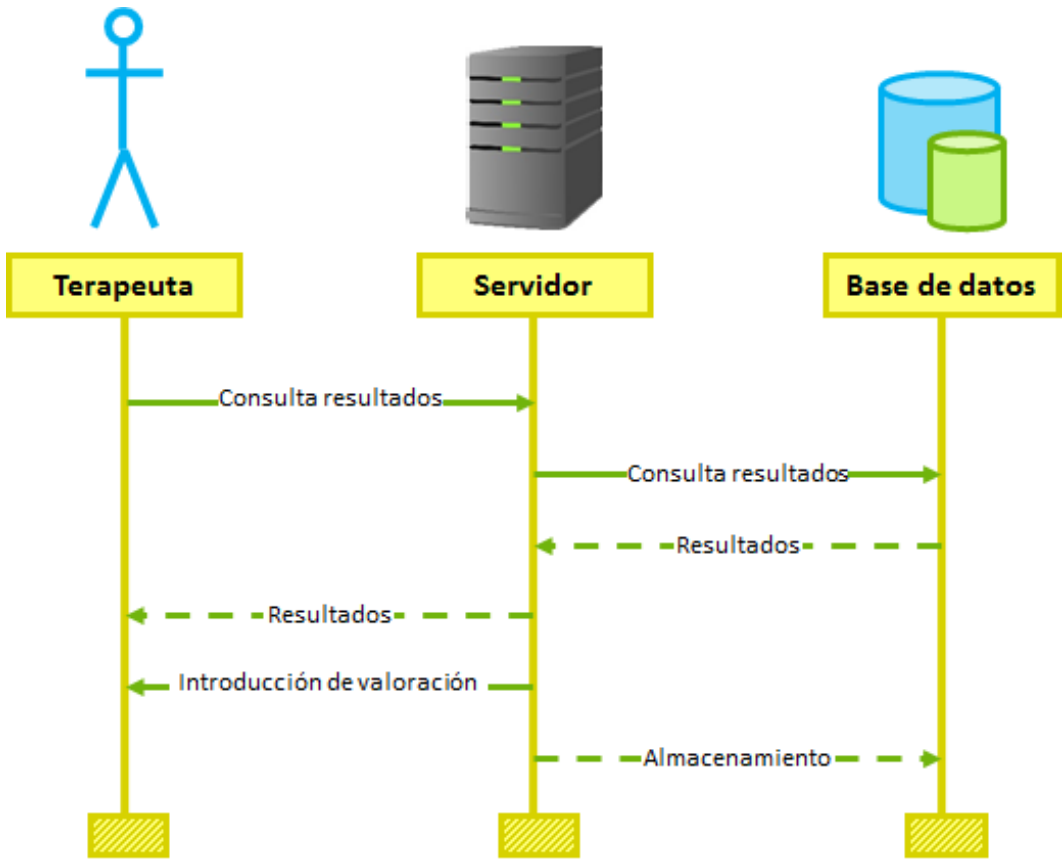

Figura 31. Diagrama de secuencia de la introducción de valoración

La Figura 31 describe el proceso de introducción de una valoración. El terapeuta consulta las respuestas a los ejercicios del bloque dadas por el paciente. Estas respuestas se encuentran almacenadas en la base de datos. A partir de estos resultados, el terapeuta emite una valoración y asigna el siguiente bloque de ejercicios. Tanto la valoración como el identificador del próximo bloque de ejercicios quedan almacenados en la base de datos asociados a ese paciente en concreto.

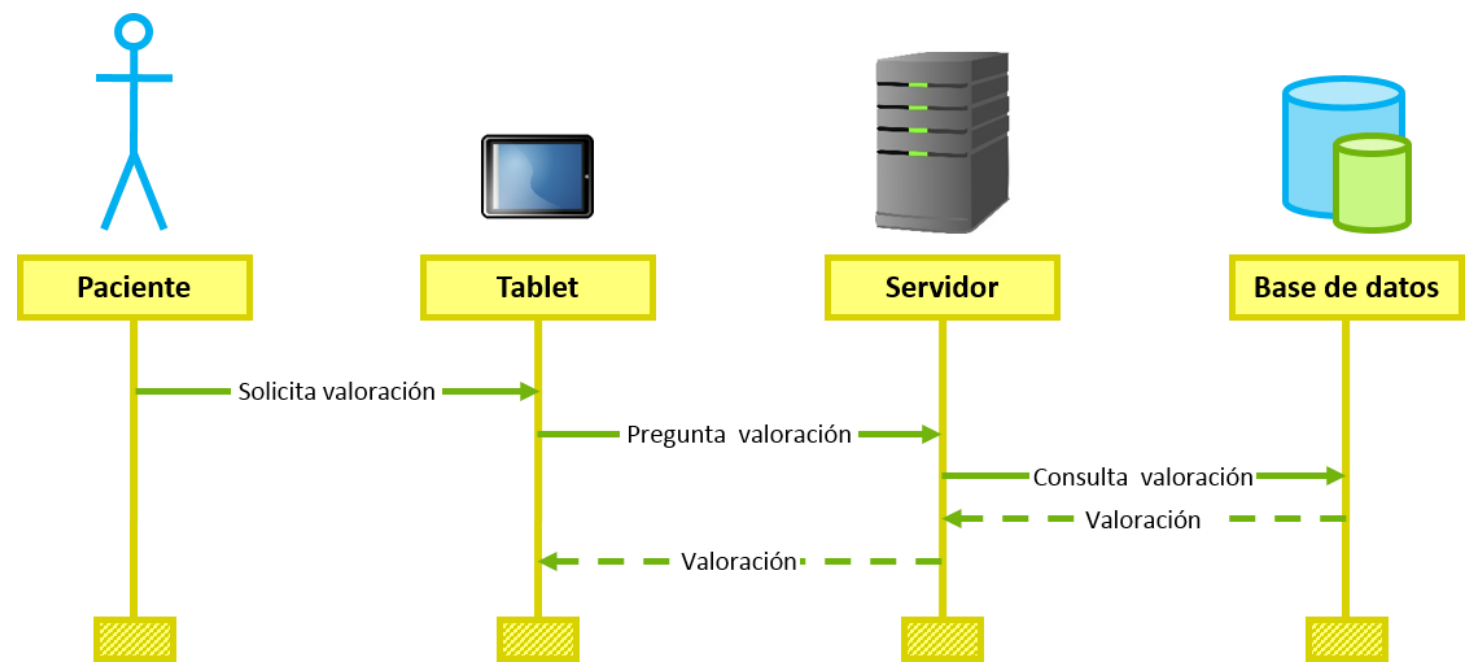

Figura 32. Diagrama de secuencia de consulta de valoración 
La Figura 32 muestra los pasos para la consulta de la valoración introducida por el terapeuta en el paso anterior. El paciente, a través de la aplicación instalada en su dispositivo, consulta la valoración emitida por el terapeuta. Para ello, la aplicación del paciente lleva a cabo una consulta al servidor, que busca la información en la base de datos y se la devuelve a la aplicación del paciente.

\subsection{Diseño de la terapia de estimulación cognitiva}

El trabajo de ingeniería llevado a cabo para el desarrollo de esta solución, ha sido el diseño de un servicio de estimulación cognitiva que adaptara las sesiones de estimulación cognitiva que tanto pacientes como terapeutas realizaban de forma tradicional.

Para ello, se ha tomado como ejemplo de este tipo de ejercicios los contenidos en el Cuaderno de ejercicios de la Asociación Parkinson Madrid [APKM, 2007], si bien no se ha pretendido adaptar este cuaderno a un contexto TIC, sino que se han redefinido las necesidades de la TEC para generarla en este nuevo entorno. En los sub-apartados siguientes se presentan ejemplos de ejercicios de este cuaderno y cómo se ha procedido a diseñar un nuevo tipo de terapia a través de la introducción de la tecnología.

\subsubsection{Ejercicios de estimulación cognitiva tradicionales}

Los ejercicios de estimulación cognitiva del Cuaderno de ejercicios [APKM, 2007] se componen en 4 áreas de estimulación. Estas áreas son:

- Ejercicios de atención: se centran en la concentración del paciente ya que, como se explicó en apartados anteriores, el déficit de atención es muy característico en el deterioro cognitivo de la EP. En estos ejercicios, como se puede observar en la imagen a continuación, se presenta un bloque de letras o números y se insta al usuario a que marque unos caracteres determinados. Los hay de diversos niveles de dificultad, por ejemplo, marcando los números impares o las letras 'A' de las líneas pares (Figura 33).

\begin{tabular}{|c|c|}
\hline I) EJERCICIOS DE ATENCIÓN & Ejercicios para la HOJA DE MATERIAL 2: (Ejemplos) \\
\hline (página 13 del folleto) & Ejercicio $\mathrm{I}$ : tache el número 3. \\
\hline Ejercicios para la HOJA DE MATERIAL I: (Ejemplos) & $\begin{array}{l}\text { El: } 647 \underline{3} 881719 \underline{3} 287541 \underline{3} 4 \underline{3} \underline{3} 54687 \\
984654 \underline{3}\end{array}$ \\
\hline Ejercicio 1: tache la letra $\mathrm{A}$. & Ejercicio 2: tache el número 7. \\
\hline $\begin{array}{l}\text { IONTE A BC } \underline{A} \text { DEERETEEOTIUSIOSTE } \\
\text { RFHI } \underline{\text { S S }}\end{array}$ & $\begin{array}{l}\text { El: } 64 \underline{7} 3881 \underline{7} 19328 \underline{754134335468 \underline{7}} \\
9846543\end{array}$ \\
\hline Ejercicio 2: tache la letra $F$. & Ejercicio 3: tache el número 1. \\
\hline $\begin{array}{l}\text { IONTEABCADEERETEEOTIUSIOSTE } \\
\text { REHIAS }\end{array}$ & $\begin{array}{l}\text { EJ: } 647388 \underline{1} 19328754 \underline{1} 343354687 \\
9846543\end{array}$ \\
\hline
\end{tabular}

Figura 33. Ejemplo de ejercicios de atención

- Ejercicios de funciones ejecutivas: agrupan cuatro modelos.

- Iniciativa: los ejercicios de iniciativa están orientados a comprobar el pensamiento imaginativo del paciente. En la Figura 34 se muestran algunos ejemplos. 


\section{II) EJERCICIOS DE FUNCIONES EJECUTIVAS}

(página 16 del folleto)

Para realizar estos ejercicios necesitará unos folios de papel.

\section{a) INICLATIVA}

Ejerciclo 1: escriba el nombre de $\mathbf{3 0}$ vegetales.

Ejerclclo 2: escriba 10 nombres de personas Que empiecen por la letra $\mathbf{A}$

Ejerciclo 3: escriba 10 nombres de cludades Que empiecen por $\mathbf{C}$.

Ejerclclo 4: según la Hoja de Matertal 5, escriba nombres de personas Que empiecen por cada una de esas letras.

Ejerciclo 5: según la Hoja de Matertal 5, escriba nombres de animales Que empiecen por cada una de esas letras.

Ejerciclo 6: utilizando la Hoja de Materlal 5, escriba deportes Que empiecen por cada una de esas letras.

Ejerciclo 7: utilizando la Hoja de Matertal 5, escriba nombres de películas Que empiecen por cada una de esas letras.

\section{HOIA DE MATERIAL 5 \\ Ejerciclos de Funclones Ejecuttvas:}

Fecha:

Hora:

Tiempo empleado:

A

B

C

D

E

F

G

$\mathrm{H}$

I

J

K

L

$\mathrm{M}$

N

P

$\mathrm{R}$

Figura 34. Ejemplo de ejercicios de iniciativa

- Categorización: estos ejercicios hacen que el paciente clasifique un conjunto de elementos según lo que tengan en común. La Figura 35 detalla algunos ejemplos de estos ejercicios.

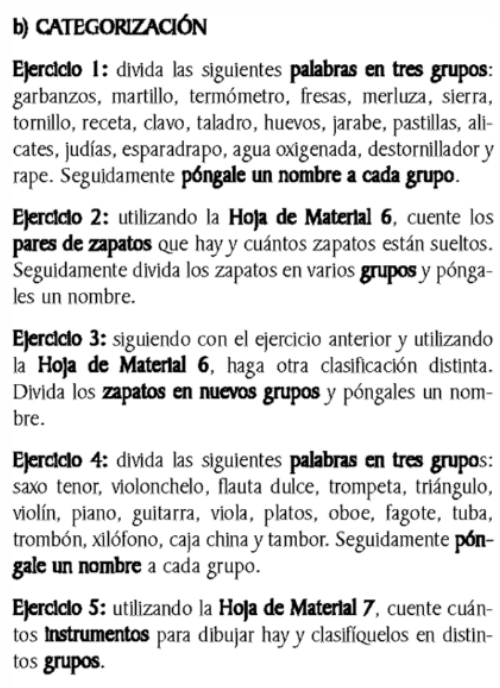

Elerciclo 3: siguiendo con el ejercicio anterior y utilizando la Hoja de Materlal 6, haga otra clasificación distinta. Divida los zapatos en nuevos grupos y póngales un nombre.

Ejerciclo 4: divida las siguientes palabras en tres grupos: saxo tenor, violonchelo, flauta dulce, trompeta, triángulo, violín, piano, guitarra, viola, platos, oboe, fagote, tuba, trombón, xilófono, caja china y tambor. Seguidamente póngale un nombre a cada grupo.

Ejerclclo 5: utilizando la Hoja de Materlal 7, cuente cuántos Instrumentos para dibujar hay y clasifíquelos en distintos grupos.

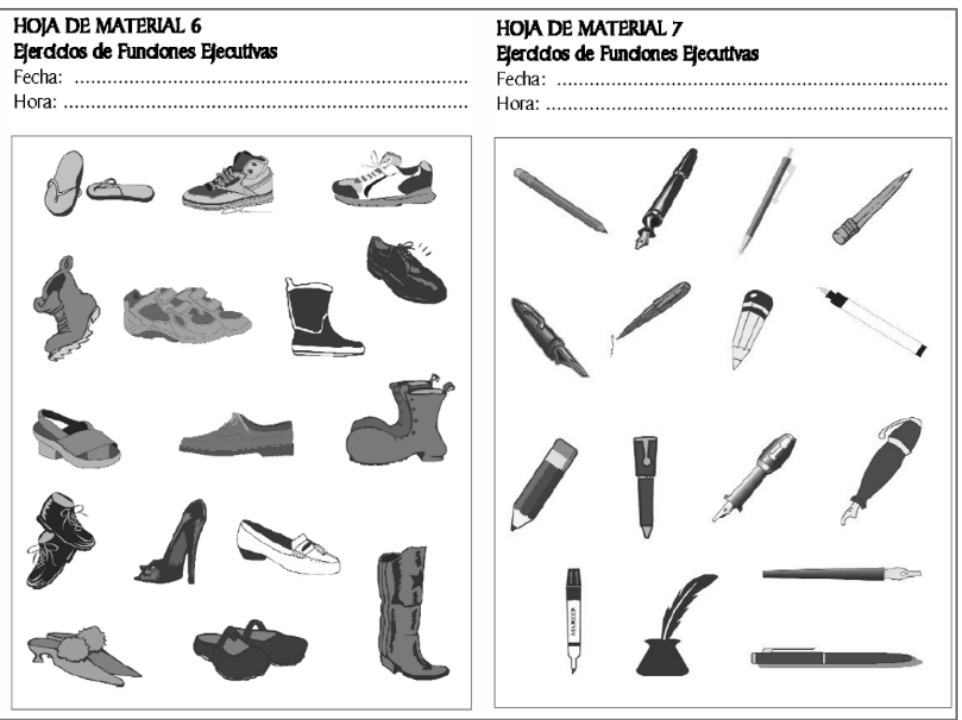

Figura 35. Ejemplo de ejercicios de categorización

- Seriación: consisten en clasificar el orden lógico de una secuencia de acciones. La Figura 36 detalla más a fondo cómo serían este tipo de ejercicios. 


\section{c) SERIACIÓN}

Ejercido I : ordene las siguientes frases de manera eue tengan una secuenda logica:

- Esperar a eue se caliente el aceite.

- Poner el huevo en la sartén.

- Encender el fuego.

- Poner aceite en la sartén.

- Poner la sartén al fuego.
Elerdio 6: ordene las siguientes frases de manera eue formen una cortversadón logjca:

- ¿Alguna cosa más?

— Sí, deme una napolitana de chocolate.

- Acuí los tiene. Pase un buen día.

- ¿De oue clase?

- Serán 3 euros.

- No, ya está bien, muchas gracias.

- Hola, buenos días. ¿Podría darme una barra de pan?

- Aquí tiene la napolitana de chocolate. ¿Querrá alguna cosa más?

- Integral.

Figura 36. Ejemplo de ejercicios de seriación

- Planificación: los ejercicios de planificación buscan la iniciativa y el ingenio del paciente para describir los pasos de una tarea o para rellenar un laberinto con restricciones. A continuación, en la Figura 37 se presenta un ejemplo de cada tipo.

\section{d) PLANIFICACIÓN}

Ejercdio 1: describa los pasos eue hay eue hacer para pintar una casa:

1.

2.

3.

4.

5 .

6.

7

8.

9.

10
Ejercido 5: una el pato con el pato, el caballo con el cabaIlo $y$ el delfin con el delifin mediante una línea teniendo en cuenta eue:

- por cada cuadradito sólo puede pasar una línea (es decir, la línea eue une los delfines no puede coincidir en el mismo cuadradito con la línea de los caballos).

- las líneas no pueden compartir cuadradito, ni cruzarse unas con otras, ni pasar por una casilla eue esté ocupada por otro animal. Las líneas deben mantener una "distancia de seguridad". Aeuí es donde reside la dificultad del ejercicio y se debe cumplir rigurosamente.

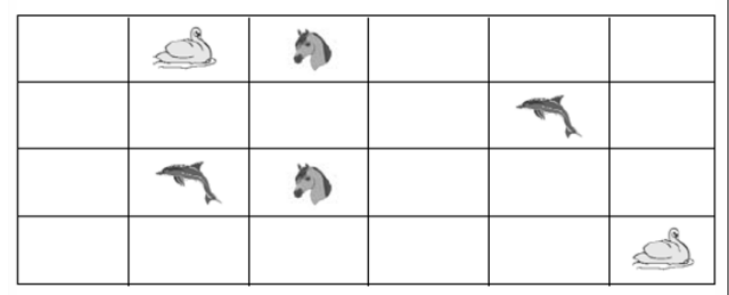

Figura 37. Ejemplo de ejercicios de planificación

- Ejercicios de memoria: por último, existen ejercicios orientados a estimular la memoria del paciente. Si bien la memoria no es una de las pérdidas más acusadas en el deterioro cognitivo asociado a la EP, también está presente. Existen diversos tipos de ejercicios de memoria. Pueden ser de memoria a largo plazo, como la Figura 38, o de memoria a corto plazo, como la Figura 39 y la Figura 40. 


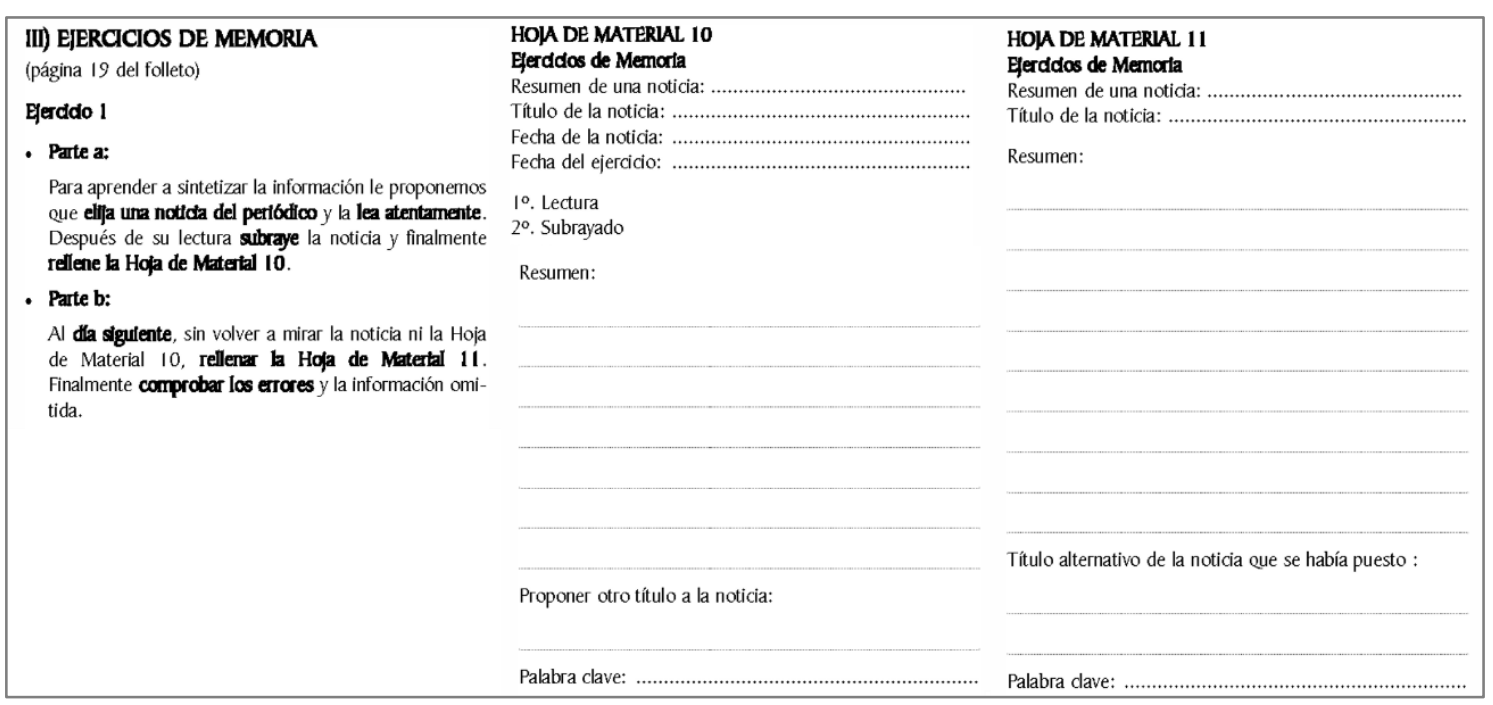

Figura 38. Ejemplo de ejercicio de memoria a largo plazo

\section{Ejerdio 2}

\section{- Parte a:}

Intente recordar esta informacion utilizando alguna estrategia.

Pijese bien en los dferentes detalles. Después le haremos preguntas sobre ellas:

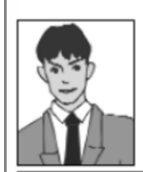

Este chico se llama Iván.

Tiene 25 ańos.

Le gusta mucho escuchar música.

Está estudiando Díseño Industríal.

\begin{tabular}{|c|c|}
\hline 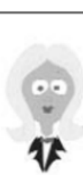 & $\begin{array}{l}\text { Esta chica se llama Sofía. } \\
\text { Tiene } 28 \text { años. } \\
\text { Es portuguesa. } \\
\text { Le gusta mucho Barcelona. } \\
\text { Trabaja como programadora. }\end{array}$ \\
\hline ह3 & $\begin{array}{l}\text { Este señor se llama Ramón. } \\
\text { Tiene } 75 \text { años. } \\
\text { Canta en una coral. } \\
\text { Actualmente está jubilado. }\end{array}$ \\
\hline
\end{tabular}

Esta señora se llama Conchita.

Tiene 48 años.

Es maestra en una escuela.

Le gustan mucho los nínos.

\section{- Parte b:}

I. ¿Qué estrategias ha utilizado?

2. Ahora sin mirar la hoja anterior, trate de cormpletar la informadín oue falta y los detalles oue recuerde.

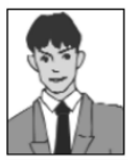

Este chico se llama

Tiene aก̃os.

¿Qué más recuerda?

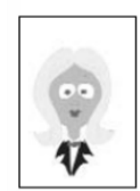

Esta chica se llama

Tiene años.

¿Qué más recuerda?

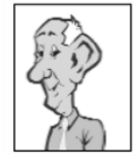

Este señor se llama

Tiene

años.

¿Qué más recuerda?

Esta señora se llama

Tiene años.

¿Qué más recuerda?

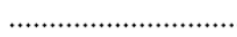

Figura 39. Ejemplo de ejercicio de memoria a corto plazo sobre personas 
Ejerddo 3: intente recordar cada uno de los objetos eue hay en esta imagen. Para ello intente utilizar una estrategia.

¿Qué estrategia ha utilizado?

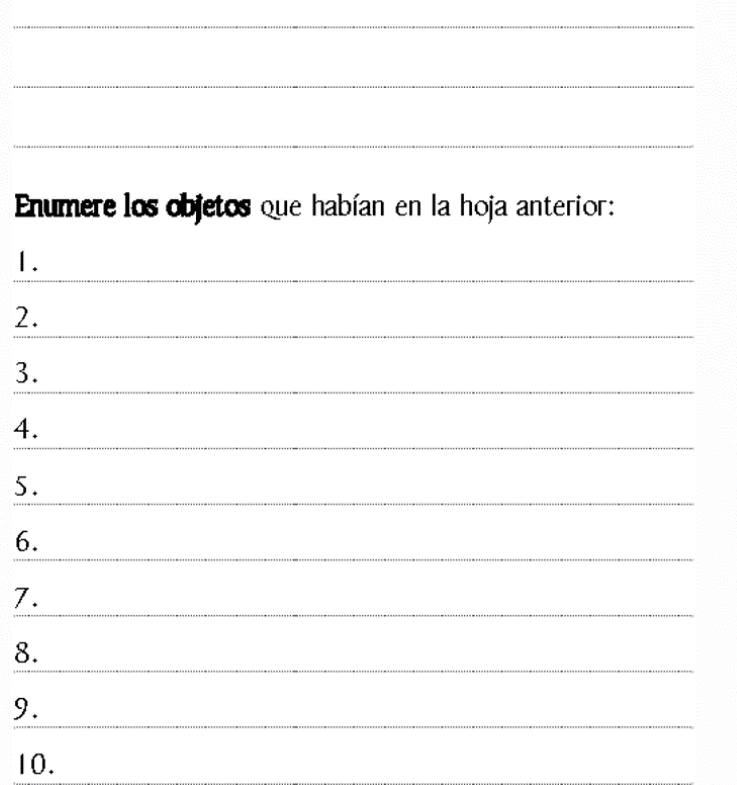

10.

Figura 40. Ejemplo de ejercicio de memoria a corto plazo sobre objetos

\subsubsection{Ejercicios de estimulación cognitiva adaptados a las TIC}

A la hora de realizar el diseño de la terapia de estimulación cognitiva adaptada a las TIC, hubo un requisito imprescindible para tener en cuenta: los ejercicios debían poder ser introducidos por los terapeutas. Para ello, se realizó un diseño en el que se dividían los ejercicios en modelos, cada uno con unas características, de forma que el terapeuta únicamente tenía que introducir los campos a través de un formulario web y los ejercicios se generaban dinámicamente en el dispositivo del paciente.

Los modelos diseñados que pretendían adaptar todos los formatos de ejercicios presentados en el cuaderno, descritos en el apartado anterior, fueron los siguientes:

- Modelo 1, con enunciado y tres respuestas alfanuméricas, donde solo una de ellas era la correcta (Figura 41).

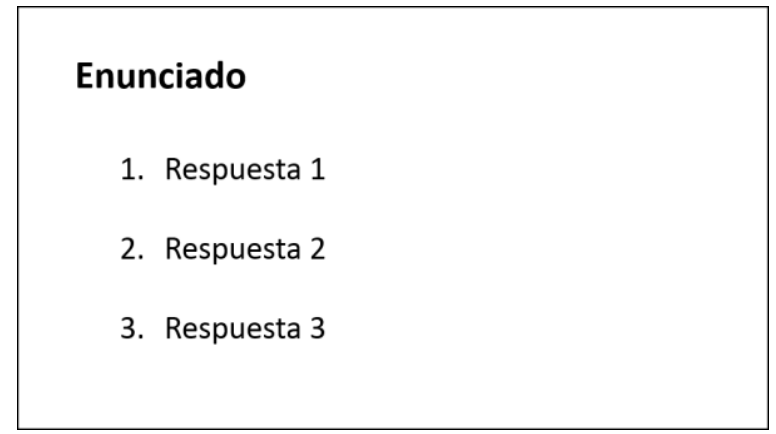

Figura 41. Diseño de ejercicio modelo 1

- Modelo 2, con enunciado y tres imágenes como respuestas, donde solo una de ellas era correcta (Figura 42). 


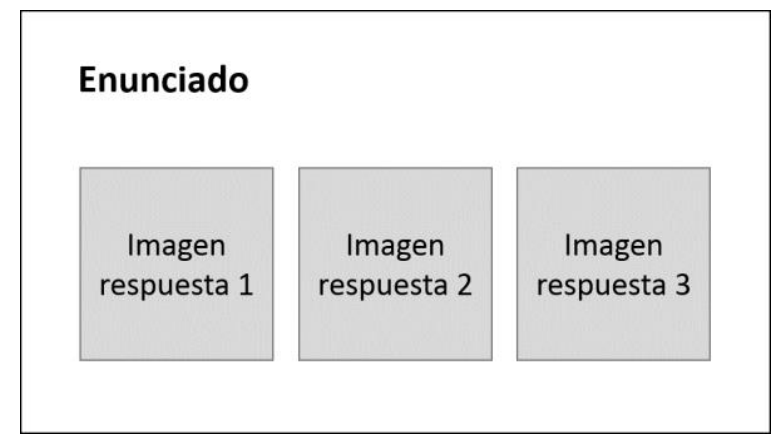

Figura 42. Diseño de ejercicio modelo 2

- Modelo 3, con una imagen previa que se presenta durante cinco segundos y, posteriormente, se presenta una cuestión sobre la misma y tres respuestas alfanuméricas. $\mathrm{Al}$ igual que en los casos anteriores, solo una respuesta era correcta (Figura 43).

\section{Observe la siguiente imagen}

Imagen previa durante 5 segundos

\section{Enunciado}

1. Respuesta 1

2. Respuesta 2

3. Respuesta 3

Figura 43. Diseño de ejercicio modelo 3

- Modelo 4, donde se presenta un enunciado y el paciente debe introducir la respuesta que considere correcta a través de un teclado accesible (Figura 44).

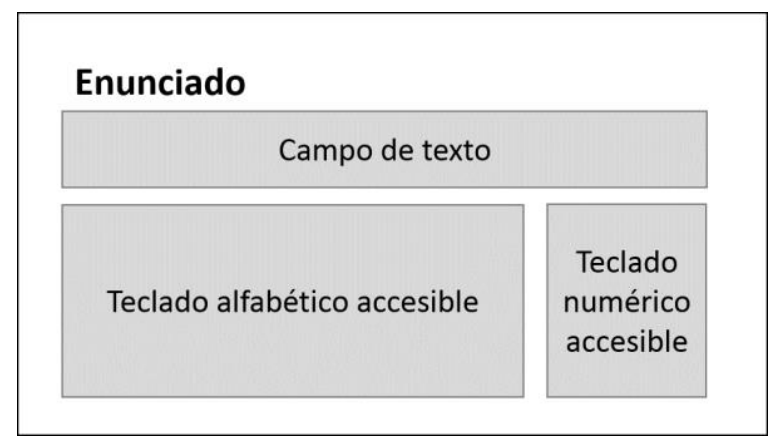

Figura 44. Diseño de ejercicio modelo 4

- Modelo 5, que muestra un enunciado y una imagen y es el paciente quien debe escribir a través de un teclado numérico accesible cuál cree que es la respuesta correcta (Figura 45).

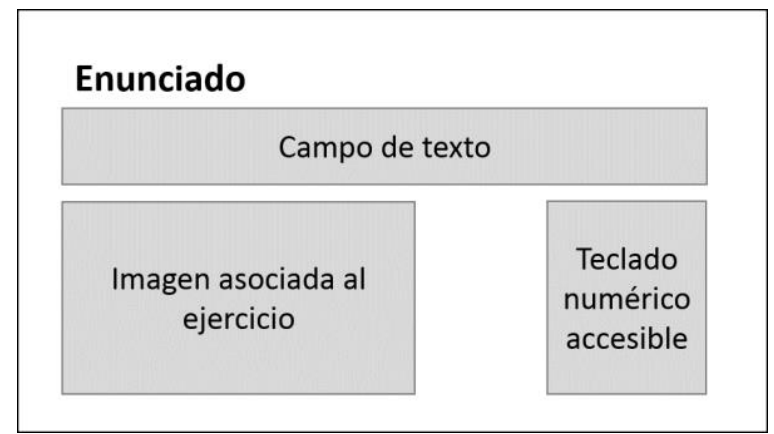

Figura 45. Diseño de ejercicio modelo 5 
Respecto a las áreas de estimulación contempladas, se realizó una modificación con respecto a las recogidas en los cuadernos [APKM, 2007] y adaptarlas a las necesidades que se habían contemplado con la experiencia de los terapeutas. Esta revisión se llevó a cabo en la reunión del 10 de julio de 2013, y las áreas acordadas fueron [Bravo, 2010]:

- Atención sostenida, que intenta estimular la atención o el estado de alerta hacia una fuente de información. Tiene que ver con dos aspectos: la duración (tiempo que este nivel se mantiene) y la consistencia (la eficacia de la ejecución).

- Atención dividida, que controla la capacidad del individuo para atender simultáneamente a múltiples tareas o a múltiples demandas de una misma tarea. Se activa cuando el ambiente nos exige atender a varias tareas o informaciones a la vez.

- Cálculo, para la estimulación y control de la capacidad de la realización de operaciones matemáticas sencillas.

- Lenguaje, que intenta evitar la pérdida del lenguaje y, además, puede estimular la iniciativa del paciente y la seriación.

- Memoria a corto plazo, para el control de la capacidad de memorización de los pacientes en un corto espacio de tiempo.

- Memoria a largo plazo, que estimula y evalúa la capacidad de memorización de los pacientes en espacios de tiempo extensos.

- Función visuo-espacial, que evalúa la habilidad para percibir el espacio y la disposición de los elementos en él.

- Funciones ejecutivas, que intentan estimular y evaluar, principalmente, la iniciativa del paciente, así como la planificación

- Ejercicios motivacionales que, si bien no están relacionados con la estimulación de ningún área cognitiva, son simples y pretenden estimular al paciente a continuar con la terapia.

Los ejercicios se agrupan por área de estimulación y nivel de dificultad. Los niveles de dificultad están asociados al diagnóstico del deterioro cognitivo del paciente, pudiendo ser preventivo (más difícil), leve o moderado (más fácil). Si bien se reconocen niveles intermedios de deterioro cognitivo como el leve-moderado y el moderado-grave, los expertos han considerado que no era necesario el realizar una organización por niveles más exhaustiva. Asimismo, debido a los problemas de atención que presentan los pacientes con EP, cada ejercicio de estimulación dispondrá de un tiempo máximo de realización definido con la creación del ejercicio.

Con respecto a la formación de los bloques, serán los terapeutas los que deben seleccionar los ejercicios que conforman el bloque para poder asignárselo a un paciente en concreto. Estos bloques pueden ser reutilizables por otros terapeutas de su asociación o de otras asociaciones si, por ejemplo, tratan un área en concreto. Estos bloques están compuestos como máximo por 9 ejercicios de estimulación cognitiva. Se llegó a este consenso porque, también debido a los problemas de atención, no se pueden realizar sesiones largas de estimulación con ellos. Ya que son 9 áreas de estimulación, se acordó que, como máximo, el bloque estuviera formado por un ejercicio de cada área de estimulación. Estos bloques de ejercicios serán los que se enviarán al dispositivo del paciente para su realización. 


\subsection{Diseño del sistema}

\subsubsection{Diagrama de despliegue}

En esta plataforma intervienen cuatro agentes:

- Tableta: dispone de una aplicación Android que se comunicará con el servidor. Será el dispositivo del usuario.

- PC: ordenador a través del que acceden a la plataforma el resto de usuarios. También puede ser un dispositivo portátil.

- Servidor: aplicación que realiza las comunicaciones con el cliente y genera los códigos de respuesta, tanto para el dispositivo del paciente como el portal web del resto de usuarios.

- Base de datos: almacena la información de usuarios y terapias.

Como las comunicaciones son seguras, la comunicación entre cliente y servidor es HTTPS. La base de datos seleccionada utiliza conector JDBC.

A continuación, en la Figura 46 se presenta el diagrama de despliegue de la solución desarrollada.

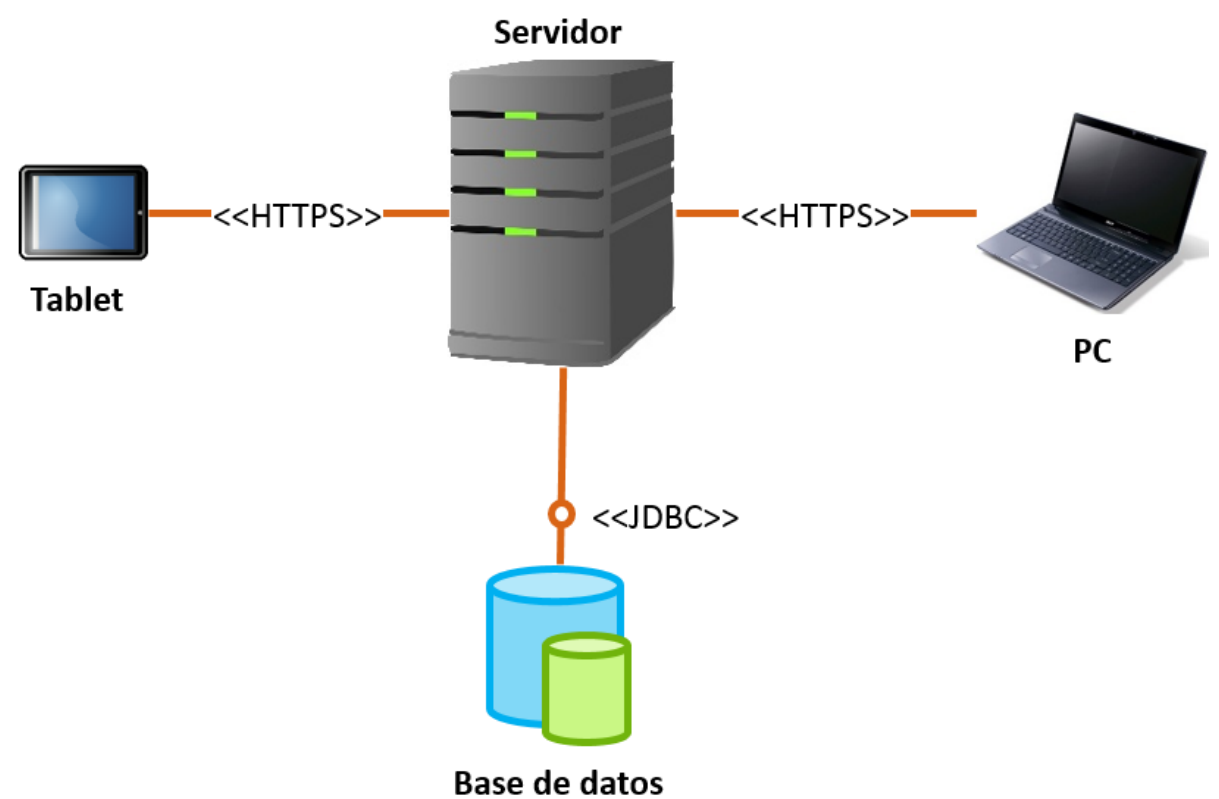

Figura 46. Diagrama de despliegue de la plataforma

\subsubsection{Diseño del protocolo de comunicación}

Se ha diseñado un protocolo ad-hoc para la comunicación entre el dispositivo del paciente y el servidor. Este protocolo funciona a nivel de aplicación en modo pregunta-respuesta, iniciando siempre la aplicación del paciente el intercambio de datos. Las unidades de datos del protocolo (PDU) implementadas se presentan en la Figura 47. 
ID PDU: PET_PAC

\begin{tabular}{|c|c|c|c|c|c|c|c|c|c|c|c|}
\hline \multirow{2}{*}{$\begin{array}{c}\text { Tipo } \\
1 \text { byte }\end{array}$} & \multirow{2}{*}{ Id } & \multicolumn{8}{|c|}{ Resultados del paciente } \\
\cline { 3 - 15 } & 8 bytes & $\%$ & Respuesta & Tiempo & $\%$ & Respuesta & Tiempo & $\ldots$ & $\%$ & Respuesta & Tiempo \\
\hline
\end{tabular}

ID PDU: RES_ID

\begin{tabular}{|c|c|c|}
\hline $\begin{array}{c}\text { Tipo } \\
1 \text { byte }\end{array}$ & $\begin{array}{c}\text { Género } \\
1 \text { byte }\end{array}$ & Nombre y primer apellido \\
\hline
\end{tabular}

ID PDU: RES_BEE

\begin{tabular}{|c|c|c|c|c|c|c|c|c|c|c|}
\hline $\begin{array}{c}\text { Tipo } \\
1 \text { byte }\end{array}$ & $\begin{array}{c}\text { Total } \\
1 \text { byte }\end{array}$ & $\begin{array}{c}\text { Modelo } \\
1 \text { byte }\end{array}$ & Imagen & Enunciado & Respuesta 1 & Respuesta 2 & Respuesta 3 & $\begin{array}{c}\text { Correcta } \\
1 \text { byte }\end{array}$ & $\begin{array}{c}\text { Tiempo } \\
1 \text { byte }\end{array}$ & $\ldots$ \\
\hline
\end{tabular}

ID PDU: RES_VAL

\begin{tabular}{|c|c|c|c|c|c|}
\hline $\begin{array}{c}\text { Tipo } \\
1 \text { byte }\end{array}$ & $\begin{array}{c}\text { Bloque } \\
1 \text { byte }\end{array}$ & $\begin{array}{c}\text { Fecha de fin } \\
10 \text { bytes }\end{array}$ & $\begin{array}{c}\text { Fecha de } \\
\text { evaluación } \\
10 \text { bytes }\end{array}$ & Nombre del terapeuta & Valoración del terapeuta \\
\hline
\end{tabular}

ID PDU: RES_GEN

\begin{tabular}{c|c|}
\hline Tipo & Código \\
1 byte & 1 byte \\
\hline
\end{tabular}

Figura 47. Unidades de datos del protocolo implementado ad-hoc

En la figura anterior se presentan en verde el campo común a todas las PDU y, en azul, los que son únicos de cada PDU.

La PDU PET_PAC (Peticiones realizadas por el paciente) es la que se envía desde el dispositivo del paciente al servidor. Siempre incluye el tipo de PDU y el identificador del usuario, que deberá introducirlo la primera vez que accede a la aplicación. La parte relativa a los Resultados del paciente solo se adjuntará en el caso de que sea un envío de resultados de un bloque de ejercicios, donde se incluirá la respuesta dada por el paciente y el tiempo que ha empleado.

La PDU RES_ID (Respuesta con la identificación) es la relativa a la identificación del paciente. Se envía del servidor a la aplicación del paciente tras la petición de la primera identificación. Se envían el género y el nombre y primer apellido. De esta forma, se personaliza la aplicación y el paciente se siente identificado.

La PDU RES_BEE (Respuesta con bloque de ejercicios de estimulación) es la asociada con el envío de un bloque de ejercicios al dispositivo del paciente. Esta PDU incluye, en primer lugar, el número total de ejercicios que se envían. Posteriormente se envían los ejercicios, siendo los campos para cada uno de ellos (marcados con el borde más grueso):

- Modelo: modelo de ejercicio: 1, 2, 3, 4 o 5 .

- Imagen asociada al enunciado del ejercicio en el caso de que dicho ejercicio sea de modelo $3 \circ 5$.

- Enunciado del ejercicio.

- Respuesta 1, respuesta 2, respuesta 3: campos asociados a las respuestas posibles para ejercicios de modelo 1,2 o 3.

- Correcta: valor de la respuesta correcta de las disponibles para los modelos de ejercicio 1,2 o 3.

- Tiempo: tiempo máximo de realización del ejercicio. 
La PDU RES_VAL (Respuesta con última valoración) muestra la respuesta a la consulta de la última valoración desde el dispositivo del paciente. Se incluyen la dificultad del bloque de ejercicios valorado, la fecha de finalización del mismo, la fecha en la que el terapeuta introdujo la valoración, el nombre del terapeuta y la valoración incluida.

La PDU RES_GEN (Respuesta general) es la relativa a mensajes informativos como, por ejemplo, identificador de usuario no encontrado en el sistema, valoración no disponible, recepción correcta de datos, etc.

\subsubsection{Metodología seguida para el diseño de las interfaces de usuario}

El diseño de las interfaces de usuario se ha llevado a cabo utilizando la evaluación heurística de diversos prototipos.

Según Nielsen [Nielsen, 1990]: "Ia evaluación heurística es un método informal de análisis de la usabilidad donde un número de evaluadores están presentes con un diseño de interfaz y lo comentan".

Las diez reglas heurísticas para el diseño de interfaces de usuario son [Nielsen, 1990]:

- Visibilidad del estado del sistema. Los usuarios deben recibir retroalimentación de lo que está ocurriendo.

- Coincidencias entre el sistema y el mundo real. La información debe estar representada de forma que al usuario le resulte familiar, incluyendo el lenguaje utilizado y la coherencia en la estructura.

- Control y libertad del usuario. Los posibles errores del usuario deben ser contemplados para evitar acciones críticas sobre el sistema.

- Consistencia y cumplimiento de estándares. Las palabras, acciones, situaciones, etc. Siempre deben significar lo mismo y los usuarios deben ser capaces de interpretarlo.

- Prevención de errores. Hay que prevenir errores y, en el caso de que no sea posible, mostrar mensajes claros.

- Reconocimiento e información del error, mejor que actualización automática sin avisar al usuario. Llevar a cabo acciones, opciones y objetivos de forma visible. Las instrucciones deben estar disponibles para cuando sea necesario.

- Flexibilidad y eficiencia de uso. El uso de atajos puede mejorar la experiencia de usuario para usuarios experimentados, aunque puede resultar invisible para usuarios nuevos. Las acciones podrían ser personalizadas por los usuarios.

- Diseño minimalista. El diálogo no debe presentar información irrelevante o inútil. El abuso de la cantidad de información disminuye la visibilidad de los puntos importantes para el usuario.

- Ayuda reconocible, diagnóstico y recuperación de errores. Los mensajes de error deben presentarse en lenguaje claro y evitar el uso de códigos. Se debe explicar el problema y ofrecer una solución al mismo. 
- Ayuda y documentación. La mejor forma de acercarse al usuario es construyendo un sistema que no necesite ayuda ni documentación, pero si es necesario, debe ser fácilmente localizable, basado en las tareas que el usuario quiera ejecutar y ofreciendo pasos concretos para conseguirlo.

Estas técnicas se han utilizado para el diseño de las interfaces de usuario de DaleMov. En las sesiones de evaluación han participado varios actores:

- Dos ingenieras de la UPM expertas en investigación y diseño de interfaces de usuario accesibles, encargadas de la implementación de la plataforma.

- Una terapeuta y una neuropsicóloga de la APKM.

- Una terapeuta de la FEP.

- Pacientes seleccionados de la APKM.

Estas sesiones se llevaron a cabo durante los inicios del diseño y la implementación. En primer lugar, se presentó por parte de la UPM un primer diseño de interfaz a la APKM a través de un documento. Posteriormente, se implementó el diseño aprobado y se realizó un pequeño experimento de usabilidad con cuatro personas con EP de la APKM. De esta forma, se pudo modificar el diseño inicial según las necesidades de las personas con EP. Cuando se finalizó la implementación de la plataforma con toda su funcionalidad, se volvió a consultar a los expertos, tanto de la APKM como de la FEP, que estuvieron probando la aplicación para los pacientes. Una vez evaluada por ellos, se procedió a llevar a cabo el experimento con dos pacientes de la APKM. En paralelo, también se realizó una evaluación heurística de las interfaces de usuario de la aplicación web orientada al terapeuta. Cuando el resultado de la evaluación de ambas interfaces fue satisfactorio, se comenzó con los pilotos en las asociaciones.

Además, para el diseño de las interfaces, se han utilizado técnicas de accesibilidad web, tanto para las interfaces web como para la aplicación del paciente, ya que en el momento de la realización del diseño de la plataforma no existían definiciones de accesibilidad para aplicaciones móviles nativas.

El World Wide Web Consortium (W3C), organismo internacional encargado de la estandarización de las tecnologías web, ha creado la Web Accessibility Initiative (WAI) [WAI, 2016], encargada de velar por la accesibilidad web. Esta iniciativa ha determinado unas pautas de accesibilidad en este ámbito conocidas como las Web Content Accessibility Guidelines (WCAG), actualmente en su versión 2.0 (WCAG 2.0) [WCAG, 2008]. Estas guías proporcionan cuatro niveles de orientación:

- Principios: en el nivel más alto se sitúan los cuatro principios que proporcionan los fundamentos de la accesibilidad web: perceptible, operable, comprensible y robusto.

- Pautas: por debajo de los principios están las pautas. Las doce pautas, cada una asociada a un principio, proporcionan los objetivos básicos que los autores deben lograr con el fin de crear un contenido más accesible para los usuarios con distintas discapacidades. Estas pautas proporcionan el marco y los objetivos generales que ayudan a comprender los criterios de conformidad y a implementar mejor las técnicas.

- Criterios de conformidad: para cada pauta se proporcionan los criterios de conformidad verificables que permiten emplear las WCAG 2.0 en aquellas situaciones en las que existan 
requisitos y necesidad de evaluación de conformidad como: especificaciones de diseño, compras en línea, regulación o acuerdos contractuales. Con el fin de cumplir con las necesidades de los diferentes grupos y situaciones, se definen tres niveles de conformidad: A (el más bajo), AA y AAA (el más alto).

- Técnicas suficientes y recomendables: para cada pauta y criterio de conformidad, se han documentado una serie de técnicas para la comprobación de su cumplimiento. Las técnicas son informativas y se agrupan en dos categorías: aquellas que son suficientes para satisfacer los criterios de conformidad, y aquellas que son recomendables. Algunas de las técnicas recomendables tratan sobre barreras de accesibilidad que no han sido cubiertas por los criterios de conformidad verificables. También se han documentado los errores frecuentes que son conocidos.

Los criterios de conformidad están orientados a medir la accesibilidad desde distintos puntos de vista, como pueden ser el contraste de colores, el tamaño de los textos, la coherencia, la navegabilidad o la independencia del agente de usuario utilizado, entre otros.

En España, a través del Real Decreto 1494/2007, de 12 de noviembre, se reconocen los criterios de accesibilidad web definidos en las WCAG 1.0 [RD 1494/2007]. Esta adaptación fue recogida a través de la norma UNE 139803:2004, que posteriormente quedó anulada en 2012 para adaptarse a la nueva versión, la WCAG 2.0. Esta nueva norma es la UNE 139803:2012, reconocida según la Resolución de 3 de septiembre de 2012, de la Dirección General de Industria y de la Pequeña y Mediana Empresa [DGIPYME, 2012]. Según este Real Decreto, el grado de accesibilidad exigido para los organismos que tengan la obligación de tener su portal web accesible, es un AA.

\subsection{Tecnologías utilizadas}

En este apartado se describe el desarrollo de los diseños previos, detallando inicialmente las distintas tecnologías que se han empleado para ello. Para el modelado de la plataforma, se ha utilizado un modelo cliente-servidor clásico.

\subsubsection{Tecnologías web}

La implementación del servidor abarca diversas tecnologías, como son el motor que atiende a las peticiones, el lenguaje de páginas web, la base de datos y los mecanismos de seguridad.

Como motor se ha utilizado Tomcat, que es un contenedor de servlets desarrollado bajo el proyecto Jakarta en la Apache Software Foundation. Incluye un compilador Jasper que compila el código JSP para convertirlo en un servlet. Un contenedor JSP funciona sobre un servidor web que es quien recoge las peticiones de acceso y pasa al contenedor aquéllas que sean de páginas JSP y servlet, lo que significa que a veces puede introducirse en un servidor de operaciones que ya esté operativo.

Era necesario utilizar una base de datos relacional para el desarrollo de la plataforma, preferiblemente de libre distribución, por lo que se ha elegido MySQL. Una base de datos relacional es en la que los datos se organizan en tablas. Cada tabla se compone de filas y columnas. En las columnas se representan los campos de la tabla, y, en las filas, los elementos 
de la tabla con su valor de cada campo. Normalmente es necesario definir una clave principal, es decir, una columna que permite identificar de forma inequívoca a cada fila y que no es posible repetir en ninguna otra [MySQL, 2016].

Para llevar a cabo la gestión de la base de datos se utiliza JDBC para realizar las operaciones sobre la base de datos a través de un núcleo Java. La ventaja principal de utilizar el API JDBC es que todas sus funciones son las mismas, independientemente de la base de datos que se esté utilizando.

En el desarrollo de la parte web, a la que acceden terapeutas y administrador del sistema, se han utilizado tres lenguajes: HTML, JSP y XML.

HTML (HyperText Markup Language, Lenguaje de marcado de hipertexto) es un lenguaje que sirve para escribir documentos de texto presentado de forma estructurada, con enlaces que conducen a otros documentos o a otras fuentes de información que pueden estar en la misma máquina o en máquinas remotas de la red. Todo ello se puede presentar acompañado de contenido multimedia. Es el lenguaje por excelencia de creación de páginas web. El principal problema que presenta es el de ser un lenguaje estático, por lo que no se pueden modificar las páginas bajo demanda una vez se han implementado.

Para dotar de dinamismo a esta parte del sistema, se han utilizado páginas web JSP (JavaServer Pages, Páginas para Servidor en Java). Esta tecnología fue creada por Sun Microsystems con el objetivo de minimizar la programación y separar la funcionalidad de la presentación. Combina la utilización de etiquetas HTML con el uso de Java. Estas páginas se interpretan a través de Tomcat, convirtiéndose en un servlet que genera el contenido HTML, una vez se solicita al servidor, incluyendo las respuestas a las peticiones (por ejemplo, el resultado de una consulta a la base de datos).

Por otro lado, también se utiliza un servlet Java que atiende a las peticiones por parte de la aplicación del paciente. Este servlet está siempre a la escucha en el servidor. Sun Microsystems los introdujo por esta razón, para dotar de interactividad a los servidores web. Los servlets procesan datos y generan una respuesta utilizado el protocolo HTTP, por lo que tienen las mismas ventajas que cualquier programa escrito en Java.

\subsubsection{Android}

Android es un sistema operativo que surgió con el fin de estar integrado en dispositivos móviles, inicialmente en teléfonos inteligentes. La ventaja que presenta con respecto a otras plataformas es que está basado en Linux, que es libre, gratuito y multiplataforma.

Las aplicaciones integradas para dispositivos basados en Android y las desarrolladas para ellos están basadas en Java y son interpretadas por la máquina virtual Dalvik. El sistema operativo brinda acceso a todas las interfaces que accedan a las funciones del dispositivo, como pueden ser la agenda de contactos o las conexiones de red.

A continuación, la Figura 48 presenta la arquitectura de Android: 


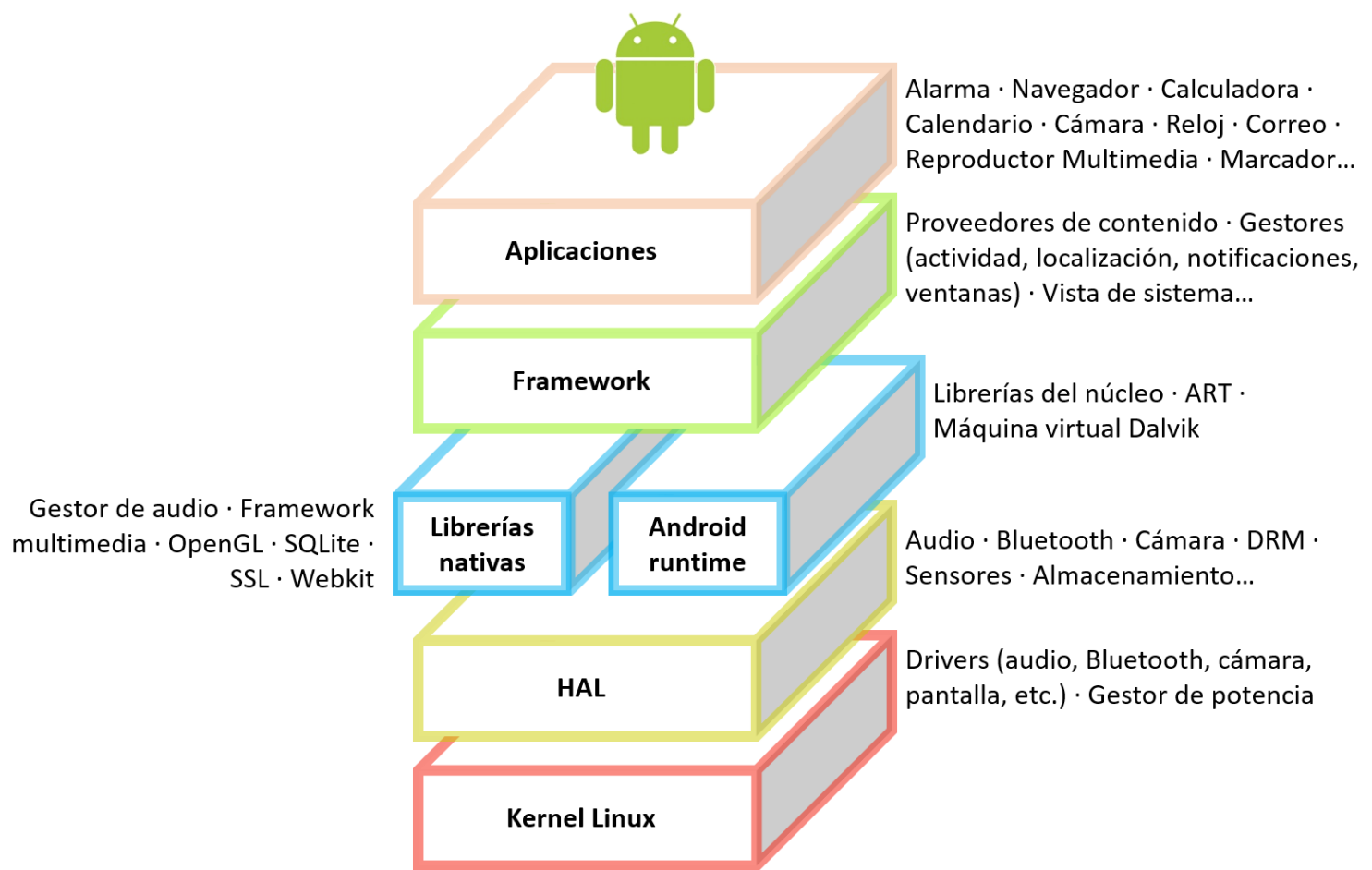

Figura 48. Arquitectura de Android [AS, 2016]

Las aplicaciones desarrolladas, como se puede apreciar en la imagen anterior, acceden a las funciones del sistema a través de un marco de desarrollo de aplicaciones.

A día de hoy, Android ha pasado por 14 versiones comerciales. Los nombres de las versiones están basados en dulces y siguen un orden alfabético. La evolución de las versiones pensadas para su utilización en una tableta, ordenadas por sus fechas de aparición se presenta en la Figura $\underline{49}$.

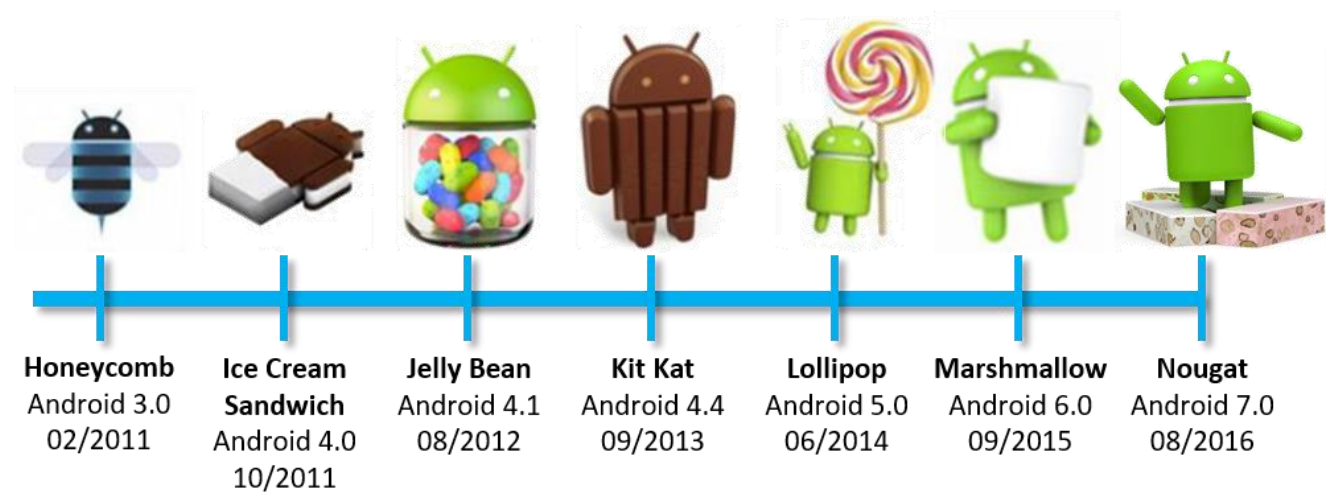

Figura 49. Versiones de Android [AD, 2016]

La fragmentación de Android surge por los cambios de versión. A la vista de la Figura 49 se puede constatar que, con las últimas versiones, hay un cambio por anualidad. Android es un sistema operativo en constante proceso de mejora. Continuamente se van añadiendo modificaciones que aportan un mayor rendimiento y que presentan nuevas funcionalidades por la demanda creciente de usuarios de dispositivos que lo incluyen como sistema operativo. Esto da, por un lado, una gran flexibilidad, ya que gracias a las versiones cambiantes de Android este puede adaptarse casi a cualquier hardware. El mayor problema que presenta para la comunidad de 
desarrolladores es que, si el hardware va mejorando sus prestaciones, hay que ir avanzando a la misma velocidad con los desarrollos para Android.

La versión estable de la aplicación del paciente está basada en Android 4.4 y es con la que se han realizado los experimentos de este trabajo de investigación. Se barajó la posibilidad de migrarlo a la versión 5.0 pero, debido al comienzo de las primeras pruebas piloto y a la escasa implantación en los dispositivos al inicio de dicha versión, se decidió continuar con la aplicación con compatibilidad para la versión 4.4. A día de hoy, según el avance de la técnica, podría migrarse a las últimas tecnologías web (HTML5, CSS3 y JavaScript), que están disponibles en los nuevos dispositivos conectados independientemente de su naturaleza (smartphones, tabletas, televisiones de última generación, etc.).

\subsection{Mecanismos de seguridad}

Uno de los requisitos capturados, como se expuso en el apartado dedicado al análisis, es la securización de los datos sensibles.

Según la Comisión Europea, los datos sensibles de definen como una categoría especial de datos personales que incluyen el origen racial o étnico, las opiniones políticas, las convicciones religiosas o filosóficas, la afiliación sindical y el tratamiento de datos relativos a la salud o la vida sexual [CE 45/2001]. Su tratamiento se rige por normas más estrictas, por lo que la seguridad aplicada a su transmisión es mayor.

En España es la Ley Orgánica de Protección de Datos de Carácter Personal la que regula la información sensible (LOPD) [LOPD, 1999]. Para los desarrollos e implantación de las soluciones implementadas para las aplicaciones de este trabajo de investigación se ha aplicado la LOPD, en particular, lo recogido en el Título VIII, De las medidas de seguridad en el tratamiento de datos de carácter personal, del [RD 1720/2007], donde se define el nivel de seguridad que debe tener cada tipo de datos y las medidas de seguridad obligatorias

En este caso, el nivel de seguridad es alto, categoría en la que se incluyen datos relativos a la ideología, religión creencias, origen racial, salud, vida sexual, actos de violencia de género y datos de tráfico y localización de los operadores de comunicaciones electrónicas. Al tratar datos personales del paciente en este tipo de plataforma, asociada a la EP, se tratan temas de salud del individuo. Para este nivel de seguridad es necesario cumplir las medidas de nivel de seguridad básico y medio, además de medidas asociadas únicamente al nivel alto, como se presenta en la Tabla 44.

Tabla 44. Medidas se seguridad nivel alto

Nivel de seguridad

Heredado de nivel básico
Medidas de seguridad

Documento de seguridad

Régimen de funciones y obligaciones del personal

Registro de incidencias

Identificación y autenticación de usuarios

Control de acceso

Gestión de soportes

Copias de respaldo y recuperación 


\begin{tabular}{|l|l|}
\hline \multirow{2}{*}{ Heredado de nivel medio } & $\begin{array}{l}\text { Responsable de Seguridad } \\
\text { Auditoría bianual } \\
\text { Medidas adicionales de Identificación y autenticación de usuarios } \\
\text { Control de acceso físico }\end{array}$ \\
\hline \multirow{2}{*}{ Propio de nivel alto } & $\begin{array}{l}\text { Seguridad en la distribución de soportes } \\
\text { Registro de accesos } \\
\text { Medidas adicionales de copias de respaldo } \\
\text { Cifrado de telecomunicaciones }\end{array}$ \\
\hline
\end{tabular}

Por todo lo anterior, se han tomado las siguientes medidas:

- Definición de un nivel de seguridad alto para datos almacenados de forma electrónica y comunicaciones.

- Redacción de un documento de seguridad en el que se contempla toda la información referida en los puntos siguientes.

- Definición de los perfiles de usuario según la Tabla 45.

Tabla 45. Datos almacenados de cada usuario según su perfil

\begin{tabular}{|l|l|l|}
\hline Tipo de usuario & \multicolumn{2}{l}{ Descripción } \\
\hline Paciente & $\begin{array}{l}\text { Paciente de Parkinson } \\
\text { registrado en alguna de las } \\
\text { Asociaciones de la FEP que } \\
\text { participen en el piloto }\end{array}$ & $\begin{array}{l}\text { Nombre y apellidos } \\
\text { Fecha de nacimiento } \\
\text { Asociación a la que pertenece } \\
\text { Número de asociado }\end{array}$ \\
\hline Terapeuta & $\begin{array}{l}\text { Terapeuta perteneciente a una } \\
\text { Asociación de la FEP que } \\
\text { colabore en el piloto }\end{array}$ & $\begin{array}{l}\text { Nombre y apellidos } \\
\text { NIF (u otra identificación) } \\
\text { Asociación a la que pertenece }\end{array}$ \\
\hline Gestor de la terapia & $\begin{array}{l}\text { Personal administrativo o } \\
\text { terapeuta de alguna de las } \\
\text { Asociaciones de la FEP que } \\
\text { participen en el piloto }\end{array}$ & $\begin{array}{l}\text { Nombre y apellidos } \\
\text { NIF (u otra identificación) } \\
\text { Asociación a la que pertenece }\end{array}$ \\
\hline Administrador & $\begin{array}{l}\text { Personal de la UPM que } \\
\text { participe en el piloto }\end{array}$ & $\begin{array}{l}\text { Nombre y apellidos } \\
\text { NIF (u otra identificación) }\end{array}$ \\
\hline
\end{tabular}

- Se lleva a cabo un registro de incidencias de todos los errores ocurridos en el servidor en un archivo de log, ya sean relativos a problemas internos en el servidor, usuarios desconocidos o cortes en las comunicaciones. Además del archivo de log del servidor, los datos enviados entre la aplicación del paciente y el servidor se almacenan en un documento XML para cada paciente que puede ser consultado a través de la plataforma por el usuario que ostente el rol de administrador de la asociación a la que pertenece el usuario para comprobar posibles errores en el envío de datos entre el servidor y la aplicación del paciente o viceversa. En este fichero, se registra la fecha, la hora, la operación realizada y el error ocurrido. 
- El control de acceso a nivel informático se lleva a cabo a través de identificador y contraseña. El registro de cada acceso también se almacena en ficheros XML.

- Con respecto al acceso físico a los locales donde se encuentran los sistemas de información, el servidor y las bases de datos para prestar el servicio se encuentran ubicados en el Centro de Cálculo del Departamento de Ingeniería Telemática y Electrónica, perteneciente a la UPM. Este centro solo es accesible por los administradores del sistema, que han sido autorizados por dicho departamento. Además, se lleva un control de accesos a este Centro cuando el personal no es administrador del sistema.

- No está permitida la extracción de la información en otro tipo de almacenamiento físico, como pueden ser discos duros portátiles, CD-ROM, pen drive ni ningún otro dispositivo similar.

- Se realizan copias de seguridad periódicas. Estas copias son diarias a las $20 \mathrm{~h}$ como respaldo en el caso de que ocurra algún problema.

- La política de generación de contraseñas incluye la generación de una aleatoria, que deberá ser modificada en el primer acceso del usuario. Con respecto a la autenticación de la aplicación del paciente, únicamente se utiliza un identificador, debido a las limitaciones que presenta.

- Cifrado de las comunicaciones cuando contienen información sensible, como se describe en párrafos posteriores.

En esta plataforma se transmiten datos personales y de salud de los pacientes, por lo que determinadas PDU deberán ser securizadas. Se ha decidido no securizar toda la información transmitida, ya que, por ejemplo, la PDU que envía la información del bloque de ejercicios no utiliza información sensible, por lo que se manda en claro.

Para la seguridad se ha utilizado SSL (Secure Sockets Layer, Capa de Conexión Segura). Este protocolo proporciona servicios de autenticación y privacidad entre los extremos de la comunicación, utilizando una infraestructura de clave pública. Estos servicios garantizan la identidad del remitente y la integridad del mensaje.

Además de estas consideraciones de seguridad, se tuvo en cuenta la necesidad de informar al paciente del tratamiento de sus datos de carácter personal, así como de las posibles fotografías, filmaciones o grabaciones que se llevaran a cabo con el fin de divulgar los resultados de la experimentación. Para ello, en las evaluaciones con pacientes que se realizaron durante el proceso de DCU, los participantes debían completar un formulario informativo en el que debían dar su consentimiento, tal y como se presenta en el Anexo I. Cuestionario para el consentimiento del paciente.

A la hora de llevar a cabo la experimentación una vez finalizada la implementación y la verificación técnica y funcional de la plataforma, las asociaciones diseñaron un consentimiento para los pacientes a nivel interno, que debían rellenar si querían participar en este proceso.

Por último, como la implementación y la experimentación de este trabajo está incluido en un proyecto de I+D+i (DaleMov) fue necesaria su evaluación por el Comité de Ética de la UPM. Para ello, se entregó firmado el formulario incluido en el Anexo II. Formulario Comité de Ética. Universidad Politécnica de Madrid. 


\subsection{Implementación de las interfaces de usuario}

\subsubsection{Aplicación Android para el paciente}

La aplicación Android del paciente permite tanto el acceso a través de la pulsación en su icono como a través de un widget de gran tamaño en el escritorio de la tableta, como se puede ver en la Figura 50.

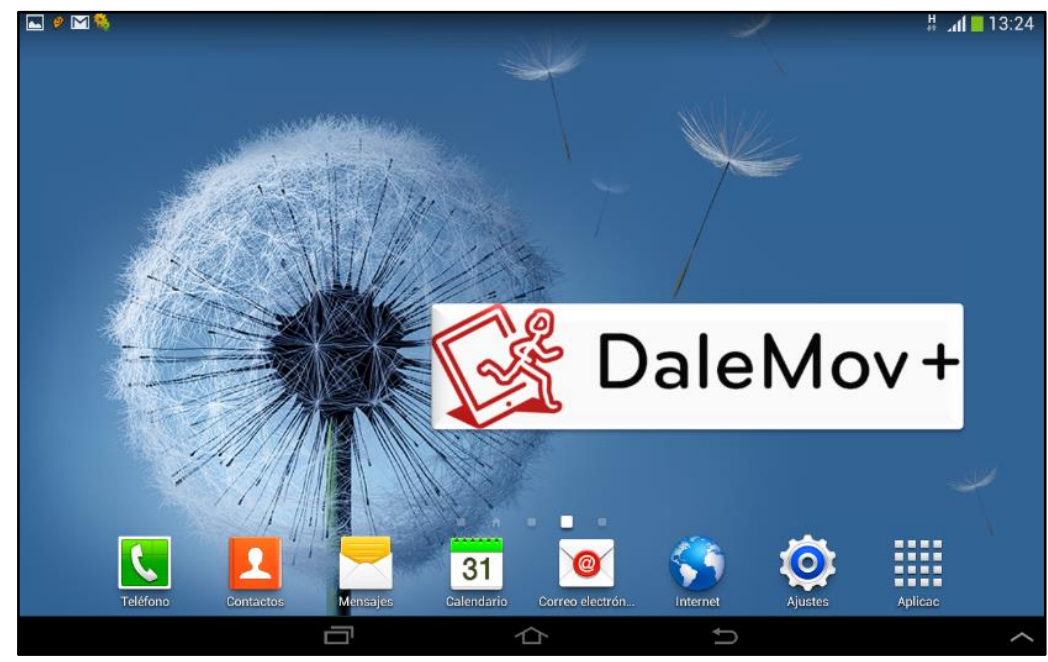

Figura 50. Widget de DaleMov

Una vez se pulsa el widget, se inicia la aplicación del paciente. El diagrama de navegación se presenta en la Figura 51.

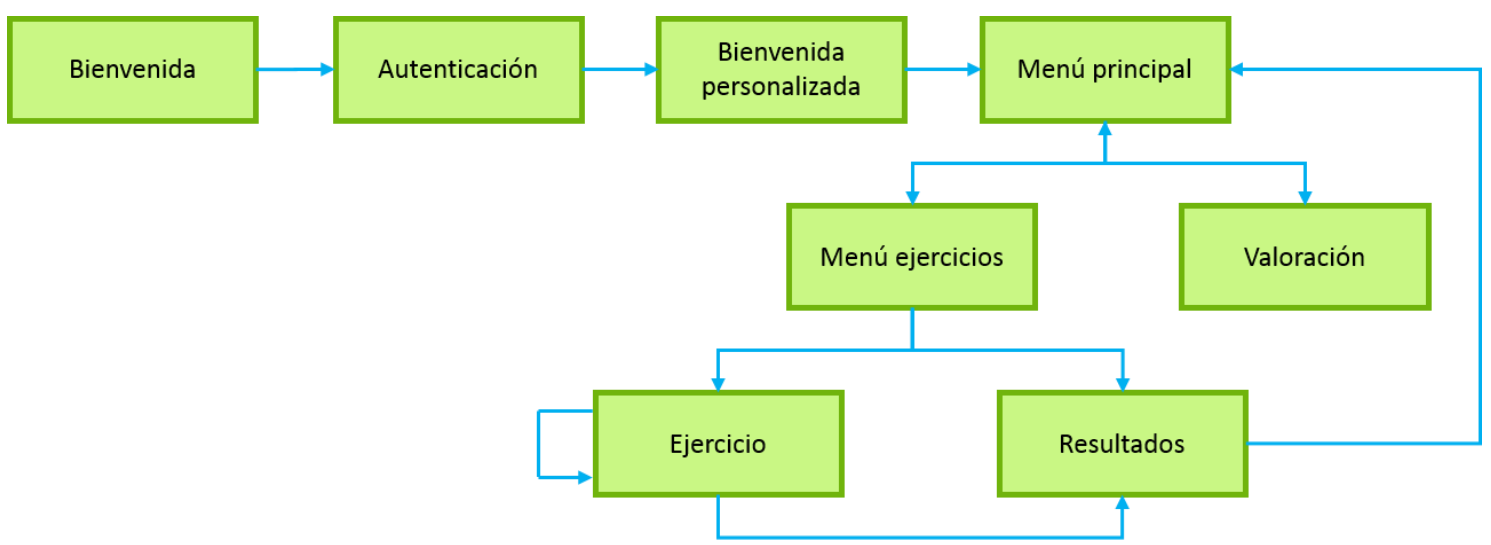

Figura 51. Diagrama de navegación de la aplicación del paciente

La primera pantalla que se presenta es la de bienvenida, donde, tras la primera autenticación del paciente, se mostrará su nombre y apellidos para que sienta que la terapia ha sido diseñada específicamente para él. La Figura 52 presenta la pantalla de bienvenida. 


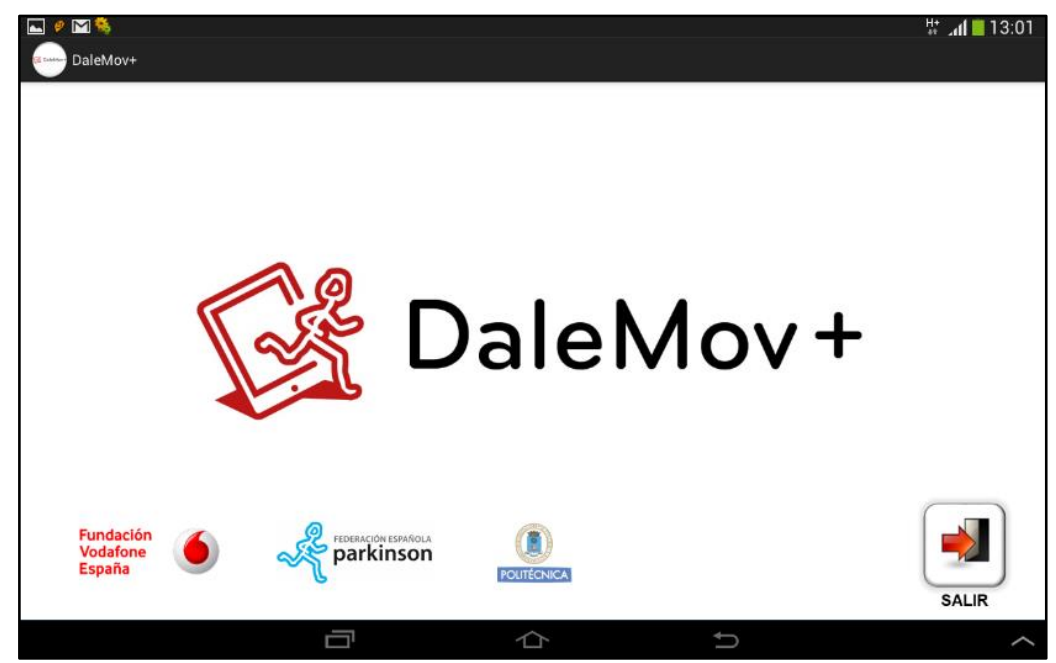

Figura 52. Pantalla de bienvenida de DaleMov

Posteriormente, el paciente debe autenticarse, introduciendo su clave de acceso tal y como se lo haya especificado el terapeuta que le llevará la terapia (Figura 53).

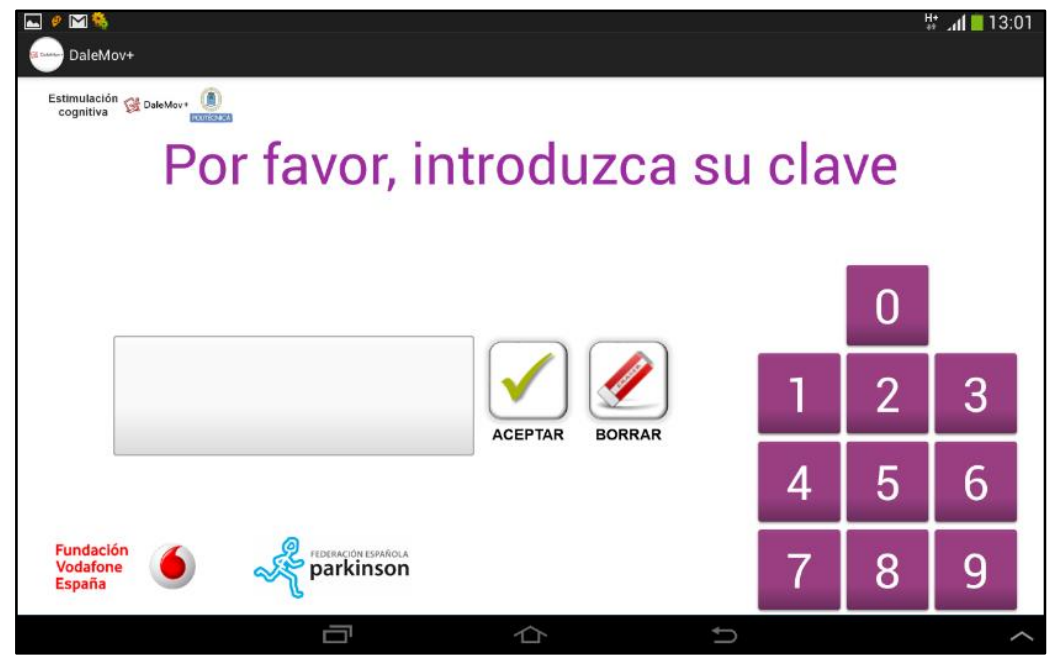

Figura 53. Pantalla de autenticación

Una vez se ha autenticado, se le presentará la pantalla de bienvenida personalizada con los datos recibidos desde el servidor (Figura 54) y el menú de opciones posibles (Figura 55).

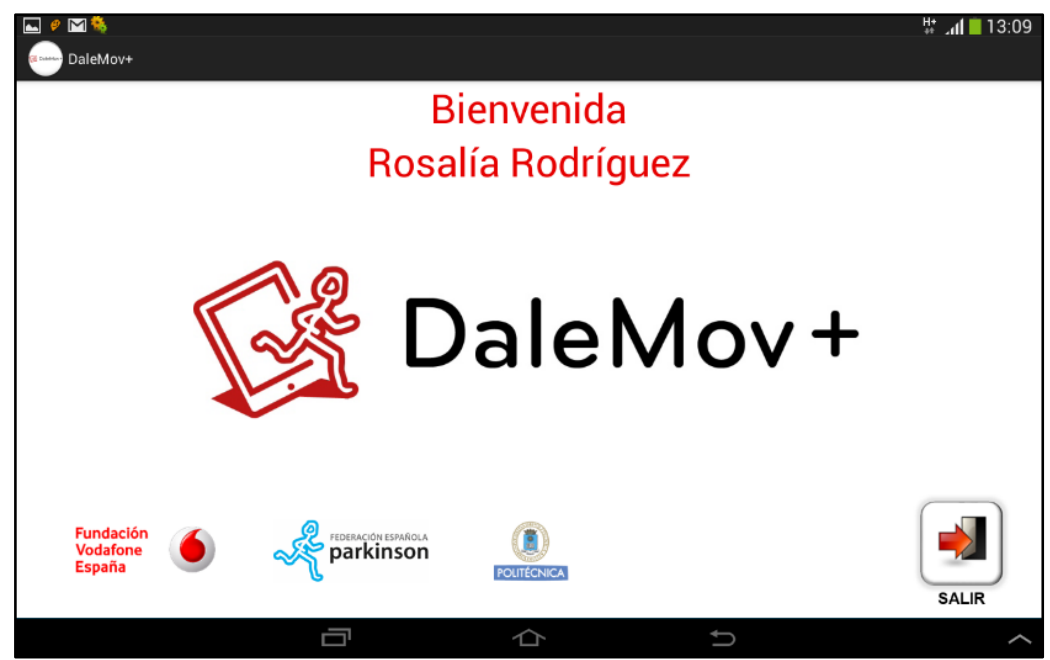

Figura 54. Pantalla de bienvenida personalizada 


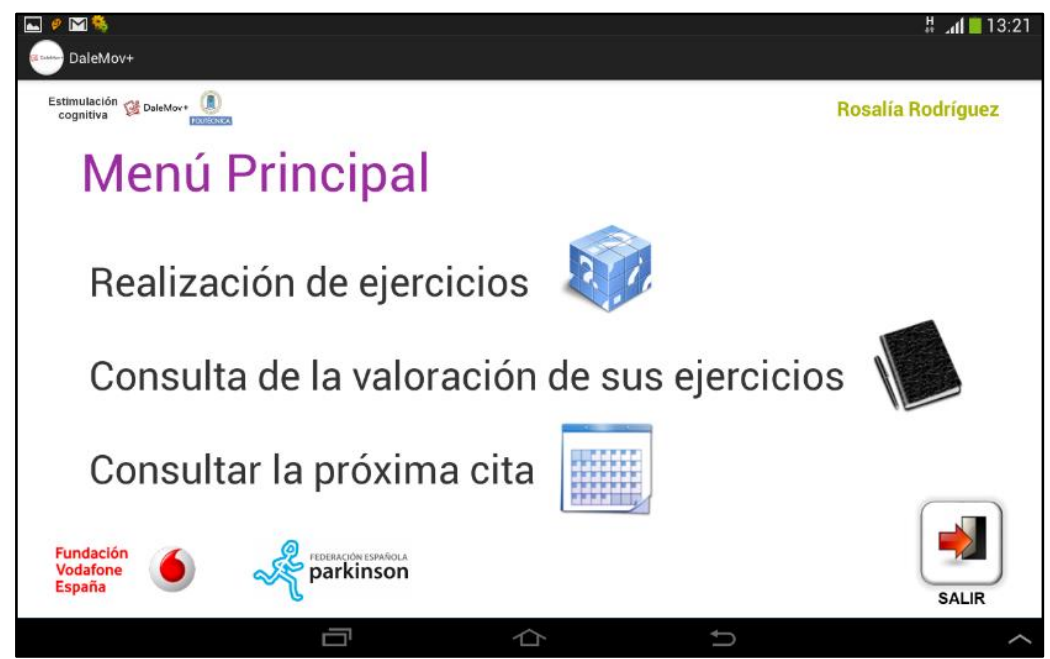

Figura 55. Menú principal de la aplicación del paciente

Este menú presenta tres opciones posibles:

- Realización de ejercicios, donde se puede descargar el siguiente bloque de ejercicios definido por el terapeuta para ese paciente en concreto.

- Consulta de la valoración de sus ejercicios, donde el paciente puede consultar la última valoración introducida por el terapeuta.

- Consulta de la próxima cita, donde el paciente puede obtener la fecha de la próxima cita presencial con su terapeuta. Pese a que esta funcionalidad está implementada, no se detallará al quedar fuera de los objetivos de la tesis.

Con respecto a la realización de ejercicios, cuando el paciente pulsa esta opción, aparece el menú de ejercicios con la interfaz de la Figura 56.

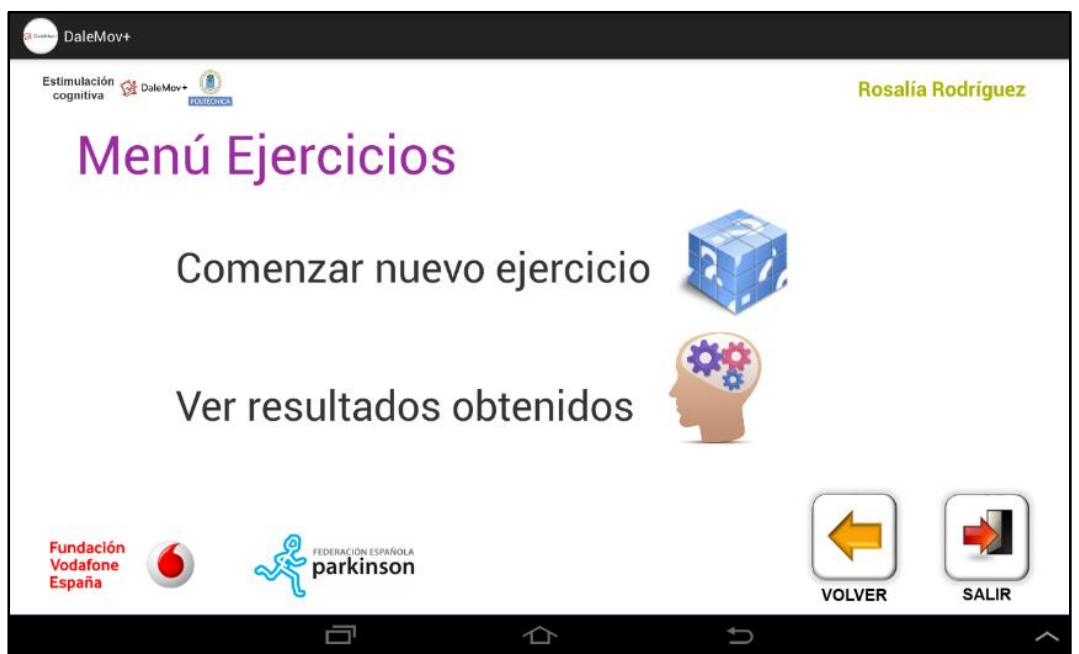

Figura 56. Menú de ejercicios de la aplicación del paciente

Si el paciente pulsa Comenzar nuevo ejercicio, se realizará la petición al servidor y se enviará el bloque de ejercicios que el terapeuta le ha asignado a ese paciente en concreto. Los ejercicios se muestran, según su modelo, de la siguiente forma:

- Modelo 1, con enunciado y tres respuestas alfanuméricas (Figura 57). 


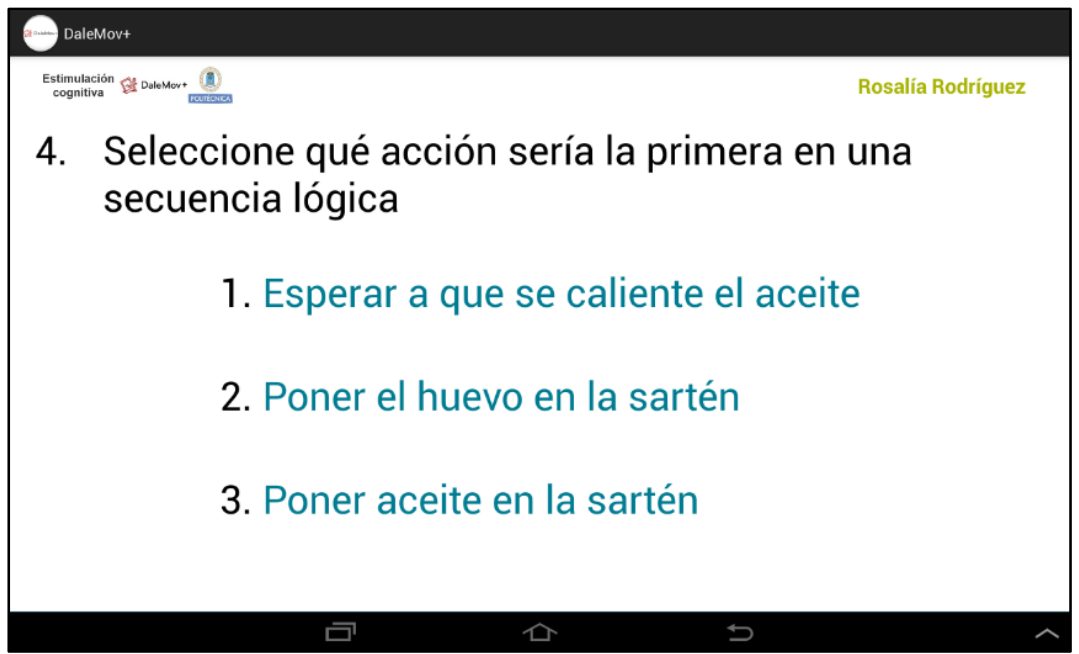

Figura 57. Ejemplo de ejercicio modelo 1

- Modelo 2, con enunciado y tres imágenes como respuestas (Figura 58).

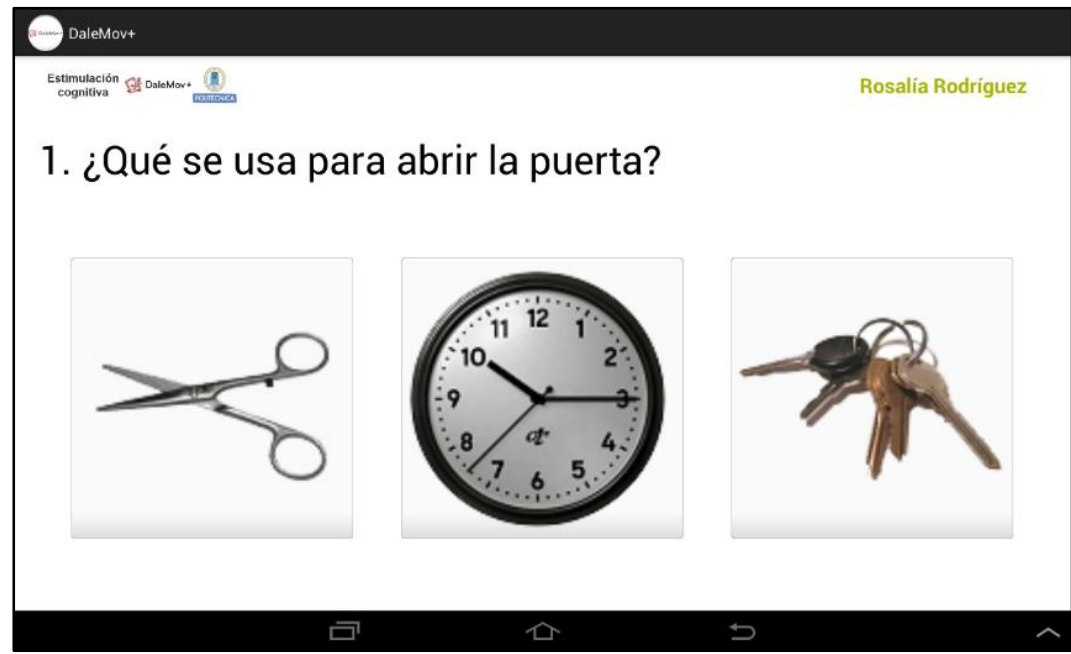

Figura 58. Ejemplo de ejercicio modelo 2

- Modelo 3, con una imagen que permanece 5 segundos y luego un enunciado y tres respuestas alfanuméricas sobre la imagen previa (igura 59).

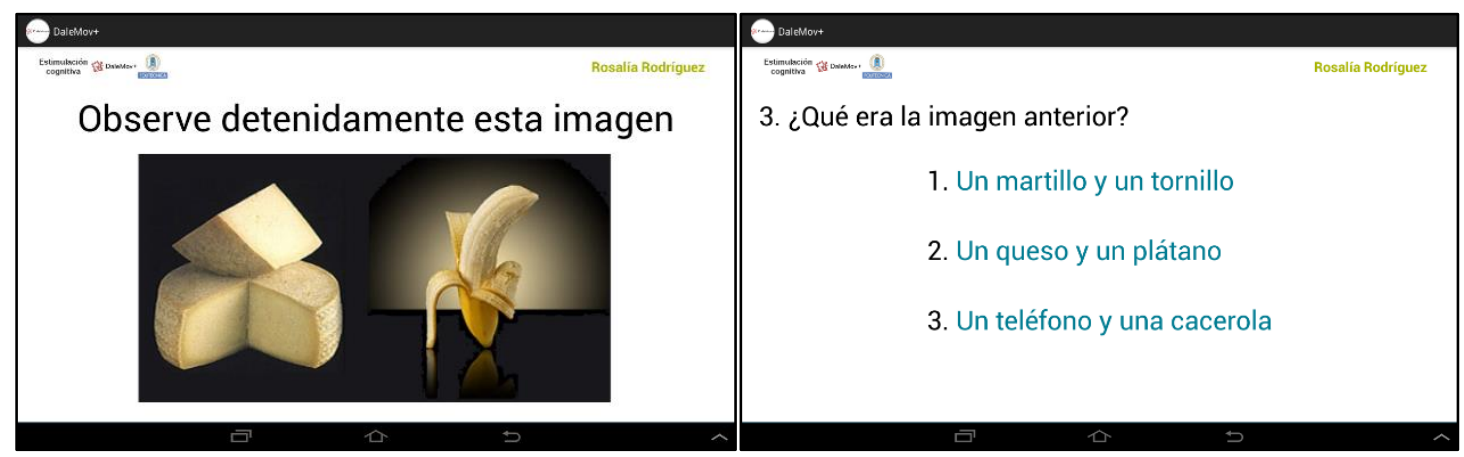

Figura 59. Ejemplo de ejercicio modelo 3

- Modelo 4, con un enunciado y un teclado alfanumérico accesible para que el paciente escriba la respuesta (Figura 60). 


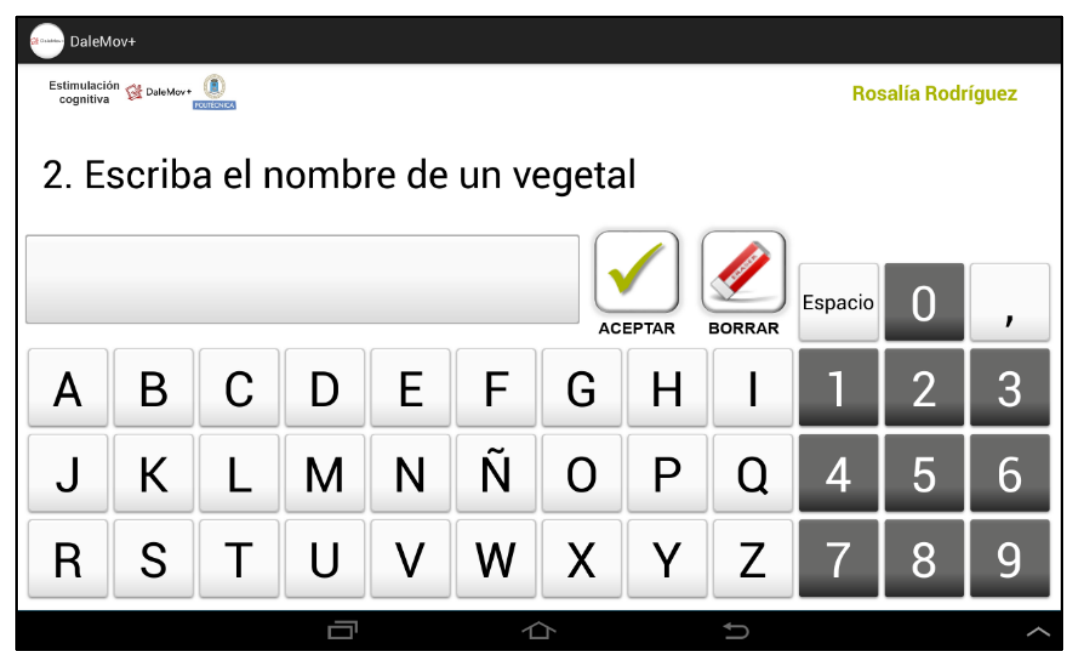

Figura 60. Ejemplo de ejercicio modelo 4

- Modelo 5, con una imagen, enunciado y teclado numérico accesible para que el paciente introduzca la respuesta de forma manual (Figura 61).

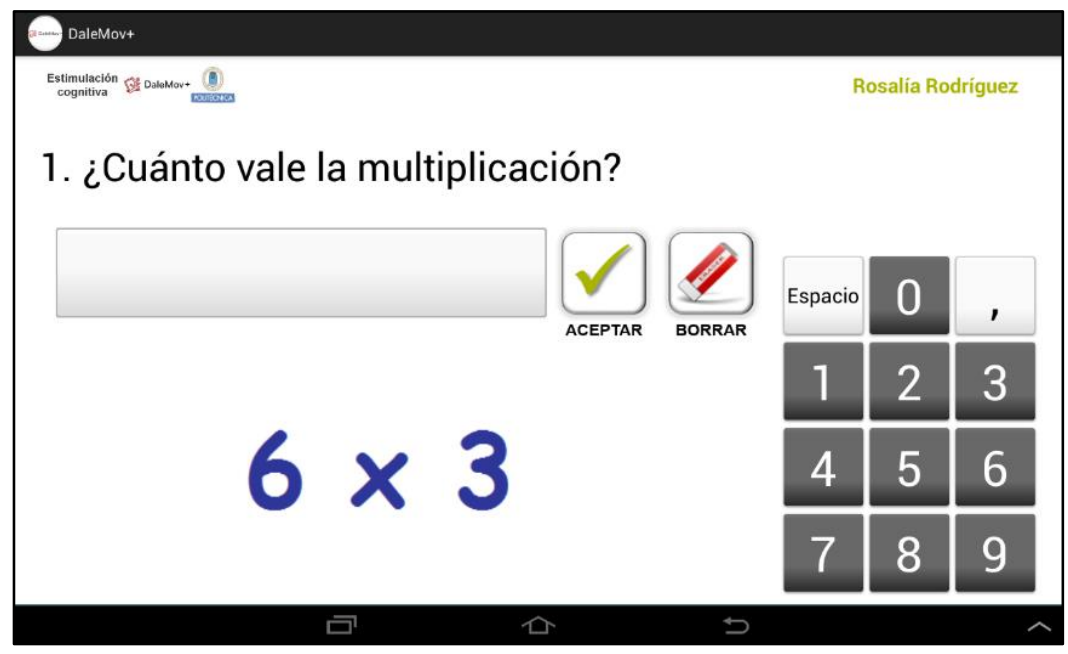

Figura 61. Ejemplo de ejercicio modelo 5

Cuando el paciente finaliza el bloque de ejercicios, se le presenta un mensaje y una imagen motivante, que cambia según el porcentaje de respuestas correctas (modelos 1, 2 y 3 ). Esta pantalla también se muestra en Ver resultados obtenidos (Figura 62).

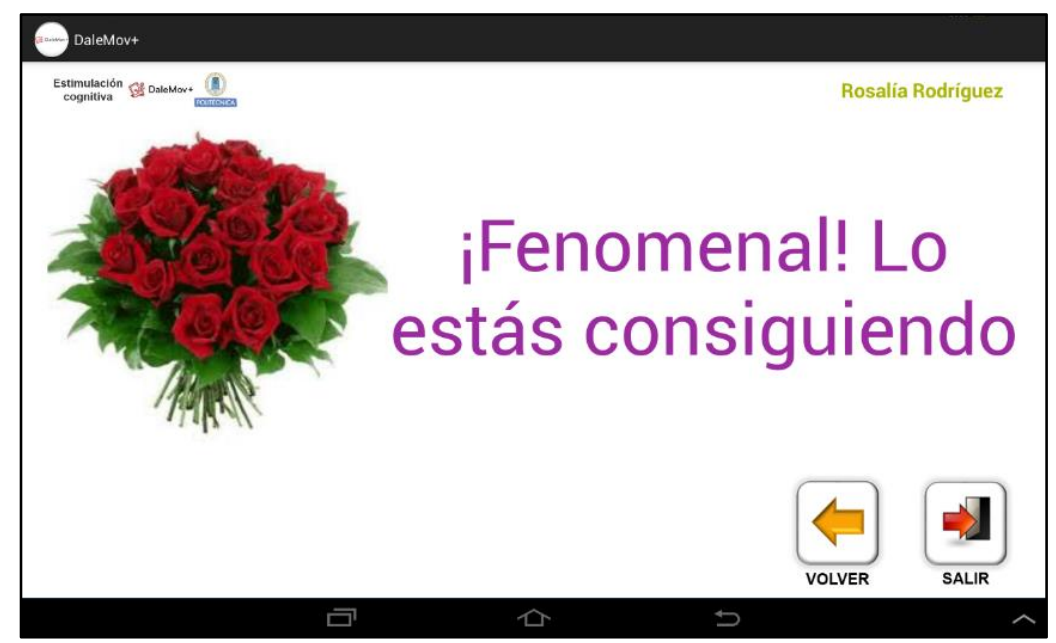

Figura 62. Ejemplo de resultados del paciente tras la realización de un bloque de ejercicios 
Por último, a través del menú principal el paciente puede seleccionar el consultar la última valoración introducida por su terapeuta, que tendría el formato de la Figura 63.

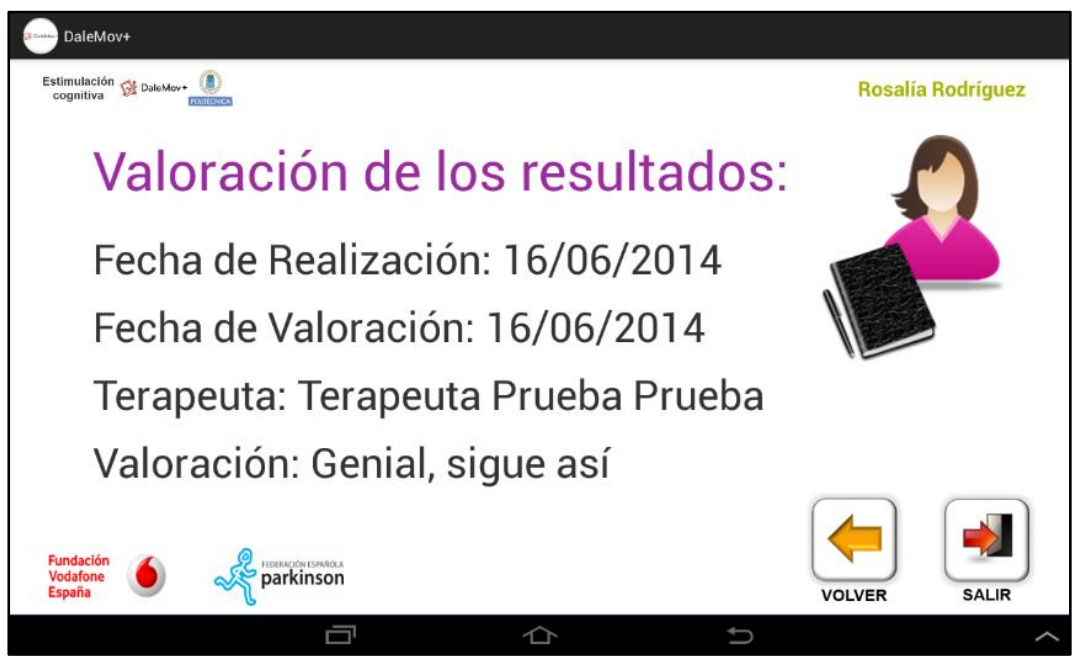

Figura 63. Ejemplo de valoración del terapeuta

Para la implementación de esta aplicación se han tenido en cuenta criterios de accesibilidad, así como temporizadores para evitar pulsaciones muy seguidas debidas a los problemas motores asociados a la EP. Asimismo, se ha contemplado tanto la gestión de errores de conectividad y errores del usuario para hacer la aplicación lo más robusta posible.

\subsubsection{Plataforma web de seguimiento de la terapia y gestión de usuarios}

La página de autenticación es común, independientemente del perfil del usuario (terapeuta, asociación o federación) y se presenta en la Figura 64. Esta interfaz es la misma para todos los usuarios que acceden a través de la web. En la presente memoria de tesis doctoral, únicamente se detallará la interfaz de gestión de las terapias, omitiéndose la información relativa a otros perfiles al quedar fuera del alcance de este documento.

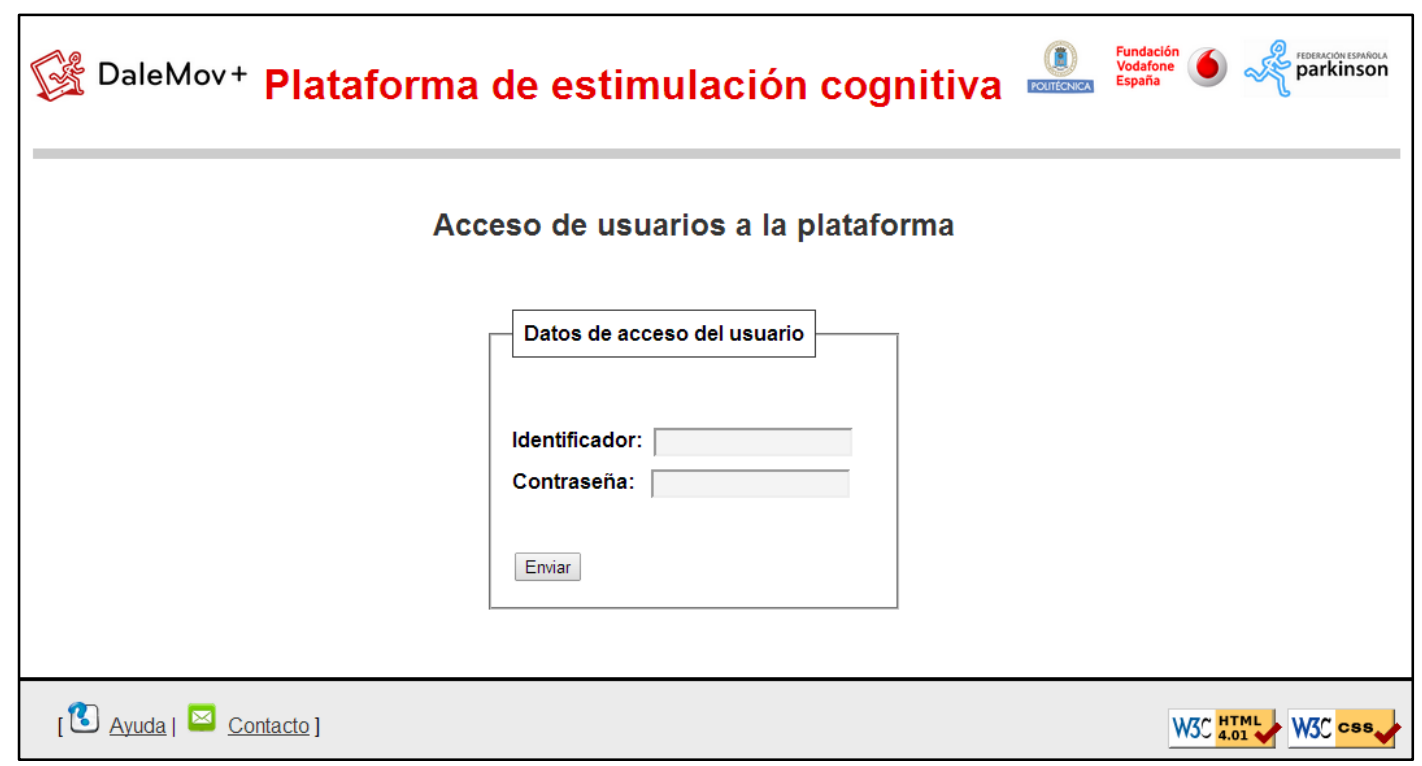

Figura 64. Página de autenticación 
En el caso de seguimiento de la terapia, se le presenta el menú con las opciones posibles, organizadas por funcionalidad común. La Figura 65 muestra el diagrama de navegación entre las operaciones que puede llevar a cabo el terapeuta a través de la plataforma.

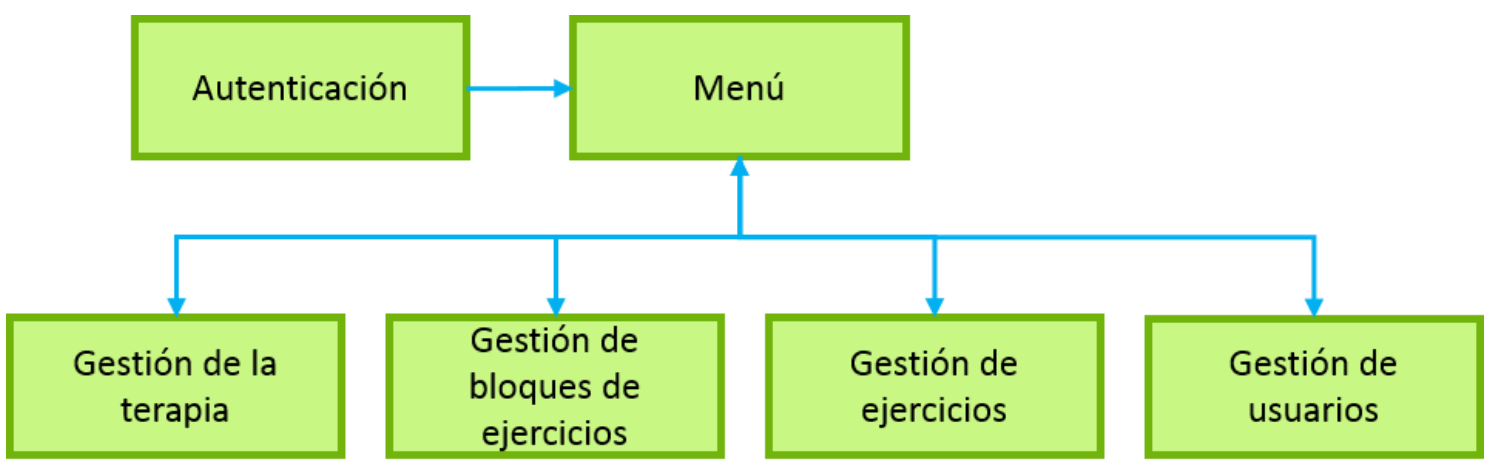

Figura 65. Diagrama de navegación por la plataforma para el perfil de terapeuta

Las operaciones que puede realizar son:

\section{- Relativas a la gestión de la terapia:}

- Asignar primer bloque de ejercicios a pacientes nuevos: mediante esta opción, se selecciona a un paciente para la asignación del primer bloque de ejercicios que deberá realizar la primera vez que decida realizar un bloque de ejercicios. Una vez se asigne este primer bloque, el paciente estará dado de alta en la terapia.

- Ver resultados de los ejercicios de estimulación pendientes de valorar: aparece la lista de los pacientes de esa asociación que tienen bloques de ejercicios pendientes de valorar. Cuando se selecciona el paciente, se valoran los ejercicios que no son de valoración automática en los que tiene que escribir la respuesta el paciente (modelos 4 y 5) y, posteriormente, el terapeuta selecciona el siguiente bloque de ejercicios que ese paciente deberá realizar y le introduce un mensaje motivante que podrá ser consultado a través de la aplicación Android del paciente. Las interfaces de la valoración de ejercicios no automáticos y de la introducción de una valoración se presentan, respectivamente, en Figura 67 y Figura 68.

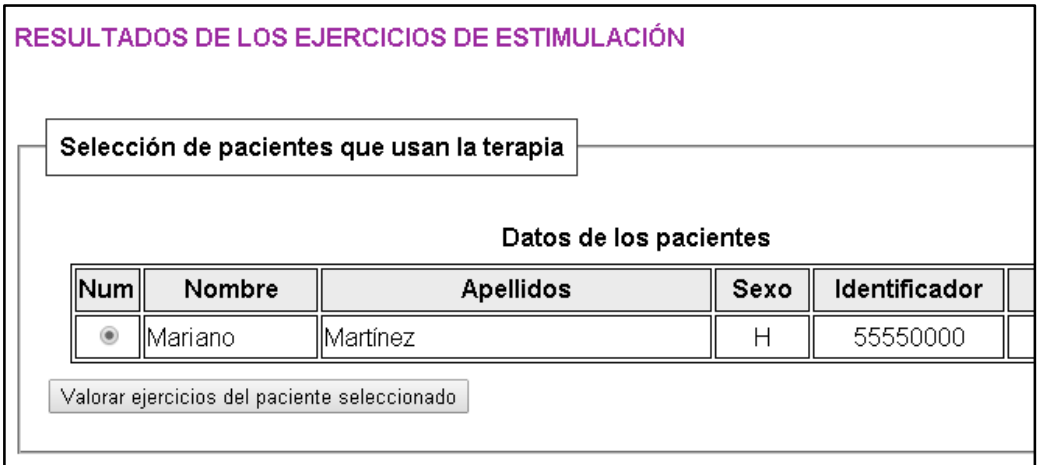

Figura 66. Selección de pacientes 


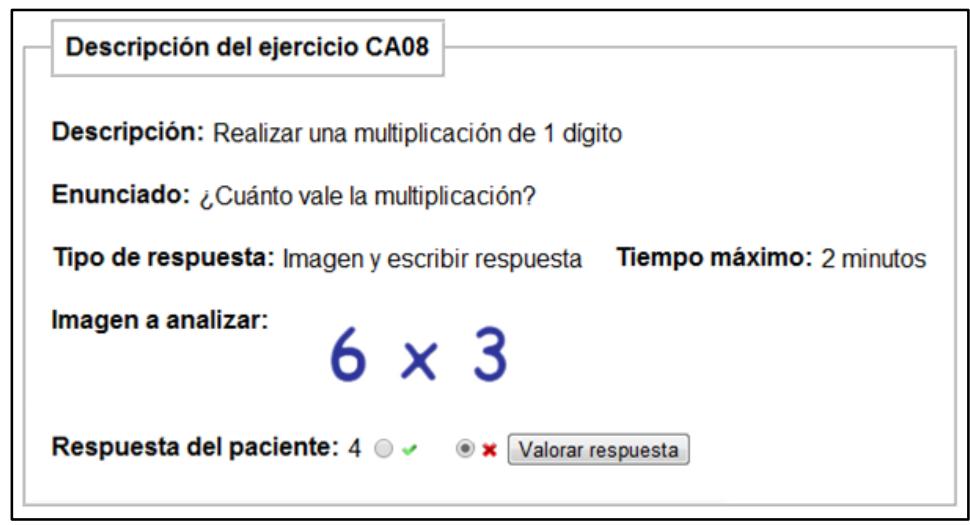

Figura 67. Valoración de ejercicio no automático

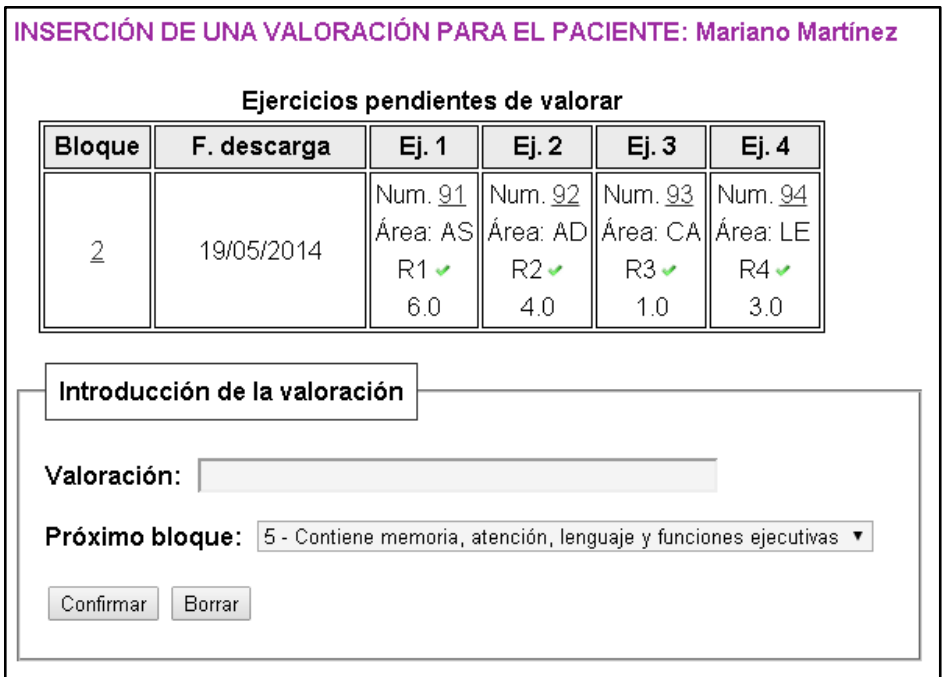

Figura 68. Introducción de valoración y siguiente bloque de ejercicios

- Modificar la última valoración introducida: el terapeuta puede modificar la última valoración que ha creado para un paciente. De esta forma, se consigue que, en el caso de que haya habido algún error por ejemplo en la asignación del último bloque de ejercicios, pueda corregirse.

- Consulta de la situación actual de los ejercicios de un paciente: mediante esta opción, el terapeuta puede consultar los bloques de ejercicios que ha realizado un paciente determinado, tanto los que se ha descargado y no ha finalizado como los que ya están valorados por los terapeutas de esa asociación. En la Figura 69 se presenta cómo es la interfaz para la consulta de este seguimiento de la terapia. 


\begin{tabular}{|c|c|c|c|c|c|}
\hline \multicolumn{6}{|c|}{ SITUACIÓN ACTUAL DE LA TERAPIA DEL PACIENTE: Mariano Martínez } \\
\hline Bloque & $\begin{array}{l}\text { Próx. } \\
\text { bloque }\end{array}$ & F. descarga & F. valoración & Terapeuta & Valoración \\
\hline$\underline{5}$ & $\underline{\underline{2}}$ & $28 / 04 / 2014$ & $05 / 05 / 2014$ & Gonzalo García Gómez & Muy bien, Mariano! \\
\hline$\underline{5}$ & $\underline{2}$ & $05 / 05 / 2014$ & $05 / 05 / 2014$ & Gonzalo García Gómez & Muy bien, Mariano! \\
\hline$\underline{5}$ & $\underline{3}$ & $06 / 05 / 2014$ & $06 / 05 / 2014$ & Gonzalo García Gómez & Sigue así \\
\hline$\underline{3}$ & $\underline{2}$ & $12 / 05 / 2014$ & $12 / 05 / 2014$ & Gonzalo García Gómez & Genial, sigue así \\
\hline \multicolumn{6}{|c|}{$\begin{array}{c}\text { Ejercicios descargados sin } \\
\text { terminar }\end{array}$} \\
\hline Bloque & \multicolumn{2}{|c|}{ F. descarga } & & & \\
\hline$\underline{3}$ & \multicolumn{2}{|c|}{$12 / 05 / 2014$} & & & \\
\hline$\underline{2}$ & \multicolumn{2}{|c|}{$12 / 05 / 2014$} & & & \\
\hline
\end{tabular}

Figura 69. Consulta de la evolución de un paciente

\section{- Relativas a la gestión de bloques de ejercicios de estimulación:}

- Creación de un bloque de ejercicios: a través de esta opción, el terapeuta puede insertar un nuevo bloque de ejercicios en la base de datos para poder asignárselo a un paciente. Estos bloques de ejercicios serán visibles por todos los terapeutas registrados en la plataforma, independientemente de la asociación a la que pertenezcan. Los bloques de ejercicios se pueden crear de forma manual, eligiendo los ejercicios que formarán el bloque, o automática, seleccionando las áreas de estimulación, el nivel de dificultad y el número de ejercicios del bloque. Las interfaces se presentan a continuación (Figura 70, Figura 71 y Figura 72).

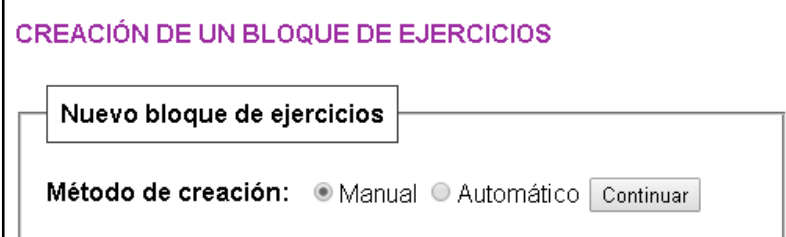

Figura 70. Selección del modo de creación del bloque de ejercicios

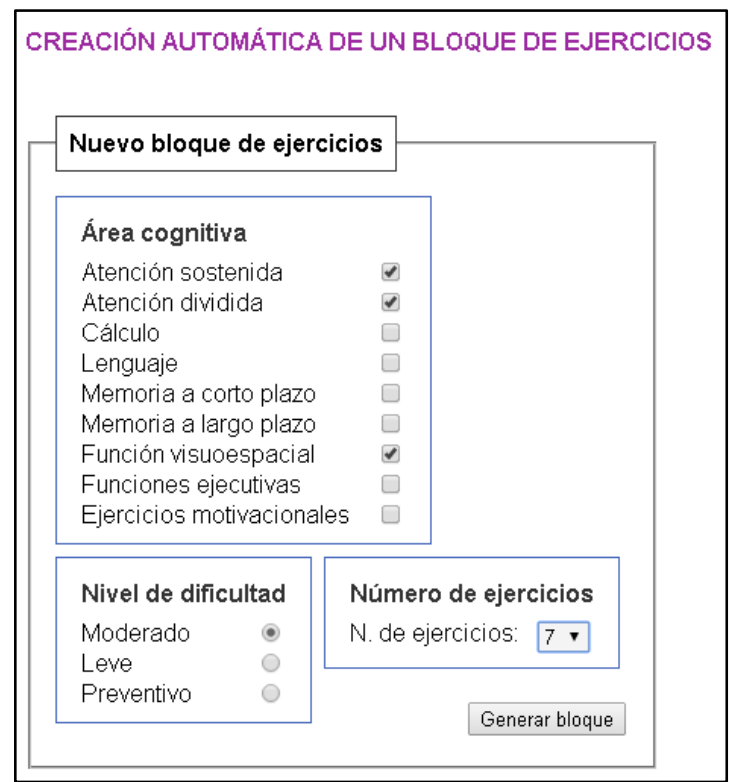

Figura 71. Parámetros para bloque de ejercicios automático 


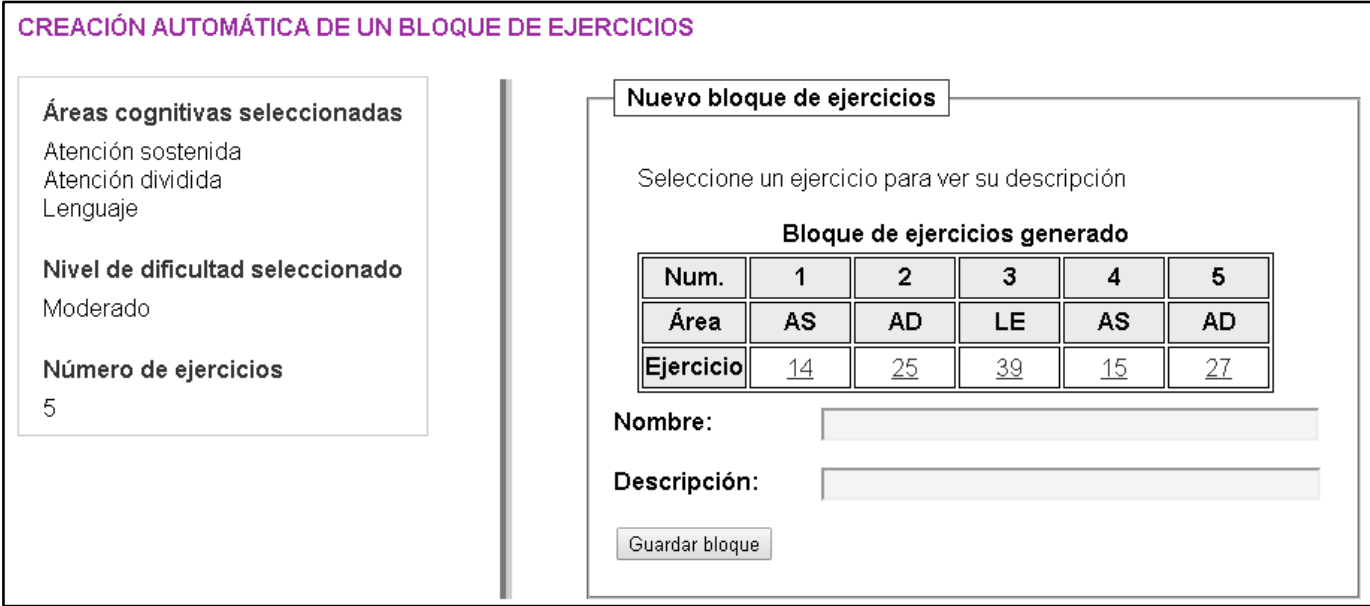

Figura 72. Asignación de nombre y descripción al bloque de ejercicios

- Consulta de los bloques de ejercicios almacenados: los terapeutas pueden consultar los bloques de ejercicios de estimulación cognitiva almacenados, tanto los creados por él como por otros terapeutas de su asociación o de otras asociaciones.

- Eliminación de un bloque de ejercicios: el terapeuta puede decidir eliminar un bloque de ejercicios para que no esté disponible para su asignación. Aunque el bloque deje de presentarse a los terapeutas, seguirá existiendo en la base de datos para poder consultar su información en el caso de que algún paciente lo haya realizado.

\section{- Relativas a la gestión de ejercicios de estimulación:}

- Información de los ejercicios de estimulación almacenados: en esta opción se presenta una tabla donde el administrador puede ver los ejercicios que hay almacenados en el sistema. En esta tabla se puede observar que los ejercicios se organizan por nivel de dificultad y por área de estimulación. Los ejercicios que se muestran son tanto los creados en la asociación del usuario como los creados por otras asociaciones que se hayan definido como públicos. Un ejercicio es público cuando se ha descargado 3 veces por pacientes distintos. Los ejercicios no están inmediatamente a disposición de todas las asociaciones porque pueden estar personalizados con aspectos específicos de un paciente concreto (como con fotografías de sus familiares). Es por ello por lo que se decidió añadir esta restricción. La pantalla con los ejercicios disponibles a nivel de cada asociación, ya sean públicos o aún no, se presenta en la Figura 73.

\begin{tabular}{|c|c|c|c|c|c|c|c|c|c|}
\hline \multicolumn{10}{|c|}{$\begin{array}{l}\text { INFORMACIÓN SOBRE LOS EJERCICIOS DE ESTIMULACIÓN ALMACENADOS } \\
\text { Elija el ejercicio para ver su descripción }\end{array}$} \\
\hline Nivel & $\begin{array}{l}\text { Atención } \\
\text { sostenida }\end{array}$ & $\begin{array}{l}\text { Atención } \\
\text { dividida }\end{array}$ & Cálculo & Lenguaje & $\begin{array}{c}\text { Memoria a corto } \\
\text { plazo }\end{array}$ & $\begin{array}{c}\text { Memoria a largo } \\
\text { plazo }\end{array}$ & $\begin{array}{c}\text { Función } \\
\text { visuoespacial }\end{array}$ & $\begin{array}{l}\text { Funciones } \\
\text { ejecutivas }\end{array}$ & $\begin{array}{c}\text { Ejercicios } \\
\text { motivacionales }\end{array}$ \\
\hline Moderado & 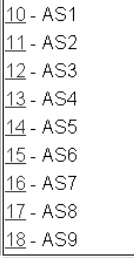 & 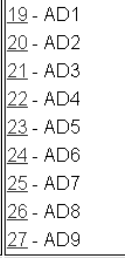 & 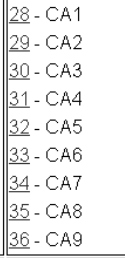 & \begin{tabular}{|l|}
$\frac{37}{38}$ - LE1 \\
$\frac{38}{39}$ - LE2 \\
$\frac{49}{40}$ - LE3 \\
41 - LE 4 \\
42 - LE6 \\
$43-$ - LE7 \\
44 - LE8 \\
45 - LE9 \\
\end{tabular} & \begin{tabular}{||l|}
$\frac{46}{47}-M C 1$ \\
$\frac{48}{-M}-M C 2$ \\
$49-M C 4$
\end{tabular} & & & & \\
\hline Leve & 91 - AS11 & & 93 - CA11 & 94 - LE11 & $\begin{array}{l}130 \text { - Memorizar } \\
\text { objetos }\end{array}$ & & & & \\
\hline Preventivo & & & & & & & & & \\
\hline
\end{tabular}

Figura 73. Tabla con los ejercicios almacenados 
- Inserción de un ejercicio de estimulación: para la inserción de un ejercicio se presentan dos pantallas: en la primera de ellas (Figura 74) se recogen los campos que todos los ejercicios van a presentar, como, por ejemplo, el enunciado. En la pantalla siguiente (Figura 75) se deben introducir los datos que dependen de cada ejercicio, como pueden ser las imágenes asociadas al mismo o la respuesta correcta en caso de que existan respuestas. Es en esta segunda pantalla se le presentan los datos que ha rellenado en la primera $y$, en el caso de que quiera modificar alguno, puede pulsar Volvery realizar las modificaciones que estime oportunas. En el caso de ejercicios que contienen imágenes, se ha creado un repositorio donde se pueden seleccionar imágenes que ya existen en la base de datos.

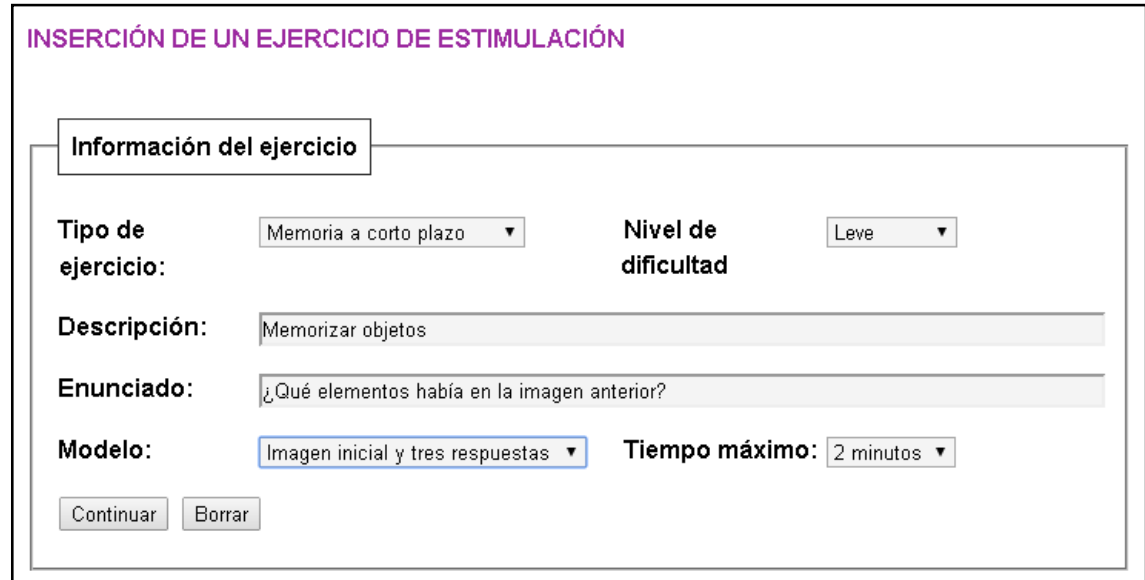

Figura 74. Primera pantalla de introducción de ejercicios

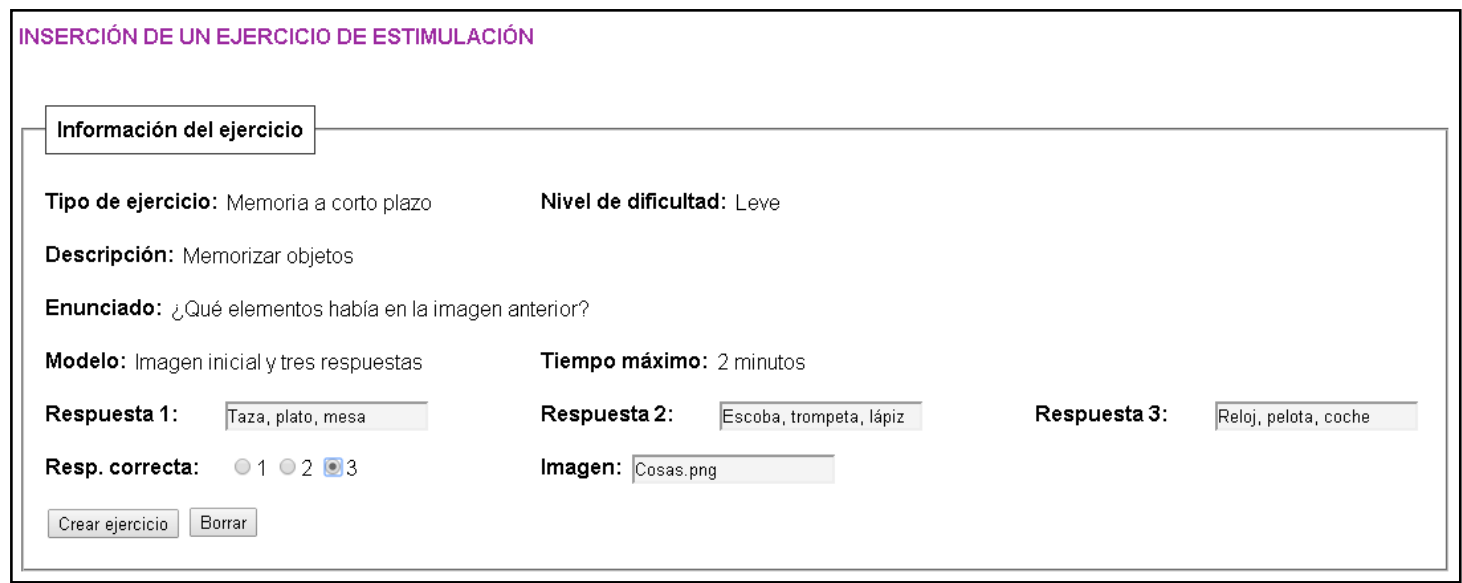

Figura 75. Segunda pantalla de introducción de ejercicios

- Modificación de un ejercicio de estimulación: los terapeutas pueden modificar ejercicios de estimulación porque hayan captado alguna errata.

- Eliminación de un ejercicio de estimulación: para eliminar un ejercicio, se presenta en primer lugar la tabla donde se muestran los números de ejercicio existentes en el sistema (ver tabla de Información de los ejercicios de estimulación almacenados). Basta con seleccionarlo, se accederá a su información y, en esta pantalla, se presentará un botón que permite borrarlo. Esto se presenta en la Figura 76. 


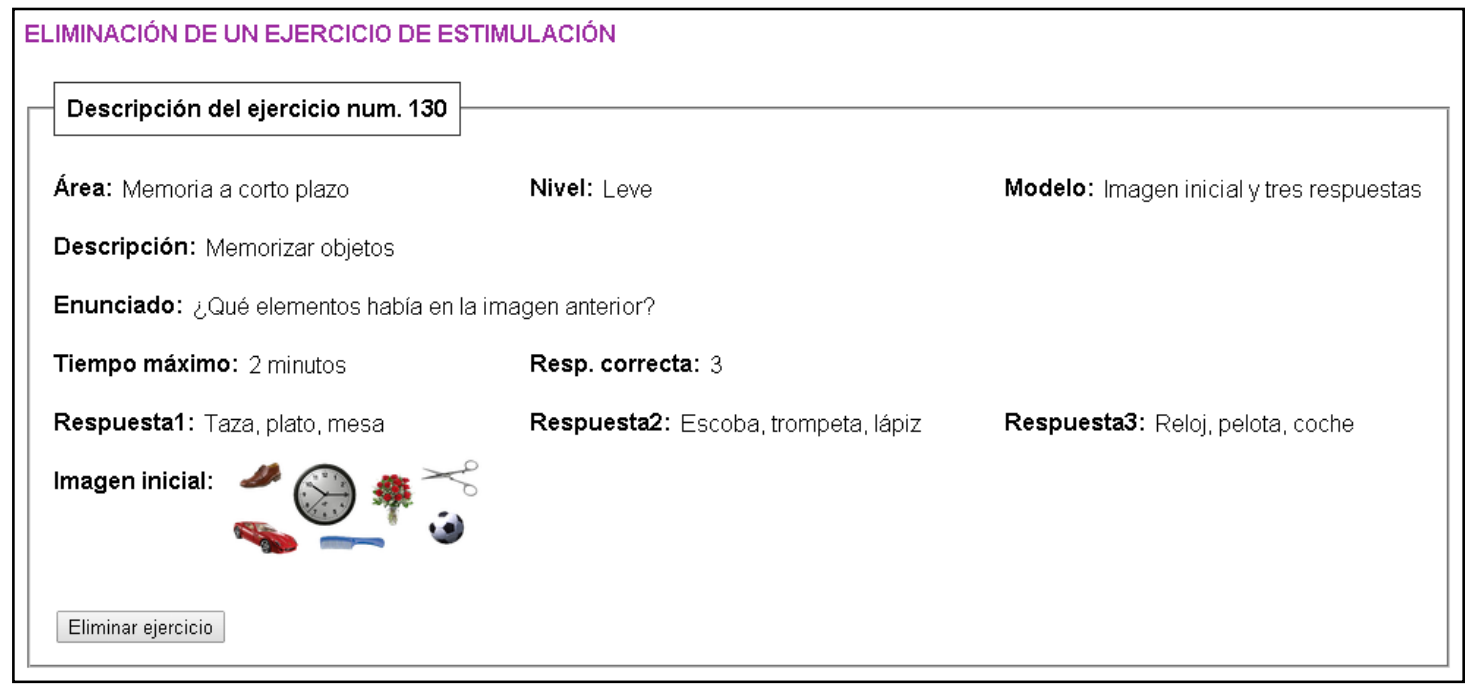

Figura 76. Eliminación de un ejercicio de estimulación

- Relativas a la gestión de los datos de los pacientes: este apartado tiene dos opciones. Se pueden buscar los datos personales de un paciente o planificarle una cita para consulta presencial que, posteriormente, el paciente puede consultar a través de su aplicación. Esta última funcionalidad, como se ha descrito anteriormente, está implementada pero no se describirá en profundidad por quedar fuera de los objetivos de la presente tesis.

- Relativas a la administración de usuarios: como en cualquier otra plataforma que requiera registro de usuarios, el terapeuta dispone de la opción de cambiar la contraseña de acceso.

\subsection{Verificación técnica y funcional}

La verificación técnica se llevó a cabo en el Hogar Digital Accesible (HDA) de la Universidad Politécnica de Madrid (UPM), situado en la Escuela Técnica Superior de Ingeniería y Sistemas de Telecomunicación [HDA, 2006]. Este entorno de pruebas es una casa de $70 \mathrm{~m}^{2}$ dotada de servicios TIC diseñados para facilitar la vida de las personas. Esta instalación permanente, inaugurada en mayo de 2006, ofrece facilidades de formación, investigación y relación con la sociedad, la industria y las entidades públicas. Se trata de una casa perfectamente acondicionada (entrada, salón, cocina, distribuidor, cuarto de baño y dormitorio) que permite la evaluación y demostración real de soluciones TIC emergentes desde los principios de diseño para todos. Asimismo, el HDA dispone de un laboratorio anexo en el que se llevan a cabo trabajos de capacitación, desarrollo e integración, y que también constituye un observatorio de usabilidad y accesibilidad de las soluciones disponibles en la casa. La distribución de este escenario de pruebas, así como fotos de las estancias que contiene, se presenta en la Figura 77. 

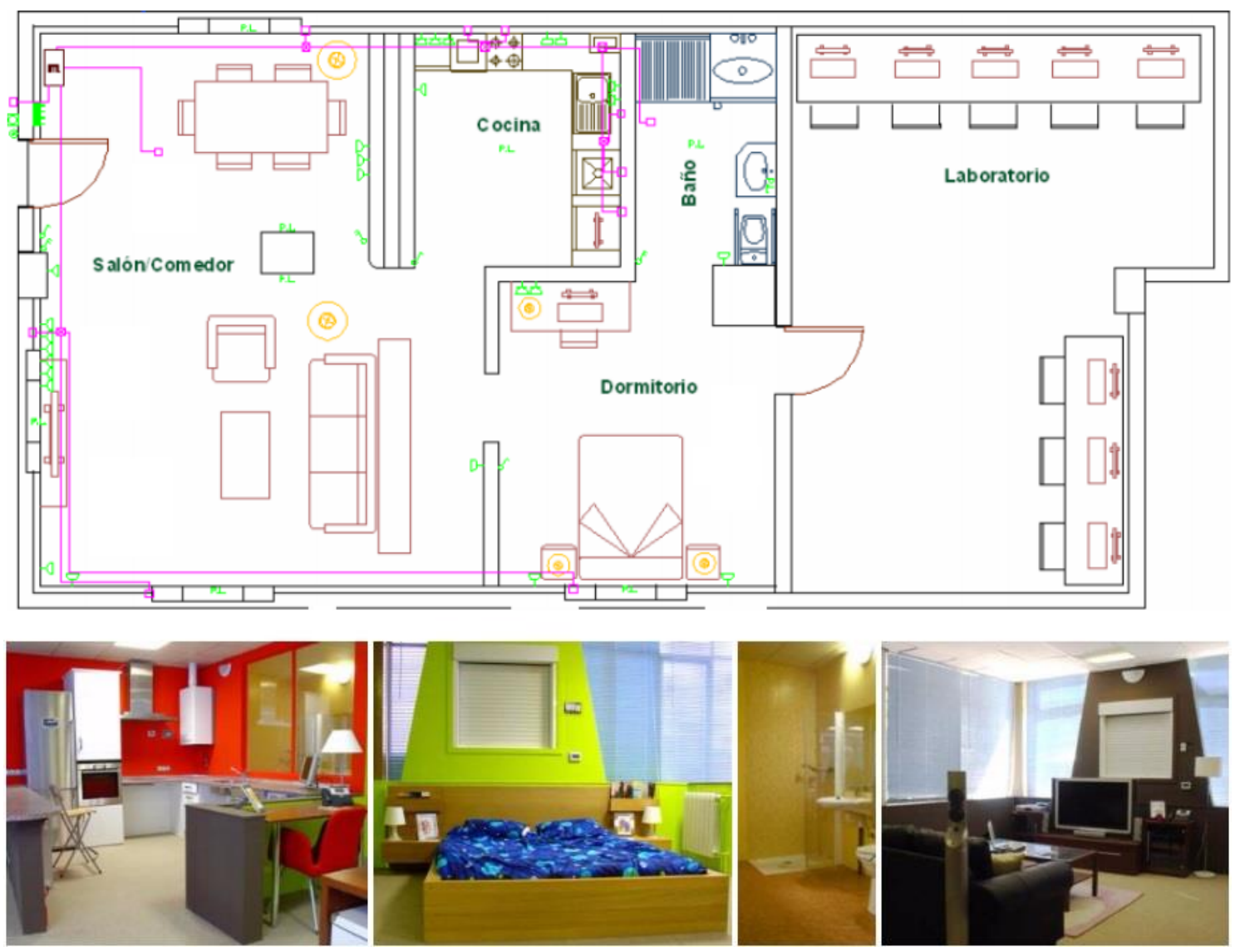

Figura 77. Hogar Digital Accesible de la UPM [HDA, 2006]

Las primeras pruebas para la verificación técnica se llevaron a cabo gracias a la colaboración de investigadores del Grupo de Investigación Sistemas Telemáticos para la Sociedad de la Información y el Conocimiento (T>SIC) de la UPM. Estos investigadores, todos ellos expertos en el área de telesalud y accesibilidad universal, llevaron a cabo diversas pruebas en el HDA, como pueden ser la utilización de la aplicación con poca luz, cortes en la comunicación durante las transmisiones, cambios de redes, etc. Estos comentarios realimentaron al sistema para garantizar su correcto funcionamiento antes de la validación de la funcionalidad, llevada a cabo por personas expertas en EP.

Para llevar a cabo la verificación funcional, se contó con la ayuda de la APKM y con la Federación Española de Parkinson (FEP). En la APKM se llevaron a cabo las pruebas con usuarios, principalmente con terapeutas que comprobaron que la funcionalidad definida en las fases anteriores estaba correctamente contemplada en las aplicaciones finales, tanto las de pacientes como las de terapeutas. La FEP evaluó los manuales de usuario que se iban preparando para los pilotos en las asociaciones con usuarios reales, comprobando que el lenguaje utilizado era el correcto y que se describían todos los pasos a seguir para completar cada acción de forma apropiada. Este proceso se llevó a cabo a mediados del año 2014.

\subsection{Relevancia de la implementación de la plataforma}

En el Capítulo 4. Determinación de requisitos de la Terapia de Estimulación Cognitiva para la enfermedad de Parkinson (EP) se definió cómo se llevó a cabo la recogida de requisitos de usuario, en este caso concreto, siguiendo un proceso de DCU. Gracias a ello, se ha conseguido 
obtener tanto los requisitos de la TEC como las necesidades de las personas con EP cuando se enfrentan a las TIC. Con esta colección de parámetros se ha conseguido la definición del modelo perseguido en esta tesis doctoral. Tras el trabajo de investigación realizado, ha sido posible el desarrollo de una plataforma TIC que implemente el modelo. Esta plataforma ha tenido en consideración todos los aspectos que se recogieron con los usuarios finales (pacientes con EP y terapeutas responsables de las TEC en las asociaciones de Parkinson), por lo que se considera una plataforma completa y viable para llevar a cabo la experimentación.

La experimentación en este trabajo es muy importante. Gracias a ella, se puede corroborar que la definición de los parámetros de la TEC y que las necesidades de las personas con EP en un entorno TIC que se han recogido en esta memoria son relevantes y aportan un conocimiento científico novedoso. Asimismo, gracias a la implementación del modelo, definido en la fase 4 del proceso de validación de las hipótesis (apartado 2.3. Metodología para la validación de las hipótesis), se puede llevar a cabo una experimentación formal que permita evaluar las mejoras reflejadas en las hipótesis de partida, definidas a partir de la optimización de la TEC en los aspectos de eficiencia, satisfacción en el uso y adherencia al tratamiento.

La definición del experimento y los resultados de pacientes y terapeutas tras el mismo se define en el capítulo siguiente: Capítulo 6. Experimentación y resultados, donde se utilizará la plataforma desarrollada para definir el éxito alcanzado con los trabajos previos. 


\section{Capítulo 6. Experimentación y resultados}

El sexto capítulo de la memoria de esta tesis doctoral se centra en la experimentación llevada a cabo con los usuarios finales. En él, se describirán en detalle las metodologías de validación de la experiencia de usuario, el proceso de experimentación en sí mismo y los resultados obtenidos tras su realización.

\subsection{Resultados perseguidos con la experimentación}

La experimentación llevada a cabo en este trabajo de investigación estaba orientada a la confirmación de la satisfacción de los usuarios, tanto pacientes como terapeutas, a la hora de realizar las Terapias de Estimulación Cognitiva (TEC) utilizando las TIC. Para ello, se midió la experiencia de usuario (UX).

La UX se definió en el Capítulo 4. Determinación de requisitos de la Terapia de Estimulación Cognitiva para la enfermedad de Parkinson (EP). En este capítulo, se detallarán las metodologías de UX más utilizadas, así como el proceso llevado a cabo para la elección de la idónea en el ámbito que nos ocupa.

\subsection{Metodologías de evaluación de UX}

\subsubsection{Metodologías de la investigación}

En el caso que nos ocupa, queremos probar a través del desarrollo de varios experimentos, la percepción de utilidad y satisfacción del uso de los usuarios finales de la plataforma descrita en el capítulo anterior, estos son, pacientes diagnosticados de EP y sus terapeutas.

Una vez definido el tipo de estudio a realizar y tras establecer las hipótesis de la investigación, se debe concebir la manera práctica y concreta de responder a las preguntas de investigación. Esto implica seleccionar o desarrollar una metodología de investigación y aplicarla al contexto particular de su estudio. Diseño se refiere al plan o estrategia concebida para responder a las preguntas de investigación. El diseño señala al investigador lo que debe hacer para alcanzar sus objetivos de estudio, contestar las interrogantes que se ha planteado y analizar la certeza de las hipótesis formuladas en un contexto en particular [González, 2008].

La investigación es la indagación para descubrir algo [RAE, 2014, 5]. Sin embargo, a la hora de trabajar en el campo científico se utiliza la investigación científica, más orientado a la revisión de la literatura para la generación de nuevo conocimiento a través de un procedimiento reflexivo, sistemático, controlado y crítico [Shuttleworth, 2008] [Ander-Egg, 1980]. Para ello, se utiliza el método científico. El método científico consiste en la observación de un fenómeno y, 
posteriormente, la generación de una hipótesis que contrasta y emite posteriormente unas conclusiones derivadas de dicho contraste de hipótesis [Pita, 2002].

Existen diversos tipos básicos de investigación, como son [Kothari, 2004]:

- Descriptiva vs. analítica: el primer tipo se basa en hechos de cualquier naturaleza, cuestionarios, informes, etc. con el propósito de generar una investigación en la que no se tenga control de las variables, sino que, únicamente, se describe el resultado tras la investigación. Son investigaciones llevadas a cabo a partir de los resultados de un experimento. En el segundo tipo, el investigador utiliza hechos o información analizándola para generar una evaluación crítica, por lo que controla las variables a utilizar previamente al experimento.

- Aplicada vs. fundamental: la primera busca el encontrar la solución a un problema. La segunda se centra en la generación de teorías que puedan ser utilizables en cualquier ámbito.

- Cuantitativa vs. cualitativa: la investigación cuantitativa se basa en la medida de una cantidad, por lo que solo es adecuada para la investigación de unos fenómenos determinados. La investigación cualitativa está más centrada en fenómenos de calidad, como pueden ser comportamientos humanos. Se suelen utilizar entrevistas o cuestionarios.

- Conceptual vs. empírica: la primera es relativa a teorías abstractas, normalmente en el campo de la filosofía. La segunda se centra en la experimentación en entornos reales.

- Otros tipos de investigación: suelen ser variación de los tipos básicos anteriores cuando no se adaptan al propósito de la investigación, al tiempo o al entorno.

Como se ha comentado previamente, se pretende evaluar la utilidad y la satisfacción de las personas con EP y sus terapeutas a la hora de utilizar las TIC para llevar a cabo terapias de estimulación. A partir de este hecho, se ha definido la metodología a emplear en este trabajo de la siguiente forma:

- Investigación descriptiva, ya que era necesario basarse en hechos. No había control de las variables, puesto que lo que se pretendía era que el usuario expresara su percepción y posteriormente analizar los resultados obtenidos.

- Investigación aplicada, porque se centra en un ámbito muy concreto: el de las terapias para que personas con EP puedan estimular su cognición utilizando las TIC y con el seguimiento de sus terapeutas.

- Investigación cualitativa, debido a que nos centramos en la calidad del servicio percibido por los usuarios finales de estas terapias.

- Investigación empírica, ya que los resultados se basan en experimentación.

Una vez definidas las metodologías de investigación en las que se centra este trabajo, se definirán las técnicas de análisis de experiencia de usuario (UX), que es lo que se pretende medir con estos experimentos. 


\subsubsection{Técnicas de medición de la UX}

Para medir la UX de un servicio se suelen tener en cuenta tres dimensiones:

- Qué se quiere analizar: actitud o comportamiento.

- Qué datos se quieren obtener: cualitativos o cuantitativos.

- Contexto durante la investigación.

Se ha llevado a cabo una investigación para averiguar cuáles son los métodos más apropiados en este escenario, considerando que los datos a adquirir tendrán un enfoque cualitativo y estarán enmarcados en el contexto de la realización de terapias de estimulación cognitiva para personas con EP utilizando las TIC.

En el apartado 4.2. Metodología para la captura de requisitos se hico una breve introducción a la UX, dando especial importancia a los cinco factores que intervienen en su evaluación. Estos factores son el propio usuario, sus factores sociales, sus factores culturales, el contexto de uso y el producto en sí. En el caso concreto de este trabajo de investigación, se va a evaluar la UX relativa al producto, donde es muy importante la usabilidad de la plataforma para garantizar el éxito del modelo desarrollado.

Centrándonos en la usabilidad como mecanismo principal para la evaluación de la UX, se ha hecho un estudio de la bibliografía existente para comprobar los test más utilizados. Los test de usabilidad en el contexto de las TIC están principalmente enfocados a entornos web y, debido a la composición del modelo tanto con tecnologías web como con tecnologías móviles que presentan una gran similitud en el uso de las tecnologías web, se ha decidido utilizar este tipo de test para comprobar la usabilidad de la plataforma. A día de hoy, en el mercado hay multitud de test de usabilidad. Los más importantes que pueden aplicarse en el escenario definido son [Martín, 2015] [Rubin, 2008]:

- Entrevistas y encuestas: permiten la recolección de información cualitativa de las motivaciones de uso de una plataforma.

- Pruebas moderadas: se evalúan las funcionalidades específicas de un diseño concreto que se espera que presenten mayor dificultad en la interacción.

- Card sorting: busca aunar los criterios respecto a la ubicación de los contenidos, jerarquías y navegación.

- Pruebas beta: para identificar los problemas de interacción, errores de carga y compatibilidad de navegadores en las etapas finales del desarrollo.

- Evaluaciones heurísticas: análisis experto de la usabilidad.

En el Capítulo 4. Determinación de requisitos de la Terapia de Estimulación Cognitiva para la enfermedad de Parkinson (EP) se definieron las entrevistas y las pruebas que se llevaron a cabo con el comité de expertos, formados principalmente por terapeutas de estimulación cognitiva y por pacientes que participaron durante las fases del DCU. En estas fases, se realizaron pruebas moderadas y card sorting, ya que se iban evaluando parcialmente las mejoras añadidas y se buscaba consenso respecto al diseño y a la organización de los contenidos, tanto en la aplicación del paciente como en la del terapeuta. Asimismo, también se hizo un análisis experto de la 
usabilidad, llevado a cabo por la doctoranda y otros miembros del grupo de investigación T>SIC, que tenían experiencia en estas evaluaciones heurísticas gracias a la realización de otros proyectos de investigación. Es por ello, que la forma de evaluación que se definió como más alineada con los objetivos perseguidos con la experimentación fueron las encuestas. Este método presentaba numerosas ventajas respecto al resto [USDHHS, 2016]:

- Son perfectos para la investigación descriptiva, ya que, cuanto más cerradas sean las cuestiones a evaluar, más fácil será el análisis de los resultados.

- Al ser un escenario cuya investigación es cualitativa al tratar de analizar comportamiento humano, los cuestionarios se adaptan muy bien.

- Son ideales para poder hacer pruebas con usuarios sin estar presente y así no interferir en el experimento.

- Se puede recoger multitud de información, como la facilidad de aprendizaje o la satisfacción en el uso.

- Es fácilmente adaptable a las necesidades de una persona con EP.

- Se puede controlar mejor el tiempo para la realización de un cuestionario que, por ejemplo, de una entrevista.

- Se pueden dejar campos de observaciones y propuestas de mejora.

Por todo lo anterior, se eligieron los cuestionarios como método de evaluación de la UX. Estos cuestionarios se diseñaron con la colaboración de la APKM antes de comenzar con la experimentación. Teniendo en cuenta los problemas de atención que presenta el colectivo de las personas con EP, fue un requisito muy importante de diseño que no llevara más de diez minutos el completar cada cuestionario. Además, también se consideró la importancia de utilizar texto para las respuestas apoyado por imágenes debido a la utilidad de la iconografía en las personas con deterioro cognitivo. Los cuestionarios finalmente generados se presentan en el Anexo III. Cuestionarios para la evaluación.

\subsection{Proceso de experimentación}

\subsubsection{Descripción de los pasos seguidos}

Se ha diseñado, realizado y evaluado un experimento para comprobar el grado de satisfacción de los usuarios cuando utilizan las TIC en el entorno de las TEC para personas con EP.

También se ha pretendido apreciar la curva de aprendizaje del uso de la aplicación por parte de los pacientes.

La experimentación se ha llevado a cabo en varias fases:

1) Planteamiento del experimento.

a) Definición de los perfiles de usuario que debían escogerse para llevar a cabo el experimento.

b) Diseño del experimento.

c) Descripción del método de evaluación de la experiencia de usuario. 
2) Realización del experimento.

a) Selección de la muestra final de usuarios.

b) Realización del experimento en tres asociaciones. El primer piloto se llevó a cabo a pequeña escala para evaluar las primeras impresiones sobre la plataforma implementada. Las asociaciones participantes fueron Madrid por su participación durante el diseño y Extremadura y Cataluña por el alto interés inicial que mostraron para incluir tecnología en las TEC.

c) Si los resultados eran positivos, realización del mismo experimento en otras tres asociaciones más. En el caso contrario, si el problema de aceptación en estas tres era relativo a la tecnología seleccionada, se adaptaría la solución en otro entorno tecnológico. En el caso de que el problema fuera relativo a la TEC, se redefinirían los parámetros de la misma con la colaboración de más asociaciones durante el proceso de diseño.

d) Obtención de los resultados mediante el método de evaluación.

3) Extracción de resultados y análisis de los mismos.

En este apartado únicamente se describirá el experimento realizado y no nos centraremos en los resultados obtenidos tras llevarlo a cabo. Estos resultados se detallarán en el apartado siguiente.

Una vez se finalizaba cada fase, se llevaba a cabo un análisis del proceso realizado para comprobar que se cumplía fielmente a la especificación inicial del experimento. Este análisis se realizó de forma conjunta con la APKM y con la Federación Española de Parkinson por su conocimiento de las labores realizadas en T>SIC en el ámbito de las TIC aplicadas a la EP y por la colaboración con la doctoranda en otros proyectos de investigación.

\subsubsection{Planteamiento del experimento}

Como se ha detallado anteriormente, esta fase se divide en otras tres: definición de los perfiles de usuario, diseño del experimento y descripción del método de evaluación.

\subsubsection{Requisitos de la muestra de usuarios}

Con el fin de llevar a cabo el experimento, ha sido necesario definir una serie de requisitos que deben cumplir los usuarios. Para ello, se han definido dos perfiles de usuario:

- Pacientes, que realizarán terapias de estimulación cognitiva.

- Terapeutas, que supervisarán esas terapias.

\section{(a) Requisitos de los pacientes}

Los perfiles de los pacientes debían cumplir los requisitos presentados a continuación:

- Deterioro cognitivo asociado a EP preservado, leve, leve-moderado, moderado, moderado-grave.

- Paridad entre hombres y mujeres. 
- Mayor rango de edad posible.

- Poco o ningún acercamiento a las TIC.

- Se pretendía que en el experimento participaran entre ocho y diez pacientes por asociación.

Dentro de cada asociación, los terapeutas llevaban a cabo la selección de pacientes. Los parámetros de inclusión de pacientes en esta experimentación fueron los que se han presentado en la lista previa. En el caso de que hubiera demasiados pacientes para colaborar en esta experimentación, los terapeutas de cada asociación fueron los que decidieron cuáles se excluían según sus criterios.

\section{(b) Requisitos de los terapeutas}

Los requisitos definidos para la selección de terapeutas fueron los siguientes:

- Especialistas en terapias de estimulación cognitiva asociada a EP.

- Perfiles: logopedas, trabajadores sociales, psicólogos.

- Se buscó que los terapeutas seleccionados fueran los que normalmente realizan las terapias de estimulación cognitiva en las asociaciones.

\subsubsection{Diseño del experimento}

El experimento se llevó a cabo durante tres semanas con cada paciente, realizando una sesión de estimulación cognitiva por semana. Estas sesiones se realizaban en las asociaciones sin que hubiera ningún agente externo para asegurar que el paciente estaba lo más cómodo posible.

Estas sesiones estaban compuestas por el inicio de la aplicación en la tableta, identificación del usuario y realización de bloques de ejercicios de estimulación cognitiva. Previamente a la realización del experimento, los pacientes no habían interactuado con la aplicación, por lo que la primera sesión fue su primer contacto con ella.

Las sesiones se configuraron de la siguiente manera:

1) En la primera sesión, el terapeuta explicaba al paciente el funcionamiento de la aplicación. Además, le guiaba según iba avanzando y estaba presente durante todo el proceso. Una vez que el paciente finalizaba un bloque de ejercicios de estimulación cognitiva, el terapeuta definía el siguiente a realizar y, si aún no se había agotado el tiempo de la sesión, el paciente lo comenzaba.

2) En la segunda sesión, el terapeuta no guiaba al paciente, pero se encontraba en la sala para ayudarle en caso de que fuera necesario y para definir el nuevo bloque de ejercicios a ejecutar en el caso de que sobrara tiempo.

3) En la tercera sesión, el paciente realizaba la terapia sin ninguna ayuda del terapeuta. El paciente debía avisar al terapeuta en el caso de que hubiera finalizado el bloque de ejercicios que se le había asignado.

En total, cada sesión no podía ocuparle al paciente más de 20 minutos para que no aparecieran problemas de atención asociados a la EP. Por ello, según el perfil del paciente, se podían realizar más o menos bloques de ejercicios, pero se aseguraba que, al menos el paciente hubiera 
completado uno. Como se definió en el Capítulo 5. Materiales y métodos, cada bloque consta como máximo de 9 ejercicios y no se utilizó ningún ejercicio cuyo tiempo máximo de realización fuera superior a 2 minutos, por lo que, el tiempo máximo para finalizar un bloque fue de 18 minutos.

Una vez finalizada cada sesión de las descritas en el apartado anterior, se entregaba un cuestionario al paciente en el que se pretendía obtener su grado de satisfacción. De esta forma, no se intervenía en la terapia, sino que, una vez finalizada cada sesión, el paciente rellenaba el cuestionario según su percepción global. El terapeuta únicamente completaba el cuestionario al final de la tercera sesión con ese paciente.

Se diseñaron dos tipos de cuestionarios, uno orientado al paciente y otro orientado al terapeuta. En ambos casos, se definió un número máximo de 10 preguntas expresadas en un lenguaje claro para que no hubiera lugar a error y evitar pérdidas de atención por parte de los pacientes. Finalmente, el cuestionario para los pacientes constó de 7 preguntas y el de los terapeutas, de 9 preguntas.

Estos cuestionarios se presentan el en Anexo III. Cuestionarios para la evaluación.

\subsection{Realización del experimento}

Una vez planteado el experimento, se procedió a llevarlo a cabo en un entorno real. La realización del experimento se desglosó en selección de la muestra final de usuarios y se llevaron a cabo dos pilotos: uno en 3 asociaciones y otro, tras el análisis de los resultados y la extracción positiva de resultados, en otras 3 asociaciones. En este apartado se detalla la muestra final de usuarios.

\subsubsection{Distribución de las asociaciones participantes en el experimento}

Para la selección de las asociaciones, aunque en la metodología que se planteaba utilizar el experimento no estaba contemplado, se decidió incluir criterios de diversidad geográfica. Para ello, se han seleccionado seis asociaciones en las que se contemplan zonas tradicionalmente rurales y zonas urbanas, así como distribución entre norte y sur.

En la Figura 78 se presenta esta distribución geográfica entre las provincias a las que pertenecían las asociaciones participantes.

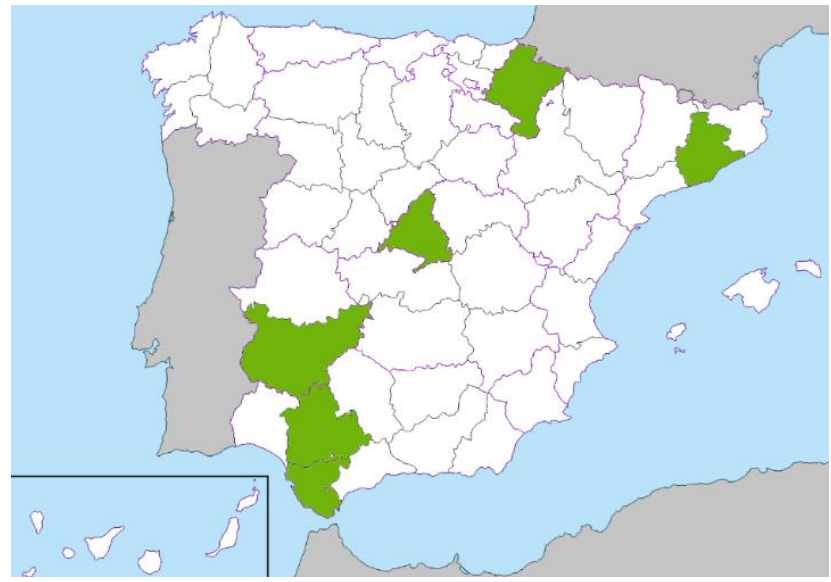

Figura 78. Regiones de las asociaciones de EP que han participado en el experimento 
Las asociaciones de la figura anterior, según su distribución de norte a sur y de oeste a este, son las siguientes:

- Asociación Navarra de Parkinson, con sede en Pamplona.

- Associació Catalana per al Parkinson, con sede en Barcelona.

- Asociación Parkinson Madrid, con sede en Madrid.

- Asociación Regional Parkinson Extremadura, con sede en Mérida (Badajoz).

- Asociación de Parkinson de Sevilla, con sede en Sevilla.

- Asociación Parkinson Bahía de Cádiz, con sede en San Fernando (Cádiz).

A la hora de presentar los resultados, se han organizado las asociaciones de Parkinson por el orden en el que se ha llevado a cabo la experimentación y se denominan en las tablas y gráficos por el nombre de la región a la que dan servicio.

La Tabla 46 presenta el nombre que se utilizará en esta memoria para denominar a cada asociación, logo, denominación completa y URL y la fecha en la que se realizó la experimentación. Se presentan en el orden en el que se llevó a cabo esta experimentación.

Tabla 46. Denominación de asociaciones y fecha de experimentación

\begin{tabular}{|c|c|c|c|}
\hline Nombre & Logo & Denominación completa y URL & Fecha \\
\hline Madrid & Parociacion & $\begin{array}{l}\text { Asociación Parkinson Madrid } \\
\text { http://www.parkinsonmadrid.org/ }\end{array}$ & Junio, 2014 \\
\hline Extremadura & $\begin{array}{l}\text { ASOCIACION } \\
\text { REGIONAL } \\
\text { PARIINSON }\end{array}$ & $\begin{array}{l}\text { Asociación Regional Parkinson Extremadura } \\
\text { http://www.parkinsonextremadura.org/ }\end{array}$ & Julio, 2014 \\
\hline Cataluña & & $\begin{array}{l}\text { Associació Catalana per al Parkinson } \\
\text { http://www.catparkinson.org/ }\end{array}$ & Julio, 2014 \\
\hline Cádiz & & $\begin{array}{l}\text { Asociación Parkinson Bahía de Cádiz } \\
\text { http://parkinsonbahiadecadiz.org/ }\end{array}$ & Septiembre, 2014 \\
\hline Navarra & & $\begin{array}{l}\text { Asociación Navarra de Parkinson } \\
\text { http://www.anapar.org/ }\end{array}$ & Septiembre, 2014 \\
\hline Sevilla & & $\begin{array}{l}\text { Asociación de Parkinson de Sevilla } \\
\text { http://www.parkinsonsevilla.org/ }\end{array}$ & Septiembre, 2014 \\
\hline
\end{tabular}

\subsubsection{Muestra de pacientes}

En este apartado se describe la muestra final de pacientes que han participado en el experimento. A continuación, en la Tabla 47 se presenta un resumen de los pacientes participantes en cada asociación. 
Tabla 47. Resumen de pacientes participantes

\begin{tabular}{|l|l|l|l|l|l|l|l|}
\hline Asociación & № pacientes & № hombres & \multicolumn{2}{l}{ № mujeres } & \multicolumn{2}{l|}{ Edad mín. } & \multicolumn{2}{l|}{ Edad máx. } & Edad prom. \\
\hline Madrid & 10 & 4 & 6 & 60 & 78 & 70,60 \\
\hline Extremadura & 8 & 6 & 2 & 59 & 75 & 68,63 \\
\hline Cataluña & 8 & 6 & 2 & 52 & 80 & 68,75 \\
\hline Cádiz & 8 & 6 & 2 & 63 & 87 & 76,50 \\
\hline Navarra & 4 & 2 & 2 & 70 & 87 & 78,75 \\
\hline Sevilla & 7 & 3 & 4 & 60 & 84 & 74,00 \\
\hline Total & 45 & 27 & 18 & 52 & 87 & 72,22 \\
\hline
\end{tabular}

Para cada paciente, los terapeutas que participaron en el experimento rellenaron una ficha donde se recogían los siguientes datos:

- Edad.

- Sexo.

- Estadio: fase de evolución de la EP.

- Estado cognitivo: leve, leve-moderado, moderado, moderado-grave, grave.

- Experiencia TIC: se entiende por experiencia TIC el uso de teléfonos móviles o la interacción con un PC a nivel usuario.

Pese a que inicialmente se planteó que en la experimentación debían participar entre ocho y diez pacientes por asociación, por motivos ajenos a esta investigación en la asociación de Sevilla uno de los pacientes tuvo que dejar el experimento y en la asociación de Navarra únicamente pudieron participar 4 pacientes.

\subsubsection{Muestra de terapeutas}

La muestra de terapeutas fue coherente con los requisitos presentados inicialmente. Todos los terapeutas seleccionados fueron los que realizaban a diario terapias de estimulación cognitiva con los pacientes de forma tradicional. Es por ello, que todos disponían de una amplia experiencia en el seguimiento del deterioro cognitivo en personas con EP.

En cuanto a su formación, la mayoría eran trabajadores sociales y, en menor porcentaje, logopedas y psicólogos.

\subsection{Experimentación adicional en domicilio}

Debido al gran éxito en la aceptación de la plataforma, se llevaron a cabo experimentos de pacientes en domicilio adscritos a cinco de las asociaciones participantes en los experimentos anteriores. A estos pacientes se les entregó una tableta con la aplicación instalada y una tarjeta SIM 4G por cortesía de la Fundación Vodafone España.

Los requisitos definidos para los pacientes que debían realizar la terapia desde su domicilio fueron los mismos que para los pacientes en asociación. 
Con respecto a los terapeutas, la dinámica no fue la misma que en las asociaciones. Tradicionalmente, los terapeutas que suelen desplazarse a los domicilios de los pacientes son fisioterapeutas. Estos fisioterapeutas fueron formados por los terapeutas que participaron en la experimentación en las asociaciones para que pudieran llevar a cabo la experimentación en domicilio.

\subsection{Resultados de los experimentos}

Los resultados completos de los cuestionarios tras la experimentación en asociaciones se recogen en el Anexo IV. Datos de los cuestionarios. Experimentación en las asociaciones y los obtenidos en la experimentación en domicilio en el Anexo V. Datos de los cuestionarios. Experimentación en domicilio. En este apartado se presentarán las observaciones y mejoras que han añadido en los cuestionarios tanto los pacientes como los terapeutas que han participado en la experimentación.

\subsubsection{Adaptación de los resultados de los cuestionarios}

Como se ha presentado en apartados previos, los cuestionarios diseñados y utilizados para la experimentación se encuentran recogidos en el Anexo III. Cuestionarios para la evaluación. Como recordatorio, las preguntas que contienen son las siguientes:

\section{Cuestionarios para los pacientes:}

1) Puedo realizar fácilmente la estimulación cognitiva utilizando la tableta.

2) Me parece divertido hacer los ejercicios y la terapia de esta manera.

3) He aprendido rápido a realizar la estimulación cognitiva con la tableta.

4) No he tenido ningún problema para utilizar la aplicación con ayuda del terapeuta (2 y 3 응 sin ayuda del terapeuta).

5) Me motiva el poder ver la valoración realizada por el terapeuta para corregir mis resultados.

6) En general, me gusta realizar la estimulación cognitiva con la tableta.

7) Si pudiera, realizaría la terapia en casa con este sistema.

\section{Cuestionarios para los terapeutas:}

1) Creo que a los pacientes les gusta realizar la terapia con la tableta.

2) Creo que el paciente puede usar la tableta él solo.

3) La aplicación web que uso para adaptar los ejercicios y valorar a los pacientes es sencilla de usar y completa en relación con las funciones que ofrece.

4) Veo útil poder consultar la información de los ejercicios a través de la web.

5) Creo que es sencillo añadir nuevos ejercicios a los bloques.

6) Los ejercicios se adecúan a los requisitos de un paciente de Parkinson.

7) Considero que la forma de consultar los resultados de los pacientes es apropiada. 
8) El realizar la terapia de esta forma no me quita más tiempo que de la forma tradicional.

9) Creo que sería útil para los pacientes que también pudieran realizar la terapia desde sus casas utilizando este sistema.

Para presentar los resultados, se ha optado por dar una puntuación numérica a cada posible respuesta de los cuestionarios, tanto de los pacientes como de los terapeutas. De esta forma, se ha conseguido ponderar las medias de los resultados y obtener unos resultados mucho más visibles para poder proceder a su análisis. A cada respuesta se le asigna un número entero decreciente entre 5 y 1 según disminuye el nivel de aceptación del servicio. Los valores de cada respuesta y la abreviatura con la que se presentan en las relaciones de resultados se muestran en la Tabla 48.

Tabla 48. Puntuaciones y abreviatura de cada respuesta a los cuestionarios

\begin{tabular}{|l|r|r|}
\hline Respuesta & Abreviatura & Puntuación \\
\hline Totalmente de acuerdo & TA & 5 puntos \\
\hline De acuerdo & A & 4 puntos \\
\hline Indiferente & I & 3 puntos \\
\hline En desacuerdo & D & 2 puntos \\
\hline Totalmente en desacuerdo & TD & 1 punto \\
\hline
\end{tabular}

\subsubsection{Observaciones de pacientes y terapeutas}

En este apartado se desglosan las observaciones y mejoras de pacientes y terapeutas durante los experimentos, agrupados por asociación.

\subsubsection{Asociación Parkinson Madrid}

Los resultados globales de todos los pacientes para cada pregunta y sesión de la experimentación en la APKM se presentan en la Figura 79.

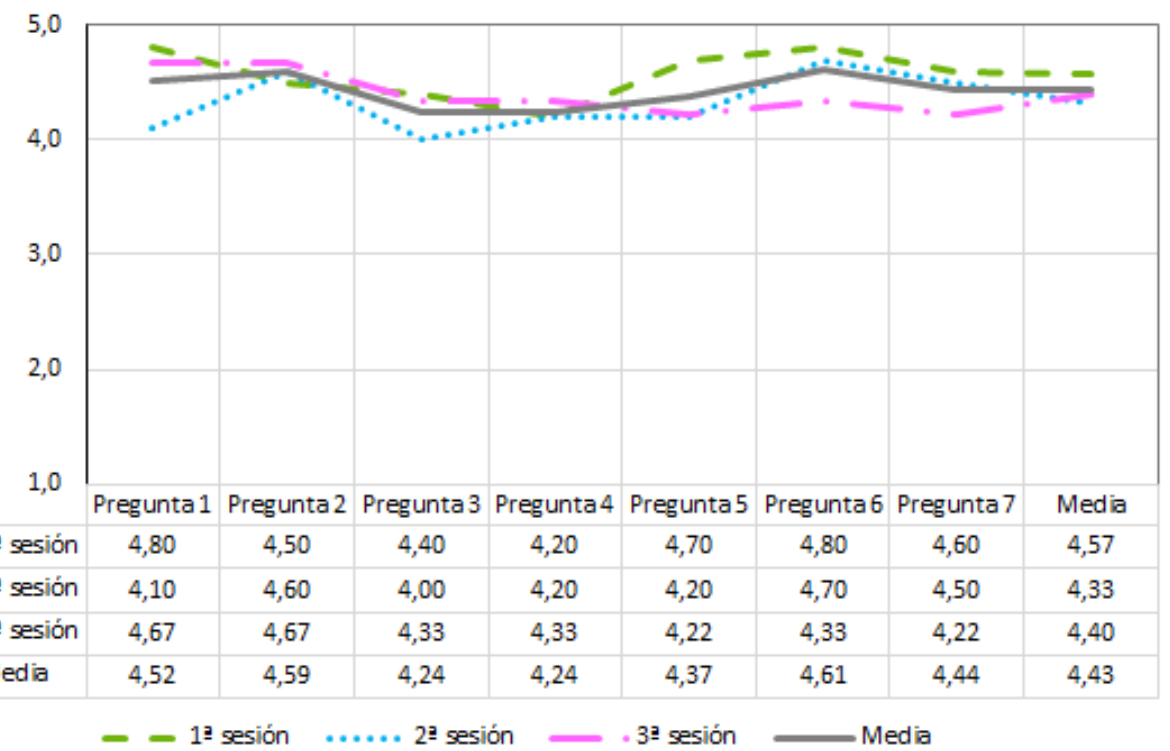

Figura 79. Madrid. Resultados globales de la experimentación en la asociación 
Con respecto a la facilidad de uso, los pacientes destacan que es muy útil para pensar, aunque uno de ellos (Paciente 7) indica que necesita ayuda para realizar los ejercicios. En este ámbito, los terapeutas subrayan los valores positivos que se han obtenido.

Con respecto a si a los pacientes les parece divertido la realización de la terapia de esta forma, los terapeutas destacan que se añade un valor añadido de entusiasmo y no disminuye a lo largo de las sesiones.

Con respecto a la facilidad de aprendizaje, los terapeutas acentúan que todos los pacientes han aprendido rápido a utilizar la aplicación.

Con respecto a los problemas en la utilización, todos los pacientes destacan la sencillez excepto uno (Paciente 7), al que le costó aprender. Los terapeutas resaltan que es una herramienta de fácil manejo para su uso en el hogar de forma autónoma.

Con respecto a la posibilidad de visualización de la valoración introducida por el terapeuta, todos los pacientes han valorado muy positivamente el poder recibir esta realimentación.

Con respecto a si a los pacientes les gusta la realización de las terapias de esta forma, los terapeutas indican que todos los pacientes han valorado positivamente la rehabilitación utilizando la herramienta. Algo mejor en la primera sesión, quizá por el impacto de la novedad.

Por último, con respecto a la utilización en domicilio, existe una persona que prefiere llevar a cabo las sesiones de TEC en el centro, pero en general están más que dispuestos a usarlo en casa.

Sobre el cuestionario entregado a las terapeutas, se han obtenido valoraciones altamente positivas sin ningún tipo de duda. Se podría decir que, a medida que las terapeutas utilizan la aplicación y la herramienta se sienten más cómodas.

A la hora de la valoración en domicilio, su valoración también ha sido muy positiva y no han encontrado dificultades. Reclaman que sea un complemento o apoyo, pero no un sustitutivo de la terapia porque para eso es incompleto. Para los pacientes en domicilio también es importante que sea un complemento, lo ven como un valor añadido a las sesiones, sobre todo cuando no pueden acudir a ellas.

\subsubsection{Asociación Regional Parkinson Extremadura}

En esta asociación las terapeutas destacan que los resultados del Paciente 2 están marcados por el estado emocional del paciente, ya que es un estado fluctuante y sufre de apatía.

Las terapeutas de esta asociación concluyen en que creen que sería beneficioso para personas con EP, ya que califican los experimentos como una experiencia positiva. Los pacientes prefieren realizar los ejercicios en la tableta de forma habitual para, de esta forma, no tienen que preocuparse por la ortografía ni por la caligrafía. Además, las terapeutas de Extremadura han confirmado que los pacientes se concentran mejor utilizando la tableta que de la forma tradicional.

Los pacientes, gracias a la personalización de las terapias, aprecian que los ejercicios estén diseñados expresamente para ellos y realizan los ejercicios de forma más rápida que la habitual. 
Las terapeutas destacan que la mitad de los pacientes se han interesado en el hecho de poder realizar las TEC en casa con la supervisión remota de las terapeutas. Consideran que esta plataforma puede tener una repercusión positiva en la mejora de la calidad de vida de los usuarios, considerando esta experiencia altamente innovadora. Consideran que la implantación de esta terapia como alternativa a la terapia convencional de estimulación cognitiva supondría además de significativas mejoras en los usuarios, también trascendentes avances para los terapeutas, ya que les aportaría un importante ahorro de tiempo y de material. Por último, subrayan que la opción de que los pacientes puedan llevar a cabo las TEC en casa realizándoles el seguimiento remoto implica una mejora en la calidad de los servicios asistenciales prestados por la asociación.

Los resultados globales de todos los pacientes para cada pregunta y sesión de la experimentación en Extremadura se presentan en la Figura 80.

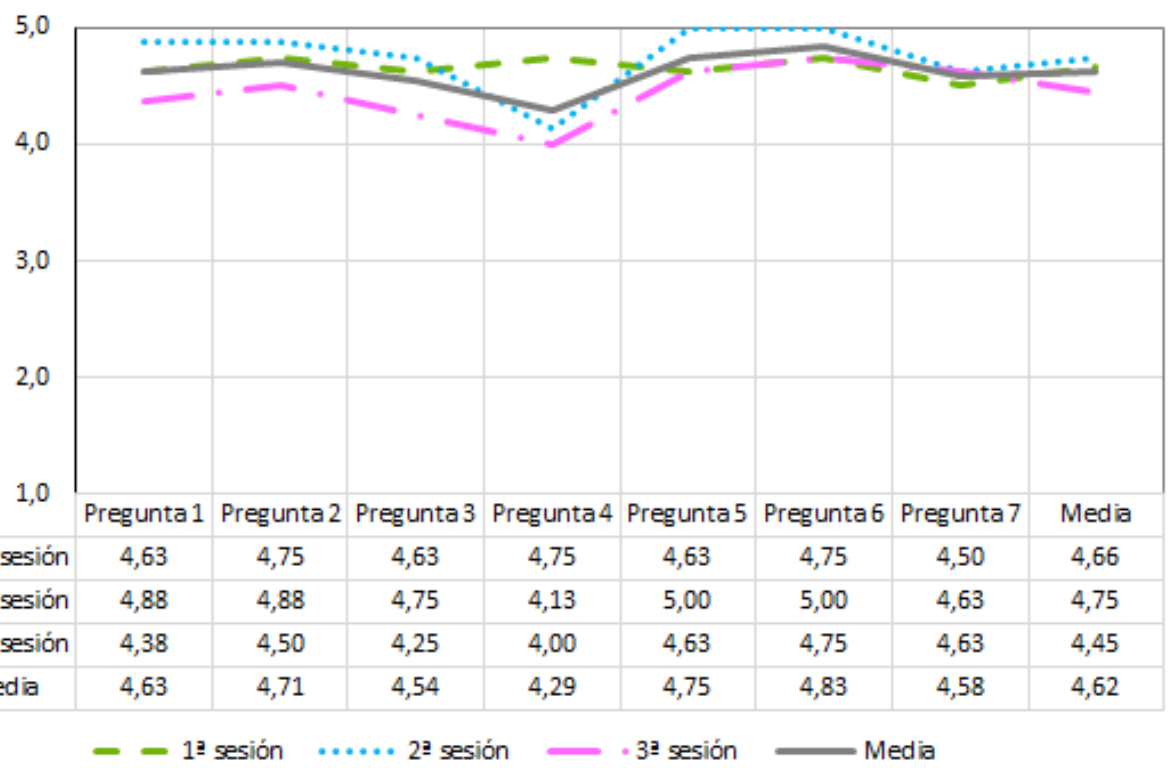

Figura 80. Extremadura. Resultados globales de la experimentación en la asociación

\subsubsection{Associació Catalana per al Parkinson}

Con respecto a la facilidad de realización de los ejercicios, los pacientes han indicado que les parece fácil, aunque los terapeutas destacan que han tenido problemas. Los terapeutas recalcan que a los pacientes les ha gustado mucho el utilizar las nuevas tecnologías para llevar a cabo las TEC, aunque eran los que no tenían demencia los que respondían mejor a la aplicación del paciente. Los pacientes con demencia, la mayoría en estado grave de deterioro cognitivo, tenían dificultades para entrar en la aplicación, aunque luego se desenvolvían bien con ella. Todos los pacientes destacan que valoran positivamente el poder consultar la valoración introducida por el terapeuta a la vista de los resultados.

Por otro lado, para los pacientes ha sido muy satisfactorio el realizar las TEC a través de esta plataforma, muchos de ellos preguntaron si lo podían seguir haciendo de esta forma. Debido a ello, todos coinciden en que les gustaría poder utilizarlo en casa.

Los terapeutas en sus cuestionaros valoran muy positivamente la aplicación, apreciando la utilidad de poder utilizar una plataforma de este tipo para complementar las terapias realizadas 
en la asociación. Destacan que todos los pacientes consideran más divertido el trabajar así que con lápiz y papel. Además, al igual que pasaba con la asociación de Extremadura, tanto pacientes como terapeutas han percibido que utilizando la tableta se distraen menos que de la forma tradicional, mejorando su capacidad de atención sostenida.

Los resultados globales de todos los pacientes para cada pregunta y sesión de la experimentación en Cataluña se presentan en la Figura 81.

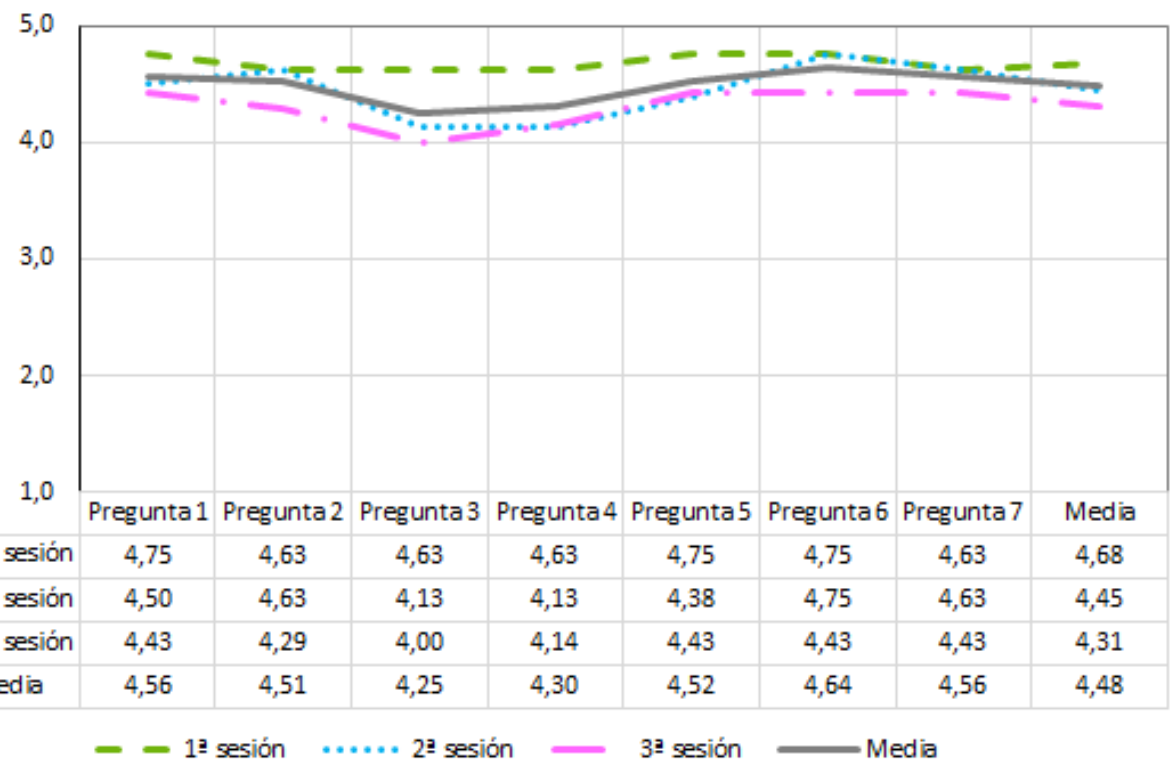

Figura 81. Cataluña. Resultados globales de la experimentación en la asociación

\subsubsection{Asociación Parkinson Bahía de Cádiz}

Los resultados globales de todos los pacientes para cada pregunta y sesión de la experimentación en Cádiz se presentan en la Figura 82.

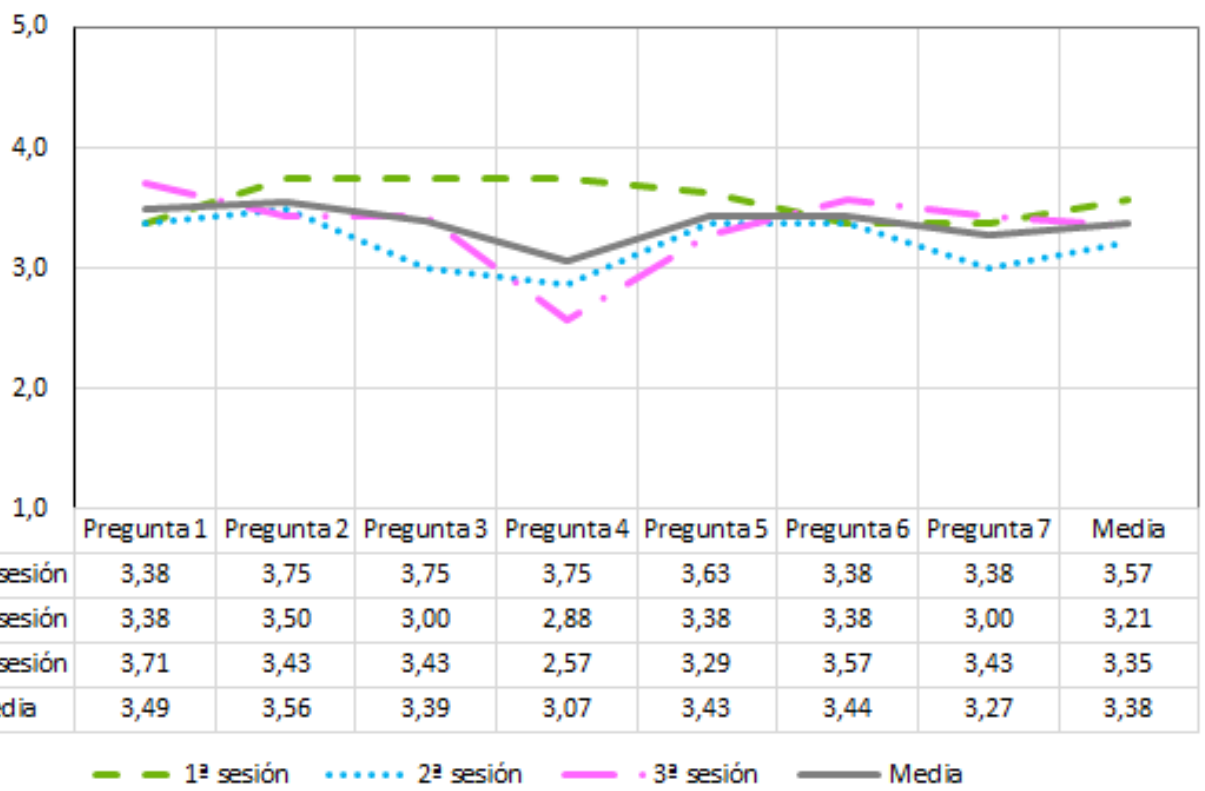

Figura 82. Cádiz. Resultados globales de la experimentación en la asociación 
Con respecto a la facilidad de uso, los terapeutas indican que, en líneas generales, los afectados manifiestan su convicción personal acerca de su capacidad para realizar por ellos mismos la actividad, si bien en la práctica pensamos que no todos ellos serían capaces de realizarlo sin algún tipo de supervisión, al menos en las primeras sesiones, ya que tienen que familiarizarse con la aplicación y la forma de tocar en la pantalla a la hora de emitir su respuesta, ya que se producen errores en las pulsaciones por diversos motivos (coordinación, impulsividad y tiempo de latencia entre respuestas, entre otros).

Con respecto a si les parece divertido el llevar a cabo las TEC de esta forma, salvo a los afectados que tienen mayor problema de movilidad y además tienen reducida en parte la capacidad visual, el agrado por los nuevos ejercicios, su presentación, y forma de realización les resulta interesante y atractivo.

Con respecto a la facilidad de aprendizaje, las terapeutas destacan que el aprendizaje en el manejo de la tableta va directamente relacionado con el nivel de deterioro cognitivo, aunque la mayoría sí que lo han aprendido con facilidad.

Por otro lado, el grado de aceptación de esta nueva modalidad de terapia ha sido bien recibida por los afectados que han participado en ella, pareciéndoles largo el periodo entre sesiones de prueba, y mostrando interés en el cuándo y cómo se va a materializar finalmente este recurso, sobre todo de cara a su aplicación en el domicilio en periodos en los que no asisten al centro. Los terapeutas recalcan que no todos los pacientes que han mostrado interés por este tipo de terapia estarían en condiciones de realizarla sin ayuda o supervisión.

Los terapeutas se declaran incapaces de valorar las preguntas 3 y 4 , relativas a las acciones recogidas en su portal web y la inserción de nuevos ejercicios respectivamente, ya que consideran que necesitarían más tiempo que el destinado a los pilotos para hacer pruebas en este entorno.

Por último, tanto pacientes como terapeutas dan una valoración positiva a las TEC a través de la tableta, ya que es una forma nueva, atractiva y amena de realizarla, resultando muy estimulante para los afectados y motivadora por el hecho de saber que su trabajo va a ser revisado y reforzado rápidamente.

\subsubsection{Asociación Navarra de Parkinson}

En esta asociación, los pacientes que han participado estaban dentro del grupo de personas con deterioro cognitivo moderado o grave. Los terapeutas destacan que, para aplicar esta plataforma a personas con este deterioro, el diseño debería ser menos monótono, ya que en estos estadios necesitan mucha estimulación visual. Destacan que a la mayoría de los pacientes les ha gustado utilizar la tableta para las TEC porque es una manera nueva y poco conocida por ellos de llevar a cabo su intervención. Consideran que la mayoría de los pacientes seleccionados para la experimentación son capaces de llevar a cabo la tarea solos siempre y cuando tengan la supervisión del terapeuta. Aun así, los terapeutas opinan que tendrían que utilizar la plataforma con pacientes en otros niveles de deterioro cognitivo para poder evaluarlo de forma más amplia.

Como conclusión, los terapeutas participantes subrayan que el programa y su planteamiento les parecen positivos y les gustan, opinando que este tipo de plataformas pueden enriquecer mucho la intervención que ellos llevan a cabo en la asociación. 
Los resultados globales de todos los pacientes para cada pregunta y sesión de la experimentación en Navarra se presentan en la Figura 83.

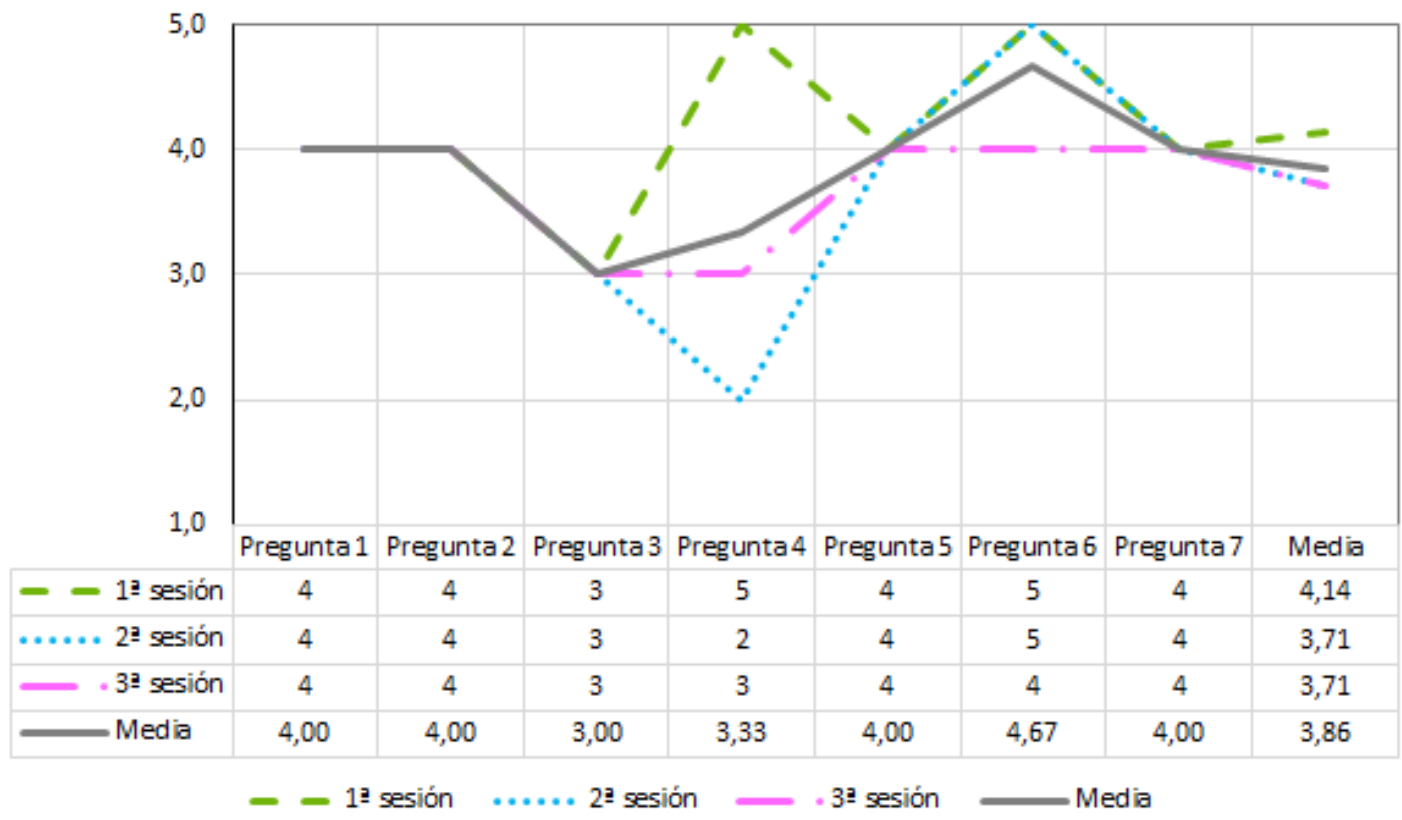

Figura 83. Navarra. Resultados globales de la experimentación en la asociación

\subsubsection{Asociación de Parkinson de Sevilla}

Los resultados globales de todos los pacientes para cada pregunta y sesión de la experimentación en Sevilla se presentan en la Figura 84.

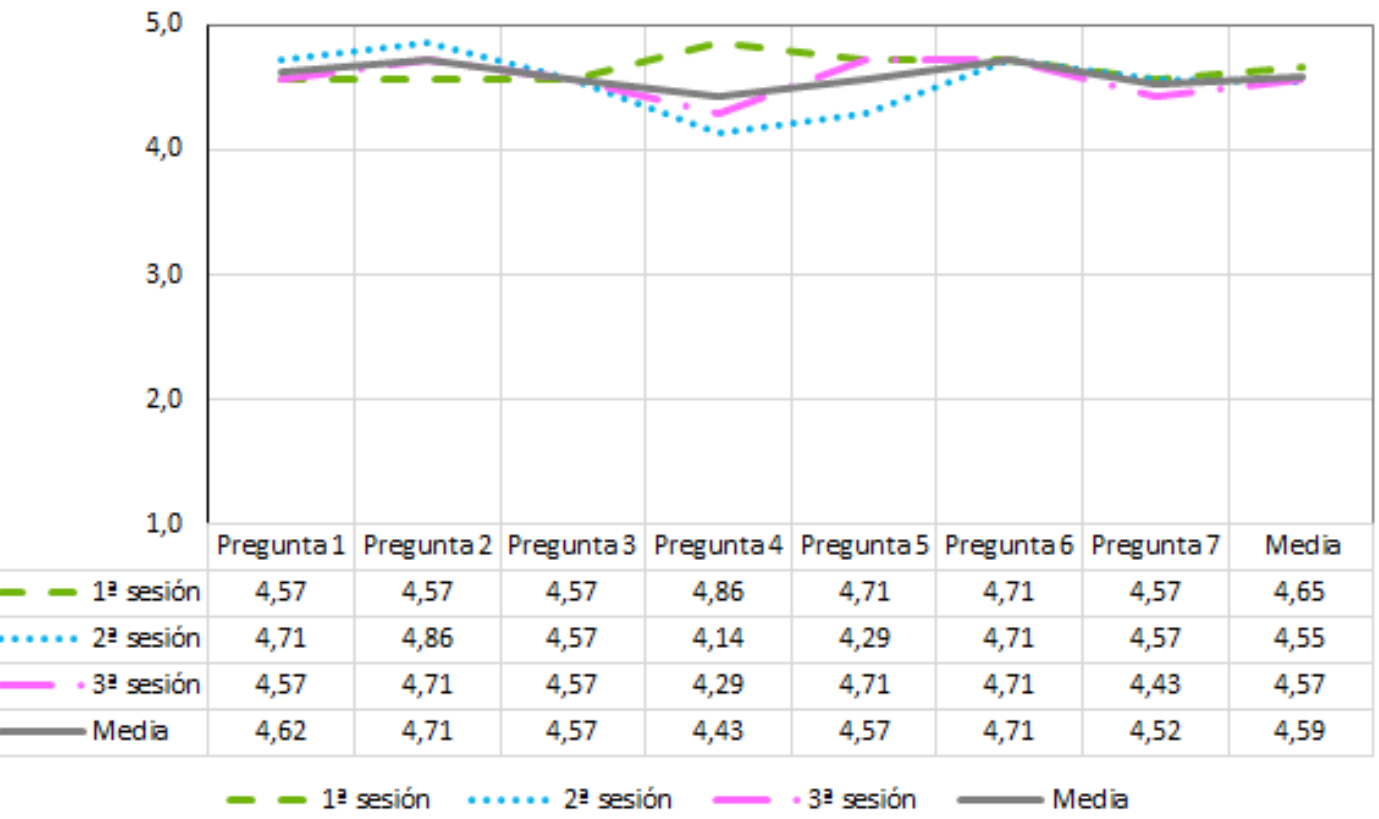

Figura 84. Sevilla. Resultados globales de la experimentación en la asociación

Con respecto a la facilidad de uso, los pacientes tenían la percepción de que podrían realizar las TEC con facilidad, pero, al no tener experiencia con las nuevas tecnologías, no presentaban soltura en su manejo. Los terapeutas destacan que los participantes que tienen más conservada 
la cognición presentaban más facilidad para recordar los pasos a seguir entre una sesión y la siguiente, pero los que ya presentaban un deterioro moderado-grave tenían más dificultad, sintiéndose menos seguros en los pasos a seguir, preguntando constantemente el procedimiento al terapeuta.

Con respecto a la motivación de poder consultar la valoración del terapeuta, los pacientes indicaron que sí les motivaba, pero se olvidaban de consultarlo entre una sesión y la siguiente.

Todos los pacientes estuvieron de acuerdo en que les gustaría llevar a cabo las TEC en casa a través de esta plataforma, ya que, según indican los terapeutas, todos estaban bastante motivados con la experimentación. Algunos pacientes sí comentaron que lo harían de forma complementaria a las sesiones presenciales en la asociación por la importancia que le dan al contacto directo, tanto con el terapeuta como con los compañeros de los grupos de terapia.

Los terapeutas destacan la motivación que supone el utilizar la tableta para las TEC, ya que muchos de los pacientes no habían tenido contacto con las nuevas tecnologías. Indican lo completa que es la aplicación y su sencillez de utilización al disponer de un diseño muy intuitivo. Recalcan que no han podido contestar a la Pregunta 5, relacionada con añadir nuevos ejercicios, porque no estaba contemplado dentro de los pilotos y no lo han realizado.

En esta asociación, los terapeutas están totalmente de acuerdo con que la aplicación trata los aspectos cognitivos presentados por una persona diagnosticada de EP. Consideran, además, que es mucho más rápido para ellos el hacer las terapias de esta forma, ya que el terapeuta no tiene que estar presente durante la realización de los ejercicios. También enfatizan en la utilidad de utilizar este tipo de terapias en domicilio.

Por último, ven muy buena la idea de la herramienta porque para los pacientes es una forma diferente y novedosa que les motiva a realizar los ejercicios. Con pacientes con capacidad para adquirir destreza en el manejo de la tableta ven viable su uso en domicilio. Sin embargo, en pacientes con menor conocimiento de nuevas tecnologías y mayor grado de deterioro cognitivo, consideran que deberían utilizar la aplicación con ayuda de un terapeuta.

\subsubsection{Análisis de resultados tras la experimentación}

En apartados anteriores se ha presentado un resumen de los resultados obtenidos que, tal y como se ha detallado, se encuentran presentados de forma mucho más amplia en Anexo IV. Datos de los cuestionarios. Experimentación en las asociaciones y Anexo V. Datos de los cuestionarios. Experimentación en domicilio. Previamente, también se ha mostrado la percepción y actitud que tienen tanto pacientes de EP como sus terapeutas tras la realización de los experimentos.

A partir de las observaciones de pacientes y terapeutas tras la experimentación presentadas en este capítulo se puede estimar la alta aceptación que ha tenido la implementación del modelo desplegado en esta tesis doctoral y las considerables mejoras que aparecen a la hora de introducir la tecnología en este contexto de uso. En todas las asociaciones han destacado la utilidad que puede tener una plataforma como la implementada a partir del modelo propuesto. Los pacientes han disfrutado de la realización de la TEC de una forma novedosa y no se ha apreciado la brecha digital, por lo que el diseño estaba muy adaptado a las necesidades de las personas con EP. Además, los terapeutas participantes en la experimentación han destacado la 
eficiencia del modelo en varios aspectos, principalmente en el ahorro de tiempo y en la gran cantidad de recursos disponibles para la personalización de las terapias.

La realización de la experimentación y la extracción de conclusiones a partir de ellas estaban reflejados en la fase 5 del proceso definido para corroborar las hipótesis, detallado en el apartado 2.3. Metodología para la validación de las hipótesis.

En el Capítulo 7. Discusión de los resultados experimentales, siguiente de esta tesis doctoral, nos centraremos en llevar a cabo un análisis mucho más amplio de los resultados obtenidos, presentando una discusión profunda sobre el alcance final de la experimentación, el análisis de los resultados anómalos y la preparación de las conclusiones finales alcanzadas tras la finalización de este trabajo de investigación. 


\title{
Capítulo 7. Discusión de los resultados experimentales
}

\author{
El séptimo capítulo de esta tesis doctoral se centra en la interpretación de los \\ resultados obtenidos en el capítulo previo, dándole sentido a los mismos. Además, \\ se comprobará la consecución de los objetivos planteados y de las hipótesis de \\ partida.
}

A lo largo de esta tesis doctoral se ha llevado a cabo la propuesta de un modelo para la realización de TEC de una forma ubicua, orientado a personas que sufren deterioro cognitivo debido a la EP. El fin perseguido es el de modernizar estas terapias desde distintos enfoques $y$ mejorar, así, la calidad asistencial prestada a los pacientes en este contexto de uso. Este modelo ha sido evaluado por los usuarios finales a los que iba destinado (pacientes y terapeutas) a través de una experimentación formal, para lo que ha sido necesario implementar una plataforma TIC a partir del modelo propuesto. Para la formulación de este modelo ha sido necesario un análisis en profundidad de las necesidades de las personas con EP y de las TEC que realizan de forma tradicional, destacando la importancia de las asociaciones de Parkinson en la administración de tratamientos no farmacológicos, entre los que se enmarca la estimulación cognitiva.

La principal motivación de la definición de este modelo ha sido el poder proporcionar nuevas herramientas a las personas con EP y a sus terapeutas, dando la posibilidad de incluir las TIC dentro de este tipo de terapias. Además, a través de la experimentación, se ha tratado de demostrar la mejora que este modelo puede suponer para ambos colectivos en los ámbitos de eficiencia en la realización de terapias, satisfacción en el uso y adherencia al tratamiento no farmacológico por parte de los pacientes con EP. Esto se encuentra recogido en los objetivos de este trabajo de investigación y en las hipótesis de partida concebidas, presentados en el Capítulo 2. Definición de hipótesis y objetivos.

En el transcurso de la memoria presentada se han ido describiendo los logros parciales, justificando por qué contribuyen a la consecución de los objetivos e hipótesis iniciales. Es por ello que este capítulo pretende recoger las aportaciones sustanciales de esta tesis doctoral al campo de las aplicaciones basadas en TIC aplicadas a personas con EP, principalmente en el ámbito de la estimulación cognitiva orientada a esta enfermedad. A partir de estas aportaciones se justificará el logro de los objetivos y, por tanto, la certificación de la validez de las hipótesis planteadas.

Como se ha descrito ampliamente en el Capítulo 3. Justificación y antecedentes, hay varios aspectos que hacen que la situación actual sea un momento idóneo para el planteamiento de este modelo. El primero de estos aspectos es que se ha constatado la importancia del movimiento asociativo en el entorno de la EP. Este movimiento ha permitido la creación de 
multitud de asociaciones orientadas al tratamiento y asesoramiento sobre esta enfermedad, ayudando tanto a familiares como a pacientes el asumir el diagnóstico y asesorándolos sobre cómo mantener durante más tiempo la calidad de vida de la persona diagnosticada.

El segundo aspecto es que se han demostrado las ventajas terapéuticas que tiene la estimulación cognitiva para personas que presentan deficiencias en su cognición. El mantenimiento durante más tiempo de las capacidades cognitivas es el beneficio más importante que se deriva de la implantación de este tipo de terapias. Esto hace que la calidad de vida del paciente permanezca estable durante un periodo más largo. Además, debido a que cuando acuden a las asociaciones de Parkinson a realizar la terapia interactúan con terapeutas y otras personas con EP, estas terapias ayudan a evitar el aislamiento que sufren estos pacientes.

En este capítulo también se ha hecho un estudio del contexto tecnológico actual. Gracias a la penetración de tecnologías móviles se ha creado una economía de escala para dispositivos conectados, lo que ha aumentado la interoperabilidad entre ellos. Por ejemplo, ya se pueden encontrar teléfonos inteligentes, tabletas y televisiones con sistema operativo Android en el mercado. Esta economía de escala ha derivado también en la disminución de los costes de fabricación de este tipo de dispositivos, abaratando, a su vez, el coste para el consumidor final. Como consecuencia de esta situación y de la capacidad de alcance de un público tan amplio, cada vez son más las aplicaciones disponibles en todos los ámbitos, como pueden ser entretenimiento, educación, finanzas o salud, entre otros. Esto hace que pueda crecer también el número de aplicaciones terapéuticas.

Por otro lado, cada vez se tiende más a la personalización de la medicina a cada paciente. Hay diversas iniciativas que promueven este tipo de asignación de tratamientos, donde es tan importante el diagnóstico como las circunstancias de la persona que lo va a recibir. El avance en el campo de las TIC hace que la asignación de tratamientos esté más adecuada al paciente, ya que, en el caso de terapias farmacológicas, se pueden diseñar algoritmos de inteligencia artificial basados en aprendizaje automático que permitan el modelado más claro de los perfiles de los pacientes. Asimismo, las TIC son muy ventajosas si se aplican a terapias no farmacológicas, ya que aportan un carácter dinámico que no existe en el caso de la asignación de estas terapias de la forma tradicional. En el caso particular de este trabajo de investigación, la introducción de las TIC ha permitido que los terapeutas tengan a su disposición muchos más recursos, gracias a la compartición de ejercicios y bloques de ejercicios entre todas las asociaciones participantes. La consecuencia directa de este incremento de los recursos es que se puede personalizar con menos esfuerzo la terapia para cada paciente, ya que se pueden aprovechar ejercicios y bloques de ejercicios creados en otra asociación distinta.

Para la definición del modelo que verifique las hipótesis, se han analizado las TEC que llevan a cabo las asociaciones de Parkinson de la manera tradicional a través del análisis de cuadernos de ejercicios [APKM, 2007], del estudio de la bibliografía existente específica para estimulación cognitiva de personas con EP y del contacto directo con los terapeutas de la APKM. A partir de este estudio se han extraído los parámetros que definen la TEC (Capítulo 4. Determinación de requisitos de la Terapia de Estimulación Cognitiva para la enfermedad de Parkinson (EP)). Estos parámetros son los requisitos funcionales y no funcionales que se recogieron junto con pacientes y terapeutas. 
Las principales aportaciones se centran en la importancia de dos conceptos: la personalización de la terapia para cada paciente y la capacidad de realimentación por el terapeuta. Además, se han añadido otros aspectos relevantes, como pueden ser la accesibilidad y la usabilidad, la compartición de recursos y la seguridad en un entorno en el que se comparte información sensible.

A modo de resumen, la Tabla 49 presenta todos los requisitos recogidos para la TEC, así como la relevancia de cada uno de ellos en el modelo planteado y su posibilidad de extrapolar estos parámetros a deterioros cognitivos debidos a otras patologías.

Tabla 49. Resumen de requisitos para la TEC

\begin{tabular}{|c|c|c|}
\hline Requisito & Relevancia* & Extrapolable \\
\hline Terapias disponibles en cualquier momento y lugar & $\bullet \bullet$ & Sí \\
\hline $\begin{array}{l}\text { Generación dinámica de los ejercicios para que los } \\
\text { puedan añadir personas no familiarizadas con las TIC }\end{array}$ & $\bullet \bullet$ & Sí \\
\hline Seguimiento por el terapeuta & $\bullet \bullet \bullet$ & $\begin{array}{l}\text { Depende de la importancia } \\
\text { del equipo terapéutico para } \\
\text { el paciente }\end{array}$ \\
\hline Realimentación al paciente por parte del terapeuta & $\bullet \bullet \bullet$ & $\begin{array}{l}\text { Depende de la importancia } \\
\text { del seguimiento }\end{array}$ \\
\hline Personalización de la terapia para cada paciente & $\bullet \bullet$ & $\begin{array}{l}\text { Puede ser complejo si se } \\
\text { utilizan imágenes específicas } \\
\text { para los ejercicios de cada } \\
\text { paciente (por ejemplo, fotos } \\
\text { de sus familiares) }\end{array}$ \\
\hline $\begin{array}{l}\text { Compartición de recursos (ejercicios y bloques de } \\
\text { ejercicios) entre asociaciones }\end{array}$ & $\bullet \bullet$ & Sí \\
\hline Interfaces accesibles & $\bullet \bullet \bullet$ & Sí \\
\hline $\begin{array}{l}\text { Cumplimiento de la legislación sobre protección de } \\
\text { datos de carácter personal }\end{array}$ & $\bullet \bullet \bullet$ & Sí \\
\hline $\begin{array}{ll}\text { Escala de relevancia: } & \bullet \text { Poco relevante. } \\
& \bullet \text { Relevante. } \\
& \bullet \bullet \bullet \text { Imprescindible. }\end{array}$ & & \\
\hline
\end{tabular}

A la vista de la Tabla 49 se aprecia que ninguno de los requisitos recogidos está categorizado como "poco relevante". Esto es debido a que, gracias al contacto con los profesionales durante todas las fases de diseño, desarrollo y evaluación, los requisitos de la TEC están muy adaptados a las necesidades de una persona con EP.

Por otro lado, para la definición del modelo también definimos como imprescindible el análisis de las necesidades de una persona con EP cuando se enfrenta a un entorno TIC. Los datos se encuentran recogidos en los requisitos funcionales y no funcionales, definidos en el Capítulo 4. Determinación de requisitos de la Terapia de Estimulación Cognitiva para la enfermedad de Parkinson (EP). También se considera una necesidad detectada el tipo de ejercicios que debe realizar cada paciente, recogidos en el apartado $\underline{5.3 \text {. Diseño de la terapia de estimulación }}$ cognitiva. 
Estas aportaciones se han enmarcado en las tres dimensiones de una persona con EP cuando se enfrenta a una plataforma de estas características, que son la cognitiva, la motora y la emocional. Es destacable que la dimensión más asociada a la EP y la más conocida, la que genera los trastornos motores del individuo, no haya sido la más relevante a la hora de definir las necesidades de estas personas. Ha sido notable la importancia de la dimensión emocional que se suponía inicialmente que no iba a estar tan reflejada en las necesidades detectadas. Por supuesto, también se encuentran muchas necesidades a nivel cognitivo.

La Tabla 50 presentada a continuación describe las necesidades de estos pacientes que se han detectado durante la recogida de requisitos. Además, para cada necesidad se reflejan las dimensiones con las que se relaciona entre las tres posibles planteadas en el objetivo: cognitiva, motora y emocional.

Tabla 50. Resumen de necesidades de una persona con EP

\begin{tabular}{|l|l|}
\hline Necesidad detectada & Dimensiones \\
\hline Elementos para la interacción del paciente con la aplicación grandes & Motora \\
\hline Curva de aprendizaje de la aplicación pequeña & Cognitiva, Emocional \\
\hline Mensajes motivantes & Emocional \\
\hline Control de las pulsaciones & Motora \\
\hline Control del tiempo de realización de los ejercicios & Motora \\
\hline Tiempo máximo de realización de los ejercicios & Cognitiva \\
\hline Ejercicios que intenten mantener la atención del paciente & Cognitiva, Emocional \\
\hline Información visual apoyada por texto & Cognitiva \\
\hline Utilización de imágenes que no sean infantiles & Emocional \\
\hline Mostrar la personalización de la terapia al paciente & Emocional \\
\hline Textos claros y breves & Cognitiva \\
\hline
\end{tabular}

Tras la visualización de la Tabla 50 es destacable, como se ha definido previamente, la importancia de la dimensión emocional y la poca relevancia que tiene la dimensión motora en este escenario en concreto. Esto es debido a la elección de tecnologías inteligentes táctiles. Como se describió en los primeros capítulos de esta memoria, los problemas motores son los que causan más dependencia en las personas con EP, principalmente por los temblores, la rigidez y la bradicinesia, síntomas que hacen que la interacción con la tableta sea más sencilla para estos pacientes que el realizar las terapias con lápiz y papel.

Para poder demostrar la adecuación de este modelo al escenario propuesto y las mejoras perseguidas en las hipótesis iniciales, ha sido necesario llevar a cabo un experimento con los usuarios finales que permitiera asegurar la validez de dicho modelo. Para ello, ha sido necesaria la implementación de una plataforma a partir del modelo propuesto. Esta plataforma se ha presentado en el Capítulo 5. Materiales y métodos, en el que se ha descrito ampliamente la implementación del modelo planteado para poder realizar la experimentación, y del Capítulo 6. Experimentación y resultados, donde se ha planteado esta experimentación y se han presentado los resultados derivados de dicha experimentación. 
Para comprobar si se han obtenido los resultados esperados, a continuación, se presentan varias gráficas con los resultados de la experimentación. Comenzaremos con las relativas a los resultados de los pacientes. Recordemos que el experimento en las asociaciones se llevó a cabo en tres sesiones. En la primera de ellas el terapeuta iba guiando al paciente. En la segunda, el paciente hacía los ejercicios y tenía el soporte del terapeuta por si le surgía alguna duda de funcionamiento. En la tercera y última sesión, el paciente realizaba la terapia él solo sin ninguna ayuda. Tras cada sesión, tanto el paciente como el terapeuta rellenaban un cuestionario.

La Figura 85 presenta los resultados globales de los pacientes por cada asociación. En esta gráfica se observa que el experimento ha sido exitoso, ya que la media de todas las sesiones en todas las asociaciones se sitúa entre 4 y 5 . Recordemos que el valor 4 equivalía a una respuesta $D e$ acuerdo y el valor 5 a Totalmente de acuerdo, por lo que se considera que los resultados son altamente positivos. La asociación de Cádiz presenta valores más bajos, debido al nivel avanzado del deterioro motor que presentaba la muestra de pacientes y por la reticencia inicial que presentaban para utilizar las TIC en este tipo de terapias, ya que consideraban que podría sustituir a las terapias que se llevaban a cabo en su asociación y no querían renunciar a ellas. Aun así, los valores no son negativos, ya que se sitúan entre el valor 3 (Indiferente) y el valor 4 (De acuerdo) sin llegar al umbral de los valores que podrían hacer que el experimento no fuera válido (por debajo de 3).

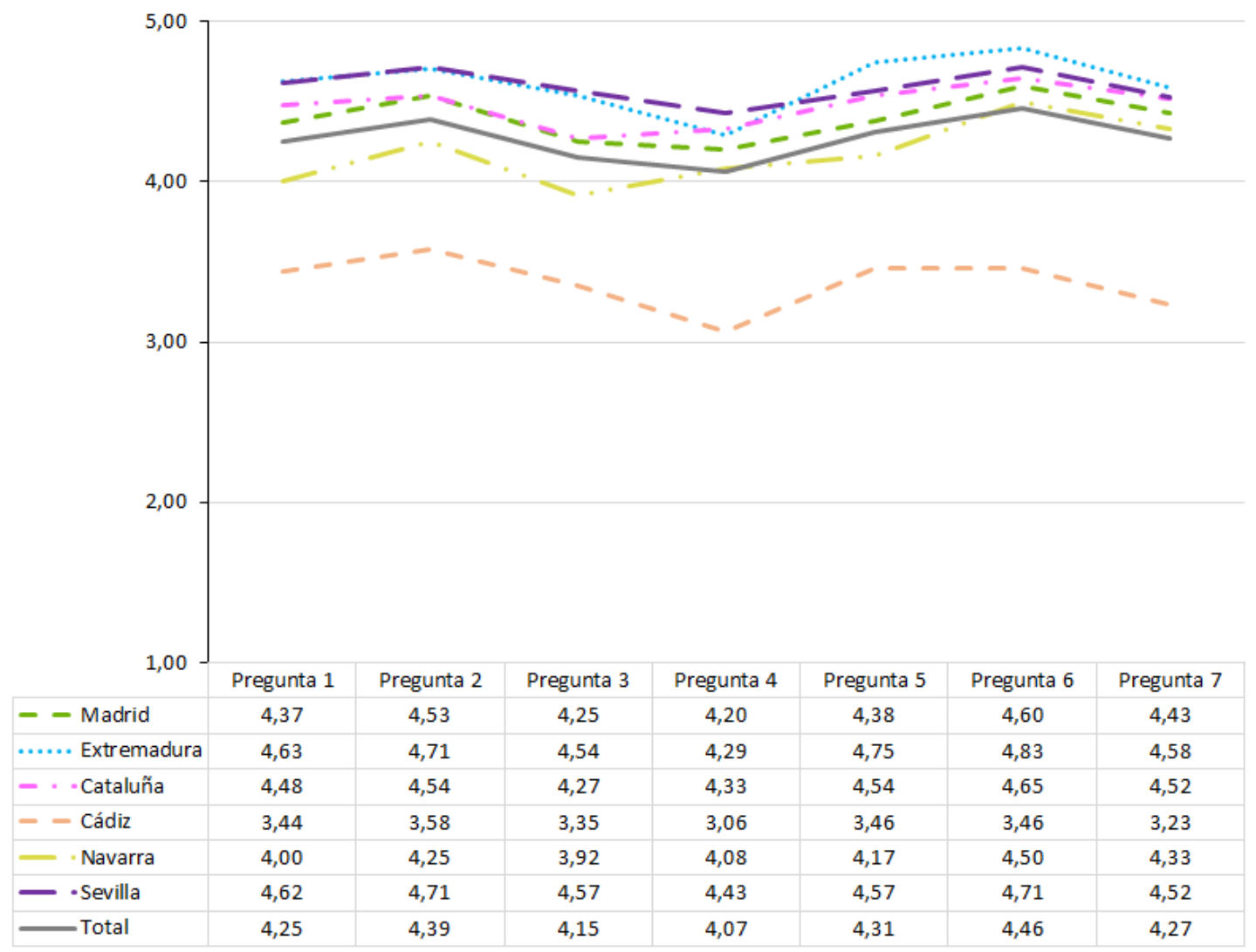

Figura 85. Resultados medios por pregunta y asociación

Asimismo, en la Figura 86 se presenta la gráfica correspondiente a la media entre sesiones global para todas las asociaciones. En este caso, el valor inferior se encuentra en la pregunta 4 (No he tenido ningún problema para utilizar la aplicación con ayuda del terapeuta $\left(2^{2}\right.$ y $3^{\underline{a}} \sin$ ayuda del terapeuta)) en la tercera sesión, donde se enfrentaban a la terapia ellos solos. Pese a ello, el 
valor está muy cercano a 4, por lo que también se considera que los resultados obtenidos son altamente satisfactorios.

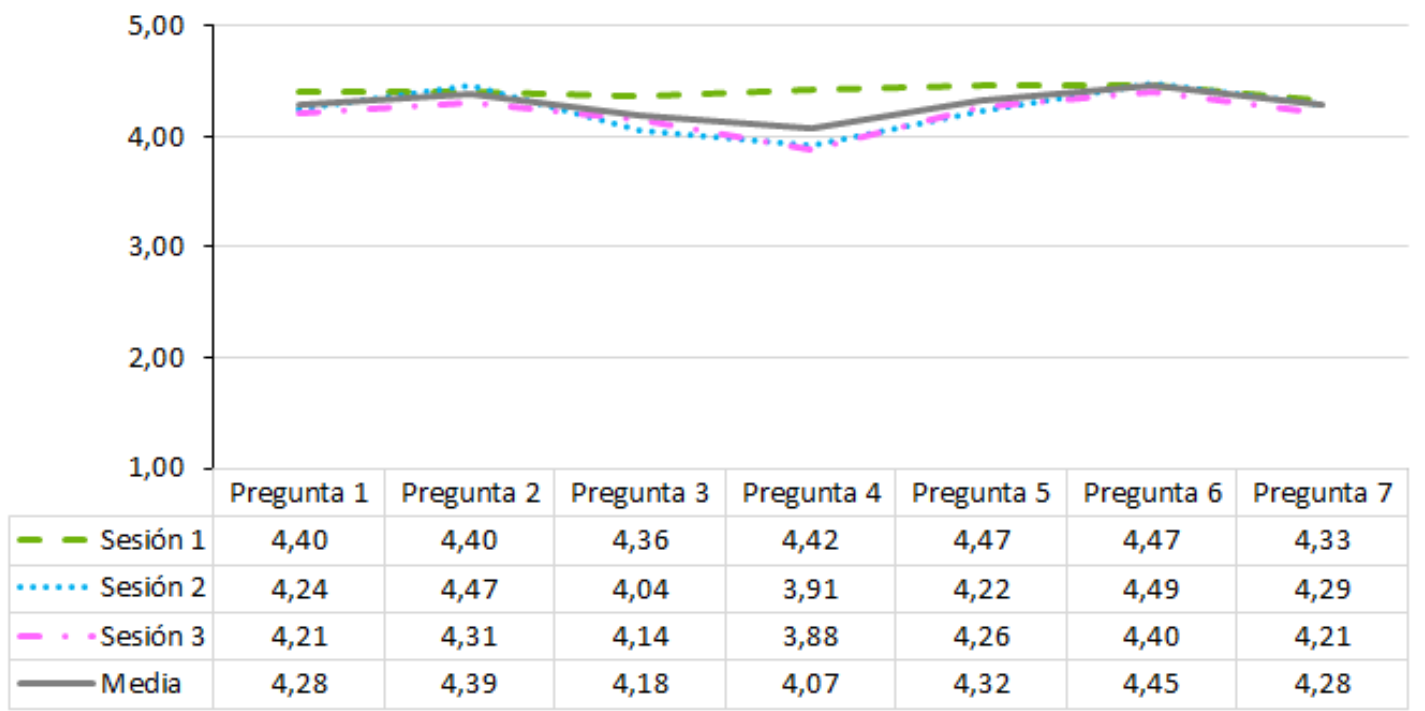

Figura 86. Resultados medios por pregunta y sesión

Debido a la diferencia en la dinámica de las sesiones, se ha considerado relevante el mostrar la varianza tanto entre las sesiones como la global. La varianza, entendida como la media de la dispersión de los valores de las respuestas, nos puede dar la noción de la variabilidad entre las respuestas entre las sesiones. Para ello, se ha calculado la media de todas las respuestas de cada paciente para cada sesión y, posteriormente, la varianza entre esas sesiones. En la gráfica de la Figura 87 se presentan el valor máximo, el valor mínimo y la media de varianza entre todos los pacientes. Este valor medio se mantiene bajo, por lo que podemos deducir que la variabilidad ha sido muy pequeña (la media de la varianza global tiene un valor de 0,12 ), lo que implica que, pese a dejar de disponer del apoyo del terapeuta, los pacientes se han adaptado bien al uso de la plataforma.

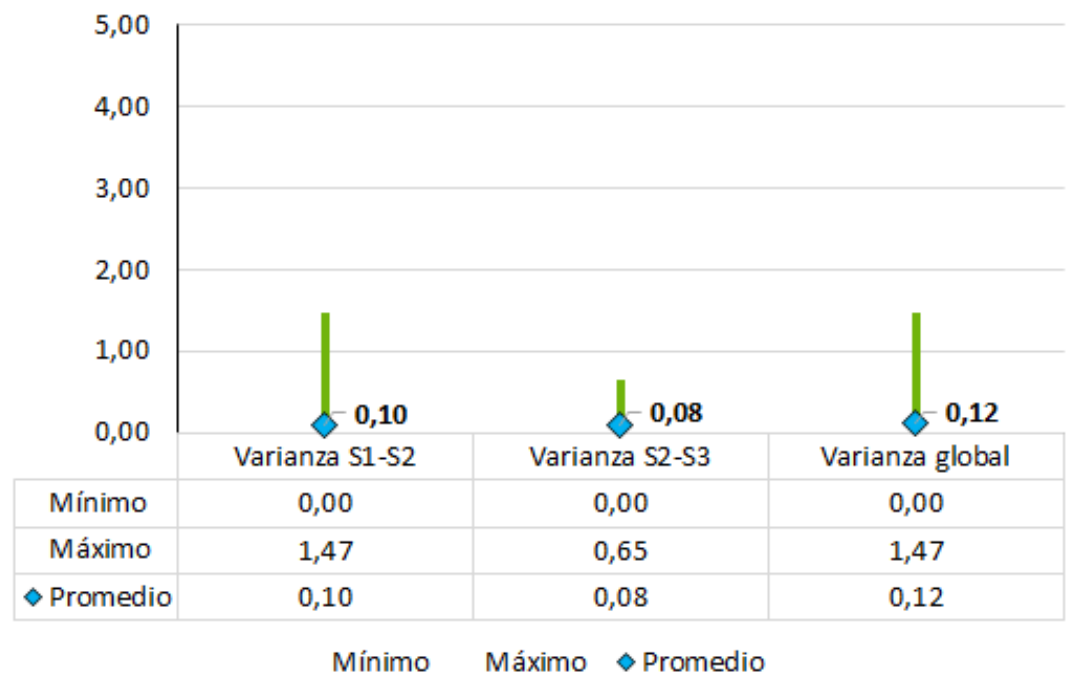

Figura 87. Varianza entre las sesiones y varianza global

En el caso de la comprobación empírica de la idoneidad de la terapia presentada en el modelo, en las figuras siguientes se presentan gráficas de resultados según diversos parámetros. Esto 
también nos permite el acotar los perfiles de los usuarios que pueden utilizar este tipo de plataforma para la realización de terapias. Comenzaremos presentando la gráfica con los valores medios de las respuestas de cada paciente según su estadio motor (Figura 88).

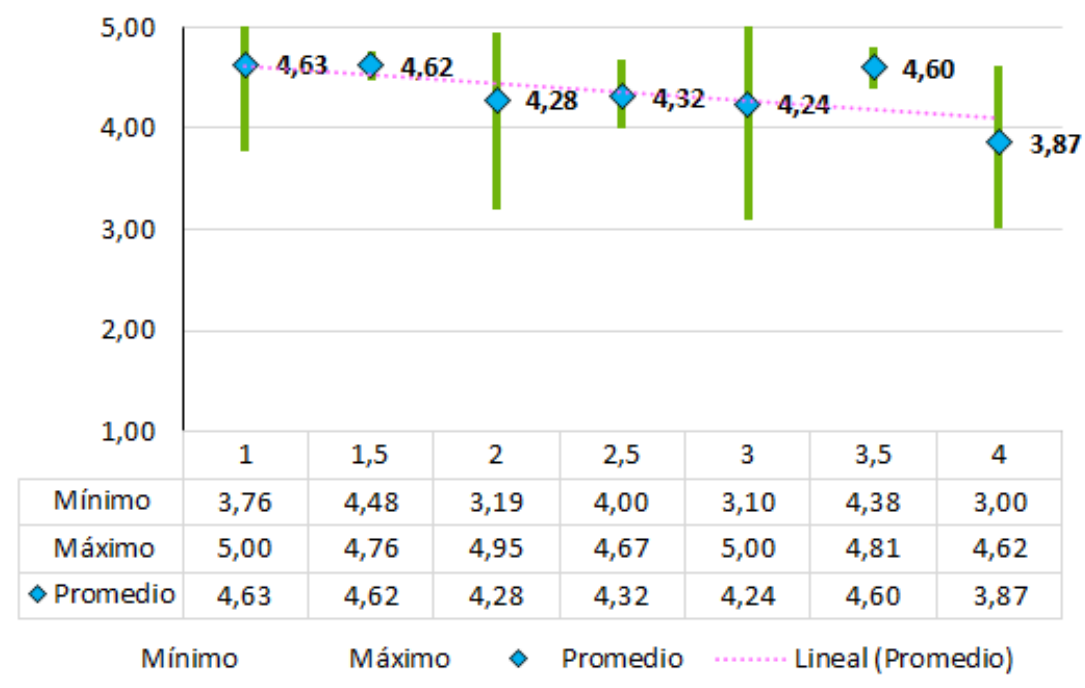

Figura 88. Máximo, mínimo y promedio de las respuestas según estadio motor

La línea de tendencia de la gráfica anterior va disminuyendo, lo que implica que el deterioro motor puede influir a la hora de llevar a cabo este tipo de terapias utilizando las TIC. Por ello, se puede acotar en un estadio motor de 3,5 el máximo deterioro para la asignación de TEC a partir del modelo planteado.

A continuación, en la Figura 89 se presenta una gráfica similar, pero clasificando a los pacientes por su estado cognitivo. Se distingue entre estado preservado $(P)$, deterioro cognitivo leve (L), leve-moderado (LM), moderado (M), moderado-grave (MG) y grave (G).

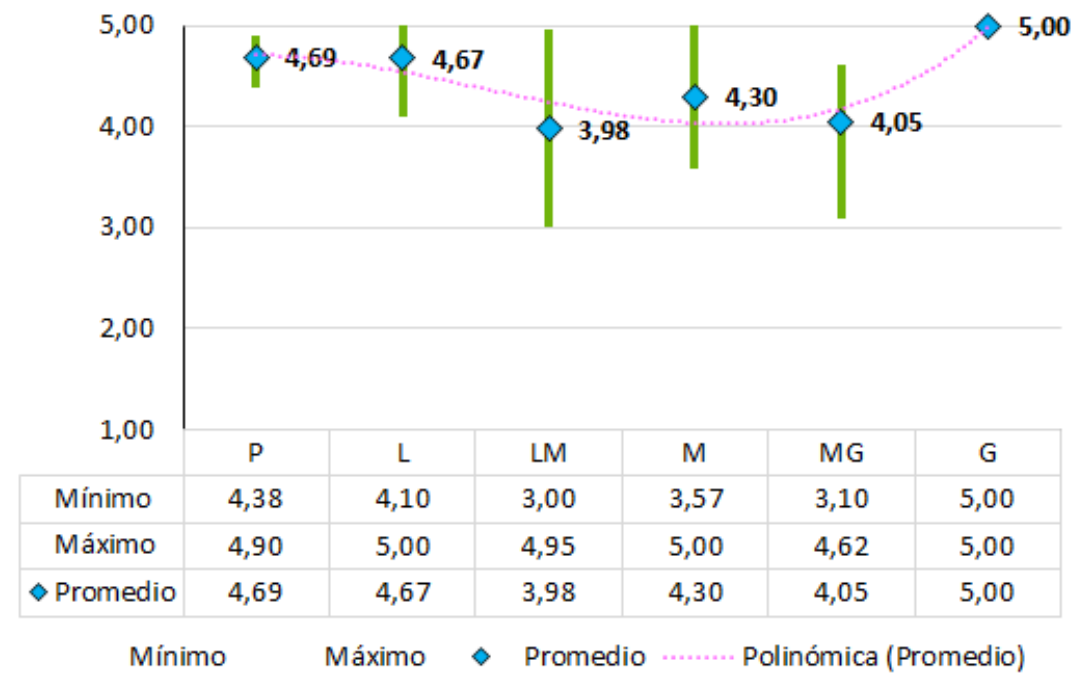

Figura 89. Máximo, mínimo y promedio de las respuestas según estado cognitivo

En esta gráfica hay más variabilidad. Se puede observar que tiende a bajar excepto en el caso del deterioro cognitivo grave. De hecho, para que la línea de tendencia fuera más realista se ha tenido que poner como polinómica de grado 3. La aceptación en el caso de pacientes con deterioro cognitivo grave alcanza el valor máximo. Este dato no se considera relevante, ya que únicamente ha participado en la experimentación un paciente que presentara este nivel de 
deterioro y no se puede extrapolar a otros pacientes con ese nivel por el tamaño de la muestra utilizada.

Tras esta contextualización de los resultados, se va a proceder al análisis de las aportaciones generadas en el contexto de esta tesis doctoral a través de la investigación realizada en ella. Estas aportaciones demostrarán el cumplimiento de los objetivos. Para ello, se vuelven a presentar los objetivos específicos descritos en el Capítulo 2. Definición de hipótesis y objetivos y se describe qué aportaciones permiten demostrar este cumplimiento. Comenzaremos con el primer objetivo específico (OBJ1).

OBJ1. Fomentar la realización de las terapias de estimulación cognitiva fuera de las asociaciones.

Para la validación de este primer objetivo, se han analizado las respuestas a la pregunta 7 del cuestionario de los pacientes, que tenía como enunciado Si pudiera, realizaría la terapia en casa con este sistema. Los resultados a esta pregunta se presentan en la gráfica de la Figura 90.

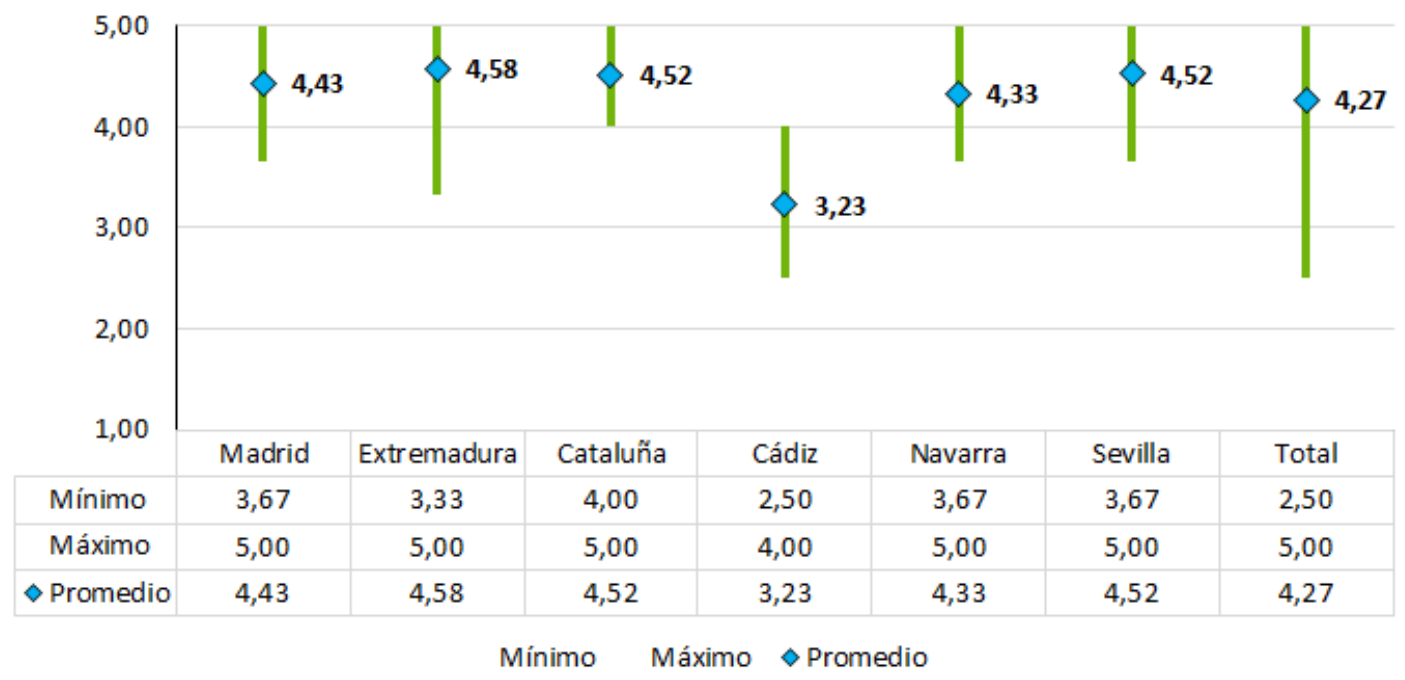

Figura 90. Máximo, mínimo y promedio de las respuestas de pacientes a la pregunta 7

Aquí la línea de tendencia se mantiene por encima de 4 excepto en el caso de la asociación de Cádiz. Esto se debe al avanzado estadio motor de los participantes y a la necesidad que tienen los pacientes de asistir a las asociaciones de Parkinson. Han sido varios los que han indicado su miedo a la utilización de las TIC en sus terapias por si dejan de ir a la asociación a realizarlas. Estos pacientes, como se ha detallado en capítulos anteriores, tienen tendencia al aislamiento, por lo que para ellos es muy importante el contacto con su asociación. En particular, en la asociación de Cádiz han considerado que el llevar a cabo la TEC de esta manera sustituiría a la asistencia a la asociación y no lo han entendido como terapia complementaria.

Además de esta gráfica, también se tienen en cuenta las apreciaciones de los terapeutas y las observaciones de los pacientes, las relativas a la utilización de este tipo de terapias. Tal y como se presentó en el apartado 6.6.2. Observaciones de pacientes y terapeutas la inmensa mayoría de ambos grupos ha destacado la utilidad y las ganas de utilizar esta plataforma en su domicilio como complemento a las terapias. Asimismo, los pacientes han percibido la utilidad de poder 
consultar la valoración de su terapeuta a la vista de sus resultados, lo que también mejoraría la adherencia al tratamiento.

Gracias al gran interés que presentan los participantes de todas las asociaciones y sus terapeutas de utilizar la plataforma en su domicilio, se puede corroborar que el OBJ1 ha sido validado con éxito.

Por otro lado, también queríamos comprobar si es posible que una aplicación basada en este modelo pudiera tener otras ventajas no tan inmediatas de apreciar. El segundo objetivo se centra en averiguar, en la medida de lo posible, una de estas ventajas, que estaría relacionada con la adherencia al tratamiento.

OBJ2. Promover la adherencia a las terapias de estimulación cognitiva como tratamiento no farmacológico para personas con enfermedad de Parkinson.

Para asegurar la adherencia a los tratamientos, es imprescindible contar con la aprobación de los pacientes a los que va destinado. Es por ello que se añadió a los cuestionarios de los pacientes la pregunta 6: En general, me gusta realizar la estimulación cognitiva con la tableta. En la Figura $\underline{91}$ se presenta la gráfica con los resultados a esta pregunta.

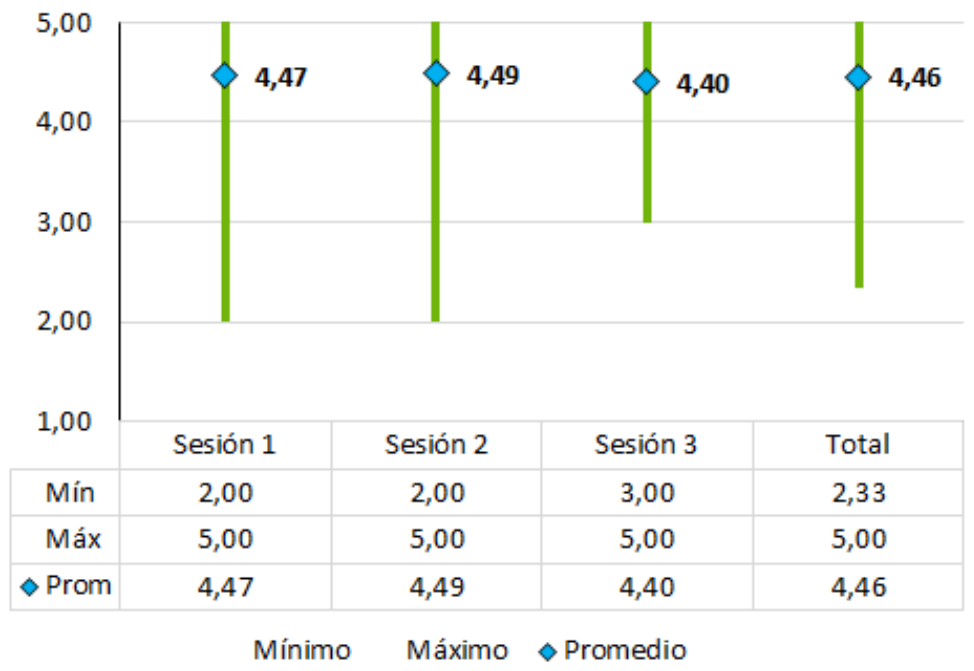

Figura 91. Máximo, mínimo y promedio de las respuestas de pacientes a la pregunta 6

Los valores medios de la gráfica anterior se mantienen en valores muy altos, rondando 4,5, y no disminuyen a lo largo de las sesiones. Además, los terapeutas han destacado en sus observaciones que aparece un componente añadido de entusiasmo que no disminuye, aunque inicialmente, debido a la dificultad que podría surgir en la tercera sesión al realizarla el paciente sin ayuda, se esperaba que este valor disminuyera considerablemente. Estos valores tan elevados nos demuestran de forma indirecta que la aplicación de los pacientes está perfectamente adaptada a sus necesidades, por lo que no perciben una dificultad adicional relevante cuando no tienen al terapeuta como apoyo a la hora de llevar a cabo la TEC y, por tanto, es una aplicación que pueden utilizar de forma autónoma.

Por todo lo anterior, se define que el OBJ2 también se ha verificado a través del trabajo de investigación realizado y de la experimentación presentada. 
Por último, el tercer objetivo específico está relacionado con el impulso de la utilización de las NNTT en este colectivo. Este objetivo se formuló de la siguiente forma:

OBJ3. Impulsar el uso de las nuevas tecnologías a las personas con enfermedad de Parkinson.

Para comprobar la validez del OBJ3 se ha comparado la utilización de la plataforma por personas con contacto con las NNTT y sin él, como se ve en la gráfica de la Figura 92.

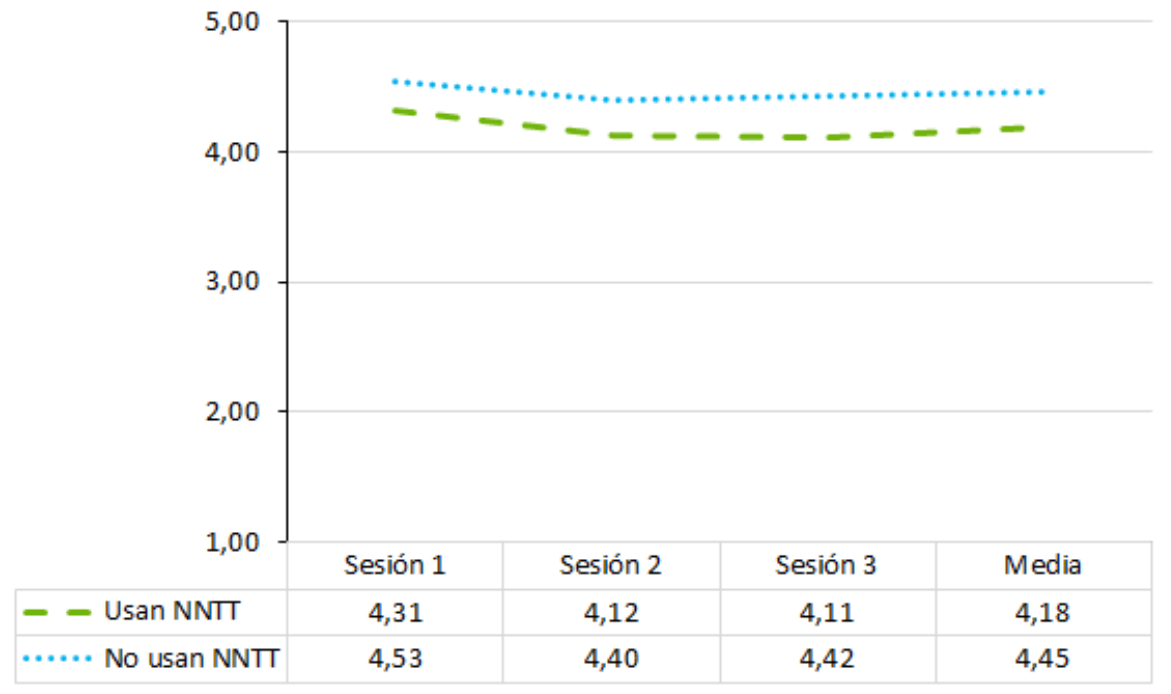

Figura 92. Comparativa de respuestas entre pacientes con/sin contacto previo con NNTT

La presentación de esta gráfica es muy relevante para darle validez al OBJ3. Se puede observar a la vista de la gráfica anterior que han dado puntuaciones más altas los pacientes que previamente no habían tenido contacto con las nuevas tecnologías. Inicialmente, se esperaba que el caso fuera al contrario y que los pacientes que utilizan a diario dispositivos electrónicos, al estar más familiarizados con ellos, tuvieran menos problemas a la hora de enfrentarse a la plataforma. Esto significa que el modelo se ha adaptado muy bien a las necesidades de los pacientes y que puede ayudar a que se elimine el miedo que las personas con EP tienen al uso de las NNTT.

Conjuntamente, para la verificación de este objetivo se presentan los resultados por sesión de la pregunta 4, cuyo enunciado es No he tenido ningún problema para utilizar la aplicación con ayuda del terapeuta ( $2^{\underline{a}}$ y $3^{\underline{a}} \sin$ ayuda del terapeuta) porque se considera relevante para comprobar la curva de aprendizaje de la plataforma desarrollada a partir del modelo planteado en esta tesis doctoral. Esta gráfica se presenta en la Figura 93. En esta gráfica se observa cómo la línea de tendencia de la media por sesión va disminuyendo, lo que implica que los pacientes han tenido algunas dificultades para defenderse en la segunda y tercera sesión al no disponer de ayuda del terapeuta. Pese a esto, los valores no han sido excesivamente bajos, ya que están muy cercanos a 4 y la media está por encima de 4 . Los valores mínimos de respuesta en las sesiones 2 y 3 son 1 (Totalmente en desacuerdo), pero únicamente ha habido un caso que haya dado esta respuesta, por lo que la media por sesión no se ha visto afectada a niveles que sean reseñables, al igual que ocurre con la media de respuestas a la pregunta 4 a lo largo de todas las sesiones. 


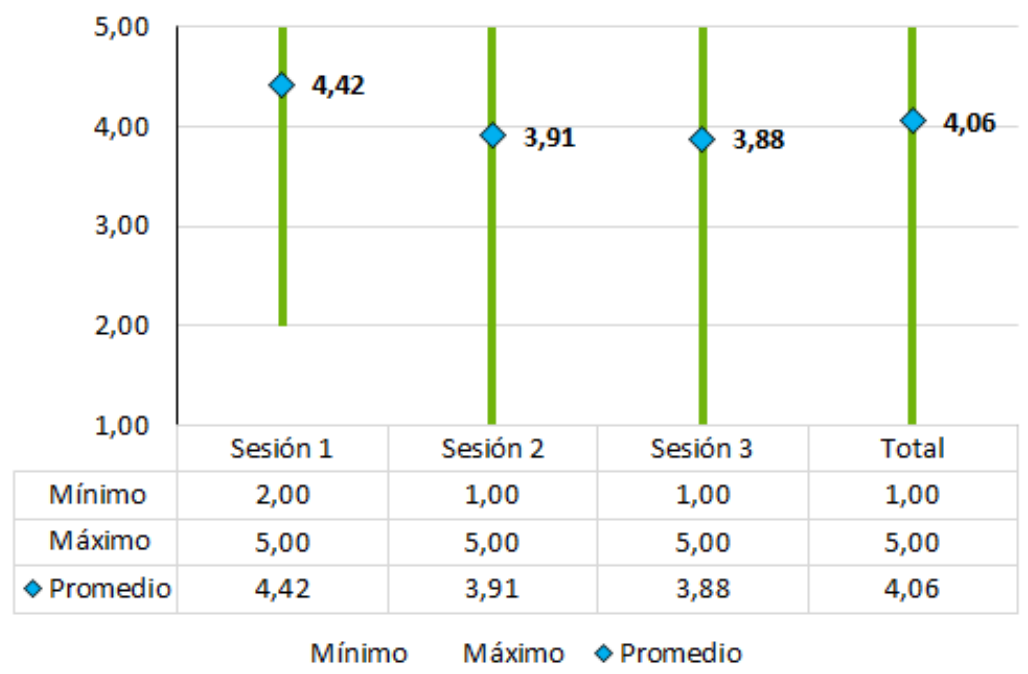

Figura 93. Comparativa entre sesiones de la pregunta 4

Después de lo presentado anteriormente se constata el cumplimiento del OBJ3 pese a las dificultades que tenía para su verificación. Para comprobar su cumplimiento totalmente sería necesario llevar a cabo una experimentación más amplia.

Una vez verificados los objetivos específicos, volvemos a recordar el objetivo principal de esta tesis doctoral:

OBJ. Mejorar la calidad, disponibilidad y versatilidad de las terapias de estimulación cognitiva tradicionales orientadas a personas con enfermedad de Parkinson mediante la introducción de las Tecnologías de la Información y la Comunicación.

La naturaleza de los objetivos específicos es la consecución de logros parciales que permitan alcanzar el objetivo principal. Debido a la consecución de todos los objetivos específicos, se puede concluir que se ha verificado el objetivo principal de esta tesis doctoral.

Para finalizar con la discusión de este trabajo de investigación, es necesario comprobar la validez de las tres hipótesis de partida. La primera de ellas se planteó desde el enfoque de la eficiencia:

HIPÓTESIS1. Las actuales terapias de estimulación cognitiva (TEC) orientadas
a personas con enfermedad de Parkinson (EP) puede mejorar su eficiencia a
través de las tecnologías de la información y la comunicación (TIC).

La segunda hipótesis de partida se centró en el incremento de la satisfacción de los usuarios a la hora de realizar la TEC:

HIPÓTESIS2. La aplicación de las tecnologías de la información y la comunicación (TIC) a las terapias de estimulación cognitiva (TEC) orientadas a personas diagnosticadas de enfermedad de Parkinson (EP) aumentan la satisfacción en el uso. 
Por último, la tercera hipótesis de esta tesis doctoral se orientó a la mejora en la adherencia al tratamiento:

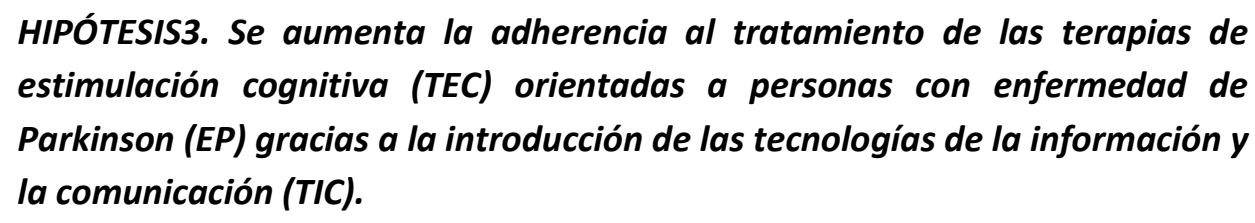

La comprobación de estas hipótesis de partida no es algo trivial pese a la consecución de los objetivos, ya que comprueba la validez del modelo evaluando su eficiencia, la satisfacción de uso y la promoción de la adherencia al tratamiento. A continuación, se presenta la Tabla 51 en la que, a modo de resumen, se contempla cada argumento de los descritos tanto en este capítulo como a lo largo de la tesis doctoral para definir en qué se mejora específicamente las terapias tradicionales utilizadas hoy en día por las asociaciones si se introduce un modelo como el presentado en esta tesis doctoral. Para completar la tabla, los argumentos se han extraído de las conclusiones de pacientes y terapeutas tras la realización de los experimentos, recogidas en el apartado $\underline{6.6 .2}$ Observaciones de pacientes y terapeutas. Los argumentos se reflejan según los tres aspectos introducidos en las hipótesis anteriores: eficiencia, satisfacción y adherencia al tratamiento. Estos argumentos se han extraído de las observaciones finales de pacientes y terapeutas tras la experimentación, y se han corroborado con el análisis de los resultados de los cuestionarios de ambos.

Tabla 51. Resumen de mejoras en las TEC que aporta el modelo planteado

\begin{tabular}{|l|l|}
\hline Argumento & Aspectos mejorados \\
\hline Entusiasmo añadido que no disminuye a lo largo de las sesiones & Adherencia al tratamiento \\
\hline Herramienta de fácil manejo para su uso de forma autónoma & Adherencia al tratamiento \\
\hline El poder visualizar la valoración es positivo para los pacientes & $\begin{array}{l}\text { Eficiencia } \\
\text { Satisfacción en el uso }\end{array}$ \\
\hline Los pacientes están más que dispuestos a utilizarlo en casa & $\begin{array}{l}\text { Satisfacción en el uso } \\
\text { Adherencia al tratamiento }\end{array}$ \\
\hline Valor añadido cuando no pueden ir a las sesiones & Eficiencia \\
\hline Muchos pacientes prefieren realizar los ejercicios en la tableta & Satisfacción en el uso \\
\hline $\begin{array}{l}\text { Aprecian la personalización y realizan los ejercicios de forma más } \\
\text { rápida que con las terapias tradicionales }\end{array}$ & $\begin{array}{l}\text { Eficiencia } \\
\text { Satisfacción en el uso }\end{array}$ \\
\hline $\begin{array}{l}\text { Esta plataforma puede tener una repercusión positiva en la mejora } \\
\text { de la calidad de vida de los usuarios }\end{array}$ & $\begin{array}{l}\text { Sficiencia } \\
\text { Satisfacción en el uso } \\
\text { Adherencia al tratamiento }\end{array}$ \\
\hline Ahorro de tiempo y de material para los terapeutas & Eficiencia \\
\hline A los pacientes les ha gustado el realizar la TEC utilizando NNTT & Satisfacción en el uso \\
\hline Más divertido para los pacientes que con lápiz y papel & $\begin{array}{l}\text { Satisfacción en el uso } \\
\text { Adherencia al tratamiento }\end{array}$ \\
\hline
\end{tabular}




\begin{tabular}{|c|c|}
\hline $\begin{array}{l}\text { Los pacientes se distraen menos utilizando las TIC, por lo que } \\
\text { mejora su capacidad de atención sostenida }\end{array}$ & $\begin{array}{l}\text { Eficiencia } \\
\text { Satisfacción en el uso } \\
\text { Adherencia al tratamiento }\end{array}$ \\
\hline A los pacientes les resulta interesante y atractivo & $\begin{array}{l}\text { Satisfacción en el uso } \\
\text { Adherencia al tratamiento }\end{array}$ \\
\hline $\begin{array}{l}\text { Los pacientes muestran interés en cómo se va a materializar este } \\
\text { recurso }\end{array}$ & Adherencia al tratamiento \\
\hline $\begin{array}{l}\text { Resulta muy estimulante y motivadora para los afectados por ser } \\
\text { una forma nueva, atractiva y amena de realizar las TEC }\end{array}$ & $\begin{array}{l}\text { Eficiencia } \\
\text { Satisfacción en el uso } \\
\text { Adherencia al tratamiento }\end{array}$ \\
\hline $\begin{array}{l}\text { Las plataformas basadas en este modelo pueden enriquecer mucho } \\
\text { la intervención }\end{array}$ & Eficiencia \\
\hline $\begin{array}{l}\text { Los pacientes estaban bastante motivados con la experimentación } \\
\text { y les gustaría utilizar una plataforma como esta de forma } \\
\text { complementaria a las sesiones tradicionales }\end{array}$ & $\begin{array}{l}\text { Satisfacción en el uso } \\
\text { Adherencia al tratamiento }\end{array}$ \\
\hline $\begin{array}{l}\text { El modelo trata los aspectos cognitivos presentados por una } \\
\text { persona con EP }\end{array}$ & $\begin{array}{l}\text { Eficiencia } \\
\text { Satisfacción en el uso } \\
\text { Adherencia al tratamiento }\end{array}$ \\
\hline La plataforma es completa y sencilla & Eficiencia \\
\hline Este modelo motiva a los pacientes a realizar los ejercicios & Adherencia al tratamiento \\
\hline
\end{tabular}

A partir de la tabla anterior se puede comprobar que se mejora en todos los aspectos que se han planteado en las hipótesis de partida de este trabajo de investigación. Es destacable cómo todos subrayan la adaptabilidad del modelo a las necesidades de una persona con EP. Además, en todas las asociaciones alaban la motivación que aparece al introducir las TIC en este tipo de terapias, aumentando la motivación de los pacientes y las ganas de utilizarlo, tanto en las asociaciones en vez de las TEC de la forma tradicional como en domicilio como terapia complementaria o cuando no puedan desplazarse a la asociación, por lo que se mejora notablemente la adherencia al tratamiento. Se considera un aspecto muy relevante la eficiencia percibida tanto por pacientes como por terapeutas, ya que para los pacientes es más sencillo llevar a cabo la terapia de esta forma porque a muchos de ellos les cuesta escribir, y los terapeutas tienen una gran cantidad de ejercicios disponibles como fruto del trabajo colaborativo con otras asociaciones de Parkinson. Por último, ambos colectivos demuestran con multitud de argumentos la satisfacción en el uso, por lo que se puede concluir que el modelo se adapta perfectamente a las necesidades que tenían inicialmente.

Todos estos argumentos desembocan en la conclusión de que las hipótesis de partida se ha verificado, por lo que el modelo está perfectamente adaptado tanto a las TEC como a las necesidades de las personas con EP, mejorando también otros aspectos como la adherencia a tratamientos no farmacológicos y la eliminación de la brecha digital de este tipo de pacientes cuando interactúan con las TIC. Esto significa que las aportaciones científicas de esta tesis doctoral son muy relevantes en este contexto, ya que se ha definido y evaluado un marco de trabajo del que pueden beneficiarse otros proyectos que se enmarquen en esta temática. 
Una vez constatada la validez de las hipótesis, en el siguiente capítulo se van a extraer las conclusiones derivadas de este trabajo de investigación. Posteriormente, se describirán las futuras líneas de investigación. 


\section{Capítulo 8. Conclusiones}

En este octavo y último capítulo de la tesis doctoral, se presentarán las aportaciones científicas generadas tras este estudio empírico, así como las conclusiones obtenidas y las futuras líneas de investigación.

\subsection{Aportaciones científicas}

En este apartado se presentan las aportaciones científicas a las que este trabajo de investigación ha dado lugar. Estas aportaciones se agrupan por naturaleza, distinguiendo entre artículos en revistas indexadas, congresos, registros software y tutorización de Trabajos Fin de Máster.

- Revistas indexadas con índice de impacto

García Vázquez, C., Moreno Martínez, E., Valero Duboy, M. A., Gómez Oliva, A., Distributed system for cognitive stimulation over interactive TV. Information Technology in Biomedicine, IEEE Transactions on, vol. 16, no 6, pp. 1115-1121, 2012. En 2012, año de publicación del artículo, esta revista ocupó el puesto 21 de 132 (primer cuarto, Q1) en el área Computer Science, Information Systems con un índice de impacto de 1,978.

Citas relevantes en revistas indexadas:

1. Costa, C. R., Iglesias, M. J. F., Rifón et al., The acceptability of TV-based game platforms as an instrument to support the cognitive evaluation of senior adults at home, PeerJ, vol. 5, 2017.

Información de la publicación (año 2015):

Índice de impacto: 2,183.

Área: Multidisplinary Sciences.

Posición: 14/63 (primer cuarto, Q1).

2. Rivas-Costa, C., Anido-Rifon, L., Iglesias, M. J. F., An Open Architecture to Support Social and Health Services in a Smart TV Environment, IEEE Journal of Biomedical and Health Informatics, 2016.

Información de la publicación (año 2015):

Índice de impacto: 2,093

Área: Computer Science, Information Systems.

Posición: 29/144 (primer cuarto, Q1). 
3. Lin, B. S., Hsiao, P. C., Cheng et al., Design and Implementation of a Set-Top Box-Based Homecare System Using Hybrid Cloud, Telemedicine and e-Health, vol. 21, n. 11, pp. 916-922, 2015.

Información de la publicación (año 2015):

Índice de impacto: 1,791

Área: Health Care Sciences \& Services.

Posición: 42/88 (segundo cuarto, Q2).

4. Silva, B. M., Rodrigues, J. J., de la Torre Díez, I. et al., Mobile-health: A review of current state in 2015, Journal of Biomedical Informatics, vol. 56, pp. 265-272, 2015.

Información de la publicación (año 2015):

Índice de impacto: 2,447 .

Área: Computer Science, Interdisciplinary Applications.

Posición: 20/104 (primer cuarto, Q1).

5. Hossain, M. S., Goebel, S., El Saddik, A., Guest editorial multimedia services and technologies for e-health (must-eh), IEEE Transactions on Information Technology in Biomedicine, vol. 16, n. 6, pp. 1005-1006, 2012.

Información de la publicación (año 2012):

Índice de impacto: 1,978

Área: Computer Science, Information Systems.

Posición: 21/132 (primer cuarto, Q1).

Citas relevantes en capítulos de libros:

1. Georgakopoulos, P., Chatzidimitriou, M., Tsolaki, M., A review of interventions with assistive technologies for patients with cognitive impairment, Handbook of Research on Innovations in the Diagnosis and Treatment of Dementia, IGI Global (Disseminator of Knowledge), pp. 118-129, 2015.

\section{- Conferencias internacionales invitadas}

García Vázquez, C. Moreno Martínez, E., Sistema de estimulación cognitiva, European Conference Design for All (Spain '08), European Design for All e-Accessibility Network (EDeAN), León, junio de 2008. Este congreso, organizado por la Red Europea de Diseño para Todos y Accesibilidad Electrónica (EDeAN), tenía como objetivo el apoyar el acceso de los ciudadanos a la sociedad de la información a través del trajo en red para una sociedad inclusiva. En él, se presentaron soluciones y experiencias innovadoras en la formación y aplicación de los principios de Diseño para Todos y la inclusión digital, abarcando temas como los derechos humanos, políticas, legislación y buenas prácticas, entre otros. Además de las conferencias, se llevó a cabo la visita al Centro de Referencia Estatal San Andrés del Rabanedo, centro dependiente del IMSERSO y situado también en León. En esta visita se presentaron prototipos y productos inclusivos, así como los relacionados con las buenas prácticas de diseño. En este centro, la doctoranda, junto con otros miembros del equipo investigador del T>SIC, presentó un sistema 
de estimulación cognitiva basado en tecnologías móviles con supervisión del personal responsable del seguimiento de este tipo de terapias. Aunque este sistema no estaba centrado aún en el deterioro cognitivo asociado a la EP, fue uno de los precursores para llevar a cabo la investigación que ha dado lugar a esta tesis doctoral. A esta visita acudieron autoridades como Amparo Valcarce (Secretaria de Estado de Política Social), Mercedes Sánchez (Directora del Real Patronato sobre Discapacidad) Francisco Fernández (Alcalde de León) y Enrique Martínez (Director General del Instituto Nacional de Tecnologías de la Comunicación).

\section{- Conferencias nacionales invitadas}

García Vázquez, C., EsCoTDT - Estimulación Cognitiva a través de la TDT, Jornadas Código y Sociedad. Software libre para el progreso social, Universidad Complutense de Madrid, Madrid, noviembre de 2011. Ponencia invitada sobre la importancia del software libre a la hora de desarrollar soluciones para personas con discapacidad que sean de bajo coste para el usuario final. En este congreso se presentó un sistema de estimulación cognitiva, basado en televisión digital terrestre e interactiva, para personas con deterioro cognitivo asociado a la EP. Este sistema contaba con la aceptación tanto de pacientes como de terapeutas tras haber llevado una amplia experimentación con ellos [García, 2012] [García, 2010].

García Vázquez, C., Moreno Martínez, E., Plataformas de estimulación cognitiva a través de TDT y móvil, Seminario sobre los avances tecnológicos y sus implicaciones en la atención a personas con Alzheimer y otras demencias, CREAD-IMSERSO, junio de 2011. Mesa redonda con expertos en el tratamiento del deterioro cognitivo, tanto a través de terapias tradicionales como de terapias basadas en TIC. En la mesa redonda, a la que la doctoranda asistió como experta, se trataron temas centrados en las posibilidades que ofrecen las TIC a personas con deterioro cognitivo, ya sea incipiente o haya desembocado en demencia, así como de la inclusión en la sociedad a través de estas tecnologías de personas que, debido a sus problemas en la cognición, pueden tender al aislamiento.

Valero Duboy, M. A., García Vázquez, C., Moreno Martínez, E., Sistema de estimulación cognitiva móvil e interactivo, Jornadas Bajo Coste, Centro de Recuperación de Personas con Discapacidad Física de Albacete, CEAPAT-IMSERSO, Albacete, julio de 2008. Ponencia y taller demostrador de prototipo móvil de estimulación cognitiva. Este prototipo, centrado en la adaptación de terapias de prevención del deterioro cognitivo, fue invitado a estas jornadas debido a la utilidad percibida por expertos (previo a la experimentación con usuarios finales) y a la gran cantidad de aplicaciones que podría tener con pequeñas modificaciones a otros problemas debido a su diseño modular. De hecho, los organizadores también prepararon un taller con terapeutas expertos en estimulación cognitiva para recibir realimentación sobre las mejoras necesarias a incluir en el sistema.

\section{- Congresos internacionales con revisión por pares}

García Vázquez, C. Moreno Martínez, E., Valero Duboy, M. A. Martínez Juez, M. T., Amor Fernández, R., Mobile and accessible cognitive stimulation service to people with Parkinson disease, Fifth International Conference on Mobile Computing, Applications and Services (MobiCASE 2013), 7-8/11/2013, París. Este trabajo fue aceptado, pero no se publicó en las actas del congreso porque no fue posible asistir a presentar el artículo. 


\section{- Congresos nacionales}

García Vázquez, C., Moreno Martínez, E., Valero Duboy, M. A. Martínez Juez, M. T., Torre Calero, M. S., Servicio ubicuo de estimulación cognitiva orientado a personas con enfermedad de Parkinson, XI Jornadas de Ingeniería Telemática (JITEL 2013), pp. 273-280, octubre de 2013, Granada. ISBN 978-84-616-5597-7. Ponencia.

Citas relevantes en conferencias internacionales con revisión por pares:

1. Lopez-Gordo, M. A., Valle, F. P., Brain-Computer Interface as Networking Entity in Body Area Networks, International Conference on Wired/Wireless Internet Communication, Springer International Publishing, pp. 274-285, mayo de 2015. Congreso.

García Vázquez, C. Moreno Martínez, E. Valero Duboy, M. A., Plataforma telemática para estimulación cognitiva vía móvil, VI Jornadas de Ingeniería Telemática (JITEL 2007), pp. 569-576, septiembre de 2007, Málaga. ISBN 978-84-690-6670-6. Póster.

\section{- Registros software}

Universidad Politécnica de Madrid, Fundación Vodafone España, Federación Española de Parkinson, DaleMov: Servicios ubicuos de estimulación cognitiva accesibles para afectados de Parkinson, Registro Territorial de la Propiedad Intelectual de la Comunidad de Madrid, n. M007249/2014, 05/02/2016. La doctoranda tiene un porcentaje de un $33 \%$ de los derechos de explotación del $50 \%$ de la titularidad de la Universidad Politécnica de Madrid.

Universidad Politécnica de Madrid, Sistema de estimulación cognitiva para pacientes con Parkinson a través de la televisión e internet interactiva y personalizable (DALE), Registro Territorial de la Propiedad Intelectual de la Comunidad de Madrid, n. M-001031/2011, 24/01/2012. La doctoranda tiene un porcentaje de un $33 \%$ de los derechos de explotación.

Universidad Politécnica de Madrid, Plataforma de estimulación cognitiva vía móvil (EsCoM), Registro Territorial de la Propiedad Intelectual de la Comunidad de Madrid, n. M-001035/2011, 24/01/2012. La doctoranda tiene un porcentaje de un $\mathbf{3 4 \%}$ de los derechos de explotación.

\subsection{Conclusiones}

Esta tesis doctoral, titulada Modelo de estimulación cognitiva ubicua para pacientes de Parkinson, ha intentado a lo largo de toda la memoria actual de presentar y evaluar un modelo que, a través de las TIC, permitirá la realización de terapias orientadas a la estimulación cognitiva. Estas terapias se centraban en el caso particular del deterioro cognitivo asociado al Parkinson.

En un primer lugar, se ha consultado en la bibliografía las necesidades específicas de una persona con EP, dando un amplio resumen de en qué consiste la enfermedad. También se ha detallado la importancia del movimiento asociativo en este contexto, ya que, gracias a las asociaciones de Parkinson, los pacientes pueden llevar a cabo terapias no farmacológicas y relacionarse con otras personas que también sufren esta enfermedad, evitando así su aislamiento. Entre estas terapias se encuentra la estimulación cognitiva.

Pese a que los síntomas más conocidos de la EP son los trastornos motores, estas personas también sufren deterioro cognitivo. Este deterioro cognitivo no es igual al asociado a otras 
dolencias (Alzheimer, demencia vascular, demencia de los cuerpos de Levy, etc.), ya que, según la causa subyacente, son unas $u$ otras áreas de la cognición las que se ven afectadas. En el caso particular de la EP, las pérdidas cognitivas más relevantes están asociadas a la capacidad de atención (tanto sostenida como dividida), la iniciativa, la percepción espacial y las funciones ejecutivas. La memoria también se ve alterada, pero no tanto como en el caso de la enfermedad de Alzheimer, por lo que el planteamiento de las terapias orientadas a la estimulación cognitiva de pacientes con EP deben estar centradas en estas áreas de la cognición, por lo que no se pueden utilizar soluciones preparadas para el tratamiento de déficits cognitivos en otros contextos.

Es por ello que, para la correcta definición del modelo, ha sido necesario contactar con las asociaciones de Parkinson, donde nos hemos puesto en contacto con expertos en TEC y con pacientes con mayor o menor grado de deterioro cognitivo. Estas personas han colaborado durante todo el proceso de diseño, llevando a cabo evaluaciones parciales de los avances, para poder dar veracidad al modelo propuesto. Para la elección de la metodología de desarrollo de este trabajo de investigación se ha tenido en cuenta la importancia de la participación del colectivo, por lo que, finalmente, se optó por utilizar una metodología de diseño centrado en el usuario (DCU). Esta metodología consta de iteraciones incrementales de diseño en las que, para cada iteración, es necesario especificar el contexto (identificar a las personas a las que se dirige el resultado de esa iteración), especificar los requisitos (definir los objetivos y expectativas de los usuarios finales), realizar el diseño y evaluarlo con los usuarios finales. En cada iteración se contaba con expertos para la especificación de requisitos y la evaluación del diseño generado finalmente. El empleo de esta metodología ha hecho que los resultados finales hayan sido altamente satisfactorios, ya que la aplicación que implementa el modelo había sido desarrollada junto con el colectivo al que iba dirigido.

Los requisitos de usuario se han agrupado en capítulos previos según si estaban orientados a los parámetros de la terapia o a las necesidades de una persona con EP a la hora de utilizar un sistema TIC. Se ha constatado la importancia de la personalización de las terapias y necesidad de la utilización de una plataforma TIC para ello. En el modelo presentado se ha tenido en cuenta la posibilidad de la compartición de recursos entre las asociaciones. Debido al diseño pensado para personas poco familiarizadas con la tecnología, para los terapeutas ha sido muy fácil el interactuar con su portal web para la introducción de nuevos ejercicios y la generación de nuevos bloques de ejercicios. El dinamismo lo da la compartición de estos ejercicios y bloques de ejercicios entre distintos terapeutas de distintas asociaciones, lo que consigue que las herramientas disponibles para la TEC crezcan de forma exponencial. Esto, a su vez, aumenta las posibilidades disponibles para la personalización de la terapia según las necesidades del paciente.

Por otra parte, se ha realizado un amplio estudio de las necesidades de una persona con EP en un entorno TIC. Se han caracterizado estas necesidades según tres dimensiones: motora, cognitiva y emocional. Pese a que los síntomas motores asociados al Parkinson son los que más limitan la independencia del individuo, se ha comprobado que, en este contexto, es la dimensión que menos influye. Sin embargo, la mayor parte de las necesidades detectadas estaban orientadas a la dimensión emocional, en la que se incluyen, por ejemplo, la necesidad de mensajes de motivación para mejorar la adherencia al tratamiento o el personalizar la aplicación del paciente para que perciba esa adaptación de la TEC a sus condiciones particulares. En la 
dimensión cognitiva se enmarca, además, la necesidad de la realimentación de los terapeutas, por lo que para los pacientes era muy importante el poder visualizar una observación de la persona que le estuviera haciendo el seguimiento de la terapia para apreciar esta personalización de la terapia. La dimensión cognitiva también ha sido muy importante, principalmente para el diseño de la usabilidad de la aplicación del paciente.

Tras la definición de los requisitos de usuario, hemos pasado al detalle de cómo se ha implementado la plataforma TIC para llevar a cabo estas terapias. La plataforma resultante se compone de una aplicación para Android, diseñada para tableta, donde el paciente realiza sus ejercicios y puede visualizar la valoración introducida por su terapeuta. Los terapeutas disponen de una aplicación basada en web para la gestión de ejercicios, gestión de bloques de ejercicios y gestión de terapias. En esta última operación se incluyen la creación y asignación de bloques de ejercicios para cada paciente, personalizando así la terapia y pudiendo añadir una valoración que el paciente pueda visualizar a través de su aplicación en la tableta.

Una vez implementada la plataforma, se procedió a la definición del experimento. Para esta definición se contó con la ayuda de expertos en EP. Se redactaron dos tipos de cuestionarios para la experimentación: uno para los pacientes y otro para los terapeutas. Además, se especificó que la experimentación en cada asociación se llevaría a cabo en tres sesiones: la primera con el terapeuta para que fuera guiando al paciente, la segunda la realizaba el paciente solo, pero con el terapeuta cerca por si le surgía alguna duda y la tercera y última sesión sin la asistencia del terapeuta. Las sesiones no durarían más de 20 minutos para que los pacientes que tuvieran déficits de atención graves pudieran llevar a cabo el experimento.

En la experimentación participaron entre cuatro y diez pacientes por asociación, con un total de 45 pacientes y doce terapeutas en las seis asociaciones participantes. Para cada uno de ellos, se rellenaba una ficha en la que se recogían su edad, su sexo, su deterioro motor, su estado cognitivo y si estaban familiarizados con las nuevas tecnologías. Cada vez que finalizaba una sesión con un paciente, se rellenaba un cuestionario. Tanto el cuestionario del paciente como el del terapeuta se centraban en cuestiones en las que se valoraba la satisfacción con el uso y la utilidad percibida. También se llevó a cabo experimentación en domicilio, donde se utilizaron los mismos cuestionarios.

Los resultados tras la experimentación en las asociaciones son muy satisfactorios. El análisis de los resultados de los cuestionarios ha sido muy positivo. A nivel global, apenas ha existido variabilidad entre las sesiones, pese a que había pacientes de todos los niveles de deterioro cognitivo y de todos los niveles de estadio motor. Pese a que ha habido resultados marcados por el estado de ánimo de los pacientes, estos no han sido reseñables y se considera que los resultados son exitosos. Con respecto a la experimentación en el domicilio de los pacientes, el resultado ha dependido mucho de la asociación. En el caso de la asociación de Madrid, cuando más evolucionaban las sesiones, los pacientes daban puntuaciones más altas. En el caso de las asociaciones de Extremadura y Navarra, las puntuaciones se han mantenido constantes en niveles altos. En Sevilla han bajado un poco en la tercera sesión, pero no para todas las preguntas, sobre todos los pacientes de edad avanzada que presentaban un mayor grado de deterioro cognitivo y para ellos fue más difícil el utilizar la aplicación de forma autónoma. En el caso de la asociación de Cataluña, las respuestas medias de los pacientes han sido bajas, hecho que se puede explicar al ser personas con el estadio motor más avanzado, por lo que se observa 
que el deterioro motor influye y que puede haber problemas a la hora de interactuar con las TIC cuando es muy elevado. En la asociación de Cádiz los resultados han sido ligeramente más bajos que en el resto, causado, según los terapeutas, por el elevado nivel de deterioro motor que presentaban los pacientes seleccionados.

Las hipótesis de partida de esta tesis doctoral, centradas en la aportación de una mejora en la eficiencia, satisfacción en el uso y adherencia al tratamiento de las TEC, han sido sobradamente confirmadas con los resultados de la experimentación. En todas las asociaciones participantes se han destacado varios aspectos en el campo de la eficiencia. Entre ellas, desde el punto de vista de los terapeutas, destacan la utilidad cuando los pacientes no pueden asistir a las asociaciones, los recursos disponibles para la personalización de terapias, el ahorro de tiempo y de material o el enriquecimiento de la intervención al utilizar una plataforma TIC basada en el modelo propuesto. Para los pacientes también es eficiente la realización de TEC de esta forma porque, debido a los problemas que muchos tienen para escribir con lápiz y papel, una solución basada en TIC puede eliminar esta barrera. Además de la eficiencia, la satisfacción en el uso es importante porque es imprescindible para mejorar la adherencia al tratamiento. De hecho, es complicado separar estos dos conceptos. Los terapeutas han detectado en los pacientes un entusiasmo añadido a la hora de llevar a cabo la TEC de esta forma que no ha disminuido a lo largo de las sesiones, gracias a que la herramienta es novedosa y fácil de usar de forma autónoma. Asimismo, tanto pacientes como terapeutas destacan el interés de utilizarlo en domicilio y su gusto por la utilización de tecnología en el contexto de la TEC. Por último, los pacientes han subrayado que es más divertido, interesante y atractivo el llevar a cabo la terapia utilizando las TIC.

Estas aportaciones de pacientes y terapeutas han ayudado a concluir que el experimento ha sido un éxito, principalmente por la utilidad que ambos colectivos han percibido de la plataforma TIC basada en el modelo propuesto. Por todo ello, se puede afirmar que el modelo planteado es más que válido para su aplicación en TEC para personas con EP.

La utilización de una plataforma basada en el modelo presentado en esta tesis doctoral puede hacer llegar a más personas con EP la ventaja de las terapias orientadas a mantener sus capacidades cognitivas durante el mayor tiempo posible. Esto deriva en el mantenimiento de su calidad de vida durante un periodo más largo e influiría en la mejora de la calidad asistencial ofrecida a las personas que sufren esta enfermedad.

Comparando la solución propuesta con los paquetes software que ofrecen las empresas, cabe destacar que, gracias a la metodología empleada para la definición del modelo, se puede garantizar que esta solución está específicamente diseñada para las necesidades de una persona con EP. Además, por la colaboración de pacientes y terapeutas en todas las fases del diseño y de la evaluación de los módulos parciales implementados, se han podido seguir sus indicaciones para poder conseguir las mejoras que se perseguían cuando se plantearon las hipótesis. Por otro lado, un valor añadido muy importante es la independencia de agentes externos, ya que se ha transferido la tecnología desarrollada a la FEP para su gestión. Esto ha sido posible porque son los propios terapeutas los que añaden los recursos a la plataforma, lo que les permite personalizar las terapias a nivel individual y enriquecer la base de datos de ejercicios y bloques de ejercicios sin tener que depender de un programador, por lo que el terapeuta es una parte activa e imprescindible en la generación de nuevos recursos. 
De hecho, este valor añadido frente a las soluciones ofrecidas por empresas, más cerradas y que no permiten hacer una transferencia tecnológica total a las asociaciones de personas con EP, hace que la plataforma presentada sea muy atractiva para su uso en las asociaciones, principalmente por esta autogestión de los recursos de la terapia por parte de los terapeutas. A partir del éxito obtenido en la experimentación, de los resultados altamente positivos de aceptación por el colectivo y la sencillez del mantenimiento, se está planteando incluir la plataforma generada a partir del modelo dentro de un proyecto de investigación a nivel europeo que dé una solución tecnológica global a la EP para favorecer la vida independiente de estas personas. Este proyecto está liderado por una empresa española.

Por otro lado, en vista al cumplimiento de las hipótesis, la solución basada en el modelo puede complementar perfectamente las TEC que se realizan en las asociaciones. A través de este trabajo se ha pretendido que no desaparezca el factor humano, tan importante para estos pacientes. No solo se le da la facilidad de personalización y seguimiento de las terapias a los profesionales, sino que, gracias a la implicación del colectivo en el diseño, también se han incluido parámetros que den a los pacientes esta sensación de que el terapeuta sigue estando tras su terapia. Con este modelo no se ha pretendido en ningún momento el sustituir las sesiones de TEC realizadas en las asociaciones, sino complementarlas o hacérselas llegar a las personas que no pueden disfrutar de ellas.

Por último, la metodología utilizada para la generación de este modelo puede ser fácilmente utilizada para el análisis de las necesidades de otros colectivos vulnerables y para la asignación de otros tratamientos no farmacológicos. Por ejemplo, se podría realizar un estudio para generar una solución similar de TEC para personas con deterioro cognitivo asociado a otras patologías o para otro tipo de terapias, por ejemplo, para el fortalecimiento de rutinas relativas a las actividades de la vida diaria. Para poder conseguir la aplicabilidad de esta solución, sería necesario llevar a cabo un análisis exhaustivo de las necesidades del colectivo y de los requisitos de la terapia, al igual que se ha descrito a lo largo de esta tesis doctoral, para poder adaptar la plataforma presentada.

\subsection{Futuras líneas de investigación}

La primera línea de investigación a explotar sería la utilización de este modelo en otro entorno tecnológico. Durante en desarrollo de esta tesis doctoral, la doctoranda tutorizó un Trabajo Fin de Máster titulado Desarrollo de un sistema interactivo para estimulación cognitiva en HTML5 [Vergel, 2013], en el que se adaptó la primera versión del modelo a tecnologías web en su totalidad, permitiendo así la interoperabilidad entre plataformas. Se llevó a cabo una verificación técnica sobre diversos dispositivos (móvil, tableta, ordenador y televisión) para comprobar su interoperabilidad entre navegadores de distintas plataformas con resultados satisfactorios. Incluyendo las últimas aportaciones que se hicieron al modelo propuesto en esta tesis doctoral, se podría plantear un experimento para ver si la tecnología seleccionada para la implementación del modelo en este trabajo (tableta) estaría influyendo de forma positiva o negativa en la realización del experimento y sería más positivo la utilización de, por ejemplo, la televisión digital e interactiva.

Otra línea de investigación posible sería la utilización de la plataforma generada a partir del modelo desde el punto de vista de la terapia ocupacional y no desde el enfoque de la 
neuropsicología, en el que se centran las TEC. En el caso de este nuevo camino, los ejercicios podrían adaptarse a actividades de la vida cotidiana para reforzar rutinas de las actividades básicas de la vida diaria.

Por otro lado, sería muy interesante el planteamiento de un ensayo clínico una vez se ha verificado la validez del modelo propuesto y la satisfacción del uso durante la fase de experimentación. Este ensayo clínico pretendería la comprobación de la mejora o mantenimiento de las capacidades cognitivas de la persona con EP utilizando una plataforma basada en este modelo. Aunque hay numerosos estudios que demuestran las ventajas de la TEC como terapia no farmacológica para el mantenimiento de estas capacidades, se puede comprobar si el administrar estas terapias a través de las TIC tiene un impacto positivo en las capacidades del paciente. Para la realización del ensayo clínico sería necesario el control de la medicación de los pacientes, ya que hay medicamentos que pueden influir en la cognición. Además, debido al impacto del estado de ánimo en esta capacidad del individuo, también sería necesario registrarlo. Las pruebas deberían llevarse a cabo durante más tiempo y con más participantes para poder extrapolar los datos. Para la evaluación del estado cognitivo, se podría utilizar el mini-examen cognoscitivo de Lobo (MEC) [Lobo, 1980], la prueba más extendida y aceptada en España para la estimación del estado cognitivo, y aplicarla al inicio y al final del ensayo clínico.

Aparte de estas ideas, a nivel tecnológico se podrían llevar a cabo líneas de investigación centradas en la incorporación de técnicas de inteligencia artificial (IA) al modelo propuesto. La IA es la ciencia de la ingeniería encargada de hacer máquinas inteligentes, en particular, programas informáticos inteligentes que traten de simular aspectos de la mente humana [McCarthy, 2007]. La IA se basa en la generación de algoritmos matemáticos para el modelado de determinados comportamientos humanos.

A partir de mecanismos de IA se podría diseñar e implementar modelos para definir el perfil de los dos grupos de usuarios que interactúan en la plataforma, que son los pacientes con EP y los terapeutas que llevan a cabo las TEC con ellos.

En el caso de los pacientes se puede aplicar la IA para la detección de patrones ocultos a simple vista que revelen características comunes en ellos. Para ello, se pueden utilizar algoritmos de clasificación (scoring) que puedan modelizar las necesidades de un paciente y, gracias a ello, asignarle una terapia que esté más adaptada a esas necesidades, personalizando aún más la aplicación de la TEC. Además, la incorporación de métodos de IA podría ayudar a definir cuáles son las características que más incluyen en la satisfacción de uso del modelo planteado. De esta forma, a través de cambios en los parámetros de la TEC (por ejemplo, complejidad de la interfaz de la aplicación, adición de nuevos modelos de ejercicios, interfaz más visual o más textual, etc.) se podría conseguir una aplicación final más completa y adaptada a las necesidades de cada paciente.

El comportamiento de los terapeutas a la hora de evaluar los resultados de un bloque de ejercicios de un paciente en concreto también puede ser modelado. Se podría llevar a conseguir que la gestión de la terapia, a partir de los resultados previos de un paciente en concreto, se lleve a cabo de forma automática. De esta forma, sería el sistema de IA el que decida qué ejercicios de los existentes en la base de datos compongan el siguiente bloque que deberá realizar el paciente. Las ventajas de la inclusión de técnicas de IA en este contexto son 
numerosas. Por un lado, los terapeutas no tendrían tanta carga de trabajo evaluando ejercicios, por lo que podrían llegar a asistir a más pacientes, pudiendo incluir, de esta manera, a muchas más personas que las que pueden acercarse a las asociaciones. Por otro lado, la gestión de la terapia sería mucho más dinámica, ya que no habría que esperar a la acción del terapeuta para que el paciente dispusiera de nuevos bloques de ejercicios para ejecutar. Sin embargo, debido a que uno de los principales valores añadidos del modelo propuesto es la supervisión por el terapeuta, no todo sería automático. El terapeuta debería seguir añadiendo la valoración de los resultados a los ejercicios, comprobando así la evolución de en la cognición de los pacientes y dándoles realimentación y motivación para mantener la adherencia al tratamiento. Para comprobar la satisfacción de los usuarios una vez se introdujeran estos avances, sería necesaria la realización de más experimentos que pudieran evaluarla.

El modelo presentado en esta tesis doctoral podría verse afectado positivamente con la introducción de técnicas de IA. Además de los casos presentados anteriormente, se podría añadir un módulo estadístico que diera al terapeuta una mejor visión del estado cognitivo del paciente y la previsión de su evolución. Así, a través de mecanismos de analítica de datos, se podría realizar la visualización avanzada de los resultados del paciente, mostrándolos de forma clara e intuitiva, pudiendo mejorar, así, la calidad asistencial que se les da a los pacientes. 


\section{Referencias bibliográficas}

Las referencias bibliográficas se muestran por orden alfabético del apellido del autor $y$, en caso de coincidencia del apellido, por año de publicación de forma decreciente.

[Accenture, 2011]

[ACP, 2016]

$[A D, 2016]$

[AENOR, 2006]

[AMIC, 2016]

[APKM, 2017, 1]

[APKM, 2017, 2]
Accenture, Nokia and Accenture Finalize Symbian Software Development and Support Services Outsourcing Agreement, News release, junio de 2011, última consulta: mayo de 2017. [En línea] https://newsroom.accenture.com/news/nokia-and-accenturefinalize-symbian-software-development-and-support-servicesoutsourcing.htm

Associació Catalana per al Parkinson, El Parkinson, Blanes i Comarca de La Selva/Alt Maresme, última consultada: enero de 2016. [En línea] http://www.parkinsonblanes.org/El Parkinson.htm

Android Developers, What is API Level?, API Guides, APP Manifest, última consulta: diciembre de 2016. [En línea]

https://developer.android.com/guide/topics/manifest/uses-sdkelement.htm|\#ApiLevels

Agencia Española de Normalización y Certificación (AENOR), UNE-EN ISO 9241-110. Ergonomía de interacción persona-sistema. Parte 110: Principios de diálogo (ISO 9241-110:2006), diciembre de 2006.

Asociación de Medios de Información y Comunicación, Informe Mobile en España y en el Mundo 2016, Informe ditrendia 2016, 2016.

Asociación Parkinson de Madrid, última consulta: mayo de 2017. [En línea] www.parkinsonmadrid.org

Asociación Parkinson Madrid, Estimulación Cognitiva. Cognipark, noviembre de 2016, última consulta: mayo de 2017. [En línea] http://www.parkinsonmadrid.org/notas/se-presenta-cognipark-elunico-tratamiento-rehabilitador-especifico-para-la-demencia-enparkinson/ 
[APKM, 2016]

[APKM, 2007]

[APS, 2017]

[AS, 2016]

[Bachlin, 2010]

[Beck, 2005]

[Benito, 2003]

[Bloem, 2015]

[Boehm, 1986]

[Boehm, 1976]
Asociación Parkinson Madrid, Guía de bienvenida, diciembre de 2016.

Asociación de Parkinson de Madrid, Cuaderno de ejercicios. Consejos sobre trastornos cognitivos para pacientes con enfermedad de Parkinson, Biblioteca Parkinson, 2007.

Asociación Parkinson Salamanca, El símbolo de la enfermedad de Parkinson, última consulta: febrero de 2017. [En línea]

http://www.parkinsonsalamanca.org/index.php?option=com conte nt\&view $=$ article \&id $=50 \&$ Itemid $=62$

Android Source, The Android Source Code. Android stack, Android, última consulta: octubre de 2016. [En línea]

https://source.android.com/source/index.html

Bachlin, M., Plotnik, M., Roggen, D. et al., Wearable assistant for Parkinson's disease patients with the freezing of gait symptom, IEEE Transactions on Information Technology in Biomedicine, vol. 14, n. 2, pp. 436-446, 2010.

Beck, J. S., Cognitive therapy for challenging problems. What to do when the basics don't work, Guilford Press, 2005.

Benito-León, J., Bermejo-Pareja, F., Rodríguez, J., Molina, J.A., Gabriel, R., Morales, J.M., Neurological Disorders in Central Spain (NEDICES) Study Group. Prevalence of PD and other types of parkinsonism in three elderly populations of central Spain, Movement Disorders, 2003.

Bloem, B. R., de Vries N. M., Ebersbach, G., Nonpharmacological treatments for patients with Parkinson's disease, Movement Disorders, n. 11, vol. 30, pp. 1504-1520, 2015.

Boehm, B., A Spiral Model of Software Development and Enhancement, ACM SIGSOFT Software Engineering Notes, ACM, n. 11 vol. 4, pp. 14-24, agosto de 1986.

Boehm, B. W., Brown, J. R., Lipow, M., Quantitative evaluation of software quality, Proceedings of the 2 nd international conference on Software engineering, IEEE Computer Society Press, pp. 592-605, 1976. 
[Brave, 2002]

[Bravo, 2010]

[Castillo, 2016]

[CCN, 2009]

[CDC, 2011]

[CDTI, 2017]

[CDTI, 2014]

[CE 45/2001]

[CE, 1978]
Brave, S., Nass, C., Emotion in human-computer interaction, The Human-Computer Interaction Handbook: Fundamentals, Evolving Technologies and Emerging Applications, J. Jacko \& A. Sears, Hillsdale, NJ: Lawrence Erlbaum Associates, 2002.

Bravo, T., Glosario Ps. General 2a PP. Conceptos de los capítulos 1 al 10 2a PP Atención y percepción, Universidad Nacional de Educación a Distancia, marzo de 2010, última consulta: mayo de 2017. [En línea] http://www2.uned.es/ca-

bergara/ppropias/Ps general I/glosario.htm

Castillo, L., Descubren punto en que proteína daña neuronas en Parkinson, Saludiario, marzo de 2016, última consulta: mayo de 2017. [En línea] http://saludiario.com/descubren-punto-en-queproteina-dana-neuronas-en-parkinson/

Centro Caren Neurorehabilitación, Enfermedad de Parkinson, 2009, última consulta: mayo de 2017. [En línea]

http://www.neurorehabilitacion.com/enfermedad de parkinson.ht $\underline{\mathrm{m}}$

Centers for Disease Control and Prevention, Cognitive impairment: $a$ call for action, now!, Healthy Aging, febrero de 2011, última consulta: mayo de 2017. [En línea]

https://www.cdc.gov/aging/pdf/cognitive impairment/cogimp poil icy final.pdf

Centro para el Desarrollo Tecnológico Industrial, ¿Qué es Horizonte 2020?, Portal español del Programa Marco de Investigación e Innovación de la Unión Europea, última consulta: febrero de 2017. [En línea] http://www.eshorizonte2020.es/que-es-horizonte-2020

Centro para el Desarrollo Tecnológico Industrial, Guía del participante Horizonte 2020, Ministerio de Economía y Competitividad, junio de 2014.

Reglamento (CE) n 45/2001 del Parlamento Europeo y del Consejo, de 18 de diciembre de 2000, relativo a la protección de las personas físicas en lo que respecta al tratamiento de datos personales por las instituciones y los organismos comunitarios y a la libre circulación de estos datos, Comisión Europea, enero de 2001.

Constitución Española, artículo 49, 1978. 
[Chakrabortya, 2013] Chakrabortya, S., Ghosha, S. K., Jamthea, A. et al., Detecting mobility for monitoring patients with Parkinson's disease at home using RSSI in a Wireless Sensor Network, Procedia Computer Science, vol. 19, pp. 956-961, 2013.

[CNMC, 2015]

Comisión Nacional de Los Mercados y la Competencia, Informe sobre los consumos y gastos de los hogares españoles en los servicios de comunicaciones electrónicas, Primer semestre de 2014, n. ESTAD/CNMC/003/15, marzo de 2015.

[CogniFit, 2017]

Cognifit, ¿Qué es CogniFit?, última consulta: junio de 2017. [En línea] https://www.cognifit.com/es/que-es-cognifit

[Conde, 2013]

Conde Melguizo, R. La accesibilidad de la persona con discapacidad a la administración electrónica: análisis sociológico de estudio de caso en el proyecto ASTIC, Tesis Doctoral, Universidad de Sevilla, julio de 2013.

[Conde, 2011]

Conde Melguizo, R., Innovación metodológica: creación de técnicas cualitativas para la investigación sociológica con personas afectadas por Parkinson, XVI Congreso Nacional de Sociología en Castilla la Mancha / ACMS, noviembre de 2011.

[CPDC, 2017]

Centro de Prevención de Deterioro Cognitivo, Servicios, Ayuntamiento de Madrid, última consulta: marzo de 2017. [En línea] http://www.madrid.es/portales/munimadrid/es/Inicio/Serviciossociales-y-salud/Salud/Centro-de-Prevencion-de-DeterioroCognitivo?vgnextfmt $=$ default $\&$ vgnextoid $=492338 \mathrm{~d} 60 \mathrm{~b} 41 \mathrm{c010VgnV}$ CM2000000c205a0aRCRD\&vgnextchannel $=0815 c 8$ eb248fe410VgnV CM1000000b205a0aRCRD

[Daraio, 2007]

Daraio, C., Simar, L., Advanced robust and nonparametric methods in efficiency analysis: Methodology and applications, Springer Science \& Business Media, 2007.

[DECSAI, 2016]

Departamento de Ciencias de la Computación e Inteligencia Artificial, Especificación de requerimientos, Universidad de Granada, 2016, última consulta: mayo de 2017. [En línea] http://elvex.ugr.es/idbis/db/docs/design/2-requirements.pdf 
[DGIPYME, 2012]

[Díaz, 2006]

[Dorsey, 2007]

[DU, 2017]

[Dunlap-Shohl, 2016]

[EFHE, 2013]

[ENBM18, 2015]

[EPDA, 2007]
Resolución de 3 de septiembre de 2012, de la Dirección General de Industria y de la Pequeña y Mediana Empresa, por la que se publica la relación de normas UNE anuladas durante el mes de julio de 2012, octubre de 2012.

Díaz F., Villanueva M. A., Balo A., López A. et al., TeleGerontología: Un nuevo recurso de apoyo gerontológico a domicilio, Revista de estudios politécnicos, vol. III, n. 5/6, 2006.

Dorsey, E., Constantinescu, R., Thompson, J. P. et al., Projected number of people with Parkinson disease in the most populous nations, 2005 through 2030, Neurology, vol. 68, n. 5, pp. 384-386, 2007.

Duke University, What is QI?, Department of Community and Family Medicine, última consulta: mayo de 2017. [En línea] http://patientsafetyed.duhs.duke.edu/module a/introduction/intr oduction.html

Dunlap-Shohl, P., Isolation and Parkinson's Disease, The hiding and the hidden, Northwest Parkinson's Foundation, 08/04/2016, última consulta: mayo de 2017. [En línea] https://nwpf.org/stayinformed/blog/2016/04/isolation-and-parkinsons-disease,-thehiding-and-the-hidden/

European Foundation for Health and Exercise, Parkinson Home Exercises, iTunes, marzo de 2013, última consulta: mayo de 2017. [En línea]

https://itunes.apple.com/es/app/parkinson-homeexercises/id473641730? $\mathrm{mt}=8$

ENBM18, Os benefícios da fisioterapia em pacientes com dolença de Parkinson, Encontro Nacional de Biomedicina, 16/04/2015, última consulta: mayo de 2017. [En línea]

https://enbmoficial.wordpress.com/2015/04/16/os-beneficios-dafisioterapia-em-pacientes-com-doenca-de-parkinson/

European Parkinson's Disease Association, Projected number of people with Parkinson disease in the most populous nations, Neurology, 2007. 
[Europa Press, 2017]

[FEP, 2017]

[FEP, 2016]

[Forgas, 1998]

[Franco, 2010]

$[\mathrm{FT}, 2015]$

[García, 2013]

[García, 2012]

[García, 2010]
Europa Press, Hasta un 85\% de los cuidadores de pacientes con Parkinson sufre estrés emocional, Infosalus, 24/02/2017. [En línea] http://www.infosalus.com/asistencia/noticia-85-cuidadorespacientes-parkinson-sufre-estres-emocional-20170224123725.html

Federación Española de Parkinson, La Federación, febrero de 2017. [En línea]

http://www.fedesparkinson.org/index.php?r=site/page\&id=299\&tit le=La Federaci\%C3\%B3n

Federación Española de Parkinson, Síntomas frecuentes, Sobre el Parkinson, junio de 2016. [En línea]

http://www.fedesparkinson.org/index.php?r=site/page\&id=24\&tit| $\mathrm{e}=\mathrm{S} \% 25 \mathrm{C} 3 \% 25 \mathrm{ADntomas}$ frecuentes\&idm $=38$

Forgas, J. P., On feeling good and getting your way: Mood effects on negotiator cognition and bargaining strategies, Journal of personality and social psychology, n. 74, vol. 3, pp. 565-577, 1998.

Franco M. A., Bueno Y., Cid T., Orihuela T. Programa GRADIOR: rehabilitación cognitiva por ordenador, Fundación INTRAS, junio de 2010, última consulta: mayo de 2017. [En línea]

http://psicologia-online.com/ciopa2001/actividades/09/index.html

Fundación Telefónica, Informe de la Sociedad de la Información en España 2014, editorial Ariel, enero de 2015.

García Vázquez, C. et al., Servicio ubicuo de estimulación cognitiva orientado a personas con enfermedad de Parkinson, XI Jornadas de Ingeniería Telemática (JITEL 2013), Granada, pp. 273-280, octubre de 2013, ISBN 978-84-616-5597-7.

García Vázquez, C. et al., Distributed system for cognitive stimulation over interactive TV. Information Technology in Biomedicine, IEEE Transactions on, vol. 16, no 6, pp. 1115-1121, 2012.

García Vázquez, C., Diseño de un modelo interactivo basado en Televisión Digital para estimulación cognitiva, Trabajo Fin de Máster, EUIT de Telecomunicación, Universidad Politécnica de Madrid, octubre de 2010. 
[García, 2009]

[García, 2006]

[García, 2000]

[Goldman, 2011]

[Goldsworthy, 2008]

[González, 2008]

[H2020, 2017]

[H2020, 2016]

[Hartson, 1998]
García Sevilla, J., Tema 2. Estrategias de intervención, Estimulación cognitiva, Departamento de Psicología Básica y Metodología, Facultad de Psicología, Universidad de Murcia, septiembre de 2009.

García Vázquez, C., Aplicación web para la planificación y valoración de ejercicios de estimulación cognitiva accesibles desde dispositivos móviles, Proyecto Fin de Carrera, EUIT de Telecomunicación, Universidad Politécnica de Madrid, noviembre de 2006.

García de Yébenes, J., La estimulación cognitiva será beneficiosa en ciertos pacientes, Terapia-Ocupacional.com, 12 de julio de 2000, última consulta: mayo de 2017. [En línea] http://www.terapiaocupacional.com/articulos/estimulacioncognitiva.shtml

Goldman, J. G., Cognitive Issues in Parkinson's Disease, American Parkinson Disease Association, 2011, última consulta: mayo de 2017. [En línea] http://www.apdaparkinson.org/cognitive-issues-inparkinsons-disease/

Goldsworthy, B., Knowles, S., Caregiving for Parkinson's disease patients: an exploration of a stress-appraisal model for quality of life and burden, The Journals of Gerontology Series B: Psychological Sciences and Social Sciences, vol. 63, n. 6, pp. 372-P376, 2008.

González Campos, M., Diseños experimentales de investigación, Monografías, 2008, última consulta: mayo de 2017. [En línea] http://www.monografias.com/trabajos10/cuasi/cuasi.shtml

European Commission, What is Horizon 2020?, Horizon 2020, última consulta: mayo de 2017. [En línea]

https://ec.europa.eu/programmes/horizon2020/en/what-horizon$\underline{2020}$

European Commission, 8. Health, demographic change and wellbeing, Work Programme 2016-2017, Horizon 2020, 2016.

Hartson, H.R., Human-computer interaction: Interdisciplinary roots and trends, The Journal of Systems and Software, no 43, pp. 103-118, 1998. 
[Hassan, 2005]

[HDA, 2006]

[Hiroshima, 2014]

[Hoehn, 1998]

[Hughes, 1982]

[IDF, 2014]

[IMSERSO, 2009]

[IMSERSO, 2004]
Hassan, Y., Martín, F., La experiencia del usuario, No solo usabilidad, septiembre de 2005, última consulta: mayo de 2017. [En línea] http://www.nosolousabilidad.com/articulos/experiencia del usuar io.htm

Cátedra COITT, Hogar Digital Accesible, Universidad Politécnica de Madrid, mayo de 2006, última consulta: mayo de 2017. [En línea] http://www.etsist.upm.es/estaticos/catedracoitt/web HD/inicio.htm

Hiroshima, Y., Miyamoto, H., Nakamura, F., et al., The protein Ocular albinism 1 is the orphan GPCR GPR143 and mediates depressor and bradycardic responses to DOPA in the nucleus tractus solitarii, $\mathrm{Br} \mathrm{J}$ Pharmacol, vol. 171, n. 2, pp. 403-14, enero de 2014.

Hoehn, M. M., Yahr, M. D., Parkinsonism: onset, progression, and mortality, Neurology, vol. 50 n. 2, pp. 318-318, 1998.

Hughes, C. P., Berg, L., Danziger, W. L. et al., A new clinical scale for the staging of dementia, The British journal of psychiatry, vol. 140, no 6, pp. 566-572, 1982.

Lowgren, J., Carroll, J. M., Hassenzahl, M. et al., The Encyclopedia of Human-Computer Interaction, 2a edición, Interaction Design Foundation, 2014, última consulta: mayo de 2017. [En línea] https://www.interaction-design.org/literature/book/theencyclopedia-of-human-computer-interaction-2nd-ed

Instituto de Mayores y Servicios Sociales, Proyectos subvencionados 2008. Plataforma TIC accesible para el mantenimiento de capacidades cognitivas en enfermos de Parkinson, Proyectos de investigación científica, desarrollo e innovación tecnológica, subvencionados en la convocatoria de 2008, dentro del Área de Acciones Estratégicas, Acción Estratégica de Salud, en el marco del Plan Nacional de Investigación Científica, Desarrollo e Innovación Tecnológica 2008-2011, julio de 2009.

Instituto de Mayores y Servicios Sociales, Libro blanco de atención a las personas en situación de dependencia en España, Secretaría de Estado de Servicios Sociales, Familias y Discapacidad, Ministerio de Trabajo y Asuntos Sociales, diciembre de 2004. 
[INE, 2016]

[INE, 2014]

[INE, 2008, 1]

[INE, 2008, 2]

[INTRAS, 2004]

[ISO 9241-210:2010]

[Istepanian, 2004]

[Jordan, 1998]

[Khetrapal, 2015]
Instituto Nacional de Estadística, Población residente en España a 1 de enero, por sexo, edad y año, Proyecciones de población 20162066, Resultados nacionales, octubre de 2016.

Instituto Nacional de Estadística, Encuesta sobre equipamiento y uso de las Tecnologías de la Información y la Comunicación en los hogares, 2014.

Instituto Nacional de Estadística, Población con discapacidad que tiene diagnosticadas determinadas enfermedades crónicas según la enfermedad por edad y sexo, Encuesta de Discapacidad, Autonomía Personal y Situación de Dependencia 2008, Discapacidades, Deficiencias y estado de Salud, Resultados nacionales: cifras absolutas, 2008.

Instituto Nacional de Estadística, Tasa de población con discapacidad que tiene diagnosticadas determinadas enfermedades crónicas según la enfermedad por CCAA y sexo, Encuesta de Discapacidad, Autonomía Personal y Situaciones de Dependencia 2008, Discapacidades, Deficiencias y Estado de Salud, Comunidades Autónomas: cifras relativas, 2008.

Fundación INTRAS, Programa GRADIOR, 2004, última consulta: mayo de 2017. [En línea] http://www.intras.es/index.php?id=456

ISO 9241-210, Ergonomics of human-system interaction. Part 210: Human-centred design for interactive systems, International Organization for Standardization, 2010.

Istepanian, R. S. H., Jovanov, E., Zhang, Y. T., Guest Editorial Introduction to the Special Section on M-Health: Beyond Seamless Mobility and Global Wireless Health-Care Connectivity, IEEE Transactions on Information Technology in Biomedicine, vol. 8, n. 4, pp. 405-414, diciembre de 2004.

Jordan, P. W., Human factors for pleasure in product use, Applied Ergonomics, vol. 29, no 1, pp. 25-33, 1998.

Khetrapal, A., Telemedicine Benefits, News Medical, 12/11/2015, última consulta: mayo de 2017. [En línea]

http://www.news-medical.net/health/Telemedicine-Benefits.aspx 
[Kothari, 2004]

[Koven, 2007]

[Kübler-Ross, 1970]

[Lauriks, 2007]

[Levy, 2002]

[Lobo, 1980]

[LOPD, 1999]

[López, 2008]

[Maguire, 2002]

[Mak, 2008]

[Maraña, 2003]
Kothari, C. R., Research methodology: Methods and techniques, New Age International, 2004.

Koven, N. S., Roth, R. M., Coffey, D. J. et al., Cognitive Performance and Self-Reported Functioning in Daily Life Among Those with Parkinson's Disease: A Brief Report, The Internet Journal of Mental Health, vol. 3, no 2, 2007.

Kübler-Ross, E., The Care of the Dying - Whose Job is it?, Psychiatry in medicine, vol. 1, n. 2, pp. 103-107, 1970

Lauriks, S., Reinersmann, A., Van der Roest, H. G. et al., Review of ICTbased services for identified unmet needs in people with dementia, Ageing Research Reviews, Elsevier, cap. 6, pp. 223-246, 2007.

Levy, M. L., Enfermedad de Parkinson, Lauterbach EC, Abordaje psiquiátrico en las enfermedades neurológicas, Psiquiatría, 2002.

Lobo, A., Escobar, V., Ezquerra, J. et al., El Mini-Examen Cognoscitivo. Un test sencillo, práctico, para detectar alteraciones intelectuales en pacientes psiquiátricos, Revista de Psiquiatría y Psicología Médica, 1980.

Ley Orgánica 15/1999, de 13 de diciembre, de Protección de Datos de Carácter Personal, Boletín Oficial del Estado, 14 de diciembre de 1999.

Lopez, V. M., Decatur, C. L., Stamer, W. D., et al., L-DOPA is an endogenous ligand for OA1, PLoS Biol, vol. 6, n.9, 2008.

Maguire, M., Bevan, N., User requirements analysis. A review of supporting methods, Proceedings of IFIP 17th World Computer Congress, Montreal, Canadá, pp. 133-148, Kluwer Academic Publishers, 2002.

Mak, M., Neurorehabilitation as a form of treatment in mental diseases, Terapia, vol.16, n. 1, pp. 47-49, 2008.

Maraña, J. L., El movimiento de vida independiente en España, El movimiento de vida independiente: experiencias internacionales, J. Vidal, Fundación Luis Vives, 2003. 
[Marchick, 1999]

[Marsh, 2009]

[Martín, 2015]

[May, 2007]

[Mayo, 2015]

[Mazilu, 2012]

[McCarthy, 2007]

[Meireles, 2012]
Marchick, A., Yu, E. Robles, L. et al., Digital Divide, Computer Science, Stanford University, 1999, última consulta: mayo de 2017. [En línea] http://cs.stanford.edu/people/eroberts/courses/cs181/projects/19 99-00/digital-divide/start.html

Marsh, E. B., No Solo un Trastorno del Movimiento: Cambios Cognitivos en la Enfermedad de Parkinson, Parkinson's Disease Foundation, 2009, última consulta: mayo de 2017. [En línea] http://www.pdf.org/pdf/fses cambios cognitivos 09.pdf

Martín, M. 6 test de usabilidad fundamentales para asegurar la experiencia de usuario, Diseño de interacción, IDA Blog, marzo de 2015, última consulta: mayo de 2017. [En línea] https://www.ida.cl/blog/estrategia-digital/test-usabilidadfundamentales-asegurar-experiencia-usuario/

May, A., Hajak, G., Gänssbauer, S. et al., Structural brain alterations following 5 days of intervention: dynamic aspects of neuroplasticity, Cerebral Cortex, vol. 17, n. 1, pp. 205-210, 2007.

Mayo Clinic Staff, Parkinson's disease Symptoms, Diseases and Conditions, Parkinson's disease, Mayo Clinic, julio de 2015, última consulta: mayo de 2017. [En línea]

http://www.mayoclinic.org/diseases-conditions/parkinsonsdisease/basics/symptoms/con-20028488

Mazilu, S.; Hardegger, M.; Zhu, Z. et al., Online detection of freezing of gait with smartphones and machine learning techniques, Pervasive Computing Technologies for Healthcare (PervasiveHealth), 2012 6th International Conference on, pp. 123-130, mayo de 2012.

McCarthy, J., What is artificial intelligence?, Formal Reasoning Group, Stanford University, noviembre de 2007, última consulta: mayo de 2017. [En línea]

http://www-formal.stanford.edu/imc/whatisai/node1.html

Meireles, J., Massano, J., Cognitive impairment and dementia in Parkinson's disease: clinical features, diagnosis, and management, Frontiers in Neurology, vol. 3, n. 88, 2012. 
[Meza-Kubo, 2010]

[MJFF, 2016]

[Molina, 2017]

[Morán, 2009]

[Moreno, 2006]

[Morley, 2014]

[Mosby, 2009]

[Muras, 2006]

[Muslimovi, 2005]

[MySQL, 2016]
Meza-Kubo, V., Morán, A. L., Rodríguez, M., IntouchFun, a Pervasive Collaborative System to Cope with Elder's Isolation and Cognitive Decline, 12th ACM International Conference on Ubiquitous Computing (UbiComp 2010), Copenhague, septiembre de 2010.

The Michael J. Fox Foundation for Parkinson's research, Web Fox Trial Finder, última consulta: enero de 2016. [En línea] https://foxtrialfinder.michaelifox.org/

Molina, B., The biggest moments in the history of iPhone, USA Today, Tech, 09/01/2017, última consulta: mayo de 2017. [En línea] https://www.usatoday.com/story/tech/news/2017/01/09/10biggest-moments-history-iphone/96337396/

Morán, A. L., Meza-Kubo, V., Towards a tele-assistance service for the cognitive stimulation of elders with cognitive decline, International Conference on eHealth, Telemedicine and Social Medicine, pp. 160165, 2009.

Moreno Martínez, E., Plataforma J2ME para la realización y seguimiento de ejercicios de estimulación cognitiva accesibles mediante un servicio web, Proyecto Fin de Carrera, EUIT de Telecomunicación, Universidad Politécnica de Madrid, noviembre de 2006.

Morley, J. E., Cruz-Oliver, D. M., Cognitive stimulation therapy, Journal of the American Medical Directors Association, 15(10), 689, 2014.

Mosby's Medical Dictionary, Gold standard, Elsevier, 2009.

Muras, J., Cahill, V., Stokes, E., A taxonomy of pervasive healthcare systems, Pervasive Health Conference and Workshops, pp. 1-10, 2006.

Muslimovi, D., Post B., Speelman J. D., Schmand B., Cognitive profile of patients with newly diagnosed Parkinson disease, Neurology, vol. 65, pp. 1239-1245, 2005.

MySQL Project. MySQL 5.7 Reference Manual, última consulta: diciembre de 2016. [En línea]

http://dev.mysql.com/doc/refman/5.7/en/ 
[Navarra, 2009]

[NeuronUP, 2017]

[NICE, 2016]

[Nielsen, 1990]

[NPF, 2017]

[NPF, 2013]

[NPF, 2011]

[Ofarrill, 2016]

[Olesen, 2012]
Gobierno de Navarra, Guía para medir la satisfacción respecto a los servicios prestados, Cartas de servicio, 2009, última consulta: mayo de 2017. [En línea] http://www.navarra.es/NR/rdonlyres/5A006CFC7EBC-4A3F-9FA5-

\section{ADA817D8/0/GuiaPARAMEDIRLASATISFACCION2012.pdf}

NeuronUP, ¿Qué es NeuronUP?, última consulta: junio de 2017. [En línea]

https://www.neuronup.com/es/plataforma-rehabilitacion-cognitiva

National Institute for Health and Clinical Excellence, Dementia: supporting people with dementia and their careers in health and social care, NICE clinical guideline 42, septiembre de 2016, última consulta: mayo de 2017. [En línea] www.nice.org.uk/guidance/cg42

Nielsen, J., Molich, R., Heuristic evaluation of user interfaces, Proc. ACM CHI'90 Conf., pp. 249-256, Seattle, abril de 1990.

National Parkinson Foundation, Non-motor symptoms, Understanding Parkinson's, última consulta: febrero de 2017. [En línea] http://www.parkinson.org/understanding-parkinsons/nonmotor-symptoms

National Parkinson Foundation, Parkinson's Toolkit: A Free Reference and Resource for Clinicians, marzo de 2013, última consulta: mayo de 2017. [En línea]

http://www.toolkit.parkinson.org/sites/toolkit.parkinson.org/files/r esources/PD\%20 The\%20Basics.pdf

National Parkinson Foundation, What's Hot in PD? Should I get a DaTsan or PET scan to confirm my diagnosis of Parkinson's disease?, febrero de 2011, última consulta: mayo de 2017. [En línea] http://www.parkinson.org/find-help/blogs/whats-hot/february$\underline{2011}$

Ofarrill, J. C., Parkinson y cognición: cómo afecta el Parkinson a las capacidades mentales, TiTi, 06/06/2016, última consulta: mayo de 2017. [En línea] http://www.2ti.es/2016/06/parkinson-cognicioncapacidades-mentales/

Olesen, J., Gustavsson, A., Svensson, M. et al., The economic cost of brain disorders in Europe, European journal of neurology, vol. 19, n. 1, pp. 155-162, 2012. 
[OMS, 2004]

[ONTSI, 2016]

[Patel, 2009]

[PDF, 2017, 1]

[PDF, 2017, 2]

[Peñas, 2015]

[Perry, 1985]

[Poewe, 2008]

[Prats, 2007]

[Pressman, 2014]
Organización Mundial de la Salud, Global Declaration for Parkinson's Disease 'Moving and Shaping', 2004.

Observatorio Nacional de las Telecomunicaciones y de la Sociedad de la Información, Perfil sociodemográfico de los internautas, Análisis de datos INE 2016, 2016.

Patel, S., Lorincz, K., Hughes, R. et al., Monitoring motor fluctuations in patients with Parkinson's disease using wearable sensors, Information Technology in Biomedicine, IEEE Transactions on, vol. 13, n. 6, pp. 864-873, noviembre de 2009.

Parkinson's Disease Foundation, What is Parkinson's Disease?, Understanding Parkinson's, , última consulta: mayo de 2017. [En línea] http://www.pdf.org/about pd

Parkinson's Disease Foundation, Statistics on Parkinson's, Understanding Parkinson's, última consulta: mayo de 2017. [En línea] http://www.pdf.org/en/parkinson statistics

Peñas Domingo, E., Gálvez Sierra, M., Marín Valero, M. et al., Libro Blanco del Parkinson en España. Aproximación, análisis y propuesta de futuro, Real Patronato sobre Discapacidad (Ministerio de sanidad, Servicios Sociales e Igualdad). Federación Española de Parkinson, 2015.

Perry, E. K., Curtis, M., Dick, D. J., et al., Cholinergic correlates of cognitive impairment in Parkinson's disease: comparisons with Alzheimer's disease, Journal of Neurology, Neurosurgery \& Psychiatry, vol. 48, n. 5, pp. 413-421, 1985.

Poewe, W., Non-motor symptoms in Parkinson's disease, European Journal of Neurology, vol. 15, n. s1, pp. 14-20, 2008.

Prats París, A., Bayés Rusiñol, A., Consejos sobre trastornos cognitivos para pacientes con enfermedad de Parkinson, Unidad de Parkinson, Centro Médico Teknon, 2007, última consulta: mayo de 2017. [En línea] http://www.aep-taray.org/portal/images/pdf/cognitiva.pdf

Pressman, R. S., Ingeniería del Software: Un enfoque práctico, 7ạ edición, McGraw Hill, 2014. 
[RAE, 2014, 1]

[RAE, 2014, 2]

[RAE, 2014, 3]

[RAE, 2014, 4]

[RAE, 2014, 5]

[RD 1720/2007]

[RD 1494/2007]

[Rego, 2010]

[REMPARK, 2015]

[Richter, 2016]
Real Academia Española, Mejorar, Diccionario de la Lengua Española, 23ạ edición, 2014.

Real Academia Española, Disponibilidad, Diccionario de la Lengua Española, 23a edición, 2014.

Real Academia Española, Versatilidad, Diccionario de la Lengua Española, 23a edición, 2014.

Real Academia Española, Ubicuo, Diccionario de la Lengua Española, 23a edición, 2014.

Real Academia Española, Investigar, Diccionario de la Lengua Española, 23a edición, 2014.

Real Decreto 1720/2007, de 21 de diciembre, por el que se aprueba el Reglamento de desarrollo de la Ley Orgánica 15/1999, de 13 de diciembre, de protección de datos de carácter personal, enero de 2008, vigente desde enero de 2010.

Real Decreto 1494/2007, de 12 de noviembre, por el que se aprueba el Reglamento sobre las condiciones básicas para el acceso de las personas con discapacidad a las tecnologías, productos y servicios relacionados con la sociedad de la información y medios de comunicación social, noviembre de 2007.

Rego, P., Moreira, P. M., Reis, L. P., Serious Games for rehabilitation. A survey and classification towards a taxonomy, Information Systems and Technologies (CISTI), 2010 5th Iberian Conference on. IEEE, pp. 1-6, junio de 2010.

REMPARK Project Workshop, abril de 2015, última consulta: mayo de 2017. [En línea] http://www.rempark.eu/

Richter, F. The Smartphone Platform War is Over, Statista, agosto de 2016, última consulta: mayo de 2017. [En línea] https://www.statista.com/chart/4112/smartphone-platformmarket-share/ 
[Rivera, 2005]

[Ronda, 2013]

[Rubin, 2008]

[SA, 2017]

[Sancho, 2007]

[Schuhfried, 2009]

[Sinapsis, 2017]

[Skiba, 2008]

[Sohlberg, 2001]
Rivera Navarro, J., Un análisis de los grupos de ayuda mutua y el movimiento asociativo en el ámbito de la salud: adicciones y enfermedades crónicas, Revista de antropología experimental, Universidad de Jaén, n. 5, 2005, última consulta: mayo de 2017. [En línea]

\section{http://revista.ujaen.es/huesped/rae/articulos2005/rivera05.pdf}

Ronda León, R., Diseño de la Experiencia de Usuario: etapas, actividades, técnicas y herramientas, No solo usabilidad, junio de 2013, última consulta: mayo de 2017. [En línea]

http://www.nosolousabilidad.com/articulos/uxd.htm?utm source= feedly

Rubin, J., Chisnell, D., Spool, J., Handbook of Usability Testing: How to Plan, Design, and Conduct Effective Tests, Wiley, 2008.

Scrum Alliance, What is Scrum? An Agile Framework for Completing Complex Projects, última consulta: mayo de 2017. [En línea] https://www.scrumalliance.org/why-scrum

Sancho Castiello, M., Díaz Martín, R., Castejón Villarejo, P. et al., Las personas mayores y las situaciones de dependencia, Revista del Ministerio de Trabajo e Inmigración, n. 70, pp. 13-43, 2007.

Schuhfried GmbH., RehaCom catalogue, Schuhfried $\mathrm{GmbH}$, diciembre de 2009, última consulta: mayo de 2017. [En línea] http://www.schuhfried.at/fileadmin/pdf eng/catalog RehaCom en.pdf

Sinapsis.org, Enfermedad de Parkinson, Trastornos cognoscitivos, , última consulta: mayo de 2017. [En línea]

http://www.sinapsis.org/park diagnostico.html

Skiba, D. J., Games for Health, Nursing Education Perspectives, Emerging Technologies Center, vol. 29, n. 4, pp. 230-232, julio de 2008.

Sohlberg, M. M., Mateer, C. A., Cognitive rehabilitation: an integrative neuropsychological approach, New York, Guilford Press, 2001. 
[Spector, 2003]

[Tan, 2005]

[Tárraga, 1999]

[THI, 2017]

[TPG, 2017]

[Trend, 2002]

$[U C P, 2016]$

[UNE 139803:2012]

[UNE-ISO 9241-110:2006] Agencia Española de Normalización y Certificación (AENOR), UNE-EN ISO 9241-110. Ergonomía de interacción persona-sistema. Parte 110: Principios de diálogo (ISO 9241-110:2006), diciembre de 2006.

[UKY, 2017]
Spector, A., Thorgrimsen, L., Woods, B. et al., Efficacy of an evidencebased cognitive stimulation therapy programme for people with dementia: Randomised Controlled Trial, British Journal of Psychiatry, n. 183, pp. 248-254, 2003.

Tan, J., E-Health Care Information Systems: An Introduction for Students and Professionals, Jossey-Bass, 2005.

Tárraga, L., Boada, M., Morera, A. et al, Volver a empezar. Ejercicios prácticos de estimulación cognitiva para enfermos de Alzheimer, Fundació ACE, Institut Català de Neurociències Aplicades, Ed. Novartis, Barcelona, 1999.

Texas Heart Institute, What is a Clinical Trial?, Heart Information Center, , última consulta: mayo de 2017. [En línea] http://www.texasheart.org/HIC/Topics/FAQ/clinical trials.cfm

The Paciello Group, Colour Contrast Analyzer, última consulta: mayo de 2017. [En línea]

https://www.paciellogroup.com/resources/contrastanalyser/

Trend, P., Kaye, J., Gage, H., Owen, C., Wade, D., Short-term effectiveness of intensive multidisciplinary rehabilitation for people with Parkinson's disease and their caregivers, Clin Rehabil, vol. 16, pp. 717-725, 2002.

Unidos Contra el Parkinson, Los parkinsonismos o síndromes parkinsonianos, Investigación Parkinson, agosto de 2016, última consulta: mayo de 2017. [En línea]

https://portal.unidoscontraelparkinson.com/investigacionparkinson/1588-los-parkinsonismos-0-s\%C3\%ADndromesparkinsonianos.html

Agencia Española de Normalización (AENOR), UNE 139803. Requisitos de accesibilidad para contenidos en la web, julio de 2012
University of Kentuky, Information Communication Technology, College of Communication and Information, última consulta: mayo de 2017. [En línea] https://ci.uky.edu/sis/ict 
[USDHHS, 2016]

[Vera, 2006]

[Vergel, 2013]

[WAI, 2016]

[WCAG, 2008]

[WFOT, 2016]

[WHO, 2009]

[WHO, 2003]

[Zamarro, 2014]
U.S. Department of Health \& Human Services, Methods, What \& Why of Usability, última consulta: diciembre de 2016. [En línea] https://www.usability.gov/how-to-and-tools/methods/index.html

Vera Cuesta, H., Vera Acosta, H., Álvarez González, L. et al., Disfunción frontal en la enfermedad de Parkinson idiopática, Revista de Neurología, enero de 2006.

Vergel Martín, T., Desarrollo de un sistema interactivo para estimulación cognitiva en HTML5. Trabajo Fin de Máster, ETS Ingeniería y Sistemas de Telecomunicación, Universidad Politécnica de Madrid, abril de 2013.

Word Wide Web Consortium, Web Accessibility Initiative (WAl), 2016, última consulta: mayo de 2017. [En línea] https://www.w3.org/WAl/

World Wide Web Consortium, Web Content Accessibility Guidelines (WCAG) 2.0, diciembre de 2008, última consulta: mayo de 2017. [En línea] https://www.w3.org/TR/WCAG20/

World Federation of Occupational Therapists, Collaboration between WFOT and WHO, 2016, última consulta: mayo de 2017. [En línea] http://www.wfot.org/Groups/WorldHealthOrganisationWHO.aspx

World Health Organization, Human Factors in Patient Safety. Review of Topics and Tools. Report for Methods and Measures Working, Group of WHO Patient Safety, abril de 2009.

World Health Organization, Adherence to long-term therapies. Evidence for action, Noncommunicable Diseases and Mental Health, 2003.

Zamarro, J., Miguel Ángel Valero, nuevo director del Ceapat, Revista Autonomía Personal, Instituto de Mayores y Servicios Sociales (IMSERSO), Ministerio de Sanidad, Servicios Sociales e Igualdad, Gobierno de España, 11 de diciembre de 2014. 
[Zimmerman, 2015] Zimmerman, R., Living with Parkinson's, ed. Paperbak, octubre 2015, última consulta: mayo de 2017. [En línea]

https://books.google.es/books?id=mdnZCgAAQBAJ\&pg=PT18\&lpg=

PT18\&dq=denial+anger+bargaining+depression+acceptance+parkin son\&source=bl\&ots=ZELuPw3u Q\&sig=fDE6xLM3wXPxt4unm85K4i xkX2M\&hl=es\&sa=X\&ved=0ahUKEwiM7fj0p8LRAhXHbxQKHT84C20 Q6AEIPJAE\#v=onepage\&q=denial\%20anger\%20bargaining\%20depre ssion $\% 20$ acceptance $\% 20$ parkinson $\& f=$ false 


\title{
Anexo I. Cuestionario para el consentimiento del paciente
}

\author{
En este primer anexo se recogen la información relativa al tratamiento de datos de \\ carácter personal, a la fotografía y a la filmación de las sesiones llevadas a cabo por \\ los pacientes para la evaluación de los prototipos que se han ido desarrollando \\ durante el proceso de Diseño Centrado en el Usuario.
}

\section{Hoja de Consentimiento Informado}

Le estamos pidiendo que participe en la verificación tecnológica de un dispositivo de tipo tableta para la utilización de una aplicación de estimulación cognitiva por parte de pacientes con Parkinson.

Participando en esta validación nos ayuda a comprobar la utilidad y la idoneidad de la tableta como dispositivo para este proyecto.

Firmando esta hoja nos está dando permiso para usar las frases que usted diga y los vídeos y fotos que podamos realizarle, con el objetivo de evaluar el dispositivo y mostrar los resultados de esta evaluación. No usaremos su nombre ni cualquier otra información identificable. Las fotos o vídeos que le hagamos no se utilizarán para anuncios comerciales ni publicaciones. Este estudio se realiza con el único objetivo de investigar y mejorar el proyecto. Cualquier información personal que nos dé será considerada estrictamente confidencial, y no se asociará con su identidad en nuestros resultados.

Estamos evaluando el dispositivo, no a usted. No hay respuestas incorrectas o malas, sino que los problemas que puedan surgir hoy cuando utilice el dispositivo nos van a ser siempre útiles para conocer cómo sería su manejo por parte de usuarios reales. Esperamos poder elegir un dispositivo adecuado para esta aplicación gracias a sus comentarios.

Si durante la sesión se siente incómodo/a en algún aspecto, siéntase libre de dejarlo en cualquier momento.

Si está de acuerdo con estos términos, por favor, indíquenos su conformidad firmando a continuación:

Fecha:

Nombre:

Firma: 


\section{Anexo II. Formulario Comité de Ética. Universidad Politécnica de Madrid}

En este anexo se recoge el formulario firmado por Miguel Ángel Valero, investigador principal del proyecto DaleMov, que se entregó al Comité de Ética de la Universidad Politécnica de Madrid con fecha 18 de octubre de 2013.

FORMULARIO PARA EVALUACIÓN POR EL COMITÉ DE ÉTICA

Proyectos de investigación con seres humanos: Protección de datos personales

\begin{tabular}{|l|l|}
\hline Nombre del responsable & Miguel Ángel Valero Duboy \\
\hline Título del proyecto & $\begin{array}{l}\text { Extensión y mantenimiento del sistema DaleMov para uso } \\
\text { multiasociación (DaleMov+) }\end{array}$ \\
\hline $\begin{array}{l}\text { Departamento/Grupo de } \\
\text { Investigación }\end{array}$ & $\begin{array}{l}\text { Grupo de Investigación Sistemas Telemáticos para la Sociedad } \\
\text { de la Información y el Conocimiento }\end{array}$ \\
\hline $\begin{array}{l}\text { Centro/Instituto de } \\
\text { I+D+i/Escuela }\end{array}$ & $\begin{array}{l}\text { Escuela Técnica Superior de Ingeniería y Sistemas de } \\
\text { Telecomunicación }\end{array}$ \\
\hline
\end{tabular}

\section{Cuestionario}

1. Los investigadores firmantes de la propuesta demuestran ser conocedores de los procesos y protocolos que deben cumplir relativos a la protección de datos:

1.1. Ley Orgánica 15/1999, de 13 de diciembre, sobre la Protección de Datos de Carácter Personal.

1.2. Real Decreto $1720 / 2007$ de 21 de diciembre, por el que se aprueba el Reglamento de desarrollo de la Ley orgánica 15/1999 (BOE № 17 de 19 de enero de 2008, pág. 41034136).

1.3. Ley $41 / 2002$, de 14 de noviembre, ley básica reguladora de la autonomía del paciente y de derechos y obligaciones en materia de información y documentación clínica. 
2. Los miembros del equipo investigador se comprometen a respetar la confidencialidad de los datos personales de este estudio y harán explícito este compromiso ante todas las personas que participen en el proyecto.

3. Si ha lugar (p.ej. en caso de utilización de encuestas) se incluye el consentimiento informado, en el que se explicita que el encuestado puede ejercitar su derecho de cancelación, así como que otorga su permiso para procesar dichos datos de forma automatizada.

4. Finalmente, el abajo firmante declara conocer la legislación relativa a la protección de datos, y se compromete a cumplirla.

Fdo.: Miguel Ángel Valero Duboy

Investigador Principal del Proyecto

Madrid, a 18 de octubre de 2013 


\title{
Anexo III. Cuestionarios para la evaluación
}

\author{
En este primer anexo se presentan los cuestionarios definidos para la evaluación de \\ los pilotos tanto con pacientes como con terapeutas, para comprobar el grado de \\ satisfacción de utilización de las TIC en este ámbito de aplicación.
}

\section{III.1. Resumen de los cuestionarios}

Como se ha comentado en apartados anteriores, los cuestionarios diseñados para valorar el grado de aceptación del servicio, tanto de pacientes como de terapeutas, pretenden recoger la mayor cantidad de información posible de los experimentos. Sin embargo, debido a los problemas de atención de este tipo de pacientes, se ha optado por cuestionarios con pocas preguntas ( 7 en el caso de los pacientes y 9 en el de los terapeutas) que se pudieran contestar en un tiempo reducido.

Para el diseño de los cuestionarios se ha utilizado un lenguaje claro, conciso y sencillo. De esta forma pretendíamos conseguir que la pregunta llegara claramente al destinatario, sin malentendidos. Además, para la definición de las respuestas, se utiliza texto apoyado por iconografía fácilmente interpretable, con contraste de colores suficiente y asociado con la realidad, ya que se basan en expresiones del rostro humano. Posteriormente, a las respuestas de los cuestionarios se le asignaba un valor numérico, como se presenta en la Tabla 52.

Tabla 52. Valores de las respuestas a los cuestionarios

\begin{tabular}{|l|c|l|}
\hline Respuesta & Iconografía utilizada & Valor numérico \\
\hline Totalmente de acuerdo & & \\
\hline De acuerdo & & \\
\hline Indiferente & & \\
\hline En desacuerdo & $\ddots$ & 3 \\
\hline Totalmente en desacuerdo & $\ddots$ & 2 \\
\hline
\end{tabular}




\section{III.2. Cuestionarios para los pacientes}

Su participación completando este cuestionario es especialmente valiosa para evaluar el sistema de ayuda a la estimulación cognitiva, usando una tableta, para afectados de Parkinson. Por favor, responda a estas preguntas y consulte a su terapeuta si tiene alguna duda.

Muchas gracias y confiamos en que su ayuda será lo más útil posible.

Estos datos son necesarios para recoger de forma adecuada la información. El cuestionario es totalmente privado y confidencial. Por favor, no deje nada en blanco.

\begin{tabular}{|l|l|l|}
\hline Fecha de utilización & Identificador del paciente & Identificador del terapeuta \\
\hline & & \\
\hline
\end{tabular}

\section{Cuestionario de aceptación del servicio:}

1. Puedo realizar fácilmente la estimulación cognitiva utilizando la tableta.

\begin{tabular}{|c|c|c|c|c|}
\hline $\begin{array}{l}\text { Totalmente de } \\
\text { acuerdo }\end{array}$ & De acuerdo & Indiferente & En desacuerdo & $\begin{array}{c}\text { Totalmente en } \\
\text { desacuerdo }\end{array}$ \\
\hline
\end{tabular}

2. Me parece divertido hacer los ejercicios y la terapia de esta manera.

\begin{tabular}{|c|c|c|c|c|}
\hline$(\ddots$ & $\ddots$ & $\ddots$ & \\
\hline $\begin{array}{c}\text { Totalmente de } \\
\text { acuerdo }\end{array}$ & De acuerdo & Indiferente & En desacuerdo & $\begin{array}{c}\text { Totalmente en } \\
\text { desacuerdo }\end{array}$ \\
\hline
\end{tabular}

3. He aprendido rápido a realizar la estimulación cognitiva con la tableta.

\begin{tabular}{|c|c|c|c|c|}
\hline & $\ddots$ & & & \\
\hline $\begin{array}{c}\text { Totalmente de } \\
\text { acuerdo }\end{array}$ & De acuerdo & Indiferente & En desacuerdo & $\begin{array}{c}\text { Totalmente en } \\
\text { desacuerdo }\end{array}$ \\
\hline
\end{tabular}

4. No he tenido ningún problema para utilizar la aplicación con ayuda del terapeuta (2ำ y 3 o sin ayuda del terapeuta).

\begin{tabular}{|c|c|c|c|c|}
\hline \multirow{2}{*}{$\begin{array}{c}\text { Totalmente de } \\
\text { acuerdo }\end{array}$} & De acuerdo & Indiferente & En desacuerdo & $\begin{array}{c}\text { Totalmente en } \\
\text { desacuerdo }\end{array}$ \\
\hline
\end{tabular}

5. Me motiva el poder ver la valoración realizada por el terapeuta para corregir mis resultados.

\begin{tabular}{|c|c|c|c|c|}
\hline$(\ddots$ & $\ddots$ & $\ddots$ & $\ddots$ \\
\hline $\begin{array}{c}\text { Totalmente de } \\
\text { acuerdo }\end{array}$ & De acuerdo & Indiferente & En desacuerdo & $\begin{array}{c}\text { Totalmente en } \\
\text { desacuerdo }\end{array}$ \\
\hline
\end{tabular}


6. En general, me gusta realizar la estimulación cognitiva con la tableta.

\begin{tabular}{|c|c|c|c|c|}
\hline$(\ddots$ & $\ddots$ & $\ddots$ & $\ddots$ \\
\hline $\begin{array}{c}\text { Totalmente de } \\
\text { acuerdo }\end{array}$ & De acuerdo & Indiferente & En desacuerdo & $\begin{array}{c}\text { Totalmente en } \\
\text { desacuerdo }\end{array}$ \\
\hline
\end{tabular}

7. Si pudiera, realizaría la terapia en casa con este sistema.

\begin{tabular}{|c|c|c|c|c|}
\hline $\begin{array}{c}\text { Totalmente de } \\
\text { acuerdo }\end{array}$ & De acuerdo & Indiferente & En desacuerdo & $\begin{array}{c}\text { Totalmente en } \\
\text { desacuerdo }\end{array}$ \\
\hline
\end{tabular}

Sugerencias para mejorar (opcional)

Opinión personal (opcional)

Observaciones del terapeuta (opcional)

¡Muchas gracias por tu colaboración! 


\section{III.3. Cuestionarios para los terapeutas}

Su participación completando este cuestionario es especialmente valiosa para evaluar el sistema de ayuda a la estimulación cognitiva, usando una tableta, para afectados de Parkinson. Por favor, responda a estas preguntas tras la utilización de la plataforma web.

Muchas gracias y confiamos en que su ayuda será lo más útil posible.

Estos datos son necesarios para recoger de forma adecuada la información. El cuestionario es totalmente privado y confidencial. Por favor, no deje nada en blanco.

\begin{tabular}{|l|l|}
\hline Fecha de utilización & Identificador del terapeuta \\
\hline & \\
\hline
\end{tabular}

\section{Cuestionario de aceptación del servicio:}

1. Creo que a los pacientes les gusta realizar la terapia con la tableta.

\begin{tabular}{|c|c|c|c|c|}
\hline & $\ddots$ & $\ddots$ & $\ddots$ & \\
\hline $\begin{array}{c}\text { Totalmente de } \\
\text { acuerdo }\end{array}$ & De acuerdo & Indiferente & En desacuerdo & $\begin{array}{c}\text { Totalmente en } \\
\text { desacuerdo }\end{array}$ \\
\hline
\end{tabular}

2. Creo que el paciente puede usar la tableta él solo.

\begin{tabular}{|c|c|c|c|c|}
\hline & $\ddots$ & $\ddots$ & $\ddots$ & \\
\hline $\begin{array}{c}\text { Totalmente de } \\
\text { acuerdo }\end{array}$ & De acuerdo & Indiferente & En desacuerdo & $\begin{array}{c}\text { Totalmente en } \\
\text { desacuerdo }\end{array}$ \\
\hline
\end{tabular}

3. La aplicación web que uso para adaptar los ejercicios y valorar a los pacientes es sencilla de usar y completa en relación con las funciones que ofrece.

\begin{tabular}{|c|c|c|c|c|}
\hline & $\ddots$ & $\ddots$ & $\ddots$ \\
\hline $\begin{array}{c}\text { Totalmente de } \\
\text { acuerdo }\end{array}$ & De acuerdo & Indiferente & En desacuerdo & $\begin{array}{c}\text { Totalmente en } \\
\text { desacuerdo }\end{array}$ \\
\hline
\end{tabular}

4. Veo útil poder consultar la información de los ejercicios a través de la web.

\begin{tabular}{|c|c|c|c|c|}
\hline \multirow{2}{*}{$\begin{array}{c}\text { Totalmente de } \\
\text { acuerdo }\end{array}$} & De acuerdo & Indiferente & En desacuerdo & $\begin{array}{c}\text { Totalmente en } \\
\text { desacuerdo }\end{array}$ \\
\hline
\end{tabular}

5. Creo que es sencillo añadir nuevos ejercicios a los bloques.

\begin{tabular}{|c|c|c|c|c|}
\hline & $\ddots$ & $\ddots$ & $\ddots$ & \\
\hline $\begin{array}{c}\text { Totalmente de } \\
\text { acuerdo }\end{array}$ & De acuerdo & Indiferente & En desacuerdo & $\begin{array}{c}\text { Totalmente en } \\
\text { desacuerdo }\end{array}$ \\
\hline
\end{tabular}


6. Los ejercicios se adecúan a los requisitos de un paciente de Parkinson.

\begin{tabular}{|c|c|c|c|c|}
\hline$(\ddots$ & $\ddots$ & $\ddots$ & $\ddots$ \\
\hline $\begin{array}{c}\text { Totalmente de } \\
\text { acuerdo }\end{array}$ & De acuerdo & Indiferente & En desacuerdo & $\begin{array}{c}\text { Totalmente en } \\
\text { desacuerdo }\end{array}$ \\
\hline
\end{tabular}

7. Considero que la forma de consultar los resultados de los pacientes es apropiada.

\begin{tabular}{|c|c|c|c|c|}
\hline-0 & $\ddots$ & $\ddots$ & $\ddots$ \\
\hline $\begin{array}{c}\text { Totalmente de } \\
\text { acuerdo }\end{array}$ & De acuerdo & Indiferente & En desacuerdo & $\begin{array}{c}\text { Totalmente en } \\
\text { desacuerdo }\end{array}$ \\
\hline
\end{tabular}

8. El realizar la terapia de esta forma no me quita más tiempo que de la forma tradicional.

\begin{tabular}{|c|c|c|c|c|}
\hline$(\ddots$ & $\ddots$ & $\ddots$ & $\ddots$ \\
\hline $\begin{array}{c}\text { Totalmente de } \\
\text { acuerdo }\end{array}$ & De acuerdo & Indiferente & En desacuerdo & $\begin{array}{c}\text { Totalmente en } \\
\text { desacuerdo }\end{array}$ \\
\hline
\end{tabular}

9. Creo que sería útil para los pacientes que también pudieran realizar la terapia desde sus casas utilizando este sistema.

\begin{tabular}{|c|c|c|c|c|}
\hline $\begin{array}{c}\text { Totalmente de } \\
\text { acuerdo }\end{array}$ & De acuerdo & Indiferente & En desacuerdo & $\begin{array}{c}\text { Totalmente en } \\
\text { desacuerdo }\end{array}$ \\
\hline
\end{tabular}

Mejoras funcionales (opcional)

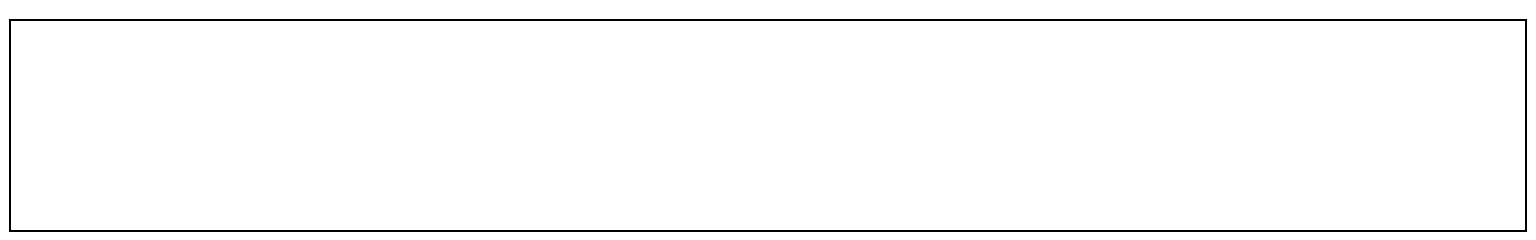

Otras sugerencias (opcional)

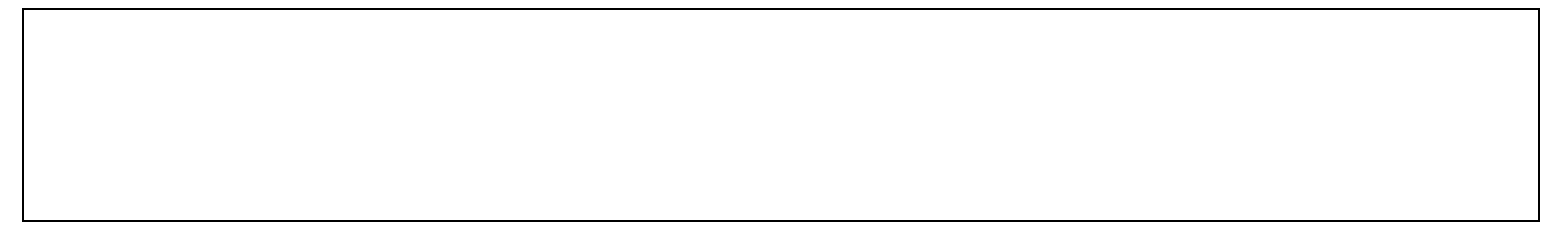

Opinión personal (opcional) 


\title{
Anexo IV. Datos de los cuestionarios. Experimentación en las asociaciones
}

\author{
El segundo anexo de este trabajo de investigación se centra en la presentación de \\ los resultados completos que se han obtenido a partir de los cuestionarios \\ repartidos durante la fase de experimentación en las asociaciones.
}

\section{IV.1. Representación de los datos}

Este anexo describe extensamente la muestra de usuarios que han participado en la experimentación en las asociaciones. Para conseguir este fin, este anexo está dividido en cuatro partes, una relativa a la muestra de usuarios y las otras tres, asociadas con los resultados obtenidos en los cuestionarios, tanto de pacientes como de terapeutas, durante esta primera experimentación.

En primer lugar, se describe de forma extensa la muestra de usuarios. Para ello, se ha realizado una tabla resumen que presenta por asociación el número de pacientes participantes en el experimento llevado a cabo en las asociaciones, el porcentaje de hombres y mujeres y las edades mínima, máxima y promedio. A continuación, se representan estos datos de forma gráfica. Posteriormente, se han creado dos gráficas relativas a deterioro, la primera de ellas relativa al deterioro cognitivo y la segunda, al deterioro motor. Por último, se presenta una gráfica relacionada con el uso de las nuevas tecnologías de los pacientes participantes. Al final del apartado relativo a la muestra de usuarios, se han añadido tablas descriptivas de la muestra de pacientes en cada asociación.

En segundo lugar, se recogen los datos de los resultados por cada asociación a nivel global, por lo que no se diferencia entre uno y otro paciente. En esta representación, se ha calculado la media de las respuestas a cada pregunta entre todos los pacientes de esa asociación.

En tercer y último lugar, se representan de forma gráfica los resultados obtenidos tras la experimentación a partir de las opiniones de los terapeutas participantes por cada asociación. Estos resultados se muestran de forma agrupada por sesiones, ya que, a la vista de los datos obtenidos, no se considera relevante el presentarlos de forma desglosada.

\section{IV.2. Muestra de pacientes}

\section{IV.2.1. Muestra global de pacientes}

La Tabla 53 presenta un resumen de la muestra global de pacientes, que se presentará de forma más amplia posteriormente a ella. Los datos reflejados en esta tabla se ilustran de forma gráfica 
a través de Figura 94, Figura 95 y Figura 96, que muestran la distribución de pacientes por asociación, la paridad entre hombres y mujeres y las edades mínima, máxima y promedio de cada asociación respectivamente.

Tabla 53. Experimentación en las asociaciones. Muestra global de pacientes

\begin{tabular}{|l|l|l|l|l|l|l|l|}
\hline Asociación & № pacientes & \% hombres & \multicolumn{2}{l}{ \% mujeres } & \multicolumn{2}{l|}{ Edad mín. } & \multicolumn{2}{l|}{ Edad máx. } & Edad prom. \\
\hline Madrid & 10 & $40 \%$ & $60 \%$ & 60 & 78 & 70,60 \\
\hline Extremadura & 8 & $75 \%$ & $25 \%$ & 59 & 75 & 68,63 \\
\hline Cataluña & 8 & $75 \%$ & $25 \%$ & 52 & 80 & 68,75 \\
\hline Cádiz & 8 & $75 \%$ & $25 \%$ & 63 & 87 & 76,50 \\
\hline Navarra & 4 & $50 \%$ & $50 \%$ & 70 & 87 & 78,75 \\
\hline Sevilla & 7 & $43 \%$ & $57 \%$ & 60 & 84 & 74,00 \\
\hline Total & 45 & $60 \%$ & $40 \%$ & 52 & 87 & 72,22 \\
\hline
\end{tabular}

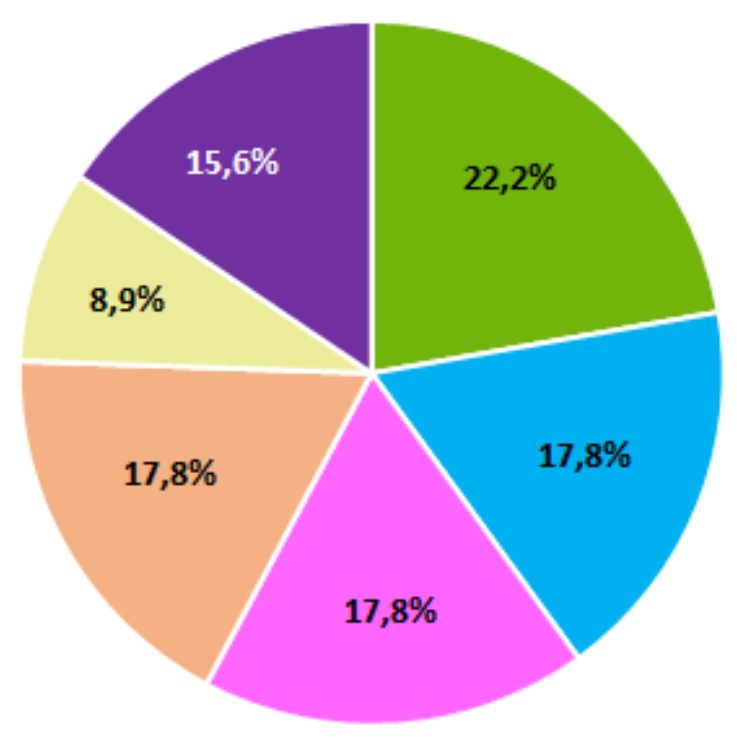

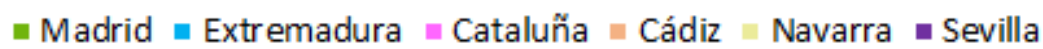

Figura 94. Experimentación en las asociaciones. Distribución de pacientes por asociación 


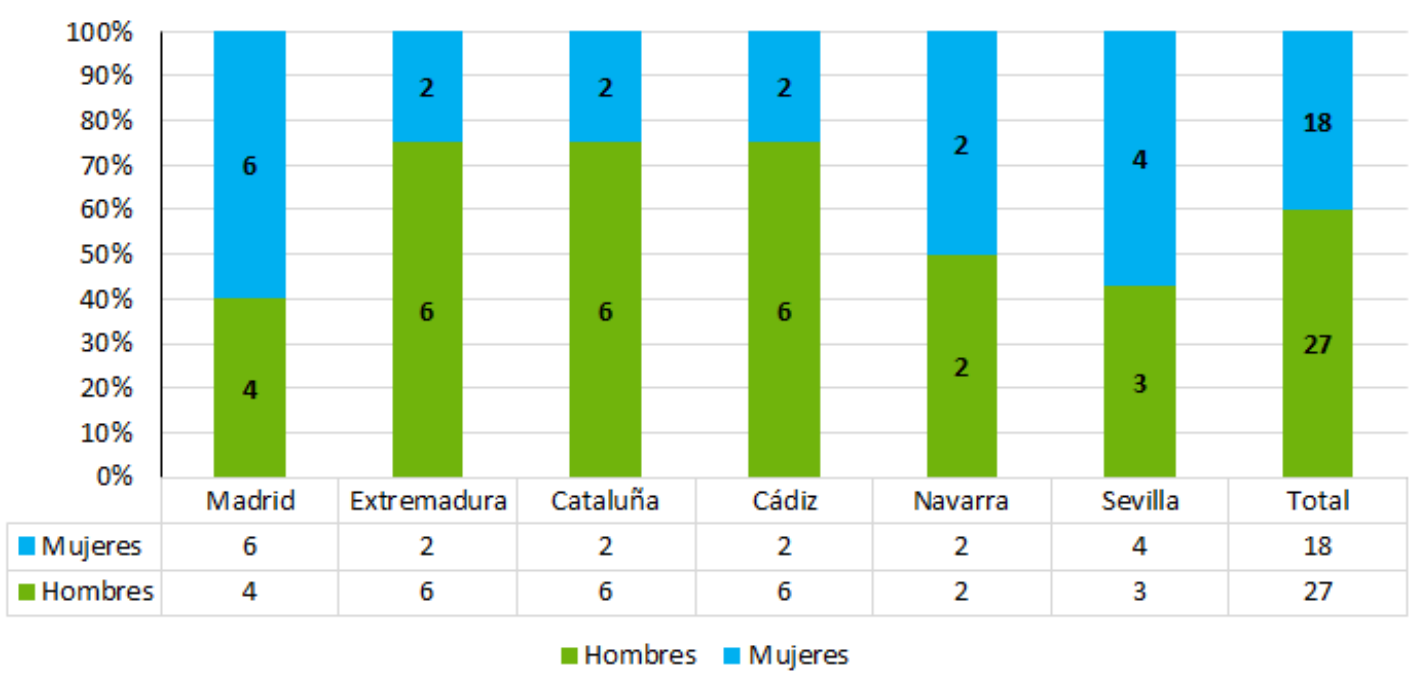

Figura 95. Experimentación en las asociaciones. Paridad entre hombres y mujeres

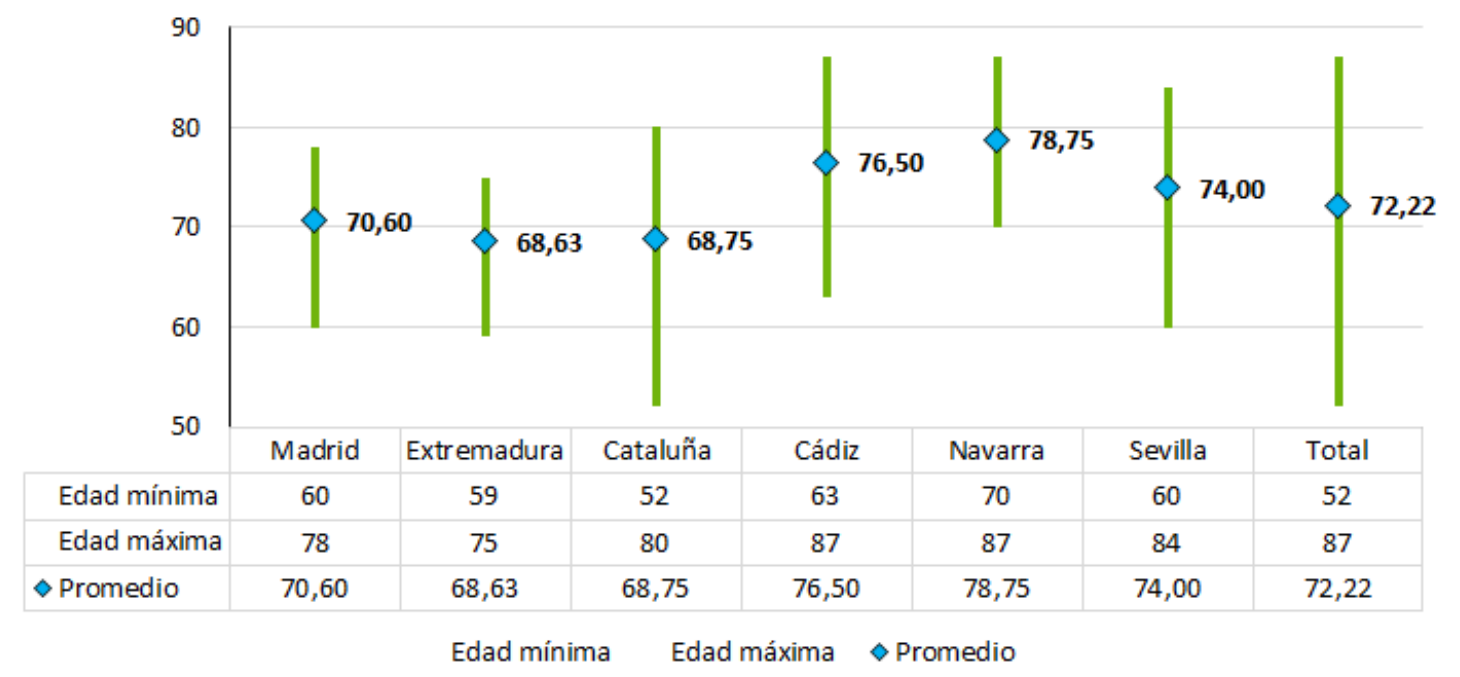

Figura 96. Experimentación en las asociaciones. Intervalo de edad y promedio

A continuación, se muestran las gráficas relativas al deterioro de la persona participante. La primera de ellas, la Figura 97, es la relativa al estado cognitivo. La segunda, la Figura 98, es la relacionada con el deterioro motor. 


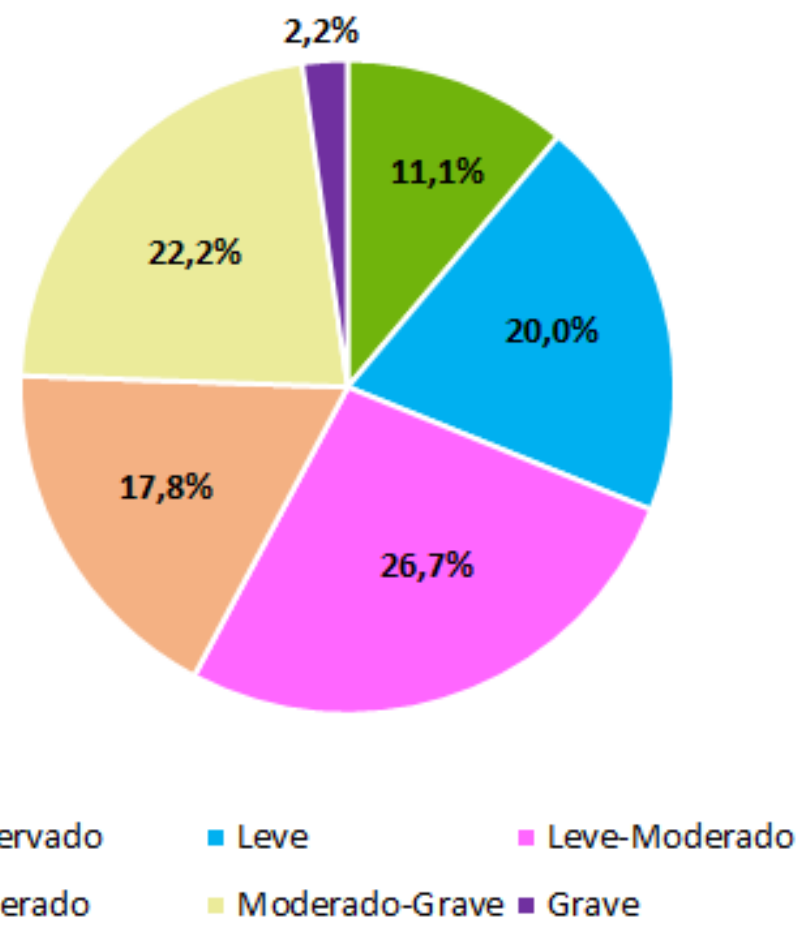

Figura 97. Experimentación en las asociaciones. Estado cognitivo

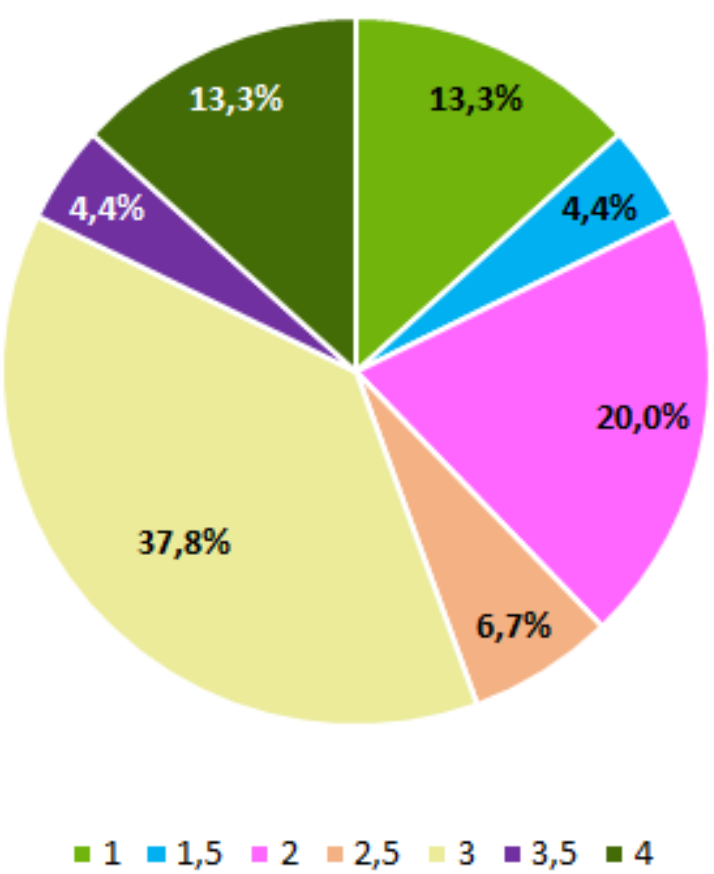

Figura 98. Experimentación en las asociaciones. Estadio motor

Por último, la Figura 99 detalla el grado de experiencia en nuevas tecnologías de los participantes en el experimento en las asociaciones. 


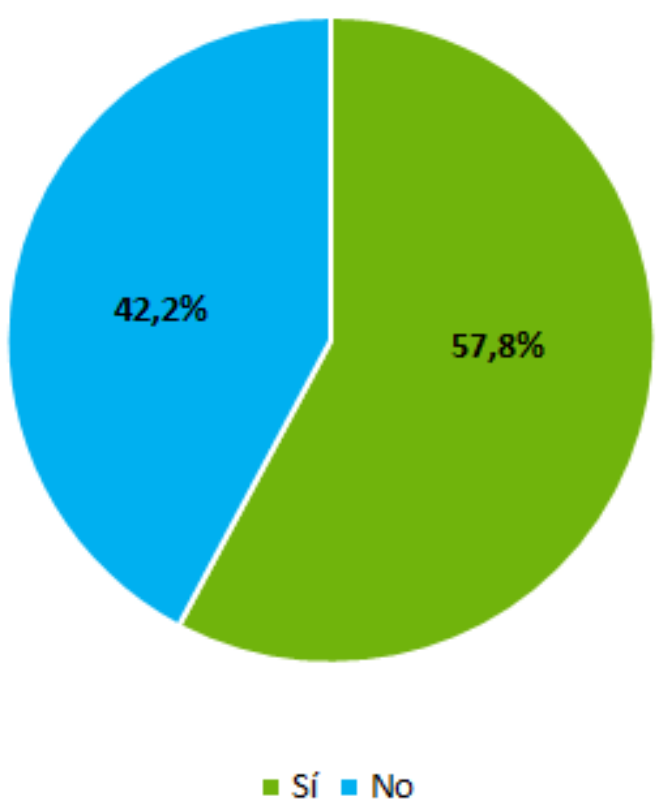

Figura 99. Experimentación en las asociaciones. Experiencia en nuevas tecnologías

\section{IV.2.2. Muestra de pacientes por asociación}

Las tablas a continuación (Tabla 54 a Tabla 59) presentan la muestra de pacientes que han participado en la realización de los experimentos llevados a cabo en las asociaciones. Estas muestras se detallan en forma de tabla. Los campos presentados son los siguientes:

- Número: identificador del paciente dentro de los participantes de esa asociación.

- Edad: edad del paciente en el momento del experimento.

- Sexo: sexo del paciente.

- Estadio: estadio dentro de la escala de Hoehn y Yahr [Hoehn, 1998].

- NNTT: experiencia en el uso de nuevas tecnologías.

- Estado cognitivo: nivel de deterioro cognitivo asociado a la enfermedad según la escala CDR [Hughes, 1982].

Tabla 54. Madrid. Muestra de pacientes en la asociación

\begin{tabular}{|l|l|l|l|l|l|}
\hline Número & Edad & Sexo & Estadio & NNTT & Estado cognitivo \\
\hline Paciente 1 & 77 & Mujer & 2 & No & Moderado \\
\hline Paciente 2 & 65 & Mujer & 3 & Sí & Moderado \\
\hline Paciente 3 & 62 & Hombre & 2,5 & No & Leve \\
\hline Paciente 4 & 78 & Hombre & 1,5 & Sí & Leve \\
\hline Paciente 5 & 69 & Mujer & 1 & Sí & Leve \\
\hline Paciente 6 & 68 & Mujer & 2 & No & Leve \\
\hline Paciente 7 & 73 & Mujer & 2,5 & No & Moderado \\
\hline
\end{tabular}




\begin{tabular}{|l|l|l|l|l|l|}
\hline Paciente 8 & 78 & Mujer & 1,5 & No & Leve \\
\hline Paciente 9 & 76 & Hombre & 3 & No & Moderado \\
\hline Paciente 10 & 60 & Hombre & 2,5 & Sí & Moderado \\
\hline
\end{tabular}

Tabla 55. Extremadura. Muestra de pacientes en la asociación

\begin{tabular}{|l|l|l|l|l|l|}
\hline Número & Edad & Sexo & Estadio & NNT & Estado cognitivo \\
\hline Paciente 1 & 73 & Hombre & 2 & No & Grave \\
\hline Paciente 2 & 71 & Hombre & 3 & Sí & Moderado \\
\hline Paciente 3 & 59 & Mujer & 3 & No & Moderado \\
\hline Paciente 4 & 70 & Hombre & 3 & No & Moderado \\
\hline Paciente 5 & 75 & Mujer & 1 & No & Leve \\
\hline Paciente 6 & 65 & Hombre & 1 & Sí & Leve \\
\hline Paciente 7 & 68 & Hombre & 1 & Sí & Leve \\
\hline Paciente 8 & 68 & & &
\end{tabular}

Tabla 56. Cataluña. Muestra de pacientes en la asociación

\begin{tabular}{|c|c|c|c|c|c|}
\hline Número & Edad & Sexo & Estadio & NNTT & Estado cognitivo \\
\hline Paciente 1 & 68 & Mujer & 3 & Sí & Moderado-Grave \\
\hline Paciente 2 & 80 & Mujer & 2 & Sí & Preservado \\
\hline Paciente 3 & 62 & Hombre & 3 & Sí & Preservado \\
\hline Paciente 4 & 71 & Hombre & 2 & Sí & Preservado \\
\hline Paciente 5 & 80 & Hombre & 4 & No & Leve-Moderado \\
\hline Paciente 6 & 64 & Hombre & 3,5 & Sí & Preservado \\
\hline Paciente 7 & 73 & Hombre & 4 & Sí & Leve-Moderado \\
\hline Paciente 8 & 52 & Hombre & 1 & Sí & Preservado \\
\hline
\end{tabular}

Tabla 57. Cádiz. Muestra de pacientes en la asociación

\begin{tabular}{|l|l|l|l|l|l|}
\hline Número & Edad & Soxo & Estadio & NNT & Estado cognitivo \\
\hline Paciente 1 & 87 & Hombre & 2 & Sí & Moderado-Grave \\
\hline Paciente 2 & 82 & Hombre & 1 & Sí & Leve-Moderado \\
\hline Paciente 3 & 63 & Mujer & 2 & Sí & Leve-Moderado \\
\hline Paciente 4 & 82 & Hombre & 4 & Sí & Leve-Moderado \\
\hline Paciente 5 & 71 & Mujer & 3 & Sí & Leve-Moderado \\
\hline Paciente 6 & 78 & Hombre & 3 & Sí & Leve-Moderado \\
\hline Paciente 7 & 77 & Hombre & 3 & Sí & Moderado-Grave \\
\hline Paciente 8 & 72 & & & & \\
\hline
\end{tabular}


Tabla 58. Navarra. Muestra de pacientes en la asociación

\begin{tabular}{|c|c|c|c|c|c|}
\hline Número & Edad & Sexo & Estadio & NNTT & Estado cognitivo \\
\hline Paciente 1 & 87 & Mujer & 3 & No & Moderado-Grave \\
\hline Paciente 2 & 78 & Mujer & 3 & No & Moderado-Grave \\
\hline Paciente 3 & 70 & Hombre & 3 & No & Moderado-Grave \\
\hline Paciente 4 & 80 & Hombre & 4 & No & Moderado-Grave \\
\hline
\end{tabular}

Tabla 59. Sevilla. Muestra de pacientes en la asociación

\begin{tabular}{|l|l|l|l|l|l|}
\hline Número & Edad & Sexo & Estadio & NNT & Estado cognitivo \\
\hline Paciente 1 & 60 & Mujer & 2 & Sí & Leve-Moderado \\
\hline Paciente 2 & 73 & Hombre & 4 & No & Leve-Moderado \\
\hline Paciente 3 & 78 & Mujer & 3 & No & Leve-Moderado \\
\hline Paciente 4 & 67 & Hombre & 2 & Sí & Leve-Moderado \\
\hline Paciente 5 & 81 & Mujer & 3 & No & Moderado-Grave \\
\hline Paciente 6 & 84 & Mujer & 3,5 & Sí & Moderado-Grave \\
\hline Paciente 7 & 75 & Hombre & 3 & No & Moderado-Grave \\
\hline
\end{tabular}

\section{IV.3. Datos globales por asociación}

Las gráficas siguientes (Figura 100 a Figura 105) describen los resultados globales por asociación, conteniendo también las tablas de datos utilizadas para su generación. Para su realización, se han tomado las medias de las respuestas de los pacientes a cada pregunta.

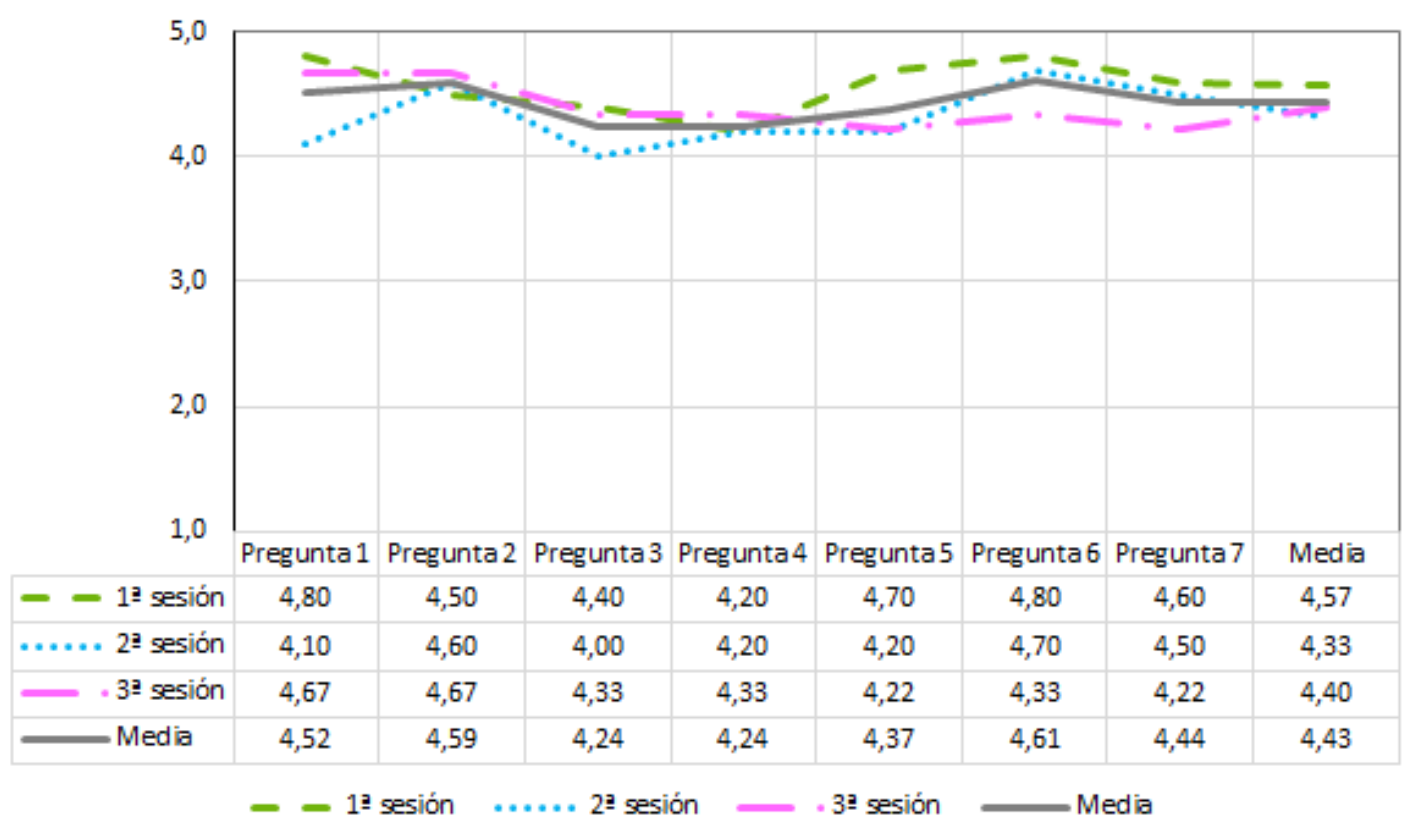

Figura 100. Madrid. Resultados globales de la experimentación en la asociación 


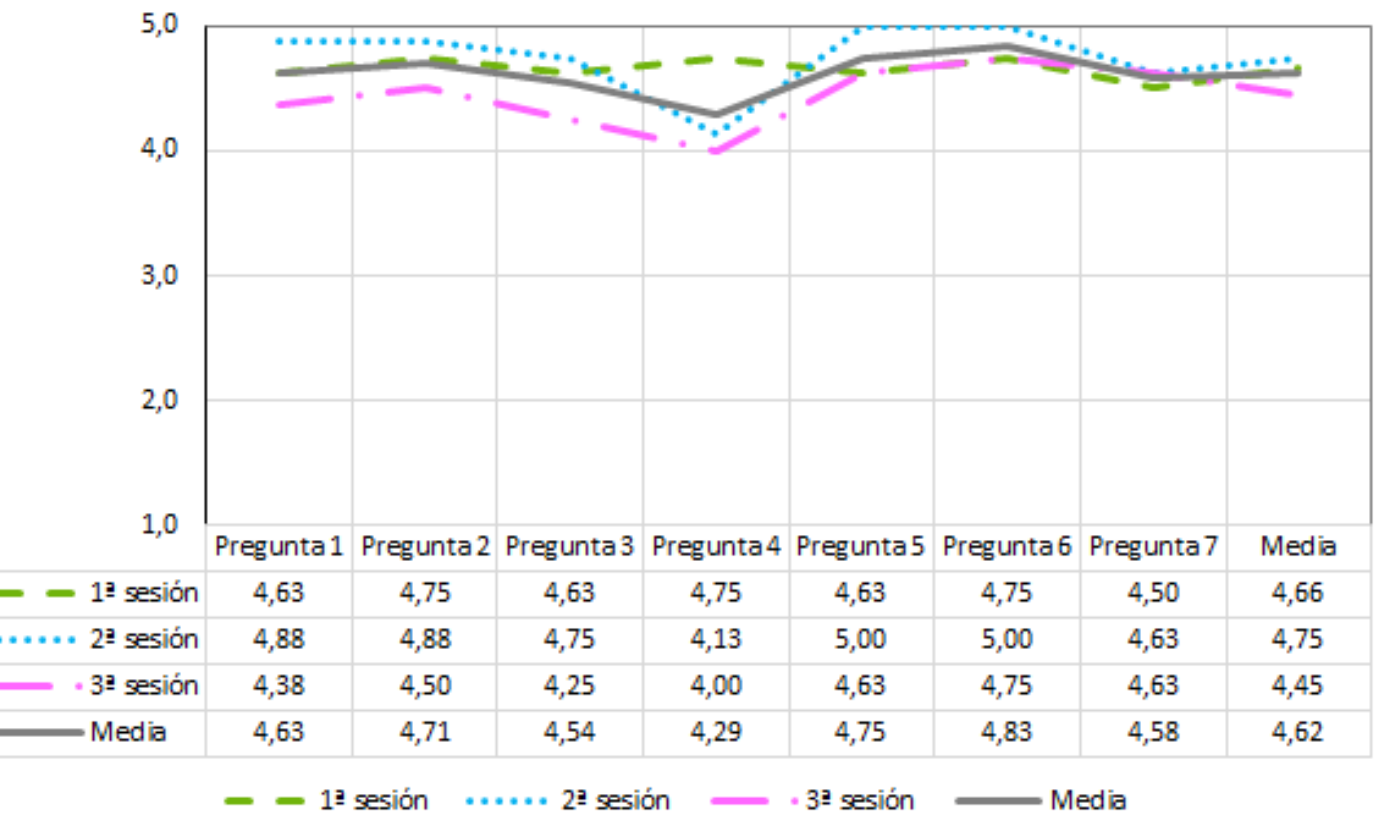

Figura 101. Extremadura. Resultados globales de la experimentación en la asociación

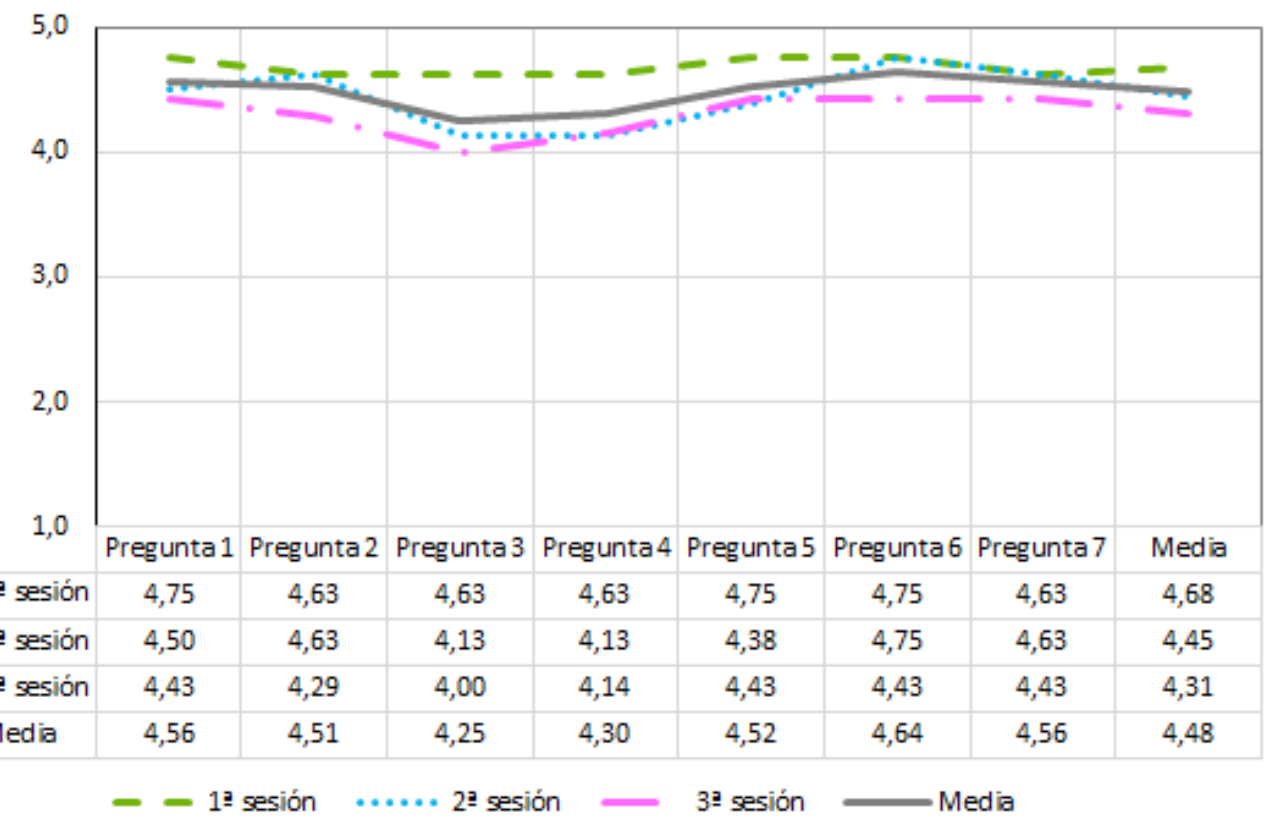

Figura 102. Cataluña. Resultados globales de la experimentación en la asociación 


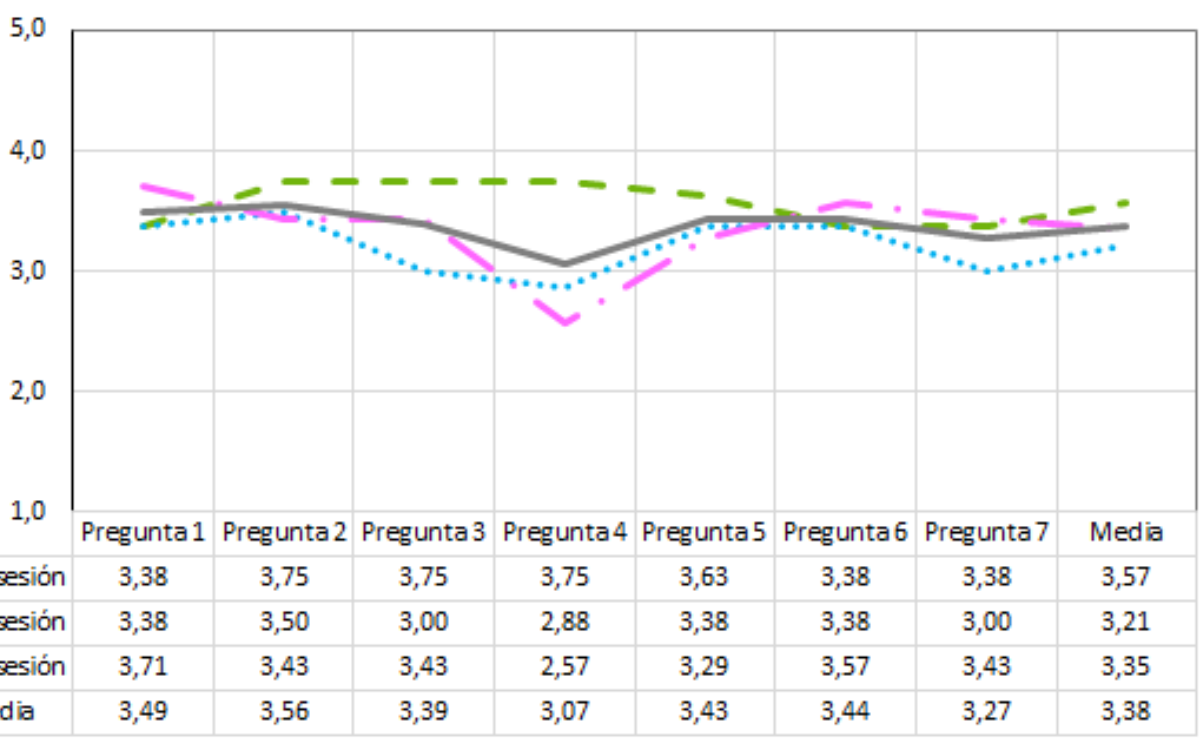

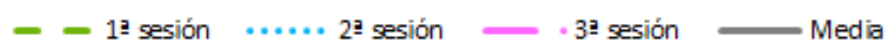

Figura 103. Cádiz. Resultados globales de la experimentación en la asociación

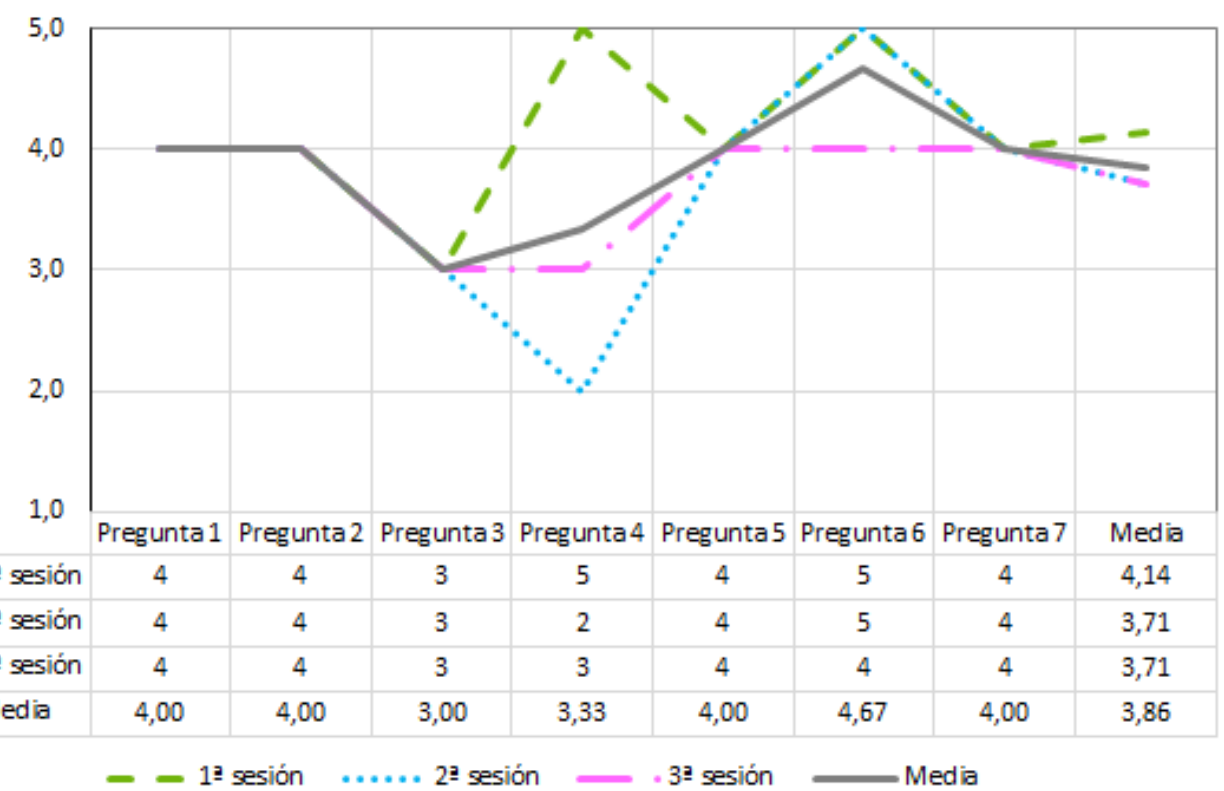

Figura 104. Navarra. Resultados globales de la experimentación en la asociación 


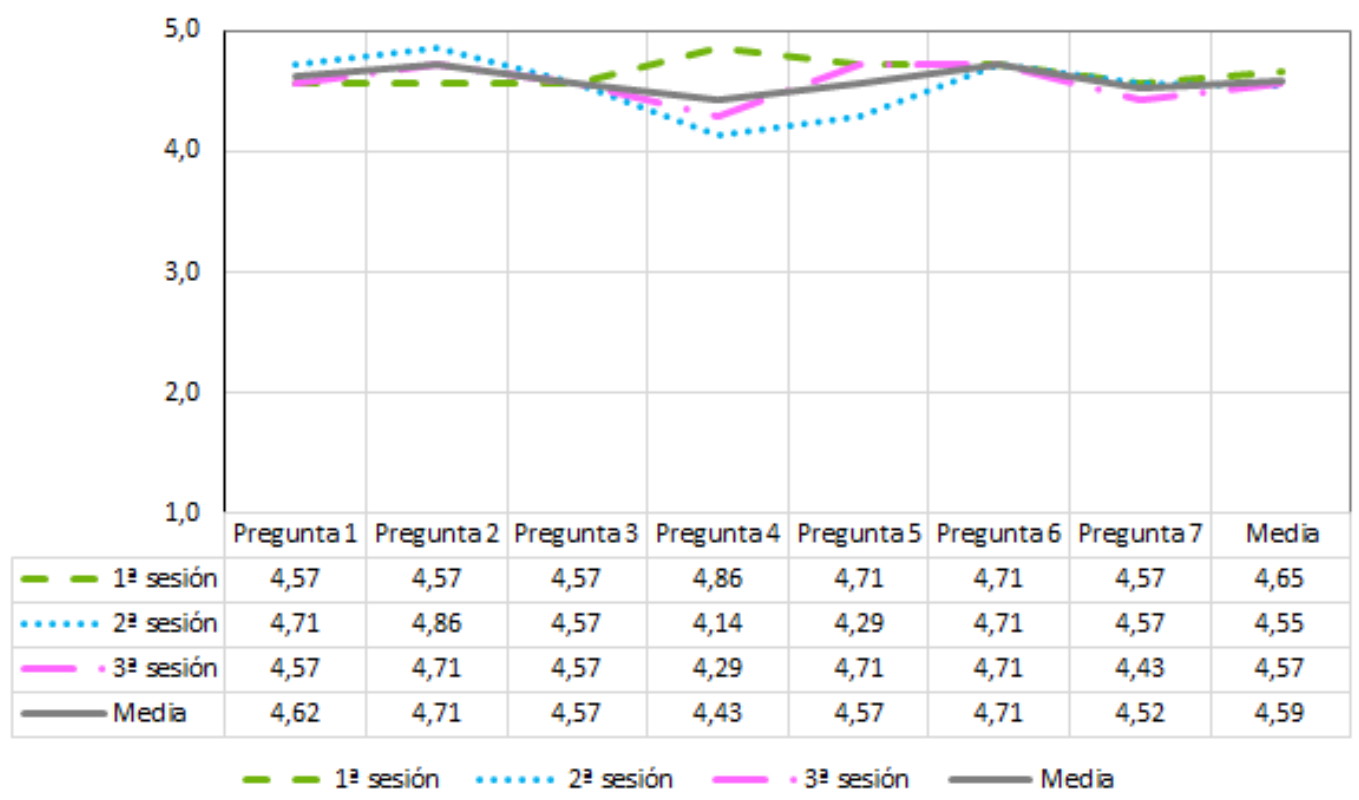

Figura 105. Sevilla. Resultados globales de la experimentación en la asociación

\section{IV.4. Datos de los cuestionarios de los terapeutas}

En la mayoría de los casos, las asociaciones no han presentado en su memoria de resultados finales los datos completos de las respuestas dadas por los terapeutas, añadiendo, de forma general, un resumen de resultados.

En el caso de la asociación de Madrid, únicamente han dado la gráfica resumen de las respuestas de las dos terapeutas participantes, haciendo la media de los cuestionarios de las dos terapeutas participantes para todas las preguntas distinguiendo por sesión, como se presenta en la Figura $\underline{106 .}$.

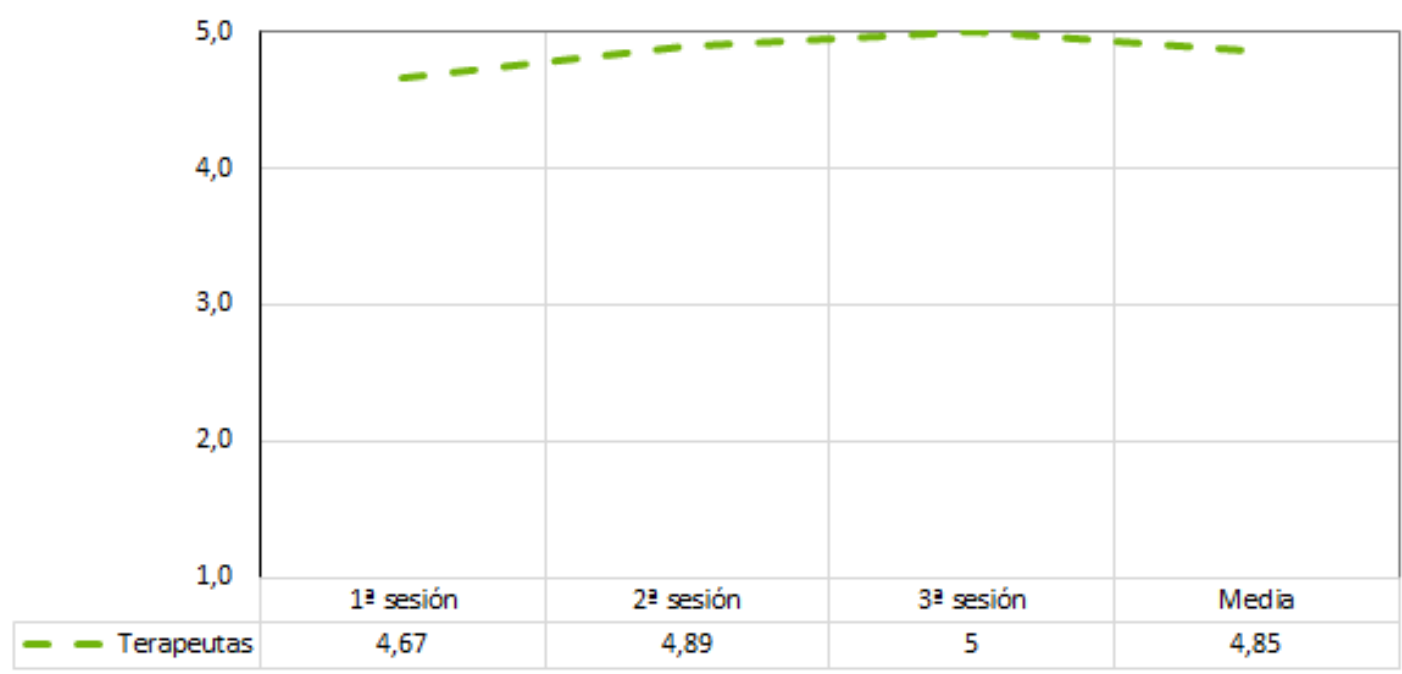

Figura 106. Madrid. Datos de las terapeutas. Experimentación en la asociación

A la vista del gráfico anterior, se observa que, a medida que las terapeutas utilizan la herramienta, se sienten más cómodas, llegando en la tercera sesión a la puntuación más alta posible en todas las respuestas y para todos los pacientes. 
En la asociación de Extremadura se han completado todos los datos de cada sesión y por terapeuta, por lo que se pueden presentar resultados más amplios. Estos terapeutas, como ya se definió en el apartado 6.6. Resultados de los experimentos, dejaron sin contestar la pregunta 3 y la pregunta 5 por opinar no conocer lo suficiente la plataforma de gestión de las terapias como para opinar sobre ella. La Figura 107 muestra sus resultados por terapeuta, pregunta y sesión.

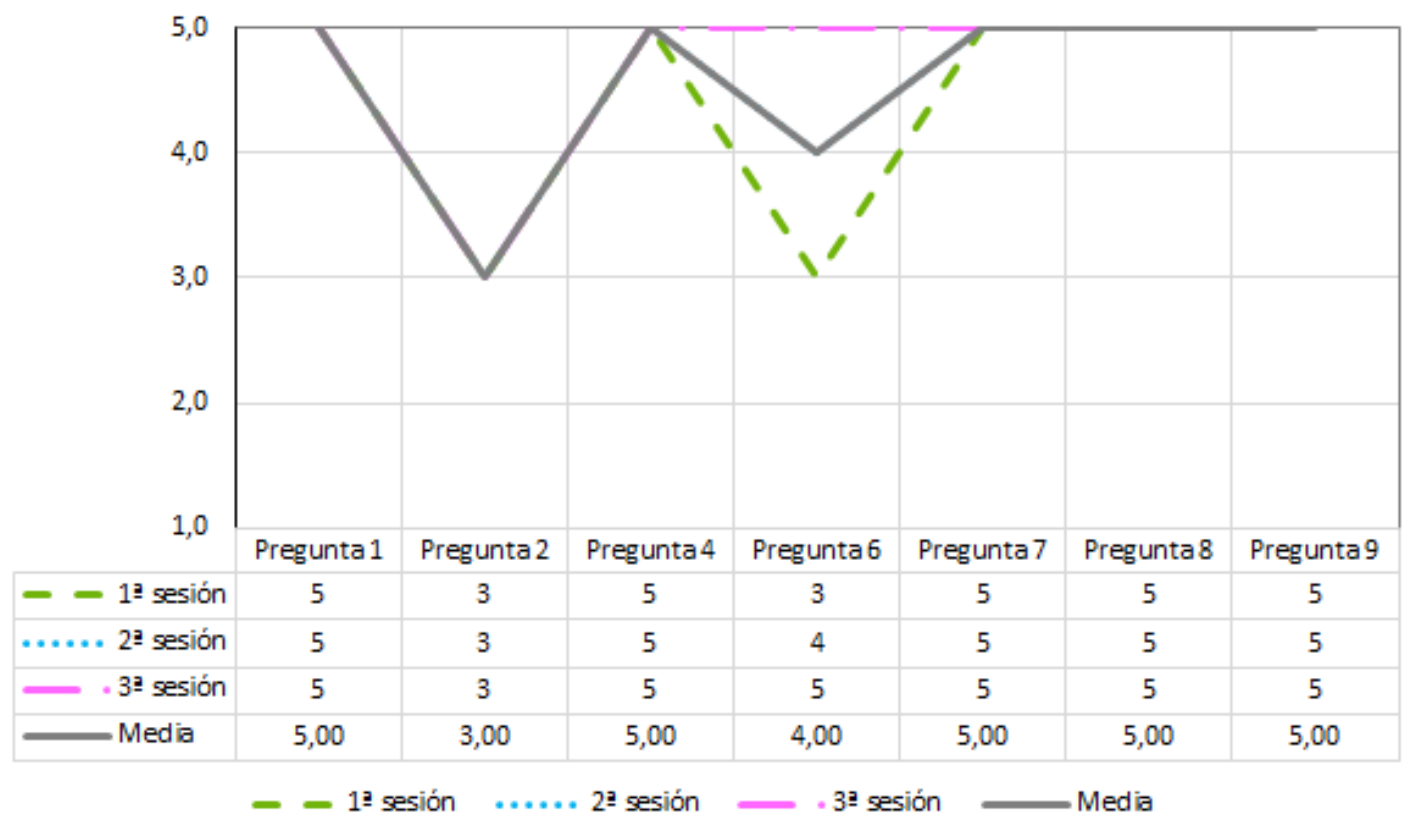

Figura 107. Extremadura. Datos de las terapeutas. Experimentación en la asociación

En la asociación de Cataluña han definido en la memoria final la media entre sesiones para cada pregunta y por terapeuta, como se presenta en la Figura 108.

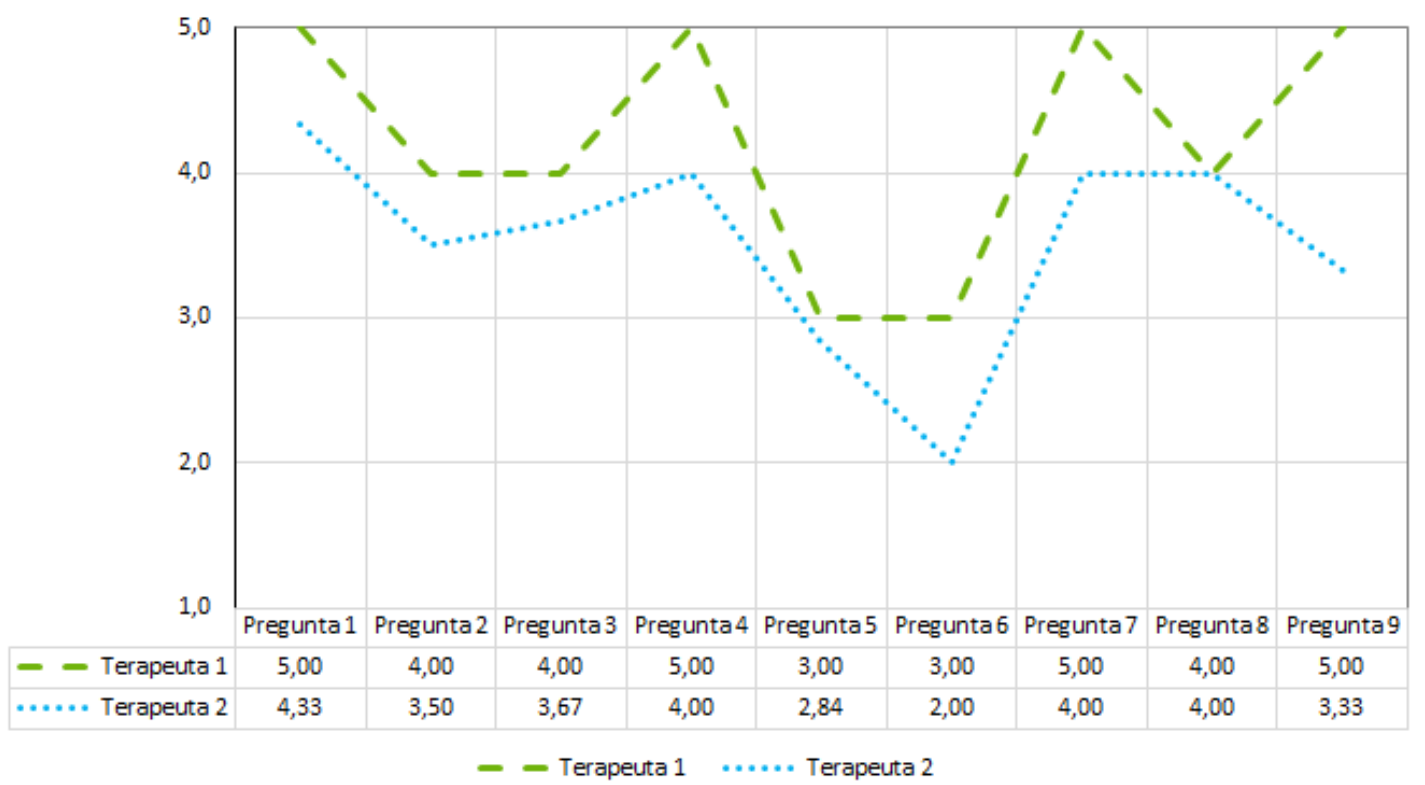

Figura 108. Cataluña. Datos de las terapeutas. Experimentación en la asociación

En las asociaciones de Cádiz, Navarra y Sevilla disponemos de los valores por sesión y pregunta a partir de la media entre las dos terapeutas, como se puede ver en la Figura 109 (Cádiz), la 
Figura 110 (Navarra) y la Figura 111 (Sevilla). En estos gráficos se puede apreciar la poca variabilidad de las respuestas de las terapeutas entre las tres sesiones.

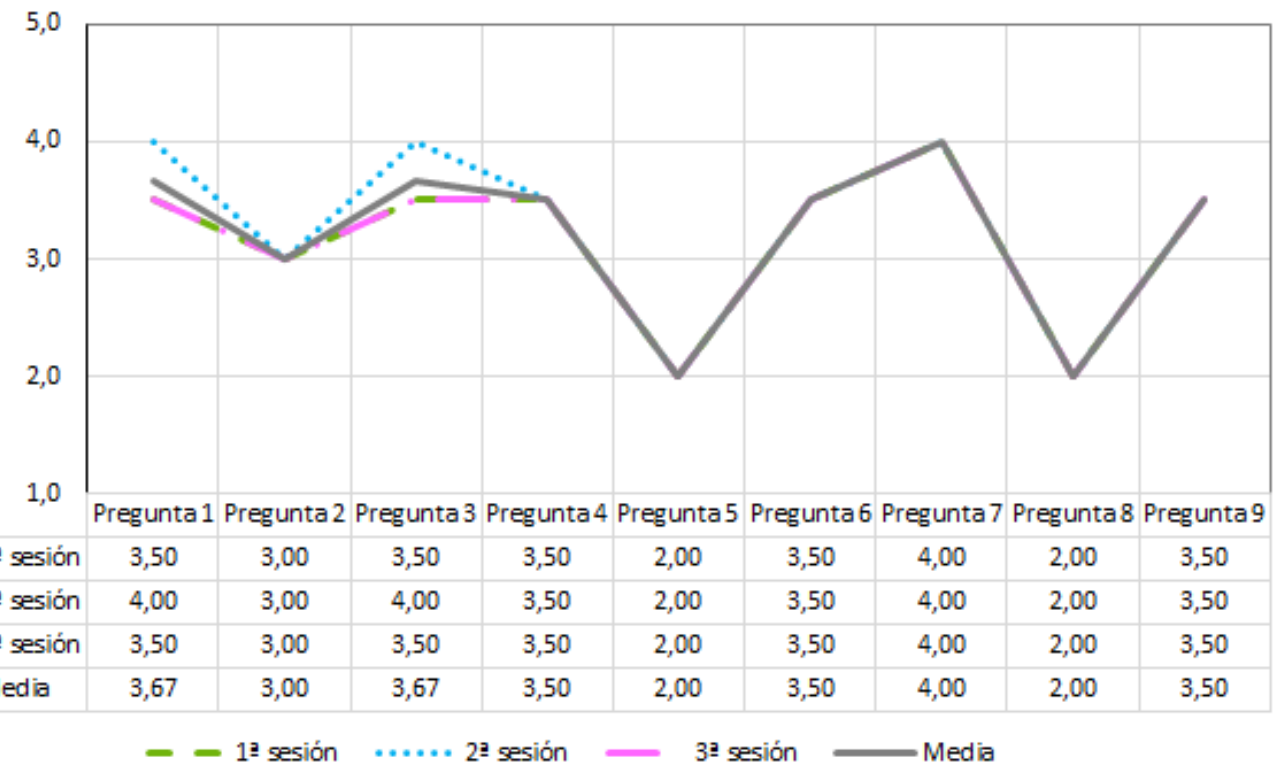

Figura 109. Cádiz. Datos de las terapeutas. Experimentación en la asociación

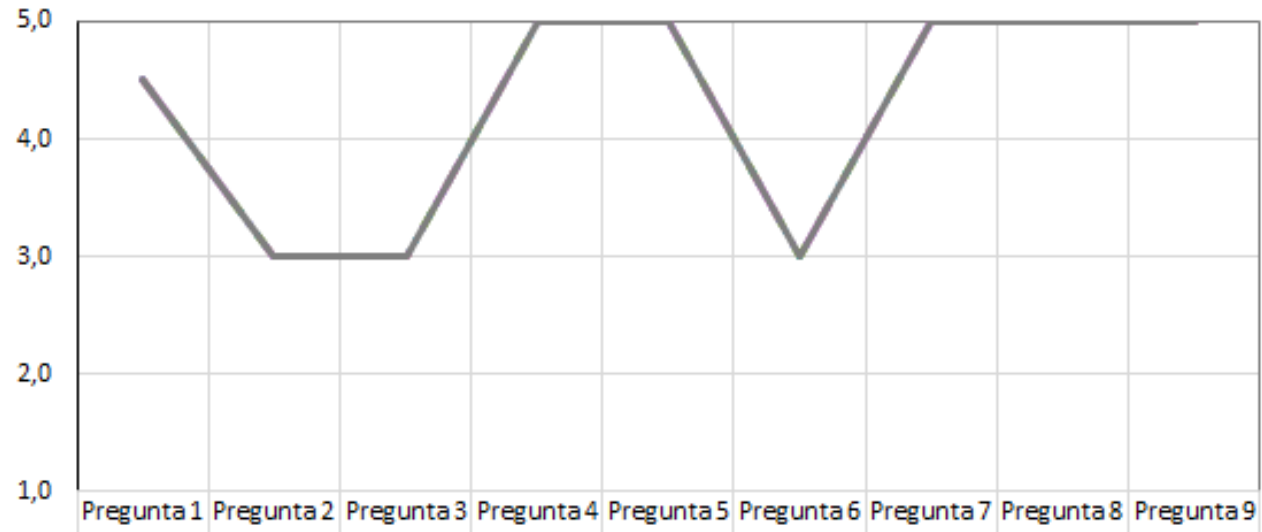

\begin{tabular}{|c|c|c|c|c|c|c|c|c|c|}
\hline-12 sesión & 4,50 & 3,00 & 3,00 & 5,00 & 5,00 & 3,00 & 5,00 & 5,00 & 5,00 \\
\hline …... 2a sesión & 4,50 & 3,00 & 3,00 & 5,00 & 5,00 & 3,00 & 5,00 & 5,00 & 5,00 \\
\hline _ 3 3a sesión & 4,50 & 3,00 & 3,00 & 5,00 & 5,00 & 3,00 & 5,00 & 5,00 & 5,00 \\
\hline Media & 4,50 & 3,00 & 3,00 & 5,00 & 5,00 & 3,00 & 5,00 & 5,00 & 5,00 \\
\hline
\end{tabular}

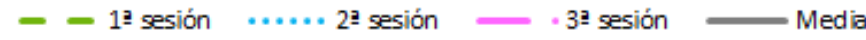

Figura 110. Navarra. Datos de los terapeutas. Experimentación en la asociación 


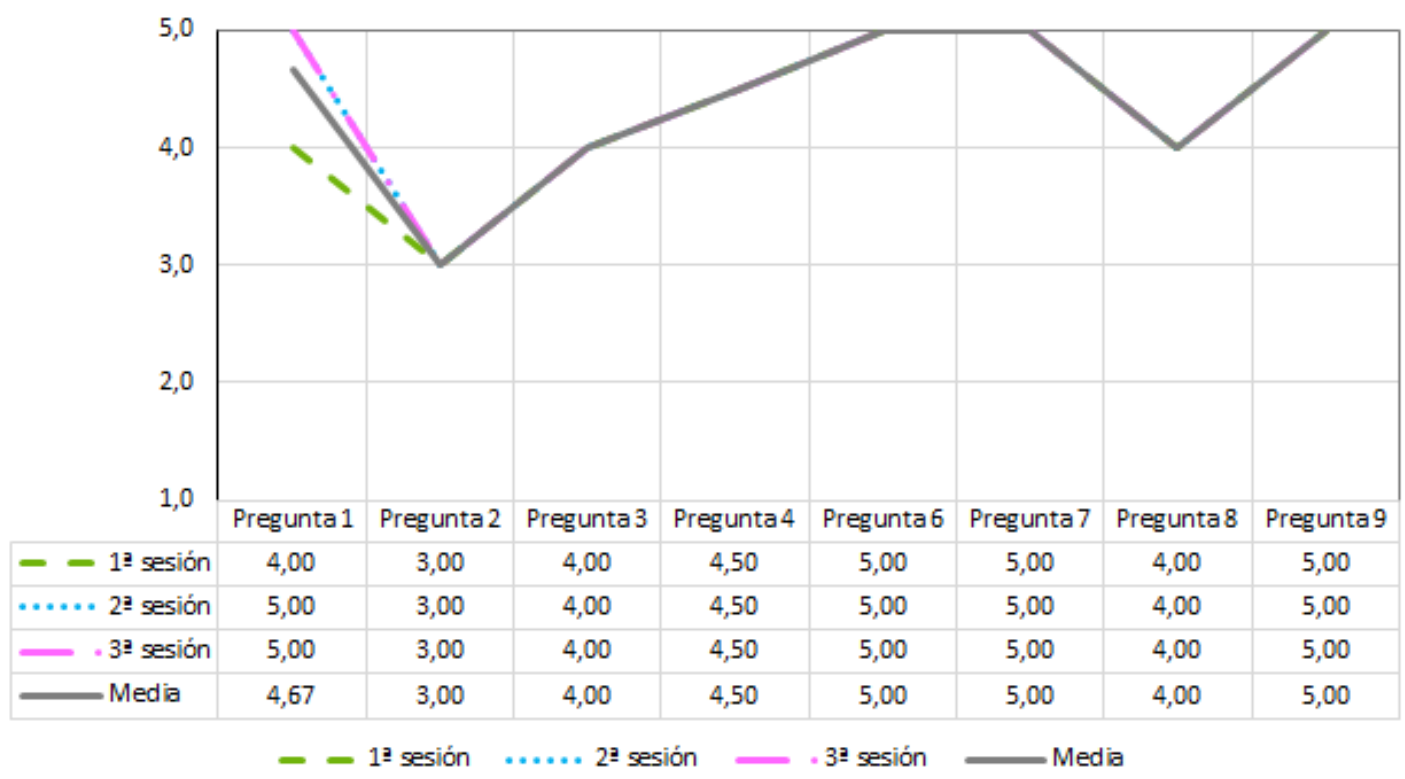

Figura 111. Sevilla. Datos de las terapeutas. Experimentación en la asociación 


\section{Anexo V. Datos de los cuestionarios. Experimentación en domicilio}

El tercer anexo de esta tesis doctoral tiene como finalidad la presentación de los resultados obtenidos de los cuestionarios repartidos a los usuarios durante la fase de experimentación en domicilio.

\section{V.1. Representación de los datos}

La forma de representación de los datos sigue la misma filosofía del Anexo IV. Datos de los cuestionarios. Experimentación en las asociaciones. La diferencia con respecto al anterior, es que no se han desglosado los resultados por sesiones, ya que todas han sido similares al tener los pacientes participantes más independencia.

Como en el caso anterior, primeramente, se presenta la muestra de usuarios. A continuación, se recogen los resultados a nivel global sin diferenciar entre asociaciones. Posteriormente, se representan los datos de cada asociación por pregunta y paciente. Para finalizar el anexo, se muestran los datos de los terapeutas.

\section{V.2. Muestra de pacientes}

\section{V.2.1. Muestra global de pacientes}

La Tabla 60 presenta la muestra global de pacientes. Los datos reflejados en esta tabla se ilustran de forma gráfica a través de la Figura 112, la Figura 113 y la Figura 114, que muestran la distribución de pacientes por asociación, la paridad entre hombres y mujeres y las edades mínima, máxima y promedio de cada asociación respectivamente.

Tabla 60. Experimentación en domicilio. Muestra global de pacientes

\begin{tabular}{|l|l|l|l|l|l|l|l|}
\hline Asociación & № pacientes & \% hombres & \multicolumn{2}{l}{ \% mujeres } & \multicolumn{2}{l|}{ Edad mín. } & \multicolumn{2}{l|}{ Edad máx. } & Edad prom. \\
\hline Madrid & 2 & $50 \%$ & $50 \%$ & 76 & 80 & 78,00 \\
\hline Extremadura & 2 & $50 \%$ & $50 \%$ & 65 & 73 & 69,00 \\
\hline Cataluña & 2 & $50 \%$ & $50 \%$ & 78 & 82 & 80,00 \\
\hline Navarra & 2 & $100 \%$ & $0 \%$ & 76 & 79 & 77,50 \\
\hline Sevilla & 2 & $50 \%$ & $50 \%$ & 57 & 75 & 55,00 \\
\hline Total & 10 & $60 \%$ & $40 \%$ & 57 & 82 & 74,10 \\
\hline
\end{tabular}




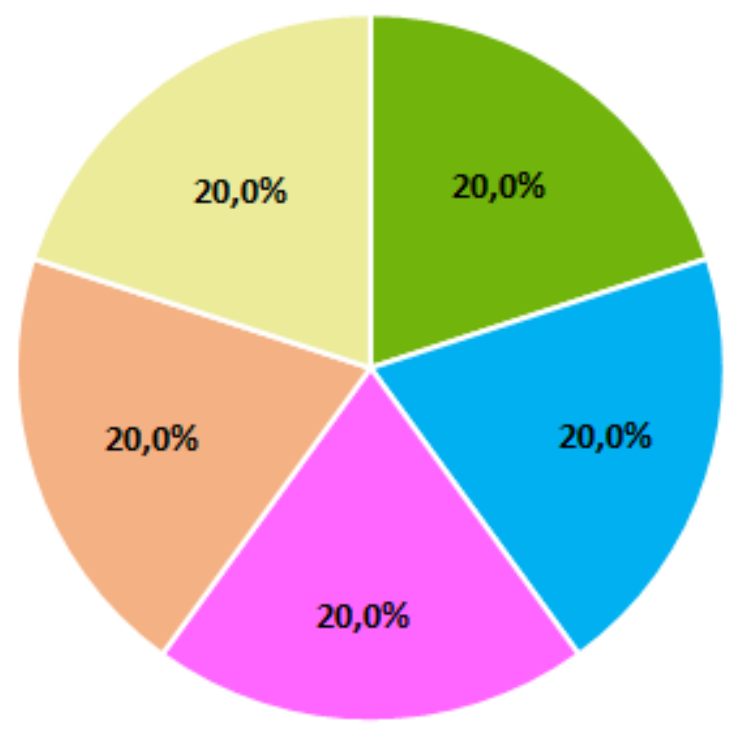

" Madrid = Extremadura $=$ Cataluña $=$ Navarra $\backsim$ Sevilla

Figura 112. Experimentación en domicilio. Distribución de pacientes por asociación

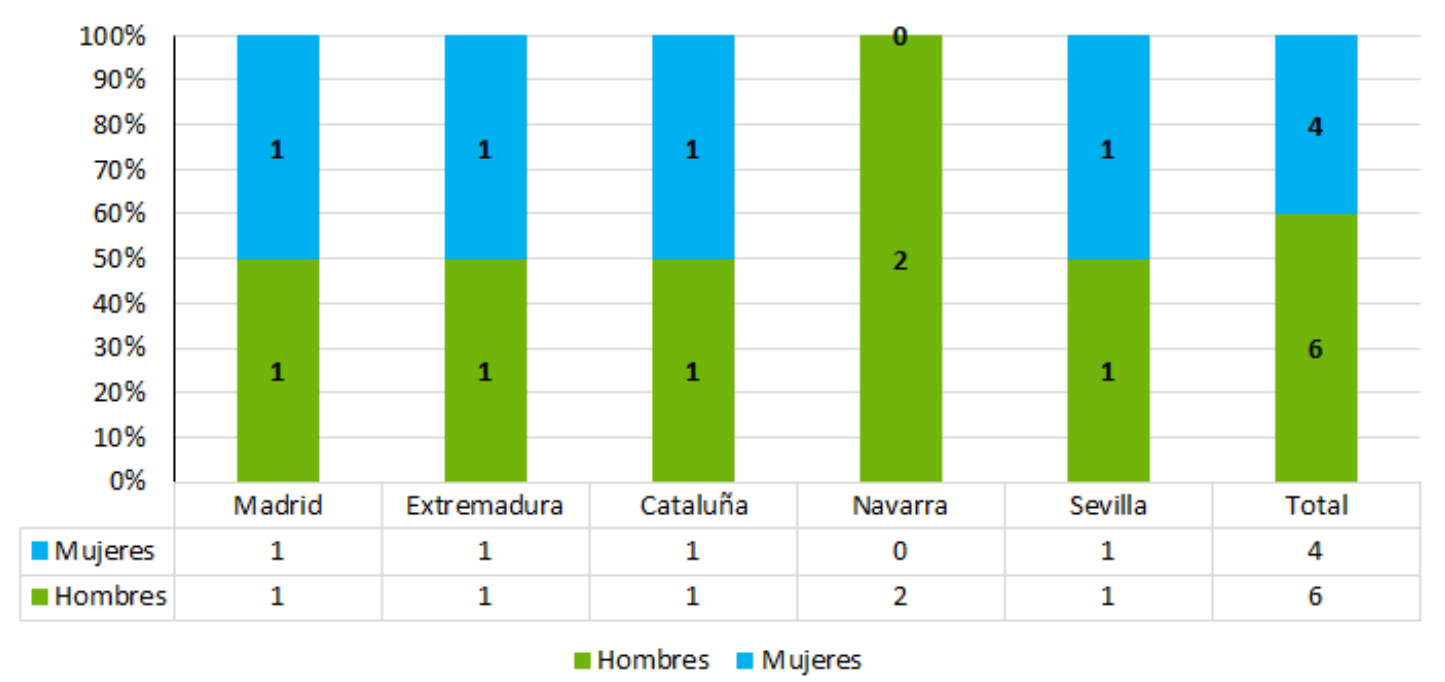

Figura 113. Experimentación en domicilio. Paridad entre hombres y mujeres 


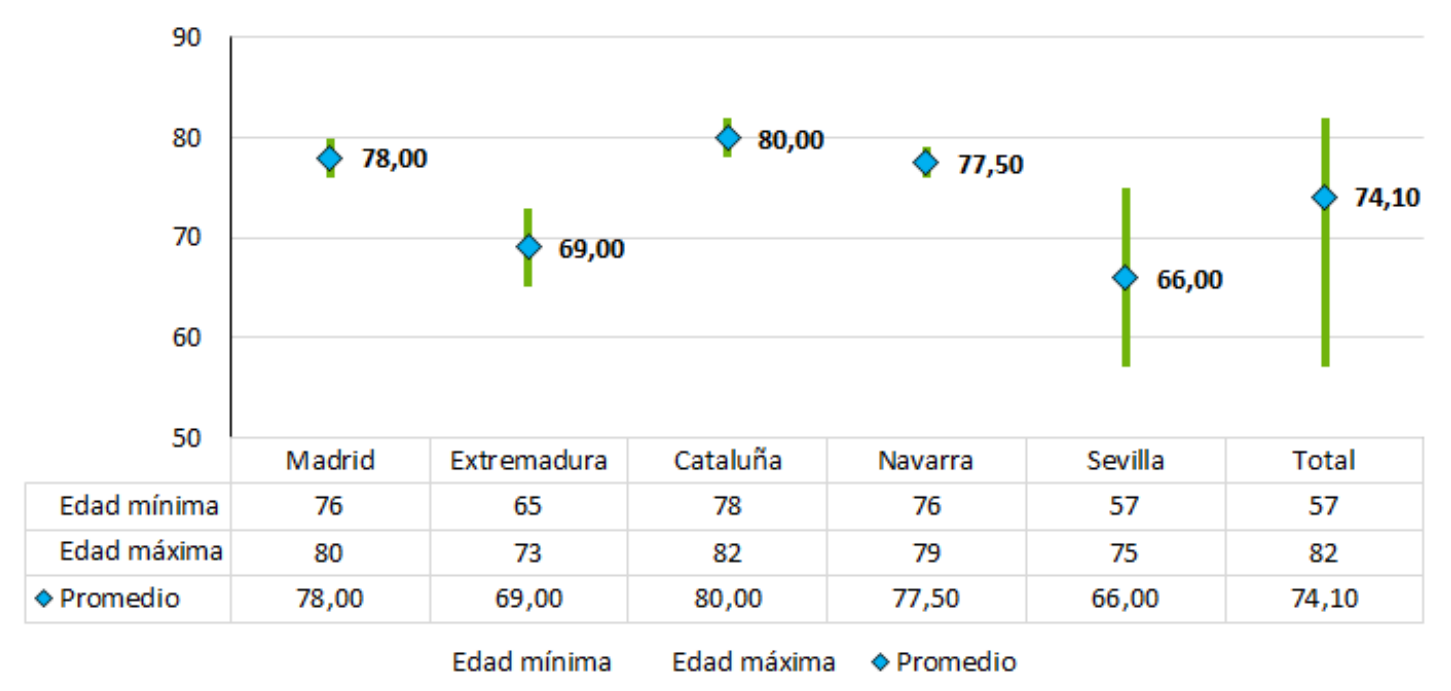

Figura 114. Experimentación en domicilio. Intervalo de edad y promedio

A continuación, se muestran las gráficas relativas al deterioro de la persona participante. La primera de ellas, la Figura 115, es la relativa al deterioro cognitivo. La segunda, la Figura 116, es la relacionada con el deterioro motor.

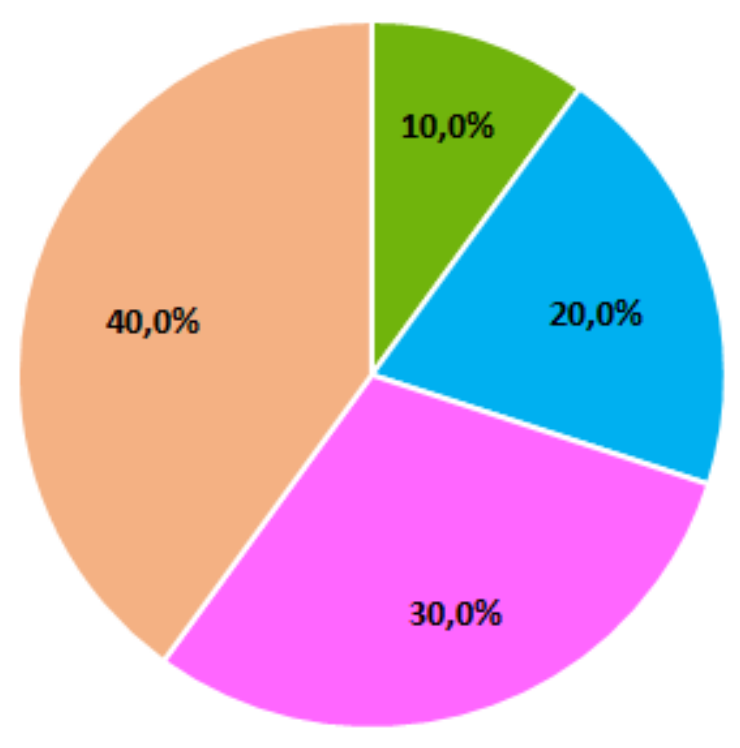

- Leve | Leve-Moderado | Moderado | Moderado-Grave

Figura 115. Experimentación en las asociaciones. Estado cognitivo 


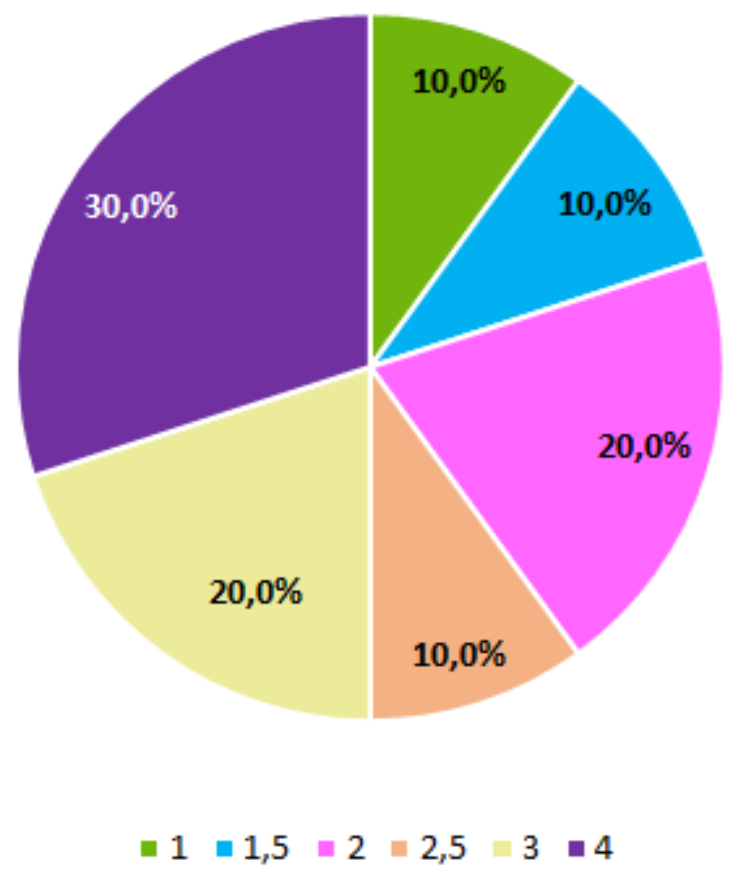

Figura 116. Experimentación en domicilio. Estadio motor

Por último, la Figura 117 detalla el grado de experiencia en nuevas tecnologías de los participantes en el experimento en las asociaciones.

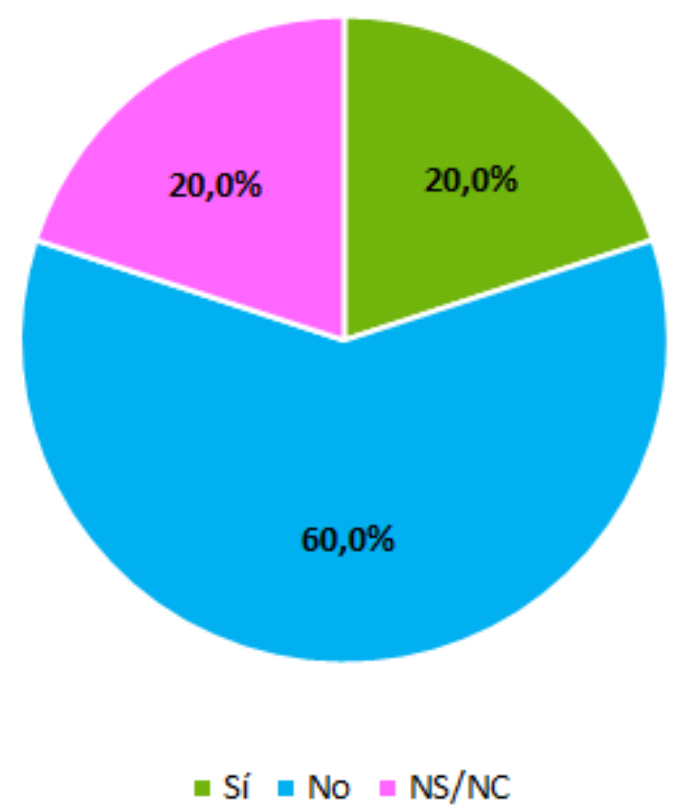

Figura 117. Experimentación en domicilio. Experiencia en nuevas tecnologías 


\section{V.2.2. Muestra de pacientes por asociación}

Las tablas a continuación (Tabla 61 a Tabla 65) presentan la muestra de pacientes que han participado en la realización de los experimentos llevados a cabo en los domicilios. El formato es el mismo que el de las tablas mostradas en el Anexo IV. Datos de los cuestionarios. Experimentación en las asociaciones. El número de paciente es correlativo a los que han participado en la experimentación en las asociaciones para cada asociación.

Tabla 61. Madrid. Muestra de pacientes en la asociación

\begin{tabular}{|c|c|c|c|c|c|}
\hline Número & Edad & Sexo & Estadio & NNTT & Estado cognitivo \\
\hline Paciente 11 & 80 & Hombre & 1,5 & No & Moderado \\
\hline Paciente 12 & 76 & Mujer & 2,5 & Sí & Leve \\
\hline
\end{tabular}

Tabla 62. Extremadura. Muestra de pacientes en la asociación

\begin{tabular}{|c|c|c|c|c|c|}
\hline Número & Edad & Sexo & Estadio & NNTT & Estado cognitivo \\
\hline Paciente 9 & 65 & Hombre & 2 & No & Moderado \\
\hline Paciente 10 & 73 & Mujer & 1 & No & Moderado \\
\hline
\end{tabular}

Tabla 63. Cataluña. Muestra de pacientes en la asociación

\begin{tabular}{|c|c|c|c|c|c|}
\hline Número & Edad & Sexo & Estadio & NNTT & Estado cognitivo \\
\hline Paciente 9 & 78 & Hombre & 4 & $\mathrm{NS} / \mathrm{NC}$ & Leve-Moderado \\
\hline Paciente 10 & 82 & Mujer & 4 & NS/NC & Moderado-Grave \\
\hline
\end{tabular}

Tabla 64. Navarra. Muestra de pacientes en la asociación

\begin{tabular}{|l|l|l|l|l|l|}
\hline Número & Edad & Sexo & Estadio & NNTT & Estado cognitivo \\
\hline Paciente 5 & 79 & Hombre & 3 & No & Moderado-Grave \\
\hline Paciente 6 & 76 & Hombre & 2 & No & Leve-Moderado \\
\hline
\end{tabular}

Tabla 65. Sevilla. Muestra de pacientes en la asociación

\begin{tabular}{|c|c|c|c|c|c|}
\hline Número & Edad & Sexo & Estadio & NNTT & Estado cognitivo \\
\hline Paciente 8 & 57 & Hombre & 3 & Sí & Moderado-Grave \\
\hline Paciente 9 & 75 & Mujer & 4 & No & Moderado-Grave \\
\hline
\end{tabular}

\section{V.3. Datos globales por asociación}

Las gráficas siguientes (Figura 118 a Figura 122) describen los resultados globales por asociación para la experimentación en domicilio, conteniendo también las tablas de datos utilizadas para su generación. Para su realización, se han tomado las medias de las respuestas de los pacientes a cada pregunta.

En primer lugar, la asociación de Madrid ha presentado como resultados la media global para los dos pacientes participantes para cada sesión, comprobándose cómo va aumentando la línea de tendencia. 


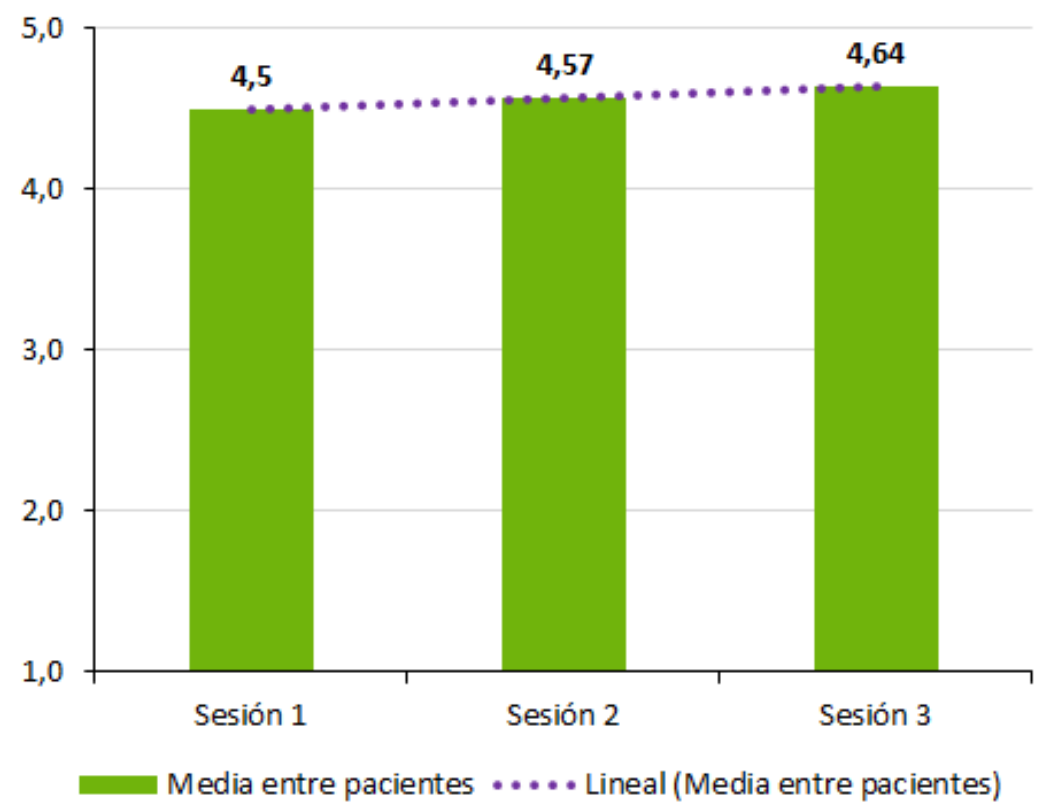

Figura 118. Madrid. Resultados globales de la experimentación en domicilio

En la asociación de Extremadura han dado los resultados por sesión y pregunta para los dos pacientes participantes en el experimento (Figura 119).

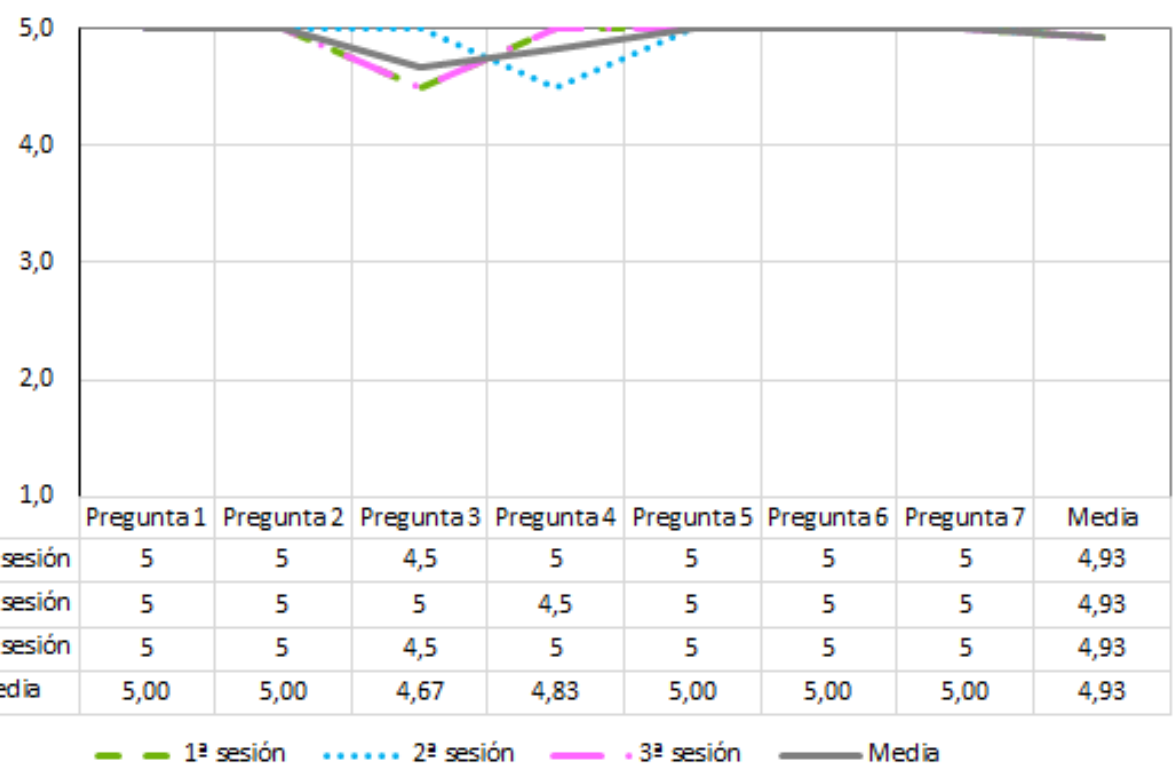

Figura 119. Extremadura. Resultados globales de la experimentación en domicilio

En la asociación de Cataluña, los terapeutas han añadido a la memoria final de resultados la media entre sesiones para cada pregunta y paciente sin distinguir entre sesiones (Figura 120). 


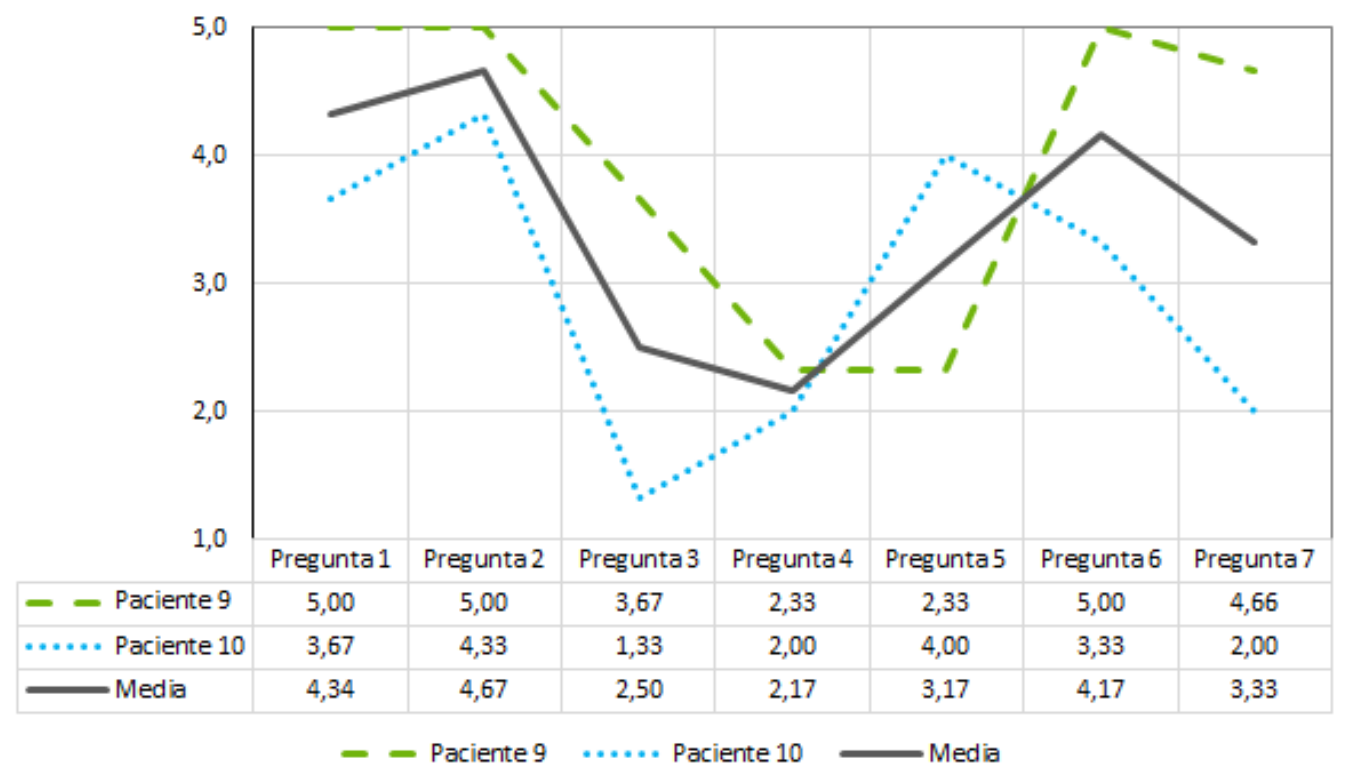

Figura 120. Cataluña. Resultados globales de la experimentación en domicilio

En la asociación de Navarra ocurre lo mismo que en el caso de Cataluña. Los datos incluidos en la memoria final están presentados por paciente y pregunta sin distinguir entre sesiones (Figura 121).

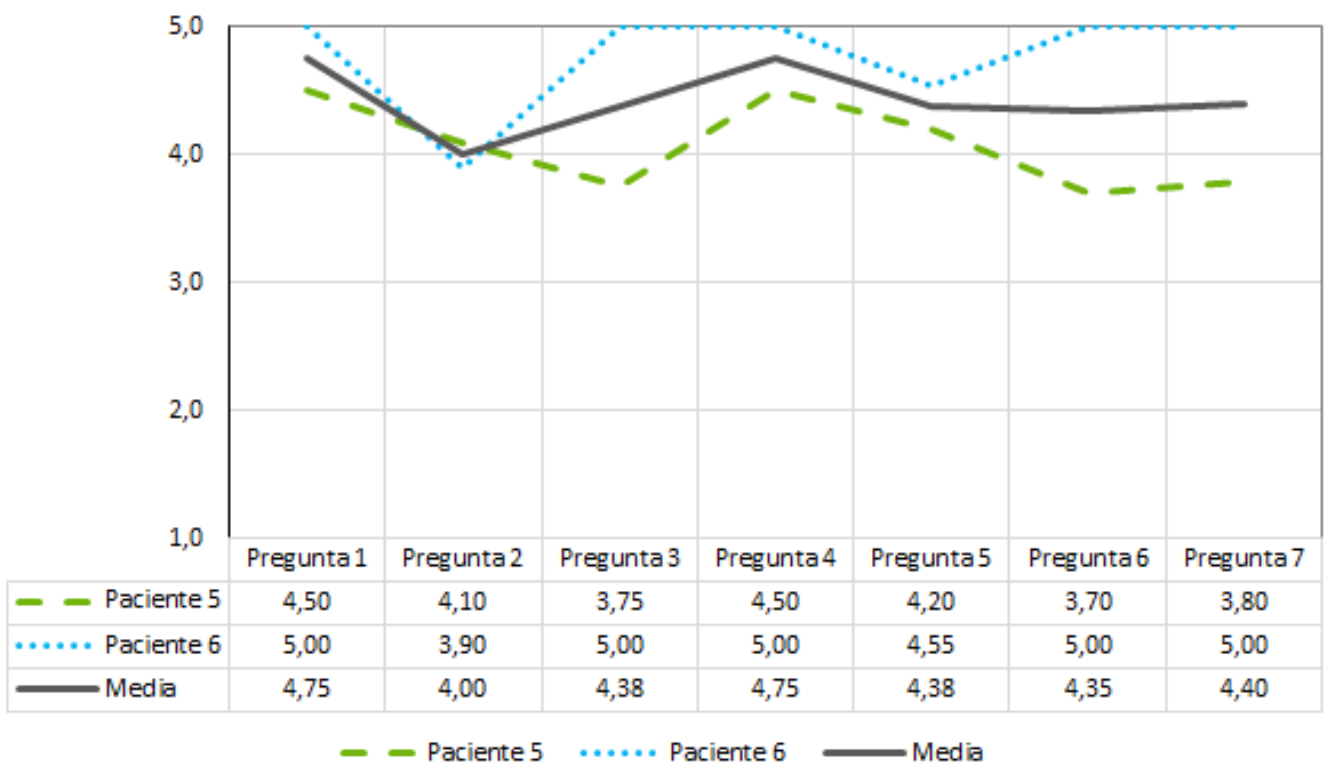

Figura 121. Navarra. Resultados globales de la experimentación en domicilio

Por último, para la asociación de Sevilla se dispone de los datos por pregunta y sesión (Figura 122). 


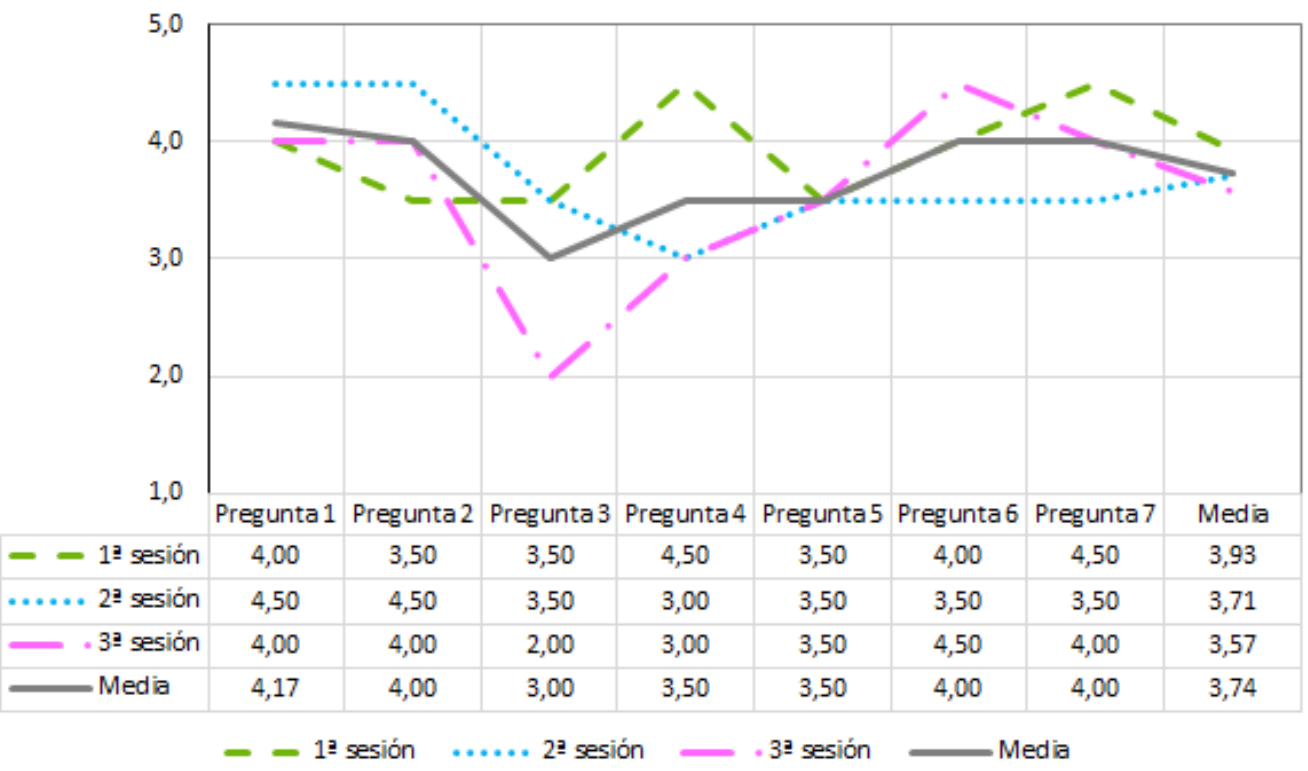

Figura 122. Sevilla. Resultados globales de la experimentación en domicilio

Se recuerda que la asociación de Cádiz no participó en la experimentación en domicilio.

\section{V.4. Datos de los cuestionarios de los terapeutas}

Los terapeutas de las asociaciones participantes en la experimentación en domicilio no han presentado datos cuantificables que puedan ser representables de forma gráfica, por lo que los datos de este apartado se han presentado en forma de conclusiones de pacientes y terapeutas en el apartado 6.6.2. Observaciones de pacientes y terapeutas. 